Andrews University

Digital Commons @ Andrews University

\title{
Leadership Development Among Youth in Latino Congregations: The Relationship of Religious Participation to Social Service Involvement and Engagement in Leadership Tasks
}

Elizabeth Tamez Mendez

Andrews University, tamezmel@andrews.edu

Follow this and additional works at: https://digitalcommons.andrews.edu/dissertations

Part of the Developmental Psychology Commons, Leadership Studies Commons, and the Sociology of Religion Commons

\section{Recommended Citation}

Tamez Mendez, Elizabeth, "Leadership Development Among Youth in Latino Congregations: The Relationship of Religious Participation to Social Service Involvement and Engagement in Leadership Tasks" (2018). Dissertations. 1667.

https://digitalcommons.andrews.edu/dissertations/1667

https://dx.doi.org/10.32597/dissertations/1667

This Dissertation is brought to you for free and open access by the Graduate Research at Digital Commons @ Andrews University. It has been accepted for inclusion in Dissertations by an authorized administrator of Digital Commons@ Andrews University. For more information, please contact repository@andrews.edu. 


\begin{abstract}
LEADERSHIP DEVELOPMENT AMONG YOUTH IN LATINO CONGREGATIONS: THE RELATIONSHIP OF RELIGIOUS PARTICIPATION TO SOCIAL SERVICE INVOLVEMENT AND ENGAGEMENT IN LEADERSHIP TASKS
\end{abstract}

by

Elizabeth Tamez Méndez

Chair: Erich W. Baumgartner 


\title{
ABSTRACT OF GRADUATE STUDENT RESEARCH
}

Dissertation

\author{
Andrews University \\ School of Education
}

\section{Title: LEADERSHIP DEVELOPMENT AMONG YOUTH IN LATINO CONGREGATIONS: THE RELATIONSHIP OF RELIGIOUS PARTICIPATION TO SOCIAL SERVICE INVOLVEMENT AND ENGAGEMENT IN LEADERSHIP TASKS}

Name of researcher: Elizabeth Tamez Méndez

Name and degree of faculty chair: Erich W. Baumgartner, $\mathrm{PhD}$

Date completed: June 2018

\section{Problem}

Personal observations and anecdotal accounts attest that some of the young people in U.S. Latino churches are developing as leaders within their congregations. This seems to come as a result of the organic or less-formalized leadership development dynamics and practices present within Latino congregations, where leaders often develop by being actively involved in leadership actions without necessarily first following a curriculum of study, completing a training program, or fulfilling a set of theological education requirements. In this way, many are acquiring roles and responsibilities by which they actively contribute towards local congregational and community life, and by which they develop as leaders through hands-on experiences. This less formalized leadership 
development dynamic in Latino congregations has yet to be empirically studied, as a means to further understand and learn from this unique characteristic that can be helpful to the church at large in our search for how to develop the next generation of leaders. Thus, there is a need to identify, describe, and empirically analyze some of the specific phenomena involved in these observed dynamics within Latino congregations that seem to be contributing towards youths' leadership development.

\section{Method}

Therefore, this descriptive and explanatory ex post facto study examined key congregational practices within Latino churches and the level of participation young people have in these as a means of analyzing the association of both with leadership development. The study drew on existing data collected through the Chicago Latino Congregational Study - Youth Survey (CLCS-YS) of 63 randomly sampled Latino congregations in different Christian denominations: Catholic, Evangelical, Mainline, and Pentecostal. The sample population consisted of 307 Latino youth ages 13 to 19.

After examining the 104 questionnaire items of the CLCS-YS for applicability, 23 were selected to analyze youth's religious participation, social service involvement, and engagement in leadership tasks, while controlling for demographic characteristics. Aspects of Positive Youth Development (PYD) theory pertaining to youth leadership development provided a means to select and create the variables studied, which were derived from socioreligious descriptions of Latino congregations that are linked to the aforementioned organic leadership dynamics. 


\section{Results}

The data analysis revealed that youth in Chicago Latino congregations have a high aggregate score for both Religious Participation and Engagement in Leadership Tasks, and both scores increase with their age. Although their aggregate score for Social Service Involvement was found to be low, the frequencies of the reported habits, actions, and behaviors regarding Social Service Involvement indicate that a high percentage of youth are involved in volunteering or social service in and out of their local congregation. A significant relationship was also found between youths' level of Religious Participation and their level of Social Service Involvement and Engagement in Leadership Tasks, with both scores increasing as their scores in Religious Participation increased.

The results of the individual survey frequencies served to create a contextual description of socioreligious phenomena present in Chicago Latino congregations, as well as a wider reference into the religious habits of Latino youth. The findings support the observations and anecdotal accounts regarding the level of engagement youth have with organic dynamics for leadership development in Latino congregations. Based on PYD theory, the study also provided a proposed set of variables and measurements by which to approach future studies on this topic. Youth congregants are involved in handson experiences such as social service projects and exercising leaderships tasks, and they are also engaging very frequently with their supportive religious community. These are all characteristics of ecological contributing contexts which PYD postulates can potentially contribute towards the leadership development of youth, and their continued contribution as leaders in adulthood (Avolio \& Vogelgesang, 2011; Murphy \& Reichard, 2011). 
Andrews University

School of Education

\title{
LEADERSHIP DEVELOPMENT AMONG YOUTH IN LATINO CONGREGATIONS: THE RELATIONSHIP OF RELIGIOUS PARTICIPATION TO SOCIAL SERVICE INVOLVEMENT AND ENGAGEMENT IN LEADERSHIP TASKS
}

\author{
A Dissertation \\ Presented in Partial Fulfillment \\ of the Requirements for the Degree \\ Doctor of Philosophy
}

by

Elizabeth Tamez Méndez

June 2018 
(C) Copyright by Elizabeth Tamez Méndez 2018

All Rights Reserved 


\title{
LEADERSHIP DEVELOPMENT AMONG YOUTH IN LATINO CONGREGATIONS: THE RELATIONSHIP OF RELIGIOUS PARTICIPATION TO SOCIAL SERVICE INVOLVEMENT AND ENGAGEMENT IN LEADERSHIP TASKS
}

\author{
A dissertation \\ presented in partial fulfillment \\ of the requirements for the degree \\ Doctor of Philosophy
}

by

Elizabeth Tamez Méndez

\section{APPROVAL BY THE COMMITTEE:}

Chair: Erich W. Baumgartner

Member: Isadore Newman

Member: Randy Siebold

Member: David Newman

External: Lionel Matthews
Dean, School of Education

Robson Marinho
Date approved 
To all the youth who teach me to see life

from a wider, deeper, and richer perspective.

You turned my world upside down.

I am indebted to you. 


\section{TABLE OF CONTENTS}

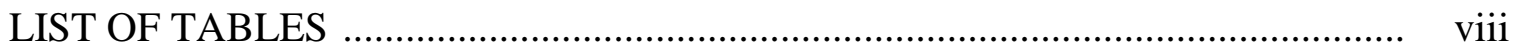

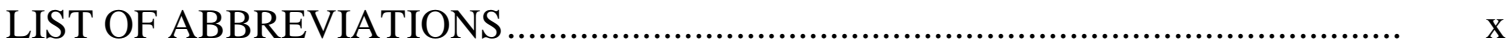

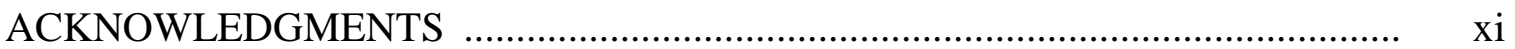

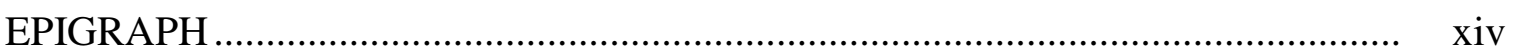

Chapter

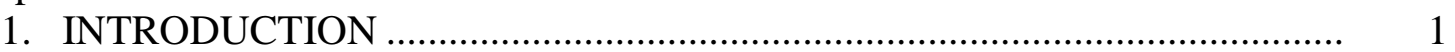

Background and Rationale ..................................................... 1

Statement of the Problem..................................................................... 4

Purpose of the Study ..................................................................... 4

Theoretical Framework ................................................................. 5

Research Questions ................................................................ 10

Significance of the Study ........................................................ 11

Assumptions......................................................................... 13

Definition of Terms...................................................................... 14

Methodology ...................................................................... 17

Limitations of Study .............................................................. 19

Delimitations of the Study ......................................................... 21

Organization of the Study ............................................................ 22

2. LITERATURE REVIEW ................................................................. 23

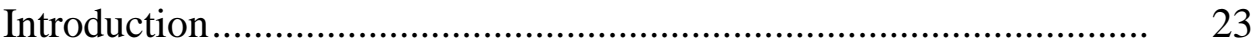

Theoretical Framework .............................................................. 25

Positive Youth Development ................................................... 25

Theoretical Overview of Positive Youth Development.......... 26

Developmental Assets Model ............................................. $\quad 30$

Positive Developmental Settings Model ................................ 31

Ecological Contributing Contexts......................................... 32

PYD and Religious Contexts .............................................. 35

PYD and Leadership Development ...................................... 38

Critique of PYD Theory ....................................................... 43

Latino Congregations and Youth ................................................... 45

National Study of Youth and Religion........................................ 46 
Socioreligious Description of Latino Congregations..................... 46

Challenges in Latino Congregations Towards Reaching Youth.... 52

Religious Participation and Pathways for Youth Leadership

Development

Religious Participation and Social Service Involvement.................. 58

Religious Participation and Engagement in Leadership Tasks...... 61

U.S. Latino Demographic Characteristics ........................................... 64

Population ......................................................................... 64

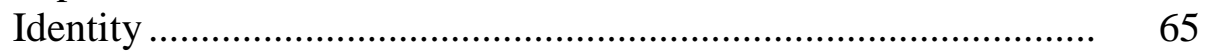

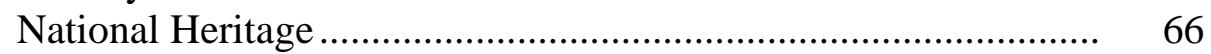

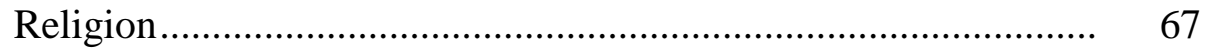

Chicago Latino Congregations Study …………………................... 72

Brief Overview........................................................................ 72

Other Studies Using the CLCS Data............................................. 73

Sociology of Religion Studies ............................................... 73

Dissertation Studies .................................................................. $\quad 75$

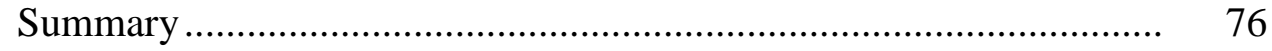

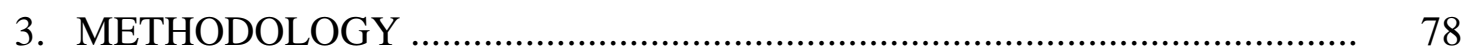

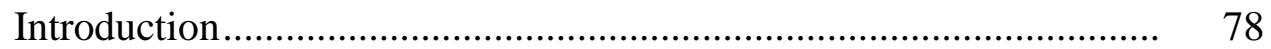

Research Design........................................................................ 78

Research Questions and Hypotheses ................................................ 83

Sources of Data of the CLCS ............................................................ 85

Geographical Location, Population, and Sampling Frame ............ 86

Survey Instrument Design.......................................................... 89

Data Collection Context and Sampling Procedures ...................... $\quad 90$

Operational Definition of Variables...................................................... 94

Coding of the Selected Variables......................................................... 95

Religious Participation................................................................ 97

Social Service Involvement …………………......................... 98

Engagement in Leadership Tasks ................................................. 99

Demographic Characteristics ..................................................... 100

Data Analysis and Statistical Treatment ........................................... 102

Summary ……...................................................................... 105

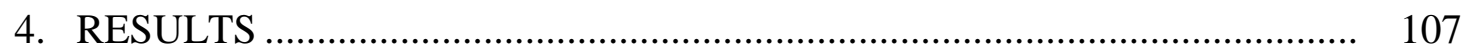

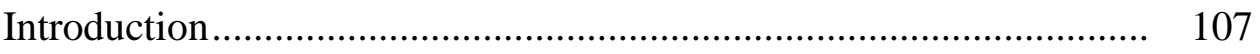

Demographics of the Sample …………………………................. 107

Research Question 1 ................................................................. 111

Research Question 2 ................................................................ 113

Hypothesis 2a ................................................................. 118

Hypothesis 2b..................................................................... 118

Research Question 3 ................................................................ 119

Research Question 4 ................................................................ 123 


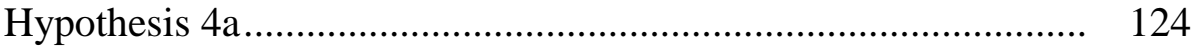

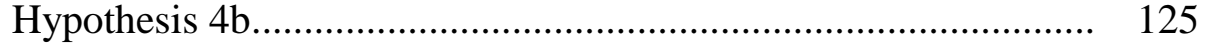

Research Question 5 ............................................................ 126

Research Question 6 ............................................................... 129

Hypothesis 6a ........................................................................ 131

Hypothesis 6b....................................................................... 133

Research Question 7 and Hypothesis 7 ............................................ 134

Research Question 8 and Hypothesis 8 ………………................... 135

Summary ....................................................................... 135

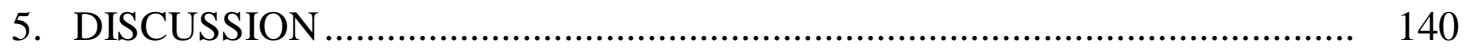

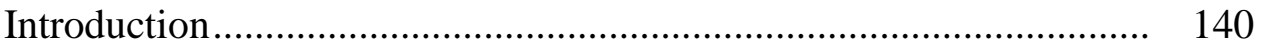

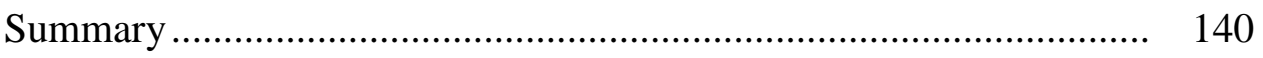

Research Findings ......................................................................... 146

General Overview of Findings ................................................. 148

Religious Participation Findings ................................................. 149

Social Service Involvement Findings ......................................... 150

Engagement in Leadership Tasks Findings ................................. 152

General Research Question Findings .......................................... 155

Discussion of the Results ................................................................ 155

Limitations and Explanatory Notes ............................................ 156

Youth, Religious Participation, and Leadership Development...... 160

Religious Participation Frequencies Comparison ................... 160

Contextual Descriptions and Implications for PYD ............... 161

Youth, Church, Social Service Involvement, and Leadership

Development .................................................................. 164

Social Service Involvement Frequencies Comparison ............ 165

Contextual Descriptions and Implications for PYD ............... 166

Youth, Church, Engagement in Leadership Tasks, and

Leadership Development .................................................... 169

Engagement in Leadership Tasks Frequencies Comparison ... 170

Contextual Descriptions and Implications for PYD ................ 170

Latino Congregations and Organic Dynamics for Leadership

Development ................................................................. 174

Conclusions........................................................................... 176

Implications for Practice ................................................................... 178

What Congregations and Church Leaders Can Do ....................... 179

What Denominational Entities Can Do........................................ 185

What Religious Educational Institutions Can Do ........................ 187

What Grant Funding Organizations Can Do................................. 188

What New Generation3 Can Do ................................................... 189

Recommendations for Further Research............................................ 189

Epilogue ............................................................................. 193 
Appendix

A. CHICAGO LATINO CONGREGATIONS STUDY YOUTH SURVEY

B. THE CHICAGO LATINO CONGREGATIONS STUDY (CLCS) METHODOLOGICAL CONSIDERATIONS REPORT

C. GENERALIZED LINEAR EQUATION MODELS 248

D. LETTER OF REQUEST FOR AUTHORIZATION FROM THE CLCS PRINCIPAL RESEARCHER.

E. LETTERS OF AUTHORIZATION FROM THE CLCS PRINCIPAL RESEARCHER.

F. IRB EXEMPTION LETTER. 264

REFERENCE LIST 266 CURRICULUM VITAE. 289 


\section{LIST OF TABLES}

1. Construct Variables of the Study .............................................................. 96

2. Demographic Characteristics of the Sample: Age, Gender, and

Denominational Affiliation ................................................................ 108

3. Demographic Characteristics of the Sample: Hispanic/Latino Group Identification, Language Usage, and Participant's Country of Birth......... 109

4. Descriptive Statistics: Religious Participation of Youth in Latino

Congregations

5. Frequencies of Individual Survey Items in Religious Participation Total

Score (Percentages) ...................................................................... 114

6. GLM ANOVA: Relationship Between Religious Participation and Demographic Variables .......................................................................... 116

7. Multiple Comparison With a Bonferroni Correction: Religious

Participation Differences Between Denominational Affiliation............... 117

8. Linear Regression Analysis Summary: Age Predicting Religious

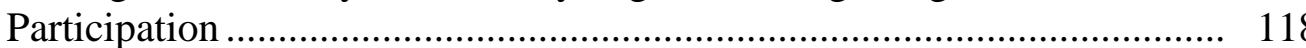

9. Linear Regression Analysis Summary: Gender Predicting Religious

Participation

10. Descriptive Statistics: Social Service Involvement of Youth in Latino

Congregations

11. Frequencies of Individual Survey Items in Social Service Involvement

Total Score (Percentages)

12. GLM ANOVA: Relationship Between Social Service Involvement and

Demographic Variables

13. Regression Analysis Summary: Gender Predicting Social Service

Involvement 
14. GLM ANOVA: Difference in Social Service Involvement by

Denominational Affiliation

15. Descriptive Statistics: Engagement in Leadership Tasks of Youth in Latino Congregations

16. Frequencies of Individual Survey Items in Engagement in Leadership

Tasks Total Score (Percentages)

17. GLM ANOVA: Relationship Between Engagement in Leadership Tasks and Demographic Variables.

18. Multiple Comparison With a Bonferroni Correction: Engagement in Leadership Tasks Differences Between Gender

19. Multiple Comparison With a Bonferroni Correction: Engagement in Leadership Tasks Differences Between Hispanic/Latino Group Identification

20. Linear Regression Analysis Summary: Age Predicting Engagement in Leadership Tasks

21. GLM ANOVA: Relationship of Gender and Level of Engagement in Leadership Tasks

22. GLM ANOVA: Differences in the Level of Engagement in Leadership Tasks by Denominational Affiliation

23. Multiple Comparison With a Bonferroni Correction: Engagement in Leadership Tasks Differences Between Denominational Affiliation

24. Regression Analysis Summary: Religious Participation Predicting Social Service Involvement

25. Regression Analysis Summary: Religious Participation Predicting Engagement in Leadership Tasks 136

26. Summary of Results for Research Questions and Hypotheses 


\section{LIST OF ABBREVIATIONS}

$\begin{array}{ll}\text { ANOVA } & \text { Analysis of Variance } \\ \text { CLCS } & \text { Chicago Latino Congregations Study } \\ \text { CLCS-YS } & \text { Chicago Latino Congregations Study-Youth Survey } \\ \text { DACA } & \text { Deferred Action for Childhood Arrivals } \\ \text { GLM } & \text { Generalized Linear Model } \\ \text { HIV/AIDS } & \begin{array}{l}\text { Human Immunodeficiency Virus and Acquired Immunodeficiency } \\ \text { Syndrome }\end{array} \\ \text { NG3 } & \text { New Generation3 } \\ \text { NSYR } & \text { National Study of Youth and Religion } \\ \text { PYD } & \text { Positive Youth Development } \\ \text { RDST } & \text { Relational Developmental Systems Theory }\end{array}$




\section{ACKNOWLEDGMENTS}

It is impossible in a few pages to express my appreciation to all the individuals and organizations who contributed towards reaching this milestone. This dissertation is a collaborative project which brought together partners from the worlds of religion, sociology, human development, and theology. It is a treasure for which I am grateful and in awe, and I want to extend my profound gratitude to each of you.

For their dedication and leadership, to my committee: Dr. Erich W. Baumgartner, Dr. Isadore Newman, Dr. Randy Siebold, Dr. David Newman, and Dr. Lionel Matthews. Dr. Baumgartner, you shaped me into a stronger scholar, saw this project in its depth from its conception, and encouraged me in faith. Dr. I. Newman, you brought light in dark times and always saw what was possible. Dr. Siebold, you taught me to be disciplined in separating my research from my consulting thoughts. Dr. D. Newman, your selfless investment into this project will always be remembered.

For his trust and commitment in extending support throughout the years: Dr. Ewin L. Hernández. By allowing me to inherit the CLCS-YS data collected, you gave this study greater depth and insight into the lives of our Latino youth and their congregations. Thank you Dr. Jessica Hamar-Martínez for facilitating the transition steps of this process.

For their research and technical support through their selfless acts and long hours invested: Dr. Richard M. Lerner and Dr. Kristina Schmid Callina at Tufts University in coaching me on PYD theory. Dr. Duane Covrig and Dr. Robson Marinho for guiding me 
to decipher the theoretical framework and Leadership Program. Dr. Carole Newman and Dr. Jennifer Morales for supporting me in the statistical analysis and cheering me on through this strenuous dissertation process. Rev. Joanne Rodriguez and Ms. Ulrike Guthrie at Hispanic Theological Initiative for always supporting my doctoral journey, believing in this calling, and rendering editorial expertise. The Hispanic Summer Program, especially Dr. Otto Maduro, and each of the professors who helped shape my epistemological and research philosophy. To the library staff at AU and BUA, particularly Mr. Jason St. Clair, Mrs. Teresa B. Martínez, and Ms. María Longoria, who did even the seemingly impossible to acquire all the bibliographical resources needed.

For their financial backing and investment: Southern Baptist Foundation through the M. May Robertson/J. W. Farmer/ H. I. Hester Doctoral Grant, AU School of Education Department through the Graduate Grants, Hispanic Woman's Network of Texas-San Antonio Chapter through the Wise Latina Grant - in particular Dr. Nancy Compean-García and Dr. Patricia-Galán-Cisneros, and to my family in Christ who gave their sacrificial offerings throughout the years as affirmation of my ministerial calling.

For their wisdom, friendship, and belief in me, thanks to each of my mentors: Dr. Elizabeth Conde-Frazier, Dr. Juan F. Martínez, and Drs. Justo and Catherine González. You have stood by me, spoken truth and life, and have opened doors throughout the years. Never could I have imagined having such an honor.

For sharing their knowledge, affirming my leadership, and being open to collaborations that enriched this process: my esteemed colleagues Dr. Mariano Ávila, Prof. Rosa María Robles de Ávila, Dr. Paul Barton, Dr. Fernando Cascante, Dr. Adlin Cotto, Dr. Gregory L. Cuéllar, Dr. Javier Elizondo, Rev. Luis López, Ms. Jane Wilson, 
Dr. Albert Reyes, Dr. Gus Reyes, Dr. Daniel R. Sánchez, Dr. Cláudio Carvalhaes, Dr. Melissa Wiginton, Dr. John Witvliet, all the members of the Southwest, Paradigm, and Success Leadership Learning Groups, the team at the Baptist University of the Américas, and the New Generation3 team-especially Mrs. Diana López who invested her time, effort, faith, and enthusiasm into this dissertation.

For their relentless love, I am immensely grateful to my parents Ruth and David for not once have they doubted that this was something I needed to do - and FINISH! Thank you to my family, friend-family, and to my congregation at Primera Iglesia Bautista in Tyler - each of you have cheered me on, prayed for me, and patiently awaited my return. I am also grateful to the BGCT, Convención, and AETH congregations, pastors, and leaders for their openness in working together throughout the years. To all my office interns and students at Baptist University of the Américas, there are not enough words by which to express my gratitude for your hard work, support, and for keeping me accountable to set an example and not give up during hard times - you make me proud!

For their open hearts: thank you to all the teens, young adults, parents, students, congregations, leaders, and denominations who throughout the decades have graciously allowed me to serve them, learn together, and share what our Lord has entrusted-for our good, and His glory. 


\section{EPIGRAPH}

Quisieron enterrarnos, pero no sabían que éramos semilla.

Proverbio Mexicano

They tried to bury us, they didn't know we were seeds. Mexican Proverb 


\section{CHAPTER 1}

\section{INTRODUCTION}

\section{Background and Rationale}

In twenty-five years of work and service among Latino congregations of varied denominations throughout the U.S., I have found that one of the key topics of concern among clergy and denominational leaders is to see more leaders emerging and developing within their congregations, particularly young leaders. The conversation often unfolds with a sense of urgency and preoccupation as to how the "next generation" or "future leaders" of the church will develop (both lay and ordained). These leaders have a heightened awareness that the future of the church, its vibrancy, impact, and direction depends on such future leadership development (Hernández, Peña, Sotelo Viernes Turner, \& Salazar, 2016; Maldonado Pérez, 2005; Martínez, 2008; Montoya, 1987).

Yet over the years, I have also noticed that people tend to think of leadership development for the church as being addressed through using a curriculum of study, implementing a new leadership program, participating in a series of specialized events, or following a set of requirements for theological education. Although these are certainly valid and contributing tools, I have observed that new leaders are emerging and developing under a different dynamic that is organically arising within our local congregations - a dynamic that we have overlooked and not yet properly recognized in research studies and at a larger institutional, denominational, or ministerial praxis level. 
Latino congregations in the U.S. typically have an average of 50 members in attendance, with either a full-time or a bi-vocational pastor, volunteer lay leaders that handle different aspects of local congregational dynamics, and families with several children (Burwell, Hernández, Peña, Smith, \& Sikkink, 2010; Martínez, 2008). These congregations also find themselves with a large percentage of younger members, who tend to be well engaged with the local congregation (Johnson-Mondragón, 2007). Of course, different local contextual factors and institutional church factors account for variants in local congregational characteristics (Hoge \& Roozen, 1979); however, this portrayal appears accurate given the demographic, socioeconomic, and cultural characteristics of the Latino population and their congregations. I have further observed that under these local congregational dynamics, as is to be expected some operational resources and skilled leaders are limited, and for this reason churches are adopting new ways of addressing these needs by developing leaders through hands-on experiences.

Although these local congregations for the most part have not implemented an intentional program or plan geared towards leadership development, especially among youth, I have met many youth who are emerging leaders in these churches. As local congregations need active and contributing members in order to meet its many needs, they have called upon some youth to take responsibilities that are de facto leadership tasks and responsibilities, ones that previously have often been reserved for adults, or have required being formally elected into such positions.

Thus, one often finds young people who direct music, engage with young children as part of the Sunday or Bible School team of teachers and aides, serve as "youth ministers" to their younger peers, handle office or administrative work, are involved in 
organizing events at church or special trips, guide community service efforts, etc. The local congregation depends on these youth's skill sets and contributions to move things forward in the church, and to serve the needs of the surrounding community.

However, in spite of their work and contribution, the adults in the local congregation typically do not consider or recognize these youth as fully functional leaders. There is a tendency to regard them as youth who perform operational tasks, but not as formal leaders. There is an unspoken notion that such formal recognition of their leadership capacities cannot be conferred or acknowledged in them until they reach a certain point in adulthood.

Nevertheless, we are observing that young people who are actively contributing to the work in their local congregations are emerging leaders who might also likely continue to fulfill leadership roles later in adulthood. In their personal stories, many current pastors, clergy, and denominational leaders tell about how they themselves had similar experiences in their teenage or young adult years as they began their active congregational work in response to the encouragement of others in their congregation and the opportunities provided to them. These opportunities early in life later contributed towards them further developing as leaders with formal titles and positions; this is my personal experience as well. These established leaders recount stories about how their leadership development started when their pastor encouraged them to preach a sermon, or a lay leader mentored them to become a Sunday School teacher, or they were approached to become part of the volunteer team that prepared school supply packages for the children in the community.

These anecdotal accounts of leadership development point to the need to further 
identify, describe, and empirically study some of the factors involved in these observed dynamics and practices within Latino congregations, for this knowledge might help us find contextually profitable answers to our local and national institutional concerns for how the "next generation" or "future leaders" of the church will develop. More fundamentally, it is important not to overlook the young people in our Latino congregations for they are so central to our future as a church. There is a need to learn more about the youth in our congregations and what are some of the practices and opportunities offered that might be supporting their leadership development.

\section{Statement of the Problem}

Some of the young people in U.S. Latino churches showing indications that they are developing as leaders within their congregations. Observational and anecdotal accounts point to the organic or less-formalized leadership development dynamics and practices that are present within Latino congregations as aspects that might be contributing to their development as leaders. However, there is still a need to identify, describe, and empirically analyze some of the specific phenomena and factors involved in these observed dynamics within Latino congregations, and how these might be contributing to youth's leadership development. The contributing factors are best studied both at the individual and institutional levels as to gain a wide view of what personal observations and anecdotal accounts attest to.

\section{Purpose of the Study}

Therefore, the purpose of this socioreligious study was to analyze the relationship of youths' religious participation in Latino congregations to their development as leaders, 
by measuring the level of youth's involvement with two selected ecological contributing factors within their congregations: social service involvement and engagement in leadership tasks.

A review of literature and pertinent studies revealed scarce empirical research available related to the topics which pertain to this study. Moreover, a past study, survey instrument, or other research tool for a direct measure between religious participation and leadership development among youth was not found at the time. Consequently, by applying concepts of Positive Youth Development (PYD) theory, two mediating factors were selected by which to identify, describe, and measure ecological contributing factors present in Latino congregations that can potentially nurture leadership development in youth. The ecological contributing factors selected for this study were social service involvement and engagement in leadership tasks. The Theoretical Framework section of this chapter and Chapter 2 provide further details regarding the selection of these two specific mediating variables.

To this end, and to obtain data from a large pool of youth participants of diverse denominations, portions of the existing data collected through the Chicago Latino Congregational Study-Youth Survey (CLCS-YS) (Burwell et al., 2010) were used to study the ecologically contributing dynamics and to construct the variables for analysis. The Chicago Latino Congregational Study (CLCS) was originally conducted through the Center for the Study of Latino Religion at the University of Notre Dame.

\section{Theoretical Framework}

Assembling the theoretical framework for this study was a challenge, for there are few research and academic literature resources for this type of study as the fields of 
leadership and youth, and religion and youth are in their emerging stages. Research in these two fields conducted within the Latino community is even more sparse. Furthermore, because of the nature of the process of leadership emergence and development, although a search was conducted to find research tools by which to measure leadership development among youth in religious contexts, a direct measure was not found at the time. Empirical research in this field of study measures skills levels, personal traits, and/or contextual factors and situations in order to predict or measure leadership development in young individuals (e.g. Rubin, Bartels, \& Bommer, 2002; Taggar, Hackett, \& Saha, 1999; Wolff, Pescosolido, \& Druskat, 2002).

Therefore, the link between religious participation and leadership development was approached through the theoretical framework of PYD, which is a theory of contemporary applied developmental science that is concerned with the lens through which youth and youth development are viewed (Lerner et al., 2013; Lerner, Phelps, Forman, \& Bowers, 2009). Positive Youth Development came as a reaction to the old developmental approach to youth which emphasized a deficit perspective of youth as problems to be managed lest they engage in at-risk behavior (e.g., drinking, drug use, teen pregnancy). In contrast, PYD emphasizes that youth are assets to be developed, and that their development occurs within a bidirectional relationship between the individuals and the multiple levels of their environments or ecologies (i.e., individual $\longleftrightarrow$ context relationships) (Lerner, Lerner, et al., 2005; Lerner \& Overton, 2008; Overton, 2013a, 2013b). Thus, when given the needed support through social or ecological contexts (e.g., families, schools, after-school programs, churches, etc.) that follow an intentional framework of positive interactions, these contribute to the healthy development and 
thriving of young people (Lerner et al., 2009; Lerner, 2002, 2004b). Some of the characteristics that need to be present in the contributing ecological contexts that support youth's positive development include: (1) providing healthy and sustained adult-youth relationships, (2) creating opportunities for youth to be actively engaged with activities that strengthen their skills and competencies, competencies that include leadership, and (3) having a mutually beneficial relationship between the context and the young person, where youth are also making meaningful contributions (Damon, 2003; Damon, Menon, \& Bronk, 2003; Larson \& Hansen, 2005; Overton, 2013a; Putnam, 2002).

Regarding leadership development, being that PYD integrates concepts of lifespan theory, it proposes that leadership development is a process that takes place over time (i.e., versus solely a genetic predisposition, or an acquired skill through specialized training, etc.) and that early leadership experiences can provide an important foundation for exercising leadership later in life (Avolio, 2005; Avolio \& Gibbons, 1988; Avolio \& Vogelgesang, 2011; Day, 2011; Day, Fleenor, Atwater, Sturm, \& McKee, 2014; Day, Harrison, \& Halpin, 2012; Day \& Sin, 2011; Murphy \& Reichard, 2011). Youth who are developing and strengthening their leadership skills early in life will more likely continue to develop and act as leaders when they reach adulthood (Murphy \& Johnson, 2011; Murphy \& Reichard, 2011). These early experiences often come in the form of opportunities through hands-on activities that are provided to youth in contexts such as community organizations, schools and colleges, and sports clubs (Larson, Hansen, \& Moneta, 2006; Murphy \& Reichard, 2011).

Accordingly, PYD gave ways of identifying, describing, and measuring some of the observed phenomena and characteristics present in Latino congregations which seem 
to be contributing to the leadership development of young congregants. From the array of activities and positive interactions that support PYD, particularly the behavioral indicator of exercising leadership (Benson, Scales, \& Syvertsen, 2011) or reaching the Sixth C Contribution (Schmid Callina, Johnson, Buckingham, \& Lerner, 2014), the topics of social service involvement and engagement in leadership tasks were selected to create the construct variables for mediating the analysis of the relationship between youth leadership development and religious participation. In other social contexts (e.g., schools and after-school programs) these two developmental activities have been hypothesized to have a positive relationship with leadership development among youth, thereby providing a possible framework by which to empirically study and analyze the relationship (Giles \& Eyler, 1994; Lerner, 2004c; Lerner, Lerner, et al., 2005).

These mediating factors were also specifically chosen because they reflect unique characteristics that make the local institutional dynamics different in Latino congregations than in other groups, such as those of the cultural majority. These are distinctive characteristics which personal observation and anecdotal accounts from published authors have identified as being present in congregations that nurture the previously described organic dynamic of leadership development among youth (see Background and Rationale section of this chapter) (Maldonado Pérez, 2005; Martínez, 2008; Tamez Méndez, 2017).

In Latino congregations, one frequently finds a rich environment of learning experiences that provide opportunities for congregants to engage in leadership tasks and exercise social responsibility towards the community (Hamar-Martínez, 2014; Martínez, 2008; Mulder, Ramos, \& Martí, 2017; Ortiz, 1993; Stepick, Rey, \& Mahler, 2009). It is 
common for congregants in Latino churches to engage in leadership tasks at all levels because there is a view of church as community or family, a sense that everyone belongs and is needed. This is especially true because many congregations do not have full-time pastors or other paid staff or ministers to do the necessary work (Hernández et al., 2016; Martínez, 2008). As for social responsibility through community service efforts aimed at addressing basic needs, these are also common practice within Latino congregations, especially as many of these churches tend to be located and serving among marginal communities low in resources (Crane, 2003; Martínez, 2008; Stevens-Arroyo et al., 2003).

Previous studies have found that social and institutional contexts which are rich in providing opportunities for practicing and engaging in leadership tasks, and for being involved in social service or service-learning efforts, help to nurture in youth a wide spectrum of characteristics and skills that promote leadership emergence and development (Cress, Astin, Zimmerman-Oster, \& Burkhardt, 2001; Strobel \& Nelson, 2007; Waldstein \& Reiher, 2001; Yates \& Youniss, 1996). Such engagement also tends to increase their intentions to become community leaders and contribute in adulthood (Giles \& Eyler, 1994; Lerner, Lerner, et al., 2005; RMC Research Corporation, 2002). However, most research regarding contributing contexts has been conducted in the setting of colleges, schools, and after-school programs (e.g. Crooks, Chiodo, Thomas, \& Hughes, 2010; Dugan \& Komives, 2007; Horn, 2011; Zimmerman-Oster \& Burkhardt, 1999); religious settings have not yet been widely studied.

Using the aforementioned theoretical framework, this study sought to provide a foundation for further assessing some of the individual congregant-level characteristics, 
as well as contextual, sociological, and developmental attributes present in Latino congregations which PYD indicates these contribute towards youth leadership development. A full description of the theoretical framework is included in Chapter 2.

\section{Research Questions}

Using the data collected through the CLCS-YS instrument, this dissertation sought to explore the relationship between factors that are of interest to answering the general research question: What is the relationship between the level of youth's Religious Participation, and their level of engagement with two contributing ecological factors characteristic of Latino congregations: Social Service Involvement and Engagement in Leadership Tasks? To this end, based on the general research question, the study addressed the eight specific research questions listed below. See pertinent sections within this chapter and Chapter 3 for the general and operational definitions of terms related to these questions.

Research Question 1: What is the level of Religious Participation among youth in Chicago Latino congregations, as measured by the aggregate score?

Research Question 2: How does the level of youth's Religious Participation, as measured by the aggregate score, relate to: denominational affiliation; age; gender; Hispanic/Latino group identification; language usage; and participant's country of birth?

Research Question 3: What is the level of Social Service Involvement among youth in Chicago Latino congregations, as measured by the aggregate score?

Research Question 4: How does the level of youth's Social Service Involvement, as measured by the aggregate score, relate to: denominational affiliation; age; gender; Hispanic/Latino group identification; language usage; and participant's country of birth? 
Research Question 5: What is the level of Engagement in Leadership Tasks among youth in Chicago Latino congregations, as measured by the aggregate score?

Research Question 6: How does the level of youth's Engagement in Leadership Tasks, as measured by the aggregate score, relate to: denominational affiliation; age; gender; Hispanic/Latino group identification; language usage; and participant's country of birth?

Research Question 7: Is there a significant relationship between Social Service Involvement and Religious Participation among youth in Chicago Latino congregations?

Research Question 8: Is there a significant relationship between Engagement in Leadership Tasks and Religious Participation among youth in Chicago Latino congregations?

\section{Significance of the Study}

This study is significant for a number of reasons. First, as a researcher it provides me with the opportunity to learn more about Latino congregational dynamics and characteristics that might be contributing towards the development of youth as leaders. This topic and the questions of this research study have been a point of personal inquiry for years in my work and my desire to see churches developing young leaders. The findings will contribute towards addressing the pressing question of how to develop the "next generation" or "future leaders" of the church (both laity and ordained ministers).

Second, as local congregations and their leaders reach out, include, and minister to the younger generations, the material and findings in this study provide information on how some of the positive practices identified within Chicago Latino congregations might be transferable and useful to support their goals for developing youth as leaders. For 
pastors and clergy, as well as denominational leaders, this study's findings can assist in their efforts to determine the focus, mission, and best practices of the church, and to justify the allocation of resources needed to serve the youth in their congregations and denominational entities.

Third, the findings in this study will be useful to educational entities such as seminaries, universities, and Bible institutes that provide training and courses related to leadership development, practical theology, and youth ministry. The findings can contribute to the curricula as well as to their strategic plans to encourage more students to consider ministry as their vocation.

Fourth, this study will add findings towards the efforts of the CLCS. The CLCS has the objective of understanding the factors that contribute to the growth and vitality of Latino congregations, the social impact of these churches in their communities through their assistance programs, the way Latino churches relate to other faith-based organizations and secular non-profits to provide services more effectively, and the role and needs of the leaders and their congregants to continue to be socially engaged. The findings will also contribute towards the projects and interests of the Center for the Study of Latino Religion, a program of the Institute for Latino Studies of the University of Notre Dame, under whose sponsorship all portions of the CLCS data collection and original study were conducted. In addition, the current study will contribute towards the efforts and projects of the donors who provided funding for the CLCS: The Pew Charitable Trusts, the Richard and Helen DeVos Foundation, the Louisville Institute, and the Annie E. Casey Foundation.

Fifth, this study is important for New Generation3 (NG3), my consulting and 
training organization, where we focus on issues of youth development among multicultural youth. The insights provided by this study in the areas of leadership development, youth religious participation, and social service involvement dynamics in Latino congregations will help our team to deepen the curriculum and training we provide among different church denominations, faith-based organizations, and publishing houses.

Finally, this study may also provide verifiable knowledge for the following fields of study: sociology of religion, leadership development, youth development, culturally diverse youth studies, theological education, and ministerial practice. It will also contribute to the much-needed literature and research regarding the role of religion in adolescent life, specifically as it relates to leadership development within Latino congregations.

\section{Assumptions}

Due to the scarcity of research studies on this study's topic, there are some conceptual and local institutional aspects that are presumed to be true based on my and other authors' observations and experience in the field (e.g., Martínez Guerra, 2004; Martínez, 2008; Mulder et al., 2017). Furthermore, some research methodology aspects are assumed in this study in light of the use of data already collected through the CLCS (Burwell et al., 2010).

The basic assumptions that underlie this study, in regards to conceptual and national and local institutional contextual aspects, are (a) that leadership development is a pressing concern among congregations and their current clergy and leaders, (b) that Latino congregations are providing opportunities for involvement in social service and 
engagement in leadership tasks, and (c) that young congregants are partaking in these opportunities.

In reference to the research data collected through the CLCS, it is assumed that (a) corresponding consent forms were signed by each participant and/or legal guardian, (b) participants were able to understand the questionnaire which was provided both in English and Spanish, (c) respondents answered honestly, (d) anonymity was guaranteed to the participants, and (e) the data collected between the years 2004 and 2007 still reflect the institutional characteristics and dynamics of Latino congregations at the time of this study.

\section{Definition of Terms}

This study utilizes specific terminology throughout. To promote common understanding and avoid miscommunication, definitions of terms and concepts as used and understood in this study are provided in this section. For operational definitions of variables and coding, see Chapter 3.

Ecological contributing factors: refers to the contextual factors present in a macro level system or ecology (e.g., institution, social group, youth program) which impact and contribute to the healthy and positive development of youth (Bronfenbrenner \& Morris, 2006; Lerner et al., 2011). Previous theoretical work and research has suggested various environmental characteristics, interactional dynamics, and social factors that are categorized as such, and which provide positive experiences, relationships, and environments. Some examples are: providing opportunities to actively engage in developmental activities such as responding to community needs through service and engaging in team work through structured projects (positive experiences); providing 
opportunities for healthy and supportive relationships such as mentors, caring adults, and peers (positive relationships); and providing and promoting an organizational culture and space where young people feel safe, valued, and encouraged (positive environment). In this study, the focus is on ecological contributing factors that have the potential to support youth's leadership development (Klau, Boyd, \& Luckow, 2006; Lerner et al., 2013; Murphy \& Reichard, 2011).

Latino: is a term constructed by the U.S. Census Bureau and used to refer to the population sector of the United States who is of Latin American or Spanish origin. The term Hispanic or Latino can be used interchangeably, and the usage of both terms has changed to adapt to a wide range of geographical and historical influences in the United States (Oquendo, 1995).

Latino congregation: is a term used in this study as referring to the proportion of the church or congregational participants who self-identified as Latino or Hispanic, independent of whether or not the congregation institutionally self-identified as a Latino or Hispanic congregation. Due to the differences in characteristics, dynamics, and organization, for Protestant churches, a congregation was included in the sampling frame if a minimum of 50 percent of its regular participants were Latino. In the case of Catholic churches, since congregations tend to be larger and the worship service dynamics are different, the threshold was lowered to a minimum of 30 percent of its regular participants being Latino (Burwell et al., 2010).

Leadership: is best understood as a gradual relational process (Clinton, 1989). Leadership is not defined by a title or position. Leadership is rather the act of engaging with, and navigating through, a series of steps that take place over time, with the goal of 
influencing a positive change towards a common purpose (Clinton, 2012; Hughes, Ginnett, \& Curphy, 2012; Kouzes \& Posner, 1987; Murphy \& Johnson, 2011).

Leadership development: denotes the process of advancement and growth of an individual's leadership skills through no formal mechanism (Avolio \& Gibbons, 1988). Leadership development is understood as a process based on experiences that span a lifetime (Avolio, 2005; Avolio \& Gibbons, 1988; Avolio \& Hannah, 2008; Avolio \& Vogelgesang, 2011; Day, 2000, 2011; Day et al., 2014; Day et al., 2012; Murphy \& Johnson, 2011; Murphy \& Riggio, 2003; Norton Jr., Murfield, \& Baucus, 2014; Stadler, 2009).

Leadership Tasks: speaks of key tasks that are related to the function of a leader, such as influencing others, public speaking, and planning events. The practice of these tasks constitutes early learning experiences in the life of a person, which continue to be built upon throughout their life (Murphy \& Reichard, 2011; van Linden \& Fertman, 1998).

Religious Participation: indicated identification and active participation or engagement, beyond attendance, with a local church or congregation with whom religious and faith values are shared (Beckford \& Demerath III, 2007; Smith, 2003). Programs generally include worship service, religious education classes, and church outreach groups (e.g., drama, choir, youth group). This study includes participants from the following faith traditions: Catholic, Mainline Protestant, Evangelical, and Pentecostal. Social Service: is conceptually defined as the mutually beneficial relationship of the individual and the community (Sherrod, Torney-Purta, \& Flanagan, 2010). It refers to involvement with the community, neighborhood, and/or church through acts of service or 
volunteer activity based on understanding of needs, ability, and commitment to contribute (Wilson \& Simson, 2006). Other terms associated with it and used interchangeably in research and literature are community service, volunteerism, and civic involvement or activism (Flanagan \& Christens, 2011; Lerner, 2004c; Roehlkepartain, Ebstyne King, Wagener, \& Benson, 2005; Wilson \& Simson, 2006); however, activism usually also includes issues related to political affiliation, democracy, civism, and patriotic ideologies, which are outside of the scope of this study.

Youth, adolescents, and young adults: are terms used interchangeably to define the target population of this study. These are participants between 13 and 19 years of age (sample population) who responded to the questionnaire in the CLCS-YS. The age range was set to correspond with that which is established within human developmental science as representative of the adolescent phase (Furlong, 2012; Nakkula \& Toshalis, 2006; Steinberg, 2017).

\section{Methodology}

The research design for this dissertation is grounded on survey research methodology, which is common in the field of sociodemographic and sociology of religion investigations. The analysis of survey-generated data serves to create a "snapshot" and shed light on phenomena unfolding at a specific place and time. Although this research design limits the findings and conclusions in that these are not representative of, and cannot be applied to the population at large, the findings do provide a contextual description of social indicators present in the setting where the survey research was conducted. These indicators are central to identifying and monitoring social trends, while also providing insight which is important to consider and integrate when developing 
policies, and programs which impact the population studied (Glewwe \& Levin, 2005;

Voas, 2007). Furthermore, the data gathered and analyzed provide a foundation for subsequent research such as longitudinal studies and comparison studies that examine the direction of social trends overtime (Voas, 2007).

To obtain data from a substantial number of participants, this dissertation was based on the secondary analysis (Smith, 2008) of portions of the quantitative data collected through the CLCS (Burwell et al., 2010). This multi-level study of Latino Christian congregations in the Chicago metropolitan area is one of the most comprehensive sources of data to date for exploring questions related to religious factors among Latinos

The CLCS utilized five different surveys which were designed for the multiple participant samples in the study. Survey 5, also referred to as CLCS-YS, is a survey of youth congregants from the sampled churches, which serves as the source of data for the analysis in this dissertation (see Appendix A). This is the first time the data of the CLCSYS have been used in a doctoral study and the data have also not been previously analyzed for other research purposes. I received full access to the dataset required for this dissertation through the authorization of the principal researcher of the CLCS (see Appendices D and E).

The data analysis and statistical treatment in this dissertation were completed using a quantitative evaluation method, based on ex post facto design Type III (Newman \& Benz, 1998; Newman, Newman, Brown, \& McNeely, 2006). Research hypotheses were tested while controlling for alternative hypotheses, as this strengthens the internal validity of the design, and also attempts to control for some of the confounding 
alternative explanations, such as the effects due to gender, age, denominational affiliation, etc. (Newman \& Benz, 1998; Newman \& Newman, 2010; Newman et al., 2006).

Statistical examinations through descriptive statistics, measures of variability, and generalized linear (GLM) analysis of variance (ANOVA) equation models (Fox, 2015; Hocking, 2013; Howell, 2010; Weiss, 2006) were conducted to determine whether there were statistically significant relationships between the predictor (Religious Participation), criterion (Social Service Involvement and Engagement in Leadership Tasks), and demographic control (age, gender, denominational affiliation, Hispanic/Latino group identification, language usage, and participant's country of birth) construct variables that were created for analysis based on the CLCS-YS.

For the analyses of research questions which contain both continuous and categorical items, independent generalized linear mixed models ANOVAs were used (Fox, 2015). Furthermore, Type I error buildup was controlled through the Bonferroni test with an alpha level set at $0.05(\alpha=0.05)$, and Type II error and effect size were controlled through a power analysis. The $F$-test was used to test the statistical significance of the proposed relationships in the hypotheses (Newman, Fraas, \& Laux, 2000; Newman et al., 2006). A full description of the research design, data analysis, and statistical treatment is found in Chapter 3.

\section{Limitations of the Study}

There are various aspects of this study that limited the results and the generalizability of these. The recommendations of this study are mainly descriptive and are limited to the local congregational contexts that reflect the characteristics of those 
who participated in the CLCS. Although the findings of this study may not be generalized to other congregations and denominations that were not part of the CLCS study, the findings nonetheless can be of general interest to others who share similar national and local institutional characteristics and who are also seeking to reach, minister, and contribute to the development of young people as leaders in their local community and congregation.

In addition, because the CLCS data are limited to Chicago Latino churches, the results therefore cannot be generalized nationally. On the other hand, there is no particular a priori reason to conclude that the findings from this study do not apply throughout the United States. The data provide a good starting point to begin examining local institutional factors, within a church context, that previous theoretical work has suggested are potentially contributing interactional and social factors for leadership development among youth. However, it is also important to consider that the items that constitute the criterion, predictor, and control construct variables were based on preexisting data resulting from the items of the original questionnaire of the CLCS-YS. Therefore, in some cases, the pool of items did not include some components that would have expressed the variables scales in a broader manner. In addition, as with all selfreporting survey instruments, the participants may not have understood the intent of the survey question and so their answer might have been based upon their individual subjective perceptions.

Moreover, the CLCS is cross-sectional data, and therefore causal inferences cannot be made about the relationships between the various variables analyzed. Yet, the findings in this dissertation can still provide some direction for future research that 
focuses more specifically on causal relationships. In addition, it can provide data for future longitudinal studies that follow the leadership development trajectory of youth.

Furthermore, consideration must be given to my bias after working for so many years among Latino congregations. Although this is a limitation, this influence was minimized as much as possible first, by relying on and citing the work and research of other authors who have documented the characteristics and dynamics of local Latino congregations; and second, by supplementing that work by conducting informal exploratory interviews among diverse Latino clergy and denominational leaders throughout the country, with the aim of hearing their accounts of their local congregations and situations. Every effort was made to avoid relying on a single source.

\section{Delimitations of the Study}

The first delimitation of this study was to include the data of only the adolescents and young adults who were between 13 and 19 years of age when they answered the CLCS-YS survey. Second, only the data of participating youth who were of Hispanic or Latino descent were selected. Third, only portions of the data collected in Part 1, Part 2, Part 3, and Part 7 of the CLCS-YS survey were analyzed in order to answer the research questions of this study. Fourth, the religious traditions or denominations that were included in the sampling frame were Catholic, Mainline Protestant, Evangelical, Pentecostal, and others, but did not include Jehovah's Witnesses, The Church of Jesus Christ of Latter-day Saints, and other groups that fit the classification of new religious movements. Finally, this study looked primarily at the relation of youth to the church as a social context, which influences their development, and thereby their leadership 
emergence and development; it did not analyze religious beliefs, spirituality, or faith factors.

\section{Organization of the Study}

This study hypothesized that religious participation among youth has a positive relationship with social service involvement and engaging in leadership tasks within Chicago Latino congregations. Chapter 1 introduces the problem, purpose, and research

questions of the study. Chapter 2 provides an overview of the relevant literature related to the topic and used to create the conceptual framework. Chapter 3 outlines the methodology of the study, describes the population, sample, variables, research hypotheses, and research design. Chapter 4 contains in detail the results of the statistical analysis conducted for this study. Chapter 5 summarizes the study, discuses findings, draws conclusions, highlights implications for practice, and gives recommendations for further research. 


\section{CHAPTER 2}

\section{LITERATURE REVIEW}

\section{Introduction}

The second chapter of this study presents seven sections which contain a summary of the results of the literature review conducted to provide the context and frame for the research question guiding this dissertation. It also includes information related to the sources from which the material was retrieved. The first section includes an examination of PYD as the theoretical framework which directs this dissertation, with an emphasis on aspects dealing with religious contexts and youth leadership development, and it includes a critique of the theory as well. Since Latino congregations serve as the ecological contributing contexts within the PYD framework under which the analysis of this dissertation study was conducted, the second section in this chapter provides a brief overview of Latino congregations and their work among youth. The third and fourth sections provide insights into the two topics of interest related to youth leadership development within PYD. Social service involvement and engagement in leadership tasks were selected as topics by which to create the construct variables for analyzing the relationship between religious participation and youth leadership development in Latino congregations. Furthermore, due to the sociological nature of this dissertation, to create a depiction of the characteristics of the target population, the fifth section provides

pertinent details regarding the sociodemographic characteristics of the U.S. Latino 
population, including an emphasis on Latino youth. In the sixth section, as this study utilized portions of the data collected through the CLCS, a brief description of the study is provided, as well as a list of other studies that also drew data from the CLCS. The final section of the chapter summarizes the findings and conclusions of the literature review.

To inform this study, a literature search was carried out by accessing various physical and virtual libraries, conducting web database searches, requesting interlibrary loans, and having conversations with experts in the field. Some of the libraries visited, both here in the United States and abroad included the James White Library at Andrews University, the Hesburgh Libraries at the University of Notre Dame, the David Allan Hubbard Library at Fuller Theological Seminary, the Paces Learning Resources Center at the Baptist University of the Américas, the Donald E. O'Shaughnessy Library at the Oblate School of Theology, and the libraries at the Universidad de Salamanca in Spain. The literature search included a review of books and handbooks, research reports, magazines, videos, and peer-reviewed journals relevant to the content of the study. In regards to journals, the review included those on the study of religion such as Journal for the Scientific Study of Religion, journals on leadership such as Leadership Quarterly, journals on adolescent development such as New Directions for Youth Development, and journals on Latino studies such as Hispanic Journal of Behavioral Sciences. In addition, the web database searches were undertaken through JSTOR, ERIC, ProQuest, and Google Scholar, among others, using keywords including Latino, Latina, Hispanic, adolescent, youth, development, leadership, religion, social service, civic engagement, leadership emergence, leadership development, positive youth development, and the various appropriate combinations of these and other pertinent keywords. 


\section{Theoretical Framework}

Assembling the theoretical framework for this study was a challenge, for there are few research and academic literature resources for this type of study as the fields of leadership and youth, and religion and youth are in their emerging stages. Research in these two fields conducted within the Latino community is even more sparse.

Furthermore, because of the nature of the process of leadership emergence and development, although a search was conducted to find research tools by which to measure leadership development among youth in religious contexts, a direct measure was not found at the time. Empirical research in this field of study measures skills levels, personal traits, and/or contextual factors and situations in order to predict or measure leadership development in young individuals (e.g. Rubin et al., 2002; Taggar et al., 1999; Wolff et al., 2002).

Therefore, the link between religious participation and leadership development was approached through the theoretical framework of PYD. The following sections present a review of pertinent theoretical work, including the two main PYD models, as well as a brief history, relevant findings of previous empirical work, and a critique of the theory.

\section{Positive Youth Development}

In brief, PYD is a theory of contemporary applied developmental science that is concerned with the lens through which youth and youth development are viewed (Benson \& Saito, 2001; Lerner et al., 2013; Lerner et al., 2009). Positive Youth Development came as a reaction to the old developmental approach to youth which emphasized a deficit perspective of youth as problems to be managed lest they engage in at-risk 
behavior (e.g., drinking, drug use, teen pregnancy) (Furlong, 2012; Kehily, 2007; Lee \& Zhou, 2004; Nakkula \& Toshalis, 2006). In contrast, PYD emphasizes that youth are assets to be developed, (Roth \& Brooks-Gunn, 2003a, 2003b), as well as active participants who can influence their own development (Petersen, Koller, Motti-Stefanidi, \& Verma, 2017), and that they have strengths and skills to contribute to the advancement of their ecologies or communities (Lerner, Lerner, et al., 2005; Lerner \& Overton, 2008; Overton, 2013a, 2013b). The healthy development and thriving of young people occurs within a reciprocal relationship between the individuals and their environments which provide them the needed support through an intentional framework of positive interactions (Lerner et al., 2009; Lerner, 2002, 2004b).

The following sections present further details regarding PYD theory and how it undergirds the relationship between religious participation and leadership development among youth in Latino congregations through the potentially mediating activities and opportunities of social service involvement and engagement in leadership tasks.

\section{Theoretical Overview of Positive Youth Development}

Positive Youth Development emerged in the 1970s (Lerner, 2002; 2006; Overton, 1998, 2006) as a perspective that arose from the work of comparative psychology (e.g., Gottlieb, 1997; Schneirla, 1957) and biology (e.g., Novikoff, 1945a, 1945b; von Bertalanffy, 1969), which focused on the plasticity and levels of integration between biological and contextual factors in developmental processes that shape ontogenetic history. The integrative and relational theoretical perspective began to appear in contemporary human developmental science, marking a break from only behavioral or 
psychological approaches to human development, which followed the Cartesian splitmechanism perspective (i.e., nature-nurture) predominant in the field up to that point (Benson \& Saito, 2001; Lamb \& Freund, 2010; Lerner et al., 2013; Lerner et al., 2009; Lerner, 2012). As an extension of applied contemporary developmental science, PYD has theoretical roots that include the following postmodern approaches (Lerner, 2006; Lerner, Fisher, \& Weinberg, 2000; López, Yoder, Brisson, Lechuga-Peña, \& Jenson, 2015): (1) philosophy of science (Pepper, 1942); (2) developmental psychology (Cairns, 1998); (3) developmental theory (Overton, 1998); (4) life-span theory (Baltes, Staudinger, \& Lindenberger, 1999); (5) bioecological and biosocial approaches (i.e., Ecological Systems Theory) (Bronfenbrenner, 1979, 1986, 2001); (6) developmental systems theory (Ford \& Lerner, 1992); and (7) relational developmental systems theory (Lerner \& Overton, 2008; Overton, 2013b).

In light of the aforementioned theoretical foundations, in particular with the principal tenet of Relational Developmental Systems Theory (RDST), PYD is framed at a meta-level by the concept that the development in an individual occurs within a bidirectional relationship between individuals and the multiple levels of their environments or ecologies (i.e., individual $\longleftrightarrow$ context relationships) (Lerner, Lerner, et al., 2005; Lerner \& Overton, 2008; Overton, 2013a, 2013b). These developmental regulations govern the course of development, its pace, direction, and outcomes; thus not only is the individual shaped and molded by experiences (i.e., there is a certain plasticity to an individual), the context (e.g., home, school, clubs, etc.) where one develops and interacts also benefits from the individual (i.e., adaptive) (Baltes, Lindenberger, \& Staudinger, 2006; Brandtstädter, 2006; Lerner, 2006; Silbereisen \& Lerner, 2007). 
Drawing from life-span theory, PYD employs a developmental organizational framework which proposes how the different stages of life are linked together and that the three adaptive processes of growth, maintenance, and regulation are part of the developmental journey from infancy through old age. Thus, a person's development is conceived as lifelong, and also, multidimensional, multidisciplinary, and multidirectional (Avolio \& Gibbons, 1988; Day, 2011; Lamb \& Freund, 2010; Lerner, 2004a).

Additionally, PYD asserts a strength-based view of youth as "resources to be developed" (Roth \& Brooks-Gunn, 2003a, 2003b), as well as active participants who can influence their own development (Petersen et al., 2017). This is a perspective which is a counterpoint to the traditional or historical Western perspectives and theories of youth development, in which youth are seen as a deficit to be managed or a problem to be solved, diminishing their social value and even perhaps verging on dehumanizing them (Furlong, 2012; Kehily, 2007; Lee \& Zhou, 2004; Nakkula \& Toshalis, 2006). This deficit perspective prompted the prolific rise of empirical research, youth programs, and social policy, which mainly focused on understanding and preventing at-risk behaviors such as drug use, violence, suicide, teen pregnancy, delinquency, among others (Larson, 2000; Lerner, Almerigi, Theokas, \& Lerner, 2005). By contrast to this negative approach, PYD views youth as an often-untapped asset to society, and in terms of their positive potential, which is honed through sustaining and building upon their talents, energy, strengths, and constructive interests (Benson, Scales, Hamilton, \& Sesma, 2006; Lerner et al., 2013; Lerner et al., 2009; Lerner, Almerigi, et al., 2005). Thus, scholars in this field have focused on investigating human strengths and the multiple contexts and characteristics of those ecological contexts that promote positive youth development. 
This positive perspective has affected not only theories and the approach to empirical research, but also the programing and interventional practices of community-based youth outreach efforts, as well as social policy perspectives (Benson et al., 2006; Lerner et al., 2013; Lerner et al., 2009; Lerner, 2004b; Lerner et al., 2011; Petersen et al., 2017). Hence, PYD is considered a highly contextual notion. Youth exist within their context, but they are also in a state of constant interaction with this context (Overton, 2013a, 2013b), a context which includes all the various interrelated social environments such as home, school, clubs, after-school programs, and church. Many adolescent experiences - and the chance to experience them — come from these contexts, and the way in which adolescents respond to these possibilities can play a significant role in shaping their development of skills such as leadership (Overton, 2013a). Researchers have found that when youth develop in environments that respond to their changing needs and that provide them with positive and sustained adult-youth relationships for at least a year, they are more likely to experience healthy outcomes (Blum, 2003; Eccles, 2004; Eccles \& Gootman, 2002; Eccles et al., 1993; Eccles \& Wigfield, 2002; Lerner, 2004a, 2004c; Rhodes, 2002; Roth \& Brooks-Gunn, 2003a, 2003b). This is especially the case in environments that also afford youth the space to act as producers of their own positive development by giving them the opportunity to strengthen the skills and competencies needed for functioning in the world, for example: taking initiative, developing leadership, learning responsibility, practicing strategic and teamwork skills, and giving back to their community (Dworkin, Larson, \& Hansen, 2003; Eccles \& Gootman, 2002; Larson, 2000; Larson \& Hansen, 2005; Larson, Hansen, \& Walker, 2005; Larson et al., 2006; Larson et al., 2004; Larson, Walker, \& Pearce, 2005; Larson \& 
Walker, 2006; Lerner, 2004a; Lerner et al., 2000; Mahoney, Larson, Eccles, \& Lord, 2005; Petersen et al., 2017).

In PYD, the ideal outcome of these developmental dynamics is termed "thriving", which refers to exemplary positive development of a young person across the adolescent years unto adulthood (Benson et al., 2011; Lerner et al., 2013). Thus, research in this field of study has focused on further understanding a combination of topics: human strengths, the multiple contexts, and the characteristics of those contexts that promote PYD (Lerner et al., 2009; López et al., 2015). In this regard, there is substantial variability among the views of different researchers (Lerner et al., 2009), and there is not yet an integrated PYD theoretical model of developmental processes or measurements with which all researchers agree (Lerner et al., 2013). However, there are two leading models in PYD research, literature, and practice - Benson's Developmental Assets (Benson, 1997, 2003, 2007; Benson et al., 2011) and Lerner's Positive Developmental Settings (Lerner, Lerner, et al., 2005). Their widespread acceptance makes them appropriate to inform the theoretical framework for this dissertation. Pertinent aspects of both models are briefly described in the following sections.

\section{Developmental Assets Model}

The PYD research focus of Peter Benson and other scholars at The Search Institute (Benson, 1997, 2003, 2007, 2008; Benson et al., 2011) has been fundamental in providing terminology and a model of organization for the internal strengths of young people and the various levels of contextual influences that promote development. Their

Developmental Assets model emphasizes 40 assets that need to be present in the lives of youth in order for them to thrive. These assets are divided into "internal" and "external 
assets and thriving occurs when these two categories of assets align. Internal assets refer to individual and psychological characteristics such as personal values, goals, and positive identity. External assets represent the contextual and relational features of the social environment where the young person is developing, for example, support, boundaries, expectations, empowerment, and a safe environment (Lerner et al., 2013). These 40 Developmental Assets have been found to be predictive of what this model presents as seven behavioral indicators of thriving: 1) school success, 2) exercising leadership, 3) helping others, 4) maintaining physical health, 5) delaying gratification, 6) valuing diversity, and 7) overcoming adversity (Leffert et al., 1998; Lerner et al., 2009; Scales, Benson, Leffert, \& Blyth, 2000). In their extensive overview of PYD theory, Benson et al. (2006) described leadership as an integral part of the PYD model, and noted that youth exercising leadership is a way for youth to affect both themselves and their social context positively. Thus, they called for further research into how the impact of youth leadership can be increased; this dissertation research contributes to the dialog on that issue. Further theoretical views regarding leadership as a developmental factor in youth's lives are explored in subsequent sections of this chapter.

\section{Positive Developmental Settings Model}

Influenced by Benson's PYD model, Lerner and colleagues have developed the Positive Developmental Settings model (Lerner, Lerner, et al., 2005), which likewise focuses on the strengths of the individual, the characteristics of ecological contexts that predict positive growth (i.e., positive developmental settings), and how these contexts influence and nurture the hypothesized personal attributes that characterize a young person who is developing their strengths into idealized adulthood. These personal 
attributes have been organized into what is termed the Five Cs of PYD, which are: 1) competence, 2) confidence, 3) connection, 4) character, and 5) caring or compassion (Eccles \& Gootman, 2002; Lerner et al., 2013; Lerner, Lerner, et al., 2005; Roth \& Brooks-Gunn, 2003a, 2003b). Subsequent research proposed that when young people have grown in these five attributes (i.e., the Five Cs) and manifest them across time, it is then hypothesized that they will in turn act in integrated and mutually reinforcing ways that contribute to self and the ecological context that is benefiting them, that is: family, community, and civil society. In this expanded model, the attribute of Contribution is what is termed the Sixth C of PYD (Lerner et al., 2005). Contribution is a composite score of four subsets: leadership, service, helping, and ideology (Schmid Callina et al., 2014). Contribution thus reflects the frequency with which, or the amount of time that, youth spend helping others, providing service to their communities, acting in leadership roles, and the extent to which contributing is important for that young person's identity and future self (Jeličič, Bobek, Phelps, Lerner, \& Lerner, 2007; Lerner, Lerner, et al., 2005; Schmid Callina et al., 2014). Therefore, in this model, thriving is defined in a young person's life as the growth and development of the attributes outlined in the Five Cs, and ultimately, the development of the Sixth C - Contribution (Lerner et al., 2013). Although the model itself originated in the late 1990s, it has only recently been tested through a longitudinal study of PYD among youth from 5th through 11th grade who participated in the 4-H program (Geldhof et al., 2014; Lerner, Lerner, et al., 2005).

\section{Ecological Contributing Contexts}

Both models are interested in investigating further how ecological contributing contexts are a source of influence towards PYD in young people, since both theoretical 
models stress the role and ability of macro level systems to positively impact the ecology of human development during the course of adolescence (Bronfenbrenner, 2001; Bronfenbrenner \& Morris, 2006; Gestsdóttir, Urban, Bowers, Lerner, \& Lerner, 2011). Furthermore, literature points out that the interest for implementing these PYD models also derives from policy makers and youth advocates as they suggest that communitylevel efforts are needed in order to nurture PYD (Cummings, 2003; Gore, 2003; Petersen et al., 2017; Pittman, Irby, \& Ferber, 2001). Although PYD terminology has not permeated religious contexts to a great extent, this interest in community-level efforts to nurture PYD is likewise conceptually expressed by churches and denominations seeking to reach, serve, and prepare youth to take on leadership in the work of the church (Davis, 2007; Johnson-Mondragón, 2007; Martínez, 2008; Rodríguez, 2015; Roehlkepartain \& Scales, 1995).

Further exploring ecological contributing contexts is a research interest that also aligns as a response to the sociological overview that Robert D. Putnam (2000, 2001, 2002) proposed regarding the importance of the social capital youth acquire through these contributing contexts. There is not the sole definition of social capital (Enfield, 2008) as it has different connotations in different fields of study (e.g., economics), but in the fields of sociology and human development social capital is, in essence, the creation of value through social networking - the idea that knowing people and connecting with them is an important and valuable attribute as it facilitates collective action for mutual benefit (Putnam, 2000; Woolcock \& Narayan, 2000). Putnam (2002) highlights that, as a result of the major social shifts of the twentieth and twenty-first centuries, we have fewer social supports and networks compared to the past, yet precisely such social capital is vital in 
holding communities together for reciprocity that leads to effective functioning. The reversal of this sociological trend is imperative for PYD, for in order to thrive, youth need to be at the center of community life, surrounded by caring adults that support them in a wide variety of contexts, including professional contexts, educational contexts, casual contexts, religious contexts, and any other contexts in which individuals interact with one another and form social networks (Eccles \& Gootman, 2002; Putnam, 2000).

Thus, churches are naturally a site for the creation of social capital because they are a context in which people interact with one another. However, the relationship between religion and social capital may go deeper than this. In a study by Ebstyne King and Furrow (2008), the findings indicated that religious youth reported higher levels of social capital than their peers. In addition, these social capital resources mediated the relationship between religiosity and moral outcomes. Thus, the relationship between churches and social capital may be somewhat reciprocal; attending church helps to develop social capital through those whom an adolescent meets and with whom they interact in the religious setting, and this social capital in turn influences the youth's propensity toward religion (i.e., practicing that which is learned in religious settings). The key concept to highlight regarding youth development and social capital is that churches provide ties and connections by which young people have access to opportunities, experiences, and forms of support, and that these promote life skill development (Scales et al., 2000)—something that has higher implications among immigrant communities, as subsequent sections will address.

Understanding the characteristics of ecological contributing contexts is imperative as previous studies found that for youth who reported three or more hours a week of 
participation in sports, clubs, or organizations at school or in the community, this was the developmental asset that was most linked to their thriving outcomes (Scales et al., 2000), yet, Roth and Brooks-Gunn (2003a) report in their evaluation research that there is a difference between traditional youth programs and those youth programs which intentionally integrate and practice the tenets of PYD. These latter programs are more likely to be associated with the presence of key indicators of PYD. Furthermore, in their extensive overview of the state of PYD research, Lerner et al. (2013) point out the need to broaden the scope of contexts within which PYD is embraced and practiced by providing youth with positive experiences, relationships, and environments. Currently the role of families, community youth programs (e.g., 4-H, YMCA), and schools are receiving substantial attention. However, there are other important contributing contexts, such as workplaces and faith communities, where the assets and developmental opportunities available need to be studied further. Although the congregations that participated in this dissertation study were not specifically identified as practicing PYD, nor were any PYD measures included in the survey questions, the current study contributes toward further understanding the opportunities and activities available for youth within Latino congregations which previous studies have recognized for their potential to enhance PYD, more specifically, the developmental asset of exercising leadership (Benson's model) or Contribution (Lerner's model).

\section{PYD and Religious Contexts}

As a result of the interest in understanding the characteristics of ecological contexts which contribute towards PYD, research has been conducted focusing on specific types of contexts. However, as previously mentioned, the majority of these 
studies have been conducted in school settings, after-school youth programs, and service learning programs in schools (e.g., Barber, Mueller, \& Ogata, 2013; Dawes \& Larson, 2011; Eccles, Barber, Stone, \& Hunt, 2003; Seon-Young, Olszewski-Kubilius, Donahue, \& Weimholt, 2008). Nevertheless, there have been a few PYD studies conducted related to church or religious contexts, and thus some initial indicators that support the relationship (Benson, Roehlkepartain, \& Rude, 2003; Eccles \& Gootman, 2002; King, 2003; Lerner, Brentano, Dowling, \& Anderson, 2002). For example, Damon and colleagues at the Stanford Center on Adolescence looked at youth's engagement in making meaningful contributions to communities (i.e., youth purpose) as a central indicator for PYD and thriving, specifically in an effort to understand potential sources of youth's purpose (Damon, 2003, 2004, 2008; Damon et al., 2003; Mariano \& Damon, 2008). Their survey study among diverse youth from grades sixth, ninth, twelfth, and college, asked participants to indicate their level of dedication to 18 categories of purpose, among which were included: general leadership, social issues, religious faith or spirituality, and community service. Additionally, interviews were conducted with 12 young people who had demonstrated high levels of active engagement in their purpose, having concrete future plans related to their purpose, two or more years of commitment to a cause, and the rationale for involvement being intention to contribute to the world beyond themselves. The findings revealed that the relationship between spirituality, religion, purpose, and different aspects of PYD provide a pathway of support for youth to reach the Sixth $\mathrm{C}$ - Contribution. Spirituality plays a role in guiding young people toward the intention to contribute (i.e., ultimately leading to Contribution), having personal goals inspired with purpose, and character development. However, it is still not known under 
what circumstances and contextual characteristics an involvement in spirituality and religion leads to Contribution.

In a similar manner, Furrow, King, and White (2004), in a study among 801 urban public high school students, found further support for religion as a positive developmental resource. The study linked the effects of religious identity to personal meaning and prosocial concern. It illustrated "how religion provides a resource for meaning and purpose and a sense of commitment to caring for others beyond themselves." (Furrow et al., 2004, p. 25). The study focused on the potential that churches and religious organizations have as a source of ideological grounding to shape a sense of purpose and commitment to the common good among youth and throughout their development into adulthood. The researchers highlighted the need for further research to understand the different aspects of the religious experience that prove most salient in shaping prosocial concerns among youth.

In a subsequent study conducted among 735 urban youths, King and Furrow (2008) found that social interaction, trust, and shared vision, which are associated with social ties embedded in religious influences, have a particularly high effect on youth's moral behavior and development. This highlights the importance of congregations and faith-based organizations as places of developmental leverage for youth.

Overall, this has been the research focus thus far regarding PYD and religion. The work has focused mainly on spirituality, religiosity, transcendence, and ideologies fostered in churches and faith-based organizations which contribute towards PYD and thriving (e.g., King \& Boyatzis, 2004; Lerner, Roeser, \& Phelps, 2008). More research needs to be conducted regarding the identification and understanding of contextual 
characteristics of churches and congregations as social contributing ecologies in youth's PYD. This dissertation contributes to this area of study by analyzing potentially contributing characteristics present in Latino congregations.

\section{PYD and Leadership Development}

In looking into the specific aspects of leadership development among youth as an indicator for PYD and thriving, for nearly a century the literature and study of this topic has been mostly associated with agricultural education and secondary educational youth development programs (i.e., after the passage of the Smith-Lever Act of 1914). However, since at least 1988, there has been a noted lack of meaningful study and very disjointed research of youth leadership development in the educational and developmental literature (Connors \& Swan, 2006). Connors and Swan (2006) reviewed the proceedings of agricultural educational publications - with agriculture, and especially the 4-H program being a prominent space for youth leadership — and found that less than five percent of the articles were actually concerned specifically with leadership, and that very few authors had written on the topic consistently and with well-developed theoretical frameworks. MacNeil (2006), in likewise reviewing the extant literature, also determined that when youth leadership is addressed at all, it is usually seen as a skill to be developed for the future rather than one to be fostered and practiced now. These observed dynamics in research are all related to the paradox of attempting to apply adult definitions and theories of leadership to youth. Adult leadership literature is characterized by a focus on issues of authority and opportunity (i.e., voice, influence, and decision-making power), especially as most studies have been conducted in military, business or other professional settings, and the structure of society is generally not inclined to afford these types of 
attributes to its youth (Bass, 1990; Klau et al., 2006; Mortensen et al., 2014). In contrast, literature that focuses on leadership among youth, tends to make greater emphasis on issues of ability development (i.e., skills, knowledge, and talents) (Klau et al., 2006; MacNeil, 2006; Murphy \& Reichard, 2011; van Linden \& Fertman, 1998). This deficit in literature goes both ways: not only is there a lack of leadership topics mentioned in the youth literature, in the general leadership literature there is also a lack of youth as the focus of research (MacNeil, 2006). For example, after examining Bass' (1990) comprehensive review of more than five thousand leadership studies, I found that not one deals with youth as leaders or leadership development for youth. Thus, youth leadership remains a largely unexplored topic, and even where such literature does exist, it is often more concerned with evaluating leadership programs for youth rather than the actual functional development of leadership skills among youth and nurturing youth as leaders (MacNeil, 2006).

In addition, Mortensen et al. (2014), who used the National Youth Leadership Initiative survey to gather data on youth leadership perspectives, found that there is a marked difference between youth and adults regarding their conceptualization of leadership. The analysis of data from 130 participants suggested that the youth participating in the study viewed leadership as available to anyone in any context, that it involves creating change and collective action, and that it requires strength of character (Mortensen et al., 2014). Similarly, Archard (2013) studied the leadership perceptions of adolescent girls in Australia and South Africa through a series of six Skype-based focus groups, and found that the girls not only recognized leadership, but felt they had participated in it. The girls were more likely to define leadership in terms of a leader's 
attributes rather than their position or role. These notions of leadership do not necessarily align with those found among more adult-centric views of what it means to lead or develop leadership, where authority and the holding of high positions are central to their leadership perspectives (MacNeil, 2006). Ricketts and Rudd (2002), who conducted a meta-analysis of the leadership development literature, found that employers often undervalue leadership as a skill in youth compared to other traits; this is perhaps unsurprising, given the difference in the conceptualization of adult and adolescent leadership. Employers can hardly be expected to value a skill that their perspective on leadership suggests cannot exist without adult authority. This disparity is particularly relevant to the present study, because the adult-centric perspective of leadership can generate a lack of regard for youth as leaders in Latino churches, it can deny them the authority needed, and can limit how they are viewed among the congregation, even when they are actively serving the needs of that congregation and making meaningful contributions.

Yet, this lack of authority is not the full extent of the problem. Even where adults might want to take a more youth-centric approach to developing leadership, in which the youth take on the role of exercising leadership with scaffolding — that is: support, demonstrating, coaching, and advising — from adults, there are complications (Mitra, Lewis, \& Sanders, 2013). Central among these, according to a case study on leadership by Mitra et al. (2013), is the lack of resources to help adults learn how to scaffold young leaders effectively, and a lack of willingness on the part of adults to admit that they need to learn these new techniques at all. Thus, not only is the adult approach to leadership different, meaning primarily that it is based on different notions of power and authority, 
but adults may struggle to teach adolescents effectively how to use this youth-centric approach to leadership, because the adults lack both the resources and the willingness to move beyond their existing competencies for teaching leadership.

Consequently, youth leadership development is still a new area of research, although it has been alluded to in the past as a thematic construct in studies that deal with topics such as transferring knowledge and preparing young people for future roles in contexts like places of worship, clubs, schools, and youth-serving organizations (e.g. 4H, Girl Scouts) (Libby, Sedonaen, \& Bliss, 2006). Within specific youth leadership development research and literature, where it does exist, there is a common theme of approaching the topic from a human development perspective, with various aspects of theories informing it, such as life-span theory, cognitive and learning theories, psychosocial dimensions, and theories of leader identity development (Klau, 2006; Murphy \& Reichard, 2011; Owen, 2012). As a result, the definitions for youth leadership development range from a focus on the early developmental experiences of youth, to personal skills, to identity and self-regulation, to demonstrated actions or processes; even if insufficient, these nevertheless provide unifying perspectives by which to conceptualize youth leadership (Libby et al., 2006).

One main concept of life-span theory integrated into PYD is the idea that leadership development is a process that takes place over time (i.e., versus solely a genetic predisposition, or an acquired skill through specialized training, etc.) and that early leadership experiences can provide an important foundation for exercising leadership later in life (Avolio, 2005; Avolio \& Gibbons, 1988; Avolio \& Vogelgesang, 2011; Day, 2011; Day et al., 2014; Day et al., 2012; Day \& Sin, 2011; Murphy \& 
Reichard, 2011). These early experiences often come in the form of opportunities through activities that are provided to youth in contexts such as community organizations (Murphy \& Reichard, 2011). For example, in a quantitative study of over 600 students at a Kentucky school district, Hancock, Dyk, and Jones (2012) studied the relationship of sports, school, and extracurricular activities to leadership skills, by analyzing the influence of different involvement roles youth had in these settings and also the adult support received. The regression analysis suggested a link between students' involvement in sports, school, and extracurricular activities, the support of their parents and other adults, and their self-reported perceptions towards their leadership skills. Furthermore, Gottfried et al. (2011) demonstrated that the life-span model of leadership development is significantly correlated with intrinsic leadership motivation - that is, the motivation to lead because one is inclined to lead or enjoys leadership — and that it is a skill that can be developed through leadership experiences early in life. Unlike extrinsic leadership motivation, which arises because of situational needs and which was uncorrelated to early leadership, intrinsic leadership motivation among youth was correlated with the same intrinsic leadership motivation displayed later in life.

Approaching the topic from a PYD perspective "stretches the boundaries of current thinking on leadership development and establishes links between the specific topic of leadership development and the much broader topic of how we all develop as members of human society" while also presenting "the challenging but important message that the process of developing leaders does not start or end in a specific training program or seminar but rather is part and parcel of the lifelong process" (Murphy \& Reichard, 2011, p. xvii). Thus, studies based on the PYD approach to leadership 
development have reported results that generally support the theory and its worth. However, it is important to point out that researchers have not only repeatedly noted the need for more research on this topic (Day et al., 2014; MacNeil, 2006; Mortensen et al., 2014), but that the existing studies have almost all been conducted in the context of educational institutions. While school and its related extracurricular activities are undeniably important in the lives of young people, the role of churches deserves more attention than what current literature has paid to it, and especially so in the Latino context, where religion is central to the life of the community (Hernández, 2007; Martínez, 2008; Sikkink \& Hernández, 2003). Hence, not only does this dissertation study help address the pervasive call for more research on youth leadership, by exploring youths' level of engagement in certain types of church-related activities that have been shown to nurture leadership development, it also helps to address the void regarding studies of the role played by churches as contributing contexts in the development of youth as leaders.

\section{Critique of PYD Theory}

Indeed, PYD is a strong theory, and one which gives ample support to considering the contextual characteristics in Latino congregations which contribute to youth leadership development. However, PYD is not free of critical views from scholars in other disciplines, and from aspects which require further empirical research. In particular, some scholars suggest that the PYD paradigm goes too far in reversing the previous split Cartesian view, and that it fails to consider its own perspective critically (Sukarieh \& Tannock, 2011). From this perspective, PYD may be seen as having reversed youth development approaches from a wholly negative inclination into a wholly positive 
approach without giving due consideration to the issue's complexity and the fact that, in reality, it has both positive and negative aspects (Sukarieh \& Tannock, 2011).

Another criticism of the PYD literature came from Larson (2000) who suggested that the existing research, up to that time, focused on very generic outcome variables which lacked the support of a substantive theoretical framework. Thus, although Larson (2000) supported the idea of PYD, he found that the literature lacked sufficient theoretical precision and did not attach sufficient importance to notions of individual agency and the underlying processes for how participation in various activities actually contributes to positive development.

A third way in which PYD could be improved is by conducting substantial research among diverse youth (Lerner et al., 2013; Lerner et al., 2009). Researchers such as Margaret B. Spencer have focused on this area of research, and they have pointed out that most PYD studies fail to consider the unique developmental experiences of youth of color, which include their socially and culturally unique contributing contexts (Spencer, 2006a; Spencer, Swanson, \& Cunningham, 1991). In this regard, studies have also found that there are specific developmental assets that are more important as predictors of PYD for youth in particular cultural and social contexts (e.g., Spencer, 2006b; Taylor, 2003;

Taylor et al., 2003; Theokas \& Lerner, 2006). This is in addition to the ability (or rather lack of) of the PYD theoretical framework and the scientific interventions used, to define "what is positive development?" This is the case because the construct of the term "positive development" or "thriving" must be understood as a philosophical one which inevitably will have different definitions or answers in different cultures. For cultures with more communal approaches to social interactions versus individualistic ones, the 
indicators of thriving will look somewhat different (Benson et al., 2006; Geddert, 2010). Although the work of Spencer and others has made valuable contributions towards approaching aspects of PYD from a different cultural and social perspective, the gap in research remains as their work has not focused on the Latino community in the U.S.

Despite the opposing perspectives and areas of knowledge lacking in PYD, it is a theory that provides the framework for understanding youth through positive perspectives, highlighting internal assets that a healthy and thriving young person should grow, and identifying characteristics of the ecological contexts which contribute towards their leadership development. All these aspects informed the research question, which sought to investigate certain characteristics, actions, and behaviors of youth in Chicago Latino congregations that pertain to their leadership development, while seeking further understanding about aspects of these particular religious ecological contexts that are especially influential.

\section{Latino Congregations and Youth}

To further identify Latino congregations as part of the ecological contexts which contribute to leadership development among youth, it is important to understand some of the particular characteristics, dynamics, and challenges within these religious contexts, as well as the ways in which these congregations interact with the young people in their communities. There are certain characteristics present in Latino congregations that make them unique among other ethnocultural congregations in the U.S. Latinos represent an increasingly important segment of the Christian population, and just as the Latino community is not homogeneous, so Latino churches are also very different one to the other, even within the same denomination. However, there are certain similar 
characteristics that tend to be present among the majority of Latino church dynamics, which are important to mention as these aid in framing this dissertation study.

\section{National Study of Youth and Religion}

Before moving further into this description of social and religious phenomena present in Latino congregations, it is important to mention that past studies, including many of those referenced within this section, have relied on the results of the National Study of Youth and Religion (NSYR) (Smith \& Denton, 2009) as their source for providing contextual descriptions and making comparisons related to the religious lives of youth. The NSYR is a longitudinal study conducted in three waves from 2002 to 2008 . The purpose of the NSYR is:

to research the shape and influence of religion and spirituality in the lives of American youth; to identify effective practices in the religious, moral, and social formation of the lives of youth; to describe the extent and perceived effectiveness of the programs and opportunities that religious communities are offering to their youth; and to foster an informed national discussion about the influence of religion in youth's lives, in order to encourage sustained reflection about and rethinking of our cultural and institutional practices with regard to youth and religion. (University of Notre Dame, 2001)

The NSYR study also identified how the religious beliefs, practices and interests varied between young people of different races, ages, gender, social classes, and ecological settings (Johnson-Mondragón, 2005; Smith \& Denton, 2009). This is one of the most widely used and referenced studies of youth and religion among scholars in the field of youth development, sociology of religion, and youth ministry.

\section{Socioreligious Description of Latino Congregations}

Latino congregations tend to be comprised of people "on the move" who are looking for better opportunities in life (i.e., work, education, housing). Thus 
congregations tend to be smaller and function as an extended-family for social support (González, 1996; Hernández, Davis, et al., 2007; Martínez, 2008). As Martínez (2008) explains, these dynamics "are related to the people [to] whom they minister, the places where they live, the leadership of the churches, the atmosphere in which they live, and the religiosity that is practiced" (p. 70). In reading through this brief description of Latino churches, it is important to point out that there are factors that differentiate the dynamics between Latino Protestant congregations and Catholic parishes. One such factor is the size of the congregations, as Catholic parishes tend to be larger, for they are established by the bishop to serve Catholics in a particular geographical area within the diocese. In contrast, Latino Protestant congregations, mainly Evangelical and Pentecostal, have smaller congregations, and are located close to where Latinos live in order to serve their particular needs. Congregants tend to live close to one another and have close relationships, cultural and ethnic homogeneity is more prevalent (Martínez, 2008), and the congregations are "built from the ground up by Latinos, for Latinos" (Hernández, 2007, p. 306).

As many of the Latino churches tend to be located and serve among marginal communities low in resources (i.e., poor urban areas, farming areas), it is common practice to provide support services to their congregants and the community, such as finding employment and housing, food and clothing assistance, tutoring and after-school programs, English and General Educational Development classes, etc. The efforts cater to the particular needs of the community, and are not always structured in a formal program or under a specific ministry title (Hernández et al., 2016; Maldonado \& Martínez, 2008; Martell-Otero, Maldonado Pérez, \& Conde-Frazier, 2013; Martínez, 2008; Mulder et al., 
2017; Rodríguez, 2011; Stevens-Arroyo et al., 2003). In fact, Hamar-Martínez (2014) studied aspects of religious switching (i.e., from Catholicism to Evangelical) among Latinos in Chicago, and she found that social outreach practices, such as church leadership helping congregation members with seeking employment, were positively correlated with engaging and retaining members. Thus, these social service aspects are key to the functioning of many Latino congregations.

Moreover, the Latino church also provides a space where positive identity is formed, which in turn helps encourage congregants to be involved in societal public life (Badillo, 2006; Barton, 2006; Martínez, 2008; Mulder et al., 2017). Hernández, Davis et al. (2007) found in their study that, regardless of denominational affiliation, Latinos who volunteered and were civically engaged through their churches were also significantly more likely to be civically engaged in their communities. Being with others who also share "common experiences of bilingualism, multiculturalism, popular religious faith, marginality, poverty, colonization, migration, and cultural alienation" (Martell-Otero et al., 2013, p. 4) helps strengthen positive identity, which is one of the greatest challenges for the Latino community, especially for young people, and one of the factors that impact one's thriving (Gracia, 2000; Koss-Chioino \& Vargas, 1999; Raffaelli, Carlo, Carranza, \& Gonzalez-Kruger, 2005; Rodríguez, 2015; Smokowski \& Bacallao, 2011; Tamez Méndez, 2015).

Furthermore, though congregants often find themselves operating in spaces within society where they are not typically given opportunities to have their voice heard and exercise leadership, within their Latino congregation they have a space to develop many of their abilities and a place where they can become leaders (Maldonado Pérez, 2005; 
Martell-Otero et al., 2013; Martínez, 2008). It is common for congregants in Latino churches to engage in leadership tasks at all levels because there is a view of church as community or family, and a sense that everyone is a part and necessary in the congregation, especially as many churches do not have full-time pastors or other paid ministers to carry on the work needed (Hernández et al., 2016; Martínez, 2008). This is one of the main reasons why Latino churches also find themselves with a large number of younger members, who tend to be well engaged with the local congregation (JohnsonMondragón, 2007), and whose education and bicultural aptitude have provided them with opportunities to learn useful skills and abilities (Koss-Chioino \& Vargas, 1999; Smokowski \& Bacallao, 2011). Quite often, young people have acquired roles, responsibilities, and opportunities in other social contexts, which they then transfer to the church context and actively contribute towards local congregational and faith-community life.

Another important role that Latino congregations play is in being a hub for social capital by providing ties and connections by which congregants have access to opportunities, experiences, and forms of support (Scales et al., 2000) — something that has higher implications among ethnically and culturally diverse communities. For example, Labissiere, Reeder Goraczko, and Stepick (2009) found the Latino churches that participated in their study based in Miami, Florida, were particularly pronounced as sites for developing social capital because many of the congregants, being immigrants, had lost their extended family ties and existing social networks upon migrating, and therefore were likely to see the churches they attended as a means by which to develop new social networks — and create new social capital. Sikkink and Hernández (2003) also 
found support for the importance of this dynamic in churches through their review of the literature. They reported that Latino churches in particular are good at bringing together people from diverse backgrounds and that this can create social capital for the youth attending these churches by opening them to interaction with alternate sources of educational goals and values. Thus, the social capital created by these diverse interactions can be redeemed by the youth to improve their educational experiences, and potentially assist with the healthy advance of other developmental assets such as their leadership skills. This dynamic may be particularly valuable to Latino youth with immigrant parents, as immigrant parents may be poorly versed in navigating aspects of the American system, such as the school system for example, and therefore may experience difficulty in helping their children to achieve desired educational outcomes (Sikkink \& Hernández, 2003).

Aside from churches being an asset to youth by serving as hubs of social capital, in his analysis of the NSYR data Hernández (2007) highlights that for Latino Protestant youth attending and being engaged in a congregation has far-reaching implications. Regular participation in a community of faith helps not only to strengthen social networks, it also creates opportunities for learning about their faith, raises youth involvement in church groups (e.g., youth ministry groups and age-specific Sunday school), fosters close-knit relationships with other peers and caring adults, provides youth with adult mentors, and increases their leadership opportunities. A total of 78 percent of Latino Protestant youth who participated in the NSYR (Smith \& Denton, 2009) reported that there is an adult in the congregation (not family) with whom they enjoy talking and who give them a lot of encouragement, and 40 percent also reported being involved in a religious mission team or service project, which are aspects previously highlighted in 
developmental theory as contributing towards the leadership development of youth. Similarly, in their ethnographic study of Protestant ministries in the Chicago area, Armitage and Dugan (2006) found that Latino youth who attended these churches emphasized their belief in the importance of the youth outreach programs in providing support and constancy when their lives otherwise often had none. Many of the youth who participated in this particular study came from single parent families, or situations in which their parents simply did not get along, and so the church provided them with a safe-haven against this unpleasant reality. This idea of the church as a support structure for youth was echoed in a literature review on Latino churches conducted by Crane (2003). From this review, themes emerged of the church as both a support and extension of the family, the church as a pillar of spirituality and strength, and religion as a wellspring of Latino culture.

Thus, Latino churches are growing in their awareness of some of the key social challenges facing Latino youth today. There have been calls from both Protestants (Martínez, 2008; Rodríguez, 2015) and Catholics (Davis, 2007; Johnson-Mondragón, 2010, 2007), among others, urging Latino churches to do more to reach out and help the youth in their communities and congregations, and these calls have not gone unanswered. Although the Instituto Fe y Vida (Johnson-Mondragón, 2010) found that existing Catholic programs did not do enough to support Latino youth, because they simply do not reach enough of their target population, it also reported that many bishops have vowed to give special focus to Latino youth populations and are increasing their outreach efforts. Social issues which disproportionally impact Latino youth, such as improving their educational attainment and having the opportunity to benefit from the Deferred Action 
for Childhood Arrivals (DACA) immigration policy, have mobilized some churches into paying special attention to the needs of youth and advocating on their behalf (Tamez Méndez, 2011; The United Methodist Immigration Task Force, 2017).

\section{Challenges in Latino Congregations \\ Towards Reaching Youth}

It is necessary to point out though, that despite these improvements towards effectively serving youth among Latino congregations, over the decades multiple challenges and disparities have also been noted, some of which are important to mention in further framing this study. For example, Rodríguez (2011) noted that the negative image many youth have of Protestant Latino churches (i.e., lack of openness, strictness, etc.), hurts the congregation's ability to connect with these vulnerable youth populations. This combined with external factors, such as the competing influences of the internet and secular culture, contributes to the reasons why churches have not yet been able to do as much as they could to improve the lives of Latino youth (Rodríguez, 2011). There is still an uphill challenge as well in dealing with the fact that many Latino congregations do not have a positive view of youth, and often ignore their potential, due to multiple cultural reasons, such as an inherited adult-centric worldview (Pinedo \& Segura, 2105; Tamez Méndez, 2015) and the clash between the ideologies among different generations of Latinos (e.g., first generation, third generation, etc.) (Gracia, 2000; Johnson-Mondragón, 2007; Martínez, 2008; Rodríguez, 2015; Smokowski \& Bacallao, 2011). Thus, the traditional role of youth in Latino churches rather falls in line with the historically negative view of youth, which, as previously mentioned, was a view and approach conceptually overturned by PYD perspectives (Sukarieh \& Tannock, 2011). Moving 
forward, these traditional views of youth and their permitted level of involvement in Latino churches may similarly benefit from the application of PYD and conceptualizing leadership development as a life-long process.

Looking into specific challenges among denominations, within the Catholic church, an article by Davis (2007) noted that, when considered by age, Latinos may comprise up to 47 percent of Catholics of childbearing age and that they tend to have larger families, but that Latino congregations often face chronic shortages of support. Thus, while Latinos may comprise an increasingly important part of the Catholic church in the U.S., they are often given disproportionately little attention. Multiple studies conducted by the Instituto Fe y Vida (Johnson-Mondragón, 2002, 2010), as well as various reports and statements issued by the U.S. Catholic Bishop (e.g., The National Pastoral Plan for Hispanic Ministry in 1987 and 1995, and Encuentro and Mission: A Renewed Pastoral Framework for Hispanic Ministry in 2002), support these conclusions and point out how youth ministry programs for Latino youth are limited in number, scope, and depth. Most of the youth ministry programs in the parishes are not reaching Latino youth because of economic, linguistic, cultural, age, and educational differences; instead, the majority of youth programs serve a population that is mostly European white, mainstream, middle-class, and English-speaking (Johnson-Mondragón, 2005).

These struggles are, in many ways, mirrored by Protestant churches as well. However, the focus of Evangelical authors regarding the challenges of working with Latino youth has been on the strain between the needs and preferences of those who are foreign-born versus U.S.-born (Crespo, 2003; Johnson-Mondragón, 2007; Martínez Guerra, 2004; Rodríguez, 2011, 2015). Socioreligious demographics play a role in the 
difference in focus; U.S.-born (second generation and higher) Latinos are more prevalent among Protestant youth than among Catholics (Hernández, 2007). Rodríguez (2011, 2015) conducted a series of case-studies in Evangelical Latino churches in various regions of the country, and found indications of this generational gap, particularly between older foreign-born ministers and younger U.S.-born Latinos. Since two-thirds of church-going Latinos attend Latino congregations (Pew Hispanic Center, 2007), more and more first-generation and second-generation+ youth find themselves coming together in these congregations. However, each represents distinctive intra-group variances in cultural, social, linguistic, and ideological adaptations (i.e., acculturation and assimilation). Thus there are differences in opinion as to where the church's attention, distribution of resources, and preferences in congregational aspects (e.g., worship styles, predominant language use, etc.) should be focused (Rodríguez, 2011, 2015).This is another challenge to be considered regarding youth engagement in religious participation and their leadership development within the Latino church.

Another challenge on which both the literature and religious leaders of diverse Christian traditions agree is the need for leadership development to be at the forefront of the Latino church's efforts. The socioreligious demographics and the generational and cultural diversity of Latinos calls for the raising of new leaders that can guide congregations and denominations to meet the current and future needs of the people (Crespo, 2003; Hernández et al., 2016; Martínez, 2008; Montoya, 1987; Ortiz, 1993; Rodríguez, 2011). The importance of Latino youth emerging as leaders has been stressed, as many can serve as a bridge that connects the diverse cultural and linguistic preferences that exist within one congregation, especially those who are bicultural and know how to 
navigate both worlds (Crespo, 2003; Hernández et al., 2016; Martell-Otero et al., 2013; Rodríguez, 2011). In his assessment of the Catholic Church in the U.S., Davis (2007) also pointed out that Hispanic youth are a strategic population in which our congregations need to invest in order to develop the leadership our congregations so urgently need. Although theological education and ordination processes have their place, one crucial strategy for success in Latino churches is fulfilling the need for leadership development from within the local congregation, thereby nurturing leaders who have the same cultural context and needs as the congregation and community (Davis, 1997; Ortiz, 1993; Rodríguez, 2011). It is normative in Latino congregations for the congregation to identify, recognize, and develop that potential leader, long before official credentials are obtained (Elliston, 1992; Hernández, 2007; Hernández et al., 2016; Maldonado Pérez, 2005; Martínez, 2008). However, as the latest study on Latinos and theological education reports, the rate at which Latinos are driving the growth of Christian churches and the community is not being matched by the development of Latino leaders to serve in Latino congregations (Hernández et al., 2016).

Regarding research challenges, in the concluding sections of their studies several authors (e.g., Hernández, 2007; Johnson-Mondragón, 2010; Mulder et al., 2017) have stressed the need to conduct further congregational-level research to learn about the religious lives of Latinos, particularly research that includes sociological and contextual factors. This is even more true of the young population, as this is a demographic about whom large gaps in literature and research still exist. This is a gap that the current study hopes to help to reduce, given its focus on religious participation of Latino youth and given sociological issues within the context of congregations such as social service 
involvement, engaging in leadership tasks, and its implications for youth leadership development.

Overall, both Catholic and Protestant congregations face similar difficulties in incorporating their increasingly young Latino membership, namely a lack of sufficient resources to accommodate them in culturally appropriate ways, while addressing the generational differences, and developing the leaders that the church needs. These problems make a substantial impact when considering, for example, that over one third of the Catholic church's membership is Latino, and the percentage of Protestant Latinos has increased substantially in recent years, particularly among Evangelical and Pentecostal groups (Mulder et al., 2017; Pew Research Center, 2015). It is beyond the scope of this dissertation to discuss these challenges in greater depth. Yet these issues are important to consider in framing and understanding the congregational contexts of the churches that participated in the CLCS. Despite the challenges that still exist in the efforts and effectiveness towards reaching and serving youth in Latino congregations, Latino congregations still possess very important characteristics which make them optimal ecological contributing contexts. Therefore, viewing the Latino church from a human development perspective one can note that it is a local social and institutional context in which one frequently finds a rich environment with learning experiences that provide opportunities for young congregants to engage actively in leadership tasks and exercise social responsibility towards the community.

\section{Religious Participation and Pathways for Youth Leadership Development}

The theoretical framework of PYD provided a means by which to study some of the observed and anecdotally identified organic dynamics and practices present in Latino 
congregations that seem to be contributing towards the leadership development of their youth congregants.

Being that youth leadership development is deemed as a process that takes place over time, that early leadership experiences can provide an important foundation for exercising leadership later in life, and that these early experiences often come in the form of opportunities through activities that are provided to youth in ecological contributing contexts such as religious organizations (Avolio, 2005; Avolio \& Gibbons, 1988; Avolio \& Vogelgesang, 2011; Day, 2011; Day et al., 2014; Day et al., 2012; Day \& Sin, 2011; Murphy \& Reichard, 2011), two such contributing activities characteristic of Latino congregations were selected to guide the empirical analysis: social service involvement and engagement in leadership tasks (Crane, 2003; Martínez, 2008; Mulder et al., 2017; Stepick et al., 2009).

Therefore, the following sections examine the literature on the two potentially contributing factors chosen to analyze the relationship between religious participation and leadership development. Social service involvement and engagement in leadership tasks are some of the many different types of activities and opportunities that literature identifies as pathways towards nurturing and strengthening youths' leadership abilities (Klau et al., 2006; Lerner, 2004c). These types of activities provide opportunities for engaging in a variety of repeated tasks that help exercise youths' skills, knowledge, and talents which contribute to leadership development (Klau et al., 2006; MacNeil, 2006; Murphy \& Reichard, 2011; van Linden \& Fertman, 1998), also known within PYD as the behavioral indicator of exercising leadership (Benson et al., 2011) or reaching the Sixth C - Contribution (Schmid Callina et al., 2014). 


\section{Religious Participation and Social Service Involvement}

Social service involvement, also denominated civic engagement or volunteer or community service in some of the literature, is essentially participation in activities that promote the public good (Lerner, 2004c; Sherrod et al., 2010; Wilson \& Simson, 2006). The review of social service involvement in the literature was conducted paying particular attention to its relationship to promoting youth leadership development and how religious participation facilitates these types of activities and opportunities. These relationships underpin the choice of social service involvement as one of the dissertation study's two primary criterion variables.

Positive Youth Development theory highlights that being involved in social service, as part of the early-life experiences and activities, has long-term effects in helping shape youth's leadership development over time (Lerner, 2004c; Murphy \& Johnson, 2011; Murphy \& Reichard, 2011). Past studies have found similar results, namely that youth who engaged in social service activities through diverse organizations that provide them these opportunities demonstrated the development of PYD characteristics in their growth — with leadership development being one of these (Mitra \& Serriere, 2012; Mohamed \& Wheeler, 2001). Social service often requires for youth to work together with someone else or a group towards helping solve a community problem. It also gives them the sense that it is possible to make a difference in the community, and it encourages them to believe in their responsibility to get involved—all these being aspects which require and develop leadership (Andolina, Jenkins, Zukin, \& Keeter, 2003; McNutt, 2013; Mitra \& Serriere, 2012). 
In terms of involving students in social service, research by Dawes and Larson (2011) suggested that such engagement can be created by opportunities provided through institutions such as churches. They interviewed 100 ethnically diverse youth with a focus on those who were civically engaged and found that involvement in social service need not be intrinsic. Of the 44 youth who reported high involvement, 38 developed that level of engagement as a result of forming a personal connection with the organization through which they serve. This suggests that community organizations such as churches, who already have a large youth membership, could engage these members through providing the opportunities for social service, and focusing not only on the tasks, but also the relationships. This is an especially important asset for Latino congregations, as studies have found that Latino youth are significantly more involved in social service when the issues were directly connected to the needs of their own community (Anglin, JohnsonPynn, \& Johnson, 2012; Sherrod et al., 2010).

Thus, in addition to their potential to function as venues for traditional youth engagement, churches may also offer unique opportunities to create social service involvement. The literature bears witness to a connection between religious participation and civic engagement - a relationship that is, with some exceptions, positive. The aforementioned relationship suggests that religious participation may be one of the most important ways of interesting youth in social service and thereby promoting the development of leadership skills through their involvement in these types of activities. Religiosity, in the context of this study, refers primarily to the act of attending church and its related activities (e.g., youth group meetings, Sunday School class, etc.) (Beckford \& 
Demerath III, 2007; Smith, 2003); therefore, the studies included in this section are only those which consider religion in this context.

Since a central activity in most religious organizations is providing for those who are less fortunate, youth are typically introduced to opportunities for social service at young ages (Youniss, 1993; Youniss, McLellan, \& Yates, 1997; Youniss \& Yates, 1997). Hodgkinson and Weitzman (1990) asked teenagers to indicate the means by which they got involved in social service, and they found that the most frequent categories were school and church, particularly through religious youth groups. Furthermore, with respect to the connection between religious participation and social service engagement, a few studies attest to this relationship. A case study by Kerestes, Youniss, and Metz (2004) of a school in Boston found that civic engagement was positively linked to religiosity. Thus, students who engaged in social service were more likely to attend church, in addition to other positive factors that the study linked to social service engagement. Similarly, in reporting on the prevalence of faith in Latinos, Hernández, Davis et al. (2007) found that religion was positively linked to social service engagement in Latinos, regardless of their denomination. Another study by Beyerlein and Hipp (2006) found that religious participation is linked to social service engagement more strongly if the congregants also participate in religious activities outside of church services, and that denomination moderates the relationship as well. Furthermore, Gibson (2008) used data collected through the NSYR, and found that intense religiosity (here meaning frequent church attendance and theological conservatism) significantly increased the likelihood of adolescent volunteerism. Finally, Perks and Haan (2010) found likewise that adolescent religious participation predicted adult social service orientation. 
Thus, we can see that religion has a well-documented positive relationship with civic engagement in most cases. In those cases where this relationship does not hold true, the person in question was already inclined toward civic engagement, making the religious aspect perhaps something of a moot point (Beyerlein \& Vaisey, 2013). The more general positive relationship suggests that civic engagement is a good choice of variable for the current study, as this study is concerned with the effect of religion on youth leadership development in Latinos. The existing literature also has not yet considered the potential interaction of civic engagement and religion on the emergence and development of leadership — especially youth leadership. Thus, the current study may make a meaningful contribution to the body of literature on religion and civic engagement.

\section{Religious Participation and Engagement in Leadership Tasks}

The second criterion variable of this dissertation study is that of engagement in leadership tasks. According to PYD theory, youth develop leadership skills as a result of lifelong developmental experiences provided through ecological contributing contexts. Thus, it is expected that from this perspective, youth engagement in leadership tasksactivities such as public speaking, organizing and planning events, or youth leadership experiences - would lead to youth leadership development. This section considers the existing literature on the relationship between leadership tasks and youth leadership development, and how religious participation contributes towards facilitating these types of activities and opportunities. 
The importance of engaging in leadership tasks in the development of youth leadership was strongly supported by Klau (2006), who studied youth leadership development using a theoretical framework in which leadership is separated from authority, and which also found that teaching students leadership comes through a strong component of practice and experience. Klau (2006) studied three specific cases of youth leadership programs with reputations for strong impact and positive results. The three cases were that of the National Leadership Council, the Jewish Leadership Organization, and the Institute for Justice and Leadership. Of the three programs studied, only one had a clear conceptualization of what leadership actually was, and this program had the strongest overall effect on participants. Of the other two programs, one focused almost exclusively on learning by doing, giving the participants a chance to practice and reflect on leadership skills and engaging them in leadership tasks such as confronting their own biases or breaking through segregation barriers. The third program lacked much emphasis on learning by doing; instead, it was focused on the notion of leadership as motivated by adult authority, and the researcher observed that its participants were confused and ultimately not as engaged. Thus, the study gave strong evidence for how engagement in leadership tasks can lead to improved youth leadership development outcomes. Engaging youth in leadership tasks serves to teach leadership in a very hands-on way, through experiences which serve to develop leadership actively rather than relying on the presentation of information about leadership that may or may not allow youth to develop the skill for themselves.

This notion of learning to lead through doing is also supported by the work of Murphy and Reichard (2011), who presented an overview of how early development 
affects the development of leadership. Their research presented the effects of early life experiences on leadership, but some of the most pronounced were the effects of everyday experiences on leadership development, including the effects of interaction with parents, and the effect of participation in extracurricular activities. All of these can be considered engagement in leadership tasks, especially extracurricular involvement which may place students in a position in which they may directly exercise leadership, for example, in team sports (Murphy \& Reichard, 2011). Thus, learning through doing and engagement in leadership tasks can have a very strong effect on the development of youth leadership.

Aside from school and extracurricular activities, religious participation may provide youth with an important venue for engagement in leadership tasks. For example, in an in-depth case study by Armitage and Dugan (2006) of a Chicago youth ministry, evidence of youth practicing several leadership tasks emerged. Members participated in altar calls, which constituted public speaking experiences, as well as in the organization of the audio and visual components of the meetings. The youth were also able to engage in direct leadership in the context of youth-based activities such as Bible reading or group prayer. These opportunities presented the youth congregants with direct leadership experience, despite teaching leadership not being expressed as a particular goal of the youth ministry. However, there were some limitations to these experiences, with the youth minister's choices for leadership roles being strongly influenced by adherence to conventional norms; the availability of leadership opportunities was also different between the genders.

Similarly, Sikkink and Hernández (2003) suggested that youth may be able to engage with leadership tasks such as reaching out to unfamiliar people and forging 
relationships, due to the nature of congregations as sites for the development of social capital. In particular, the researchers suggested that this effect is pronounced in Latino congregations as they attract a broad spectrum of people with whom youth can interact. Church attendance and participation were shown to give youth the opportunity to engage in leadership tasks at Latino churches.

Research on youth leadership development and religious participation is scarce. However, the results of these studies strongly suggest that religious participation can potentially afford opportunities for youth to engage in leadership tasks, which in turn can have a strong positive influence on the development of youth leadership.

\section{U.S. Latino Demographic Characteristics}

The Latino community in the U.S. is extremely diverse in all aspects: ethnicity, race, language usage, country of origin, cultural representations, legal status, age dynamics, socioeconomic levels, and stages of assimilation and acculturation. To frame the characteristics of the target population for this study, the following sections provide a general overview of demographic details, including aspects of population breakdown, identity, national heritage, and religious affiliation data as reported by the U.S. Census Bureau and other research institutions such as the Pew Hispanic Center.

\section{Population}

According to the U.S. Census Bureau, as of July 2014 Hispanics comprised 17 percent of the population in the United States (U.S. Census Bureau, 2015), making them the largest minority with a total of 55 million people. This figure increased by 1.15 million people from 2013 to 2014, nearly half the estimated national total population 
growth of 2.36 million for that year (U.S. Census Bureau, 2015). By 2060, the total Latino population is estimated to more than double to 119 million, at which point it will be nearly 30 percent of the total projected population (U.S. Census Bureau, 2015). Most important for this study, the Hispanic population in the U.S. is not only growing at a fast rate, but it is also comprised of a younger than average population, making it the largest and youngest minority group in the United States. In 2008 the U.S. Census Bureau reported that approximately 25 percent of the children under five years of age in the United States were Hispanic. One in five school-aged children is Hispanic and one in four newborns is Hispanic (Pew Hispanic Center, 2009a). Overall, the Hispanic population is much younger that the rest of the population in the U.S., with the median age of Hispanics being 27.7 years versus non-Hispanic whites with a median age of 41 . In total, 34 percent of Hispanics are younger than 18 years of age. In the City of Chicago, the 2010 U.S. Census reported that 28.89 percent of the total population were Hispanics, with 32.66 percent of this population group being under 18 years old (Frey, 2010). These demographic changes, which have resulted in a boom among the young Latino population, have not only changed the face of the U.S., but will continue to play a substantial role in shaping the future of the U.S. and the church.

\section{Identity}

Use of the terms "Hispanic" or "Latino" to refer to people with origins in Spanish-speaking countries was mandated for government agencies by the United States government in 1976 (Pew Hispanic Center, 2012). This mandate poses a challenge, as not all countries referenced speak Spanish, thus making inclusion of a person under the label "Hispanic" or "Latino" a very subjective process left at the discretion of those involved. 
While government agencies have typically collected data on minorities, such as African Americans or Native Americans, this data was collected on the basis of racial groups. Due to the widely differing origins of Hispanic people, Latinos are not intrinsically connected through a unifying race in the same way as other minorities are, and thus were the first ethnic group to be singled out for demographic analysis in this manner (Pew Hispanic Center, 2012). Furthermore, Latinos also do not share a common culture, as the country of origin varies significantly, and the majority of Latinos (51 percent) most closely identify with their country of origin versus a pan-ethnic label such as "Hispanic" or "Latino." What is still shared between Latinos, however, is a strong connection to the Spanish language, which 82 percent of the participants in the Pew survey reported speaking and 95 percent considered it to be important to continue speaking, although the use of the English language continues to increase among younger generations in the United States. (Pew Hispanic Center, 2012).

\section{National Heritage}

Among Latinos, 51 percent identify themselves primarily by their country of origin, or in the case of U.S.-born Latinos, by their parents' country of origin. These countries of origin vary widely. According to U.S. Census Bureau estimates, as of 2013, 64 percent of Latinos in the U.S. were of Mexican origin (U.S. Census Bureau, 2015), making up a significant majority of the Latino population. Another 9.5 percent were estimated to be Puerto Rican, 3.7 percent to be Cuban, 3.7 percent Salvadoran, 3.3 percent Dominican, and 2.4 percent Guatemalan, with the remaining 16.7 percent split between various countries in South and Central America (U.S. Census Bureau, 2015). The primary defining characteristic of Latino identity is association with the Spanish 
language, although this association is limited, thereby excluding the Latino population which speaks others languages and dialects. For example, Brazilians are not generally considered to be Latinos because the official language of Brazil is Portuguese, and only four percent of Brazilian immigrants to the United States self-identify as Hispanic or Latino for data reporting purposes (Pew Hispanic Center, 2009b). Furthermore, as the U.S.-born Latino population (i.e., second and third+ generation) continues to increase, it will become more difficult to group young Latinos as a single group. Factors such as language preferences, ethnic background, economic and educational access, religious tradition, and immigration status will further subdivide this demographic group in the future (Johnson-Mondragón, 2007).

\section{Religion}

Latinos are, as a group, more religious than the average American-especially immigrant Latinos, amongst whom 69 percent say religion is important in their lives, compared to the U.S. average of 58 percent (Pew Hispanic Center, 2012). However, only 49 percent of U.S.-born Latinos express this view, suggesting a generational shift in religiosity for immigrant families. The general demographics of religion in the U.S. have shifted in recent years—-with only 70.6 percent of Americans identifying as Christians and 22.8 percent identifying as religiously unaffiliated (Pew Research Center, 2015)and this shift has led to an increased prominence of Latinos, as a more religious group within the demographics of certain religions.

The Pew Research Center's National Survey of Latinos and Religion (2013) found that 55 percent of Latino adults identify as Catholic, approximately 22 percent as Protestant (including 16 percent evangelical and five percent mainline), three percent as 
other Christian, one percent as other, and 18 percent as religiously unaffiliated.

Furthermore, according to data from a nationally representative study of religious affiliations by the Pew Research Center (2015), Latinos now comprise 34 percent of all U.S. Catholics and eight percent of all U.S. Protestants, up from 29 percent and five percent in 2007. It is estimated that the distribution of Latinos between the Catholic and Protestant church will continue to shift, and that by 2030,50 percent of Latinos will be Protestant (Pew Research Center, 2014a). With respect to smaller denominations, 24 percent of Jehovah's Witnesses were Latino as of 2014, and seven percent of Mormons were Latino.

Latino influence has grown since 2007 in all major sectors of Christianity, and this increasing prominence of Latinos is reflected in the demographics of U.S. churches, with Latinos making up 16 percent of the total Christian population in the U.S. as of 2014 (Pew Research Center, 2014b; 2015), suggesting that Latinos make up roughly the same proportion of Christianity as they do of the total U.S. population. Interestingly, national studies report that the religious composition of Christian Latinos counts with a higher percentage of women (Pew Research Center, 2014a).

This rise of Latinos within the Christian church will continue to affect and change the nature of politics, economics, and religious expressions in the United States. Surprisingly though, this phenomenon has not been broadly recognized in mainstream culture or within denominational structures (Dias, 2013; Mulder et al., 2017). It is important to point out that Latinos are present both at congregations comprised primarily of an Anglo population, as well as ethnic churches comprised primarily by a Latino population. 
Beyond their role as spaces of spiritual and religious cultivation, Latino congregations also play a sociocultural role, and two main approaches have been noted. On one end, some congregations see their role as one of preservation and strengthening of Latino ethno-cultural identity through the customs, language, group solidarity, symbols, theological interpretations, and worship practices promoted there. On the other end, some congregations see themselves playing an adaptive role for Latino members by accentuating dynamics that accompany them in the process of assimilation and acculturation, therefore de-emphasizing Latino ethno-cultural markers, and reorienting religious and theological expressions to reflect those of the cultural majority (Calvillo \& Stanley, 2015). These are important distinctions in sociocultural dynamics, as these inevitably affect the way in which congregations interact with youth, the style of ministry towards them, and the opportunities they are provided for involvement.

Looking specifically into the religious life of Latino youth, the picture is less clear. In general, we do not know much about the role of religion in adolescent life. There has been a substantial gap in the literature in adolescent and religious studies, which has been noted for a few decades now (Smith, Denton, Faris, \& Regnerus, 2002; Weaver et al., 2000). Overall, the Public Religion Research Institute reports that more than half of the young Christian population (ages 18-29) in the U.S. are ethnic minorities. Thus, this lack of research poses an even greater challenge in understanding the lives of young Latinos, since not only do young people comprise the majority of the Latino U.S. population, religion also plays a more important role in their life when compared to youth in other ethnic groups. Studies such as Monitoring the Future (Benson, Yeager, Wood, Guerra, \& Manno, 1986) found that Hispanic youth scored higher than Whites on self- 
rated importance of religion. In addition, according to the 1996 National Household Education Survey, about 42 percent of Latino adolescents in the United States report that they attend religious services once a week or more, and about 68 percent attend services more than a few times a year (Sikkink \& Hernández, 2003).

More recently, in a comparative analysis (Johnson-Mondragón, 2005) of White and Hispanic Catholics based on survey data collected through the NSYR (Smith \& Denton, 2009), it was found that when it comes to the importance of religious faith, Hispanic teens and their parents are both significantly more likely to consider their faith "extremely" or "very" important, whether the question has to do with the role of faith in daily life or in making major life decisions. In addition, Hispanic teens tend to think about the meaning of life more often, express more interest in learning about their religion, report significantly higher levels of personal religious activity (e.g., personal prayer, reading Scripture alone, etc.), and feel closer to God than their White peers. These high levels of Latino youth religious involvement are important to consider when exploring how to develop strategies for leadership development. Unfortunately, the analysis also reported that Hispanic youth are also only half as likely to have served as an acolyte or altar server. This report is of significant interest to the current study, as traditionally in the Catholic church there has been a strong link between serving at the altar and considering leadership roles in the church via religious and priestly vocations later in life (Johnson-Mondragón, 2007).

Similarly, and likewise based on the NSYR data, Hernández (2007) reported that for Protestant youth, religious faith engulfs the totality of their lives. Protestant youth reported that it is "very important" that religious faith shape their daily life (73 percent), 
that they have "made a commitment to live life for God" (81 percent), and that they are "very interested" to learn more about their faith (55 percent). All of this translates to higher levels of religious practices such as attending church, for which 53 percent reported attending church one or more times per week. In addition, when asked whether they would attend church without their parents, 64 percent indicated they would attend at least once per week. Regarding active engagement in their churches, whereas 76 percent of Latino Protestant youth report being involved in activities "such as reading aloud" in church services, only 48 percent of their Catholic counterparts report this level of engagement.

The information provided by the above cited NSYR analyses of Latino Catholic and Protestant youth is a valuable first step. However, a major weakness of the NSYR (Smith \& Denton, 2009) is the low sample of Latino teens $(N=451)$, especially of nonCatholic youth $(N=94)$, that the study represents. Furthermore, due to the low number of non-Catholic Latino respondents in the survey, the NSYR grouped all non-Catholic religious communities such as Mainline, Evangelical, and Pentecostal traditions, under the generic label of Protestant youth, thus making it impossible to draw comparisons between the different denominational traditions (Hernández, 2007).

It is imperative that further research be conducted to gain a better and broader understanding of the religious landscape of Latino youth in this country. The present study contributes to this field by analyzing data collected through the CLCS-YS, with an age-range (13 to 19 years old) selected sample of 307 young Latino respondents representing four stratified denominational groups in the Chicago area. Moreover, in Chapter 5, the results from the frequencies on the survey items of the CLCS-YS selected 
for this study are also described and compared to the NSYR results. This provides a contextual description of socioreligious phenomena present in the Latino congregations where the survey research was conducted, and also a wider reference into the religious habits of Latino youth.

\section{Chicago Latino Congregations Study}

The CLCS generated a wealth of data through multiple survey interventions and one-on-one interviews with clergy and other congregational leaders representing various denominations. Since this dissertation analyzed portions of the youth survey data, to frame this study within the CLCS the following section provides a general description of

the CLCS, as well as a general overview of other studies and dissertations that draw data from this common source.

\section{Brief Overview}

Overall, the objective of the CLCS was to understand the particular factors that contribute to the growth and vitality of Latino congregations, the social impact of these churches in their communities through their assistance programs, the way Latino churches relate to other faith-based organizations and secular non-profits to provide services more effectively, and the role and needs of the leaders and their congregants to continue to be socially engaged. The CLCS was carried out in Chicago and completed in 2007; the study was undertaken with the objective of answering a variety of questions about the nature of Latino congregations in Chicago (Burwell et al., 2010). The CLCS was carried out using five survey instruments developed for this purpose; further details 
on the CLCS can be found in Chapter 3 of this dissertation and in Appendix B, which contains the CLCS's methodological considerations.

The CLCS identified a total of 606 churches in the greater Chicago area that were categorized as Latino churches, although some of these were not exclusively Latino and simply Anglo churches with a particularly large Latino membership. The five surveys in the CLCS were sampled from among these churches. The data used in this dissertation study is drawn from one specific survey - the fifth survey, which focused exclusively on youth churchgoers, also called the CLCS-YS. The CLCS-YS provides a large pool of data on youth and their religious participation in Latino churches, precluding the need for the researcher to spend extensive time and resources collecting this data. The data provided by the CLCS-YS also includes relevant information for studying the variables of social service involvement and engagement in leadership tasks. Thus, the CLCS is a good fit as a data source for the current study.

\section{Other Studies Using the CLCS Data}

Several existing studies have drawn on the CLCS for data. These studies can be

divided into two broad categories: studies on the sociology of religion and other doctoral dissertations.

\section{Sociology of Religion Studies}

Hernández, Davis et al. (2007) used the CLCS data to study the political views of Chicago's Latinos as they relate to religion. The researchers looked into the views of Latino religious leaders and members of their congregations regarding topics such as abortion and immigration reforms, and their political party affiliation. The study also 
reported that both leaders and members were found to demonstrate a fair degree of political activity, and a high percentage of congregation members reported that their political views were influenced by those of their religious leaders.

Hernández, Smith, Burwell, Peña, and Sikkink (2010) studied the health of Latino churchgoers through the CLCS data. In particular, these authors were interested in exploring a paradox they noted in the literature - that lower socioeconomic status of Latinos does not create correspondingly lower health. They noted that social networking can play a strong role in mitigating ill health, and sought to determine the influence of the church, in keeping with previously noted ideas that Latinos often see the church as an extension of family. However, the results of the study suggested that most Latino church outreach programs for health were unofficial and lacked resources, suggesting that these are areas ripe for improvement.

Furthermore, the CLCS data was used by Hernández, Burwell, and Smith (2007) to examine how Latino churches respond to the Human Immunodeficiency Virus and Acquired Immunodeficiency Syndrome (HIV/AIDS) epidemic. The researchers found that Latino ministers were actively providing information about HIV/AIDS in their congregations, with at least 36 percent of Latino churches having informed and educated the majority of their congregants about these issues. The following factors were found to be significant in determining whether a church had HIV/AIDS programming or not: (1) the minister had known someone who had contracted the virus; (2) the minister's own level of HIV/AIDS training; and (3) the minister's theological orientation.

Finally, there is also a preliminary research report about Latino Pentecostalism, with a particular focus on the context of immigration. In this report, Althoff (2006) used 
the CLCS demographic and congregational data to examine religious identities of Latino immigrants. Ultimately, the researcher concluded that "the conversion of Latin American immigrants to Latino Pentecostalism is a phenomenon that takes place primarily in the United States, rather than in their countries of origin" (Althoff, 2006, p. 2).

\section{Dissertation Studies}

There are two dissertation studies that make use of CLCS data, those of Ruano (2011) and Hamar-Martínez (2014). Ruano (2011) studied the engagement of Latinos in Chicago's Pentecostal churches, and found that these churches, almost unanimously, managed to achieve engagement, even in the more disadvantaged sections of Chicago's Latino population. In addition, the study offered insight into the two divisions of Pentecostalism reflected in these churches. The more traditional Pentecostal groups were characterized as more socially progressive, while the self-declared "neo-Conservative" group still managed to achieve Latino engagement but leaned more toward socially conservative viewpoints.

Hamar-Martínez (2014), on the other hand, was interested in a broader questionnamely, what factors predict religious switching among Latinos. After quantitatively analyzing data from the CLCS, the researcher identified two primary negative predictors of religious switching, namely having a formalized program for welcoming new congregation members and church leaders helping members in their search for employment.

Both of these studies contribute meaningfully to the understanding of Latino churches in Chicago, but neither was concerned with issues of youth or leadership development. 


\section{Summary}

This literature review has examined PYD theory and especially its relationship to youth leadership development and congregations playing a role as ecological contributing contexts. It has also highlighted pertinent issues regarding the opportunities Latino congregations provide for youth to be actively involved in social service and engaged in leadership tasks, and the implications of these opportunities towards developing youth as leaders. To frame the sociological and contributing developmental context portion of this study, the review also presented important descriptions about the nature of Latino churches and their outreach efforts towards youth, along with a brief overview of demographic characteristics of the U.S. Latino population. In addition, the literature review surveyed previous studies which have drawn their data from the CLCS.

Some prominent findings of the literature review include: (1) leadership development is affected by the context in which one develops and it is a life-long process, (2) leadership may develop differently in youth and adults, (3) engagement in leadership tasks and involvement in social service are important in the learning-by-doing model of leadership development, (4) Latinos are a demographic group increasingly growing in influence, and (5) there is a need to promote PYD among youth in Latino churches. Each section of the literature review has been demonstrated how this study will contribute to the scholarly discussion on issues of leadership development, youth development, social service involvement, engagement in leadership tasks, and religious participation, all in the specific context of Latino congregations. There is, therefore, both a strong theoretical foundation in the literature upon which the current study can build and a clear gap in the literature to which it can contribute. 
The aforementioned theoretical framework therefore provided a foundation for further assessing the relationship of religious participation to leadership development among youth in Latino congregations. This by way of describing, identifying and measuring some of the individual congregant-level characteristics, as well as contextual, sociological, and developmental attributes present in Latino congregations which PYD indicates contribute towards youth leadership development. A full description of the research methodology utilized for the current study is presented in greater detail in the following chapter. 


\section{CHAPTER 3}

\section{METHODOLOGY}

\section{Introduction}

The following chapter describes the general methodology that guided this descriptive and explanatory ex post facto investigation. The chapter sections present first an overview of the research design which directed this dissertation. Next, the general research question, the eight specific research questions, and the general research hypotheses are listed. Third, based on the research conducted through the CLCS, the sources of data collected are provided; these include the geographical location, population, sampling frame, survey instrument design, data collection context, and sampling procedures. Furthermore, the operational definition of the criterion, predictor, and control construct variables, as well as the coding of the variables employed in this investigation, are provided. The final sections include a description of the data analysis and statistical treatment methods, and a brief chapter summary.

\section{Research Design}

The CLCS, and therefore this dissertation study, are grounded on survey research methodology, which is common in the field of sociodemographic and sociology of religion investigations. The analysis of survey-generated data serves to create a "snapshot" and shed light on phenomena unfolding at a specific place and time. Although this 
research design limits the findings and conclusions in that these are not representative of, and cannot be applied to the population at large, the findings do provide a contextual description of social indicators present in the setting where the survey research was conducted. These indicators are central to identifying and monitoring social trends, while also providing insight which is important to consider and integrate when developing policies, and programs which impact the population studied (Glewwe \& Levin, 2005; Voas, 2007). Furthermore, the data gathered and analyzed provide a foundation for subsequent research such as longitudinal studies and comparison studies that examine the direction of social trends overtime (Voas, 2007).

To obtain data from a substantial number of participants, this dissertation was based on the secondary analysis (Smith, 2008) of portions of the quantitative data collected through the CLCS (Burwell et al., 2010). The CLCS is one of the most comprehensive sources of data to date for exploring questions related to religious factors among Latinos, and it was conducted between 2004 and 2007 by researchers at the University of Notre Dame through the Center for the Study of Latino Religion in the Institute for Latino Studies. This multi-level study of Latino Christian congregations in the Chicago metropolitan area gathered extensive quantitative and qualitative data through surveys and interviews conducted with clergy, lay leaders, and congregants.

The CLCS utilized five different surveys which were designed for the multiple participant samples in the study. Survey 5, also referred to as CLCS-YS, is a survey of youth congregants from the sampled churches, which serves as the source of data for the analysis in this dissertation (see Appendix A). This is the first time the data of the CLCSYS have been used in a doctoral study and the data have also not been previously 
analyzed for other research purposes. I received full access to the dataset required for this dissertation through the authorization of the principal researcher of the CLCS (see Appendices D and E).

Overall, the CLCS was an unprecedented effort designed to provide an in-depth look into the congregational life of Latino Christian churches (Burwell et al., 2010), specifically regarding the:

1. Growth and vitality of congregations and the influence of clergy, worship style, social outreach, and youth and family ministry programs on those outcomes.

2. Extent of community services provided by congregations, with a particular focus on its relationship to the spiritual and material well-being of families in need.

3. Formal and informal ways in which churches are networked with other faithbased organizations and community agencies in order to nurture successful strategies for providing services to families in need.

4. Role of church leaders, whether clergy or laity, in sustaining spiritually vibrant and socially engaged congregations, and also insight into their professional development needs.

In addition to these four areas of focus, other questions within the CLCS addressed the characteristics of members and leaders of Latino congregations, the relationship of religious practices on specific aspects of churchgoers' lives, religious switching, engagement in civic life, the types of activities in which community-oriented ministers engaged in, the relationship of leadership style on congregants' community involvement, and the political attitudes and behaviors of churchgoers. 
In alignment with the aims of the current investigation, the analysis focused only on the quantitative data collected through the CLCS-YS. In particular, it focused solely on those sections of the survey that pertain to aspects of youth congregants' religious participation and practices which are related to their involvement in providing social service to people in need, and their congregational commitment through engaging in leadership tasks.

Additionally, the data selection from the CLCS-YS is congruent with the purpose of the study which aims to analyze the relationship of religious participation to the leadership development of youth in Latino congregations. A research tool with a direct measure between these two factors was not found after conducting the review of literature and pertinent past research studies. Therefore, the relationship was inferred by measuring religious participation and two potential mediating variables: social service involvement and engagement in leadership tasks. For data analysis purposes, based on the survey questions selected, corresponding construct variables were created for each of the variables of interest. Further details on the specific survey sections selected and the creation of the construct variables for statistical analysis are provided under the Operational Definitions of Variables and Coding of the Variables sections of this chapter.

The PYD theoretical framework presented on Chapter 2 informed the selection of the mediating variables for analysis. Social service involvement and engagement in leadership tasks were chosen as these ecological factors present in various social settings (i.e., ecological contributing contexts), have been independently hypothesized to have a positive relationship with children's, adolescents', and young adults' leadership development and fulfilling leadership roles later in life (Giles \& Eyler, 1994; Lerner, 
Lerner, et al., 2005; Murphy \& Reichard, 2011; RMC Research Corporation, 2002; Wilson \& Simson, 2006).

As it relates to religious participation, the two aforementioned variables were also specifically selected because, as described in Chapters 1 and 2, these are ecological factors which both anecdotal observations and sociology of religion scholars have reported as being characteristic of local institutional dynamics within Latino congregations. Latino congregations are prone to promote and provide opportunities for congregants to engage with experiences in social service involvement and engagement in leadership tasks (e.g., Hernández et al., 2010; Martínez, 2008; Ramírez-Johnson, 2008; Rodríguez, 2011; Stepick et al., 2009). Identifying, measuring, and describing the presence of these ecological contributing factors both at individual and congregational levels, based on participants' reported experiences and involvement, provides a further account of these ecological dynamics present in Latino congregations and among their youth. Therefore, post analysis, the possible implications of the relationships among variables towards potentially promoting and supporting leadership development among youth in Latino congregations were addressed in Chapter 5.

Since this dissertation approaches leadership development as a process that spans different life phases (Clinton, 2012; Day et al., 2012; Stadler, 2009), conducting a subsequent longitudinal study that follows the leadership journey of young people throughout various Latino congregations would provide the insight needed to analyze indepth both the individual and congregational level dynamics which can contribute to leadership development. Although such research is beyond the scope of this study, 
nevertheless the findings can contribute towards subsequent experimental and longitudinal studies.

\section{Research Questions and Hypotheses}

Therefore, to guide the analysis of the association between variables that are of interest to this dissertation, the following general research question was formulated: What is the relationship between the level of youth's Religious Participation, and their level of engagement with two contributing ecological factors characteristic of Latino congregations: Social Service Involvement and Engagement in Leadership Tasks?

As a means for describing the levels of participation and subsequently conducting multivariate analyses, based on the general research question, the study addressed the following eight specific research questions, and their corresponding research hypotheses were also tested. For terms related to these research questions, as well as a description of the items, and the coding for the variables, see the sections within this chapter titled Operational Definitions of Variables and Coding of the Selected Variables. For general definitions of the terms related to these questions, refer to Chapter 1. For the Generalized Linear ANOVA models used for testing, see Appendix C.

Research Question 1: What is the level of Religious Participation among youth in Chicago Latino congregations, as measured by the aggregate score?

Research Question 2: How does the level of youth's Religious Participation, as measured by the aggregate score, relate to: denominational affiliation; age; gender; Hispanic/Latino group identification; language usage; and participant's country of birth?

Hypothesis 2a: There is a significant relationship between Age and the level of Religious Participation (RPi and RPii) among youth in Chicago Latino congregations. 
Hypothesis $2 b$ : There is a significant relationship between Gender and the level of Religious Participation (RPi and RPii) among youth in Chicago Latino congregations.

Research Question 3: What is the level of Social Service Involvement among youth in Chicago Latino congregations, as measured by the aggregate score?

Research Question 4: How does the level of youth's Social Service Involvement, as measured by the aggregate score, relate to: denominational affiliation; age; gender; Hispanic/Latino group identification; language usage; and participant's country of birth?

Hypothesis 4a: There is a significant relationship between Gender and the level of Social Service Involvement (SSIi and SSTii) among youth in Chicago Latino congregations.

Hypothesis $4 b$ : There is a significant relationship between Denominational Affiliation and the level of Social Service Involvement (SSIi and SSIii) among youth in Chicago Latino congregations.

Research Question 5: What is the level of Engagement in Leadership Tasks among youth in Chicago Latino congregations, as measured by the aggregate score?

Research Question 6: How does the level of youth's Engagement in Leadership Tasks, as measured by the aggregate score, relate to: denominational affiliation; age; gender; Hispanic/Latino group identification; language usage; and participant's country of birth?

Hypothesis $6 a$ : There is a significant relationship between Gender and the level of Engagement in Leadership Tasks (ELTi, ELTii, and ELTiii) among youth in Chicago Latino congregations. 
Hypothesis 6b: There is a significant relationship between Denominational Affiliation and the level of Engagement in Leadership Tasks (ELTi, ELTii, and ELTiii) among youth in Chicago Latino congregations.

Research Question 7: Is there a significant relationship between the total aggregate scores of Social Service Involvement and Religious Participation among youth in Chicago Latino congregations?

Hypothesis 7: There is a significant relationship between the level of Social Service Involvement (SSIi and SSTii) and the level of Religious Participation (RPi and RPii) among youth in Chicago Latino congregations.

Research Question 8: Is there a significant relationship between the total aggregate scores of Engagement in Leadership Tasks and Religious Participation among youth in Chicago Latino congregations?

Hypothesis 8: There is a significant relationship between the level of Engagement in Leadership Tasks (ELTi, ELTii, and ELTiii) and the level of Religious Participation (RPi and RPii) among youth in Chicago Latino congregations.

\section{Sources of Data of the CLCS}

The following section describes the sources of data and collection procedures of the CLCS. Portions of the CLCS data were used in accordance with the problem and research questions of the current study. The three section subdivisions present first, an overview of the geographical location, population, and sampling frame from where data were collected. Second, details of the CLCS-YS survey instrument design. Third, information about the data collection context and procedures and protocols that were followed. 
Geographical Location, Population, and Sampling Frame

The CLCS was conducted in Latino Christian churches in the Chicago area. More than 80 congregations participated, from which quantitative data was collected, and subsequently qualitative data was also collected from four of those congregations. However, this dissertation drew only from the quantitative data collected among congregants 13 to 19 years old. The attempt was made to survey congregations that constituted a representative sample of Latino congregations in the Chicago area. See Appendix B for full details and procedures implemented to generate the representative sample. Nonetheless, it cannot be assumed that the sample is representative of all churchgoers in Latino congregations in Chicago or the United States. To obtain a representative population sample of Latino congregations, researchers in the CLCS determined the parameters of the sampling frame by first delineating the geographic area to be included, followed by defining what constitutes a Latino congregation for the purposes of this study, and finally by constructing a list of congregations.

The geographic area included in the investigation was primarily the Chicago metropolitan area. However, CLCS researchers concluded that given the growth and expansion of the city's Latino population into nearby suburbs, delimiting the research to the Chicago city limits would artificially exclude some of the major concentrations of Latinos. Therefore, due to their historical connection, proximity, and relatively high numbers of Latinos the research's geographic area also included two adjacent suburbs. These were the suburbs of Berwyn (38 percent Latino population) and Cicero (77 percent Latino population) (Burwell et al., 2010). 
Next, to construct a definition for the term "Latino congregation," the criteria were based on the proportion of church or congregational participants who self-identified as Latino or Hispanic. While an institutional self-identification as a Latino congregation has been used in past studies, which is a viable path for constructing the definition of "Latino congregation," it has been found that some congregations or churches may have a large or even majority population of Latinos, and yet not identify as such themselves. This situation can be commonly observed primarily in the case of Catholic parishes, which would not commonly be identified in Archdiocesan official lists as a "Latino" parish in spite of having a large Latino participation, unless such a parish has a Hispanic Ministries program. Due to the differences in characteristics, dynamics, and organization, a different proportion threshold of church participants was used for Catholic churches than for Protestant churches. For Protestant churches, a congregation was included in the sampling frame if a minimum of 50 percent of its regular participants were Latino. In the case of Catholic churches, since congregations tend to be larger and the worship service dynamics are different, the threshold was lowered to a minimum of 30 percent of its regular participants being Latino. For example, in a Catholic parish it is common to report that there are 1,000 regular participants. However, that does not differentiate the various ethnic and cultural groups involved as the numbers reported are integrated under one congregation. Yet, many of these same parishes offer Spanish-language services every weekend in which most of the Latino congregants tend to participate. If there are 300 or more Latinos who attend this service, a 50 percent threshold would exclude this Catholic congregation from the sampling pool, and therefore disregard the religious experience of a substantial Latino subgroup within such congregation. 
After these two parameters of the sampling frame were set, researchers created a list of all the area congregations that fit the specifications. The list was constructed by first gathering information from several sources which included denominational or church councils, pastoral associations, para-church and community organizations, government offices, and other research on Chicago-area churches. In addition, the CLCS researchers did street-by-street explorations to identify churches that could be included on the list. They focused on ten zip code areas in which, according to the U.S. Census, the Latino population had grown significantly in the ten years prior to the study. A master list with 670 churches was created as a result of these efforts. Subsequently, the existence of a randomly selected list of congregations was verified through physical inspections. There was a total of 425 churches inspected in 20 out of the 36 zip codes on the master list. In addition, leaders representing various constituencies within the Latino religious community in Chicago where asked to verify the list. This process of verification rendered a final list, which included a total of 606 Latino congregations in the sample. The congregations were then stratified by religious tradition to comprise five categories with the following breakdown: 20 percent Catholic, 13 percent Mainline Protestant, 21 percent Evangelical, 33 percent Pentecostal, and 14 percent unknown tradition. The religious traditions considered in the research did not include Jehovah's Witnesses, The Church of Jesus Christ of Latter-day Saints, and other groups that fit the classification of new religious movements.

Five different survey instruments were designed for the multiple samples in the CLCS. The longer and more intensive and structured surveys were administered to a random sample, which includes the CLCS-YS. As part of the aim of having a broad 
denominational representation of Latino congregations in the random sample, as previously mentioned, the 606 churches on the list were stratified into five religious traditions or denominations: Catholic, Evangelical, Mainline Protestant, Pentecostal, and unknown (see Appendix A for a detailed breakdown of the religious tradition categories). Next, a random sample of 100 congregations was selected from the full list. However, the selection from each religious category occurred in proportion to its relative representation within the total sample.

\section{Survey Instrument Design}

Survey 5 (see Appendix A), also referred to as CLCS-YS, is a survey of youth congregants administered on-site at the 100 churches that constitute the random sample. Portions of Survey 5 serve as the source of data for the analysis in this dissertation. Further details on the specific survey portions used are provided in the Operational Definition of Variables section in this chapter.

Survey 5 (CLCS-YS) consists of a total of seven parts in which participants answered a total of 95 questions, some of which were subdivided into different portions. The survey sections are titled as follows: Part 1: You and Your Congregation (16 questions), Part 2: About Your Faith (13 questions), Part 3: Background Information (13 questions), Part 4: Your School Experiences and Activities (23 questions), Part 5: Your Family (eight questions), Part 6: Your Opinions About Yourself, Attitudes, and Life Experiences (17 questions), and Part 7: Social Service and Civic Activism (five questions).

The survey questions used in the CLCS-YS, and thus in this study, are based on those used in the NSYR (Smith \& Denton, 2009). The specific questions and sections 
included in the survey arose as a result of the purpose and goals of the CLCS. The survey instrument includes a section with general instructions for the participants in which they are informed of the anonymity and confidentiality of the survey, encouraged to answer honestly and not ask another person how they think they should answer, sit as far as possible from the person next to them, ask for help if they do not understand a particular question, avoid talking to others or sharing answers, and thanking them for their time, cooperation, and participation.

Moreover, given that the CLCS study targets the Latino population, to make the promotional documents and survey instruments accessible to as many participants as possible, these were made available in both Spanish and English.

\section{Data Collection Context and Sampling Procedures}

To administer Survey 5 (CLCS-YS) along with other surveys of the CLCS, a multifaceted process was followed. The data collection process described below reflects the information outlined in the CLCS Methodological Considerations report (Burwell et al., 2010) (see Appendix B). All procedures were followed according to the requirements established by the Institutional Review Board.

First, the CLCS researchers placed a phone call to the religious leaders in the 100 randomly sampled churches, and typically followed up with a visit either during church office hours or immediately after a weekend service. If the minister could not be accessed by the initial contact efforts, the help of an area Latino religious leader was enlisted to gain access. A letter introducing the project, which was signed by the Principal Investigator, was sent to each minister prior to the visits. When research assistants gave an overview and introduction of the CLCS project to the religious leaders when visiting 
the sampled churches, they did so by following a script which addressed the importance of the investigation as well as all confidentiality issues.

In the initial effort to contact congregations in which to conduct the first round of surveys (Surveys 2 and 3), of the 100 congregations sampled, 51 responded and 49 churches did not respond for various reasons. For each non-responding church, a replacement church was chosen that matched as closely as possible its denominational affiliation, congregational size, and geographic area (see Appendix B for further details on how replacement churches were selected). Lay and professional ministers responsible at the random sample churches, in a total of 82 churches (51 original and 31 replacement), completed Surveys 2 and 3 which were distributed prior to Survey 5. Assuming that replacement churches closely matched the original non-responding churches on important dimensions of denominational affiliation, congregational size, and geographic area, the response rate for the two first surveys was 82 percent. Although this dissertation study does not utilize the data collected through Surveys 2 and 3, it is important to point out this step in the process, for it allowed a relationship and research precedent to be established with these leaders and their congregations before Survey 5 (CLCS-YS) was distributed at a later time.

To reach the high 82 percent church response rate (from random sample), it took very intensive and intentional efforts from the researchers, which inevitably also influenced the congregational access and response rate for subsequent CLCS Surveys. A considerable amount of time was invested by the research team, on average 10 hours per congregation, in order to secure an interview with the minister and proceed with the first steps of the CLCS. This is a noted challenge in conducting research within Latino 
congregations, a challenge that arises from a wide array of circumstances that are common in this cultural, ethnic, and institutional context (Burwell et al., 2010; Martínez, 2008; Mulder et al., 2017). Some examples of the challenging circumstances are: high numbers of bi-vocational ministers whose time present at the church building is limited due to their full or part-time jobs in addition to their pastoral responsibilities; gaining access and trust, as research in the church context is not something with which many ministers are familiar and thus are somewhat suspicious of participating in, and congregations with large numbers of participants who are undocumented immigrants and therefore are very hesitant to allow outsiders to ask questions of their congregants. Having a team of research assistants who were mostly Latino, conversant in Spanish, and had religious backgrounds representing Catholic, Pentecostal, and Mainline Protestant traditions, helped ease some of the access and trust issues. These efforts resulted in a dataset that is exceptional because it represents the religious diversity of the Latino Christian population and the congregations, including those religious communities that are extremely difficult to reach (e.g. small congregations, denominational independent churches, and Pentecostal Latino churches).

Survey 5 (CLCS-YS) was subsequently distributed to youth attendees at the congregations in which Surveys 2 and 3 were completed; Survey 4 was also simultaneously distributed to adult attendees. When possible, Survey 5 was distributed during the main worship service to every young person within the desired age range. Due to the particular population targeted in the CLCS study, and to make the promotional documents and survey instruments accessible to as many participants as possible, these were made available in both Spanish and English. Participants were provided with 
general instructions for filling out the survey and were informed that their answers were anonymous, that these would be kept strictly confidential, and that participants were not to provide their name. To avoid misunderstandings and to protect privacy and prevent participation of respondents above and below the target age, congregational leaders and CLCS researchers informed parents and youth about the nature of the CLCS-YS survey. Furthermore, parents had the opportunity to review the questionnaire in advance and object to their child's participation in the study if desired, and all participating youth were informed that their participation in answering the survey was voluntary.

The youth congregants completed the survey before leaving the church, and altogether 607 youth at 63 of the randomly sampled congregations completed Survey 5 . Individual-level response rates varied widely by congregation depending on the data collection approach. In some locations-mostly non-Catholic congregations where the surveys were distributed during the main worship service- the ministers also strongly encouraged the participants to complete the survey before leaving the church service. By contrast, in Catholic parishes the priests or pastors tended to ask those attending the service to seek out the CLSC research team in a back room of the church building and pick up and complete the survey after the service.

The field researchers estimated the attendance at each worship service in which participants were invited to complete the survey and calculated that the response rate across all cooperating congregations was approximately 25 percent for both Surveys 4 and 5 combined. In general, smaller congregations had a higher response rate than larger congregations; in such cases, the response rate was about 55 percent. Thus, this methodology skewed the results towards congregants that participate in smaller 
congregations and are more active in their congregation, compared to respondents in many large, especially Catholic congregations.

\section{Operational Definition of Variables}

The predictor, criterion, and control construct variables were determined for this study based on the research and theoretical considerations that undergird this dissertation, as presented in Chapter 2 and summarized within this chapter. These composite variables for the model were created based on the data available through the CLCS-YS instrument (Burwell et al., 2010). Survey questions that reflected the topic within each of the construct variables were grouped for corresponding statistical analysis and calculation of the weighted aggregate scores. The following section details the operational definition of the variables; see Chapter 1 for conceptual definitions. For further details on the variables, see Appendix A, Table 1, and the chapter section titled Coding of the Selected Variables.

Religious Participation: To construct an indicator of religious participation, or the predictor variable, the following six survey items were used: 1.1, 1.2, 1.6, 1.11, 1.12a, and $1.12 \mathrm{~b}$. Survey items that are ordinal in nature were converted to weighted sum of aggregate scores, and items that are nominal or categorical were used as individual items.

Social Service Involvement: To construct an indicator of social service involvement, or a criterion variable, the following six survey items were used: 7.1a, 7.2a, 7.2b, 7.2c, 7.3, and 7.5. Survey items that are ordinal in nature were converted to weighted sum of aggregate scores, and items that are nominal or categorical were used as individual items. 
Engagement in Leadership Tasks: To construct an indicator of engagement in leadership tasks, or a criterion variable, the following five survey items were used: 1.3, $1.4,1.5,1.12 \mathrm{c}$, and $7.4 \mathrm{a}$. Survey items that are ordinal in nature were converted to weighted sum of aggregate scores, and items that are nominal or categorical were used as individual items.

Demographic Characteristics: Throughout the data analysis, several demographic measures were controlled for. This step allows insight into particular characteristics of the respondents which provide further understanding of the context and the youth involved in the study. The following survey items were used according to the pertinent indicators for demographic characteristics: a) denominational affiliation - item 2.8, b) age in years - item 3.1, c) gender - item 3.2, d) Hispanic/Latino group most identified with - item 3.4, e) language usage when reading, thinking, writing, speaking at home, and speaking with friends - items 3.5a, 3.5b, 3.5c, 3.5d, and 3.5e, and f) participant's country of birth - item 3.10a. Survey items that are ordinal in nature were converted to weighted sum of aggregate scores, and items that are nominal or categorical were used as individual items.

\section{Coding of the Selected Variables}

All items of the CLCS-YS questionnaire that were related to the construct variables Religious Participation, Social Service Involvement, and Engagement in Leadership Tasks were selected, along with those of the demographic characteristics that were pertinent to this study. See Table 1 for a general listing of the items under each construct variable. An internal consistency reliability analysis was done for each item, in accordance with alpha levels from 0.70 to 0.80 , which are acceptable ranges in the social 
Table 1

Construct Variables of the Study

\begin{tabular}{|c|c|c|c|c|c|c|c|}
\hline \multicolumn{8}{|c|}{ CRITERION, PREDICTOR, AND CONTROL VARIABLES OF THE STUDY } \\
\hline \multicolumn{4}{|c|}{ CRITERION CONSTRUCT VARIABLES } & \multicolumn{2}{|c|}{$\begin{array}{c}\text { PREDICTOR } \\
\text { CONSTRUCT VARIABLE }\end{array}$} & \multicolumn{2}{|c|}{ CONTROL VARIABLES } \\
\hline $\begin{array}{l}\text { SOCIAL SE } \\
\text { INVOLVEI }\end{array}$ & $\begin{array}{l}\text { VICE } \\
\text { ENT }\end{array}$ & $\begin{array}{r}\text { ENGAGEN } \\
\text { LEADERSH }\end{array}$ & $\begin{array}{l}\text { ENT IN } \\
\text { TASKS }\end{array}$ & $\begin{array}{r}\text { RELIGIC } \\
\text { PARTICIP }\end{array}$ & $\begin{array}{l}\text { US } \\
\text { TION }\end{array}$ & $\begin{array}{r}\text { DEMOGR } \\
\text { CHARACTE }\end{array}$ & $\begin{array}{l}\text { PHIC } \\
\text { ISTICS }\end{array}$ \\
\hline $\begin{array}{l}\text { Components: } \\
\text { (SSIi, SSIii) }\end{array}$ & $\begin{array}{c}\text { Survey } \\
\text { Question: }\end{array}$ & $\begin{array}{c}\text { Components: } \\
\text { (ELTi, ELTii, } \\
\text { ELTiii) }\end{array}$ & $\begin{array}{c}\text { Survey } \\
\text { Question: }\end{array}$ & $\begin{array}{l}\text { Components: } \\
\text { (RPi, RPii) }\end{array}$ & $\begin{array}{c}\text { Survey } \\
\text { Question: }\end{array}$ & Components: & $\begin{array}{c}\text { Survey } \\
\text { Question: }\end{array}$ \\
\hline $\begin{array}{l}\text { Participation } \\
\text { community } \\
\text { service/volunteer } \\
\text { activity }\end{array}$ & $7.1 \mathrm{a}$ & $\begin{array}{l}\text { Public } \\
\text { speaking }\end{array}$ & 1.3 & $\begin{array}{l}\text { Attendance to } \\
\text { worship } \\
\text { services } \\
\text { (frequency of) }\end{array}$ & 1.1 & $\begin{array}{l}\text { Denominational } \\
\text { Affiliation }\end{array}$ & 2.8 \\
\hline $\begin{array}{l}\text { Frequency of } \\
\text { volunteer work }\end{array}$ & $7.2 \mathrm{a}$ & $\begin{array}{l}\text { Influencing } \\
\text { others } \\
\text { (inviting } \\
\text { friends) }\end{array}$ & 1.4 & $\begin{array}{l}\text { Attendance to } \\
\text { religious } \\
\text { education class }\end{array}$ & 1.2 & Age & 3.1 \\
\hline $\begin{array}{l}\text { Time spent } \\
\text { volunteering }\end{array}$ & $7.2 \mathrm{~b}$ & $\begin{array}{l}\text { Organizing } \\
\text { events }\end{array}$ & 1.5 & $\begin{array}{l}\text { Participation in } \\
\text { worship/drama/ } \\
\text { choir program }\end{array}$ & 1.6 & Gender & 3.2 \\
\hline $\begin{array}{l}\text { Volunteer work } \\
\text { organized by } \\
\text { congregation }\end{array}$ & $7.2 \mathrm{c}$ & $\begin{array}{l}\text { Leader in } \\
\text { youth group }\end{array}$ & $1.12 \mathrm{c}$ & $\begin{array}{l}\text { Hours spent per } \\
\text { week in church } \\
\text { related } \\
\text { activities }\end{array}$ & 1.11 & $\begin{array}{l}\text { Hispanic/Latino } \\
\text { group } \\
\text { identification }\end{array}$ & 3.4 \\
\hline $\begin{array}{l}\text { Helping others } \\
\text { (not through an } \\
\text { organization) }\end{array}$ & 7.3 & $\begin{array}{l}\text { Planning } \\
\text { events, } \\
\text { leading } \\
\text { meetings, } \\
\text { public } \\
\text { speaking }\end{array}$ & $7.4 \mathrm{a}$ & $\begin{array}{l}\text { Involvement in } \\
\text { youth group }\end{array}$ & $1.12 \mathrm{a}$ & Language usage & $3.5 \mathrm{a}, \mathrm{b}, \mathrm{c}, \mathrm{d}, \mathrm{e}$ \\
\hline $\begin{array}{l}\text { Volunteer work } \\
\text { encouraged by } \\
\text { someone in } \\
\text { church }\end{array}$ & 7.5 & - & - & $\begin{array}{l}\text { Frequency of } \\
\text { attendance to } \\
\text { youth group }\end{array}$ & $1.12 \mathrm{~b}$ & $\begin{array}{l}\text { Participant's } \\
\text { country of birth }\end{array}$ & $3.10 \mathrm{a}$ \\
\hline
\end{tabular}

Source for Survey Questions: Chicago Latino Congregational Study-Youth Survey (Survey 5), 2007.

sciences (Kline, 2015). If the reliability coefficient was high $(\alpha=0.70)$, and there were no items on the variable that did not contribute to the reliability, the items in the construct variable were used in this dissertation without change.

The following sections provide the corresponding coding and scores used for the construct variables. Within the same variable indicator, some of the items included a 
different number of response choices; those were not recoded but instead were left as in the original questionnaire. For the Generalized Linear ANOVA models used for testing, see Appendix C.

\section{Religious Participation}

The overall score for the predictor aggregate construct variable Religious Participation is based upon a GLM ANOVA equation model, which is estimated by an aggregate weighted score of five items and one single categorical variable from Part 1 of the CLCS-YS instrument (see Appendix A). Some of the answers on the survey questions are nominal, while others are ordinal. Coding and scores for response options for each of the items are as follows:

$\mathrm{RP}_{1 \ldots 6}$ is religious participation items $1.1,1.2,1.6,1.11,1.12 \mathrm{a}$, and $1.12 \mathrm{~b}$.

Item 1.1 coding: $\mathrm{RP}_{1}$

Item 1.1 response options: $1=$ Never; $2=$ On special occasions only; $3=\mathrm{A}$ few times a year; $4=$ Once a month; $5=2-3$ times a month; $6=$ Once a week; $7=$ More than once a week.

Item 1.2 coding: $\mathrm{RP}_{2}$

Item 1.2 response options: $1=$ Never; $2=\mathrm{A}$ few times a year; $3=$ Once a month; $4=2-3$ times a month; $5=$ Once a week; $6=$ More than once a week.

Item 1.6 coding: $\mathrm{RP}_{3}$

Item 1.6 response options: 1 = Never; $2=$ Sometimes; 3 = Fairly Often; $4=$ Very Often.

Item 1.11 coding: $\mathrm{RP}_{4}$

Item 1.11 response options: $1=$ None; $2=$ Less than 1 hour; $3=1-3$ hours; $4=3-$ 5 hours; $5=5-7$ hours; $6=7-9$ hours; $7=$ More than 9 hours.

Item 1.12a coding: $\mathrm{RP}_{5}$

Item $1.12 \mathrm{a}$ response options: $0=\mathrm{No} ; 1=$ Yes. 
Item $1.12 \mathrm{~b}$ coding: $\mathrm{RP}_{6}$

Item $1.12 \mathrm{~b}$ response options: $1=$ Almost never; $2=$ A few times a year; $3=2-3$ times a month; $4=$ About once a month; $5=$ About once a week; $6=$ More than once a week.

Social Service Involvement

The overall score for the first criterion aggregate construct variable, Social Service Involvement, is based upon a GLM ANOVA equation model, which is estimated by an aggregate weighted score of five items and one single categorical variable from Part 7 of the CLCS-YS instrument (see Appendix A). Some of the answers on the survey questions are nominal, while others are ordinal. Coding and scores for response options for each of the items are as follows:

$\mathrm{SSI}_{1 \ldots 6}$ is social service involvement items 7.1a, 7.2a, 7.2b, 7.2c, 7.3, and 7.5.

Item 7.1a: $\mathrm{SSI}_{1}$

Item 7.1a response options: $1=$ Yes, have done it in the past 12 months; $2=$ Yes, have done it but not in the past 12 months; $3=$ No, have not done it.

Item 7.2a: $\mathrm{SSI}_{2}$

Item 7.2a response is number of times per month respondent does volunteer work. Participants self-reported times which ranged from 0 times to 56 times per month.

Item 7.2b: $\mathrm{SSI}_{3}$

Item 7.2b response options: $1=$ Less than 30 minutes; $2=$ About 1 or 2 hours; $3=$ About 3 or 4 hours; $4=$ Over 5 hours.

Item 7.2c: $\mathrm{SSI}_{4}$

Item 7.2c response options: $1=$ None; $2=$ Some; $3=$ About half; $4=$ Most $; 5=$ All.

Item 7.3: $\mathrm{SSI}_{5}$

Item 7.3 response options: $1=$ None; $2=$ Less than 1 hour; $3=2$ hours; $4=3$ hours; $5=4$ hours; $6=5$ hours; $7=6$ hours; $8=7$ hours or more. 
Item 7.5: $\mathrm{SSI}_{6}$

Item 7.5 response options: $1=$ No; $2=$ Yes.

\section{Engagement in Leadership Tasks}

The overall score for the second criterion aggregate construct variable, Social Service Involvement, is based upon a GLM ANOVA equation model, which is estimated by an aggregate weighted score of three items and two categorical variables from Parts 1 and 7 of the CLCS-YS instrument (see Appendix A). Some of the answers on the survey questions are nominal, while others are ordinal. Coding and scores for response options for each of the items are as follows:

$\mathrm{ELT}_{1 \ldots 5}$ is engagement in leadership tasks items $1.3,1.4,1.5,1.12 \mathrm{c}$, and 7.4a.

Item 1.3: $\mathrm{ELT}_{1}$

Item 1.3 response options: $1=$ Never; $2=$ Sometimes; 3 = Fairly Often; $4=$ Very Often.

Item 1.4: $\mathrm{ELT}_{2}$

Item 1.4 response options: $1=$ Never; $2=$ Sometimes; $3=$ Fairly Often; $4=$ Very Often.

Item 1.5: $\mathrm{ELT}_{3}$

Item 1.5 response options: $1=$ Never; $2=$ Sometimes; $3=$ Fairly Often; $4=$ Very Often.

Item 1.12c: $\mathrm{ELT}_{4}$

Item $1.12 \mathrm{c}$ response options: 1 = Leader; 2 = Participant.

Item 7.4a: $\mathrm{ELT}_{5}$

Item 7.4a response options: $1=$ No; $2=$ Yes. 


\section{Demographic Characteristics}

The following survey items from Part 2 and 3 of the CLCS-YS instrument (see Appendix A) constitute the control variables for pertinent indicators of demographic characteristics relevant to this dissertation: a) denominational affiliation-item $2.8, \mathrm{~b}$ ) age in years-item 3.1, c) gender-item 3.2, d) Hispanic/Latino group most identified withitem 3.4 , e) language usage when reading, thinking, writing, speaking at home, and speaking with friends-items $3.5 \mathrm{a}, 3.5 \mathrm{~b}, 3.5 \mathrm{c}, 3.5 \mathrm{~d}$, and $3.5 \mathrm{e}$, and f) participant's country of birth-items 3.10a. Coding and scores for response options for each of the items are as follows:

a) $\mathrm{DA}_{1 \ldots 4}$ is respondent's denominational affiliation, item 2.8. For data analysis purposes, the respondents' answers under this item were stratified into four religious tradition categories.

Nominally-coded variables within denominational affiliation:

$\mathrm{DA}_{1}$ response option: $1=$ Catholic; $0=$ Otherwise

$\mathrm{DA}_{2}$ response option: $2=$ Mainline Protestant; $0=$ Otherwise

$\mathrm{DA}_{3}$ response option: $3=$ Evangelical; $0=$ Otherwise

$\mathrm{DA}_{4}$ response option: $4=$ Pentecostal; $0=$ Otherwise

b) AGE is respondent's age in years, item 3.1.

c) GENDER 1,2 is respondent's gender, item 3.2.

Nominally-coded variables within gender:

GENDER $_{1,2}$ response option: $1=$ Male; $0=$ Female 
d) $\mathrm{HLGI}_{1 \ldots 11}$ is the Hispanic/Latino group that the respondent most identifies with, item 3.4.

Nominally-coded variables within Hispanic/Latino group most identified with:

HLGI $_{1}$ response option: 1 = Mexican American/Chicano; 0 = Otherwise

$\mathrm{HLGI}_{2}$ response option: $2=$ Mexican; $0=$ Otherwise

$\mathrm{HLGI}_{3}$ response option: 3 = Puerto Rican; $0=$ Otherwise

$\mathrm{HLGI}_{4}$ response option: $4=$ Cuban American; 0 = Otherwise

$\mathrm{HLGI}_{5}$ response option: $5=$ Cuban; $0=$ Otherwise

HLGI $_{6}$ response option: $6=$ Dominican; $0=$ Otherwise

HLGI 7 response option: 7 = Colombian; $0=$ Otherwise

$\mathrm{HLGI}_{8}$ response option: $8=$ Native American/Indigenous; $0=$ Otherwise

$\mathrm{HLGI}_{9}$ response option: $9=$ Central American; $0=$ Otherwise

$\mathrm{HLGI}_{10}$ response option: $10=$ South American; $0=$ Otherwise

HLGI $_{11}$ response option: $11=$ Other; $0=$ Otherwise

e) $\mathrm{LANG}_{1,2}$ is respondent's language usage when reading, thinking, writing, speaking at home, and speaking with friends, items 3.5a, 3.5b, 3.5c, 3.5d, and 3.5e. For data analysis purposes, the respondents' answers under these items were stratified into two language usage categories, those being English Dominant and Spanish Dominant. Nominally-coded variables within language usage:

LANG $_{1,2}$ response options: 1 = English Dominant; 2 = Spanish Dominant 
f) $\mathrm{COB}_{1 \ldots 9}$ is participant's country of birth, item 3.10a.

Nominally-coded variables within country of birth:

$\mathrm{COB}_{1}$ response option item 3.10a: $1=$ Outside of U.S.; $0=$ Otherwise

$\mathrm{COB}_{2}$ response option item 3.10a: $2=$ In the U.S.; $0=$ Otherwise

$\mathrm{COB}_{3}$ response option item 3.10a: 3 = In Puerto Rico; 0 = Otherwise

\section{Data Analysis and Statistical Treatment}

The following section provides a general outline of the data analysis and statistical treatment procedures that were employed in this dissertation. Both procedures aligned with the purpose, problem, and research questions of this study. The calculations were conducted through the Statistical Package for Social Sciences software, version 24.

Being that this dissertation utilizes data from previously conducted research through the CLCS, an ex post facto research design Type III was utilized to guide the analysis (Newman et al., 2006). Research hypotheses were tested while controlling for alternative hypotheses. This strengthens the internal validity of the design, and also attempts to control for some of the confounding alternative explanations, such as the effects due to gender, age, denominational affiliation, etc. (Newman \& Benz, 1998; Newman \& Newman, 2010; Newman et al., 2006).This design is congruent with research that is related to the field of sociology, as the most significant social problems, by their very nature, require ex post facto analysis since the independent or predictor variable has already occurred and cannot be manipulated (Kerlinger, 1973; Newman et al., 2006).

It is important to point out that since the CLCS is not based on an experimental design, it was not possible to randomly assign and manipulate the predictor variable, and therefore have total internal validity that would allow the inference of causation 
(Kerlinger, 1973; Newman et al., 2006). Because of these weaknesses, there is also the risk of improper interpretation of results due to the lack of control (Kerlinger \& Lee, 2000). However, because this current study was guided by hypotheses and by past and present theoretical frameworks, it is possible to test relationships of interest to this investigation, as expressed within the hypothesis statements.

Although an ex post facto research design also limits the findings and conclusions, as these are not representative of and cannot be applied to the population at large (i.e., external validity), the findings do provide a contextual description of social indicators present in the setting where the survey research was conducted (Glewwe \& Levin, 2005; Newman et al., 2006; Voas, 2007). Furthermore, this research design helps identify a narrow set of variables from a wider span, which could potentially be manipulated in future studies (Newman et al., 2006)

Moving on to the statistical calculations, first, to answer the research questions, data were analyzed using descriptive statistics through methods of central tendency. The purpose of descriptive research is to describe the state of affairs that exist at a certain moment in time, therefore, it is non-experimental, and it is a research type which is frequently used in social science research (Kothari, 2004). This first portion of the analysis thereby described the general trends and characteristics of the sample population. Second, methods of measures of variability were used to analyze the research questions and describe the data distribution (i.e., frequencies, variance, and standard deviation). Third, GML ANOVA statistical examinations were used to analyze the variance in predicting the relationship between Religious Participation, the two construct criterion variables (Social Service Involvement and Engagement in Leadership Tasks), while 
controlling for demographic variables (i.e., gender, denominational affiliation, Hispanic/Latino group identification, language usage, participant's country of birth, and age). An analysis of variance was also used to co-vary some of the variables for testing the alternative hypotheses. This, while controlling for Type I error buildup through the Bonferroni test with an alpha level set at $0.05(\alpha=0.05)$, and Type II error and effect size through a power analysis (Newman et al., 2000). Finally, the $F$-test was also used to test the statistical significance of the proposed relationships in the hypotheses. The $F$-test was chosen because it is very robust, and it also allows for the assumptions of random selection of subjects and normal distribution of the variables to be violated without doing serious harm to the procedure (Newman et al., 2006).

Generalized linear ANOVA models and multiple linear regression techniques were used to answer the research questions because these statistical techniques are commonly used, they are flexible, and statistical models can be written to reflect the research question of interest (McNeil, Newman, \& Fraas, 2012). A GML is a flexible generalization of ordinary linear regression that allows for response variables that have error distribution models other than a normal distribution, and it allows as well the inclusion of both categorical and continuous predictor variables (Fox, 2015; Howell, 2010). Generalized linear models generalize traditional linear regression by allowing the linear model to be related to the outcome variable via a link function, and by allowing the magnitude of the variance of each measurement to be a function of its predicted value. Generalized linear models accommodate statistical models that reflect linear, Poisson, and logistic regression models (Consul \& Famoye, 1992; Fox, 2015). 
In this study, the GML ANOVA models allowed for the comparison of more than two group means on continuous criterion variables, as well as the categorical predictor variable, and continuous covariates (Fox, 2015; Hocking, 2013; Howell, 2010; Weiss, 2006). Because GML is a generalized form of ANOVA, it can replace most other statistical procedures (e.g., $t$-test, etc.) and be used to test the majority of research hypotheses with less Type I error (Fox, 2015; Howell, 2010). Since GML ANOVAs and multiple linear regression allow for writing the models that reflect the specific research question being asked, one can test relationships between multiple predictor variables, whether it is between categorical variables, between categorical and continuous variables (coded as binary variables), or between continuous variables (Bottenberg \& Ward, 1963; McNeil et al., 2012; Newman, 1976; Weiss, 2006).

\section{Summary}

This chapter presented an overview of the methodology used for the data analysis and statistical treatment of this dissertation in accordance with the purpose, problem, and general research question of this investigation. This descriptive and explanatory ex post facto study examined the reported actions and behaviors of youth in Chicago Latino congregations through analyzing the survey data collected by the Chicago Latino Congregational Study utilizing the CLCS-YS instrument. The analysis focused on three categories of interest: level of Religious Participation, level of Social Service Involvement, and level of Engagement in Leadership Tasks within the congregation. The description also includes pertinent demographic characteristics of youth in these congregations. The analysis concluded with the testing of the relationships between the 
criterion and predictor variables. The results of the data analyses described in this chapter are presented in detail in Chapter 4. 


\section{CHAPTER 4}

\section{RESULTS}

\section{Introduction}

The following chapter presents the results and findings obtained after conducting the data analysis as per the statistical methodology described in Chapter 3 of this study. The first section within this chapter provides the general demographic characteristics of the sample for the study. Followed by the results to the specific research questions and research hypotheses tested in order to answer the general research question. The results for each research question include and report on frequencies for each of the survey questions (see Table 1) utilized to draw data from for the analysis. The final section includes the chapter summary, along with a table containing a summary of all the research questions and research hypotheses for quick reading. For details on the coding of the criterion, predictor, and control variables analyzed in the current investigation, see Chapter 3, under the section titled Coding of the Selected Variables.

\section{Demographics of the Sample}

Although 607 youth at 63 randomly sampled congregations completed the CLCSYS (see Appendix A), the data analysis only included the responses of 307 participants $(N=307)$ due to cases which were disqualified for either being outside the desired age rage (13 to 19 years old) or the ethnocultural background (Hispanic/Latino) sought for 
this study. The demographic characteristics of the sample are represented in two tables.

Table 2 contains the age, gender, and denominational affiliation demographic characteristics of participants. Table 3 contains the Hispanic/Latino group identification, language usage, and participant's country of birth information. All results in Table 2 are listed for the total sample of 307 youth $(N=307)$, and Table 3 lists results for only 302 youth $(N=302)$ from the sample population, due to missing cases in the data set.

Table 2

Demographic Characteristics of the Sample: Age, Gender, and Denominational Affiliation

\begin{tabular}{lccc}
\hline $\begin{array}{l}\text { Demographic } \\
\text { Characteristics }\end{array}$ & $\begin{array}{c}\text { Frequency } \\
N=307\end{array}$ & $\begin{array}{c}\text { Percent } \\
100 \%\end{array}$ & $\begin{array}{c}\text { Valid Percent } \\
100 \%\end{array}$ \\
\hline Age & 168 & 54.8 & 54.8 \\
$13-15$ & 90 & 29.3 & 29.3 \\
$16-17$ & 49 & 15.9 & 15.9 \\
$18-19$ & 155 & & \\
Gender & 128 & 50.5 & 54.8 \\
Female & 24 & 41.7 & 45.2 \\
Male & & 7.8 & \\
Missing & 76 & & \\
Denominational Affiliation & 7 & 24.8 & 25.3 \\
Catholic Church & 100 & 2.3 & 2.4 \\
Mainline Church & 118 & 32.6 & 33.2 \\
Evangelical Church & 6 & 38.4 & 39.1 \\
Pentecostal Church & & 1.9 & \\
Missing & & & \\
\hline
\end{tabular}


Table 3

Demographic Characteristics of the Sample: Hispanic/Latino Group Identification, Language Usage, and Participant's Country of Birth

\begin{tabular}{|c|c|c|c|}
\hline Demographic Characteristics & $\begin{array}{c}\text { Frequency } \\
N=302\end{array}$ & $\begin{array}{c}\text { Percent } \\
100 \%\end{array}$ & $\begin{array}{c}\text { Valid Percent } \\
100 \%\end{array}$ \\
\hline \multicolumn{4}{|c|}{ Hispanic/Latino Group Identification } \\
\hline Mexican American & 103 & 34.1 & 35.2 \\
\hline Mexican & 81 & 26.8 & 27.6 \\
\hline Puerto Rican & 55 & 18.2 & 18.8 \\
\hline Dominican & 1 & 0.3 & 0.3 \\
\hline Colombian & 2 & 0.7 & 0.7 \\
\hline Native American & 4 & 1.3 & 1.4 \\
\hline Central American & 33 & 10.9 & 11.3 \\
\hline South American & 10 & 3.3 & 3.4 \\
\hline Other & 4 & 1.3 & 1.4 \\
\hline Missing & 9 & 3.0 & \\
\hline \multicolumn{4}{|l|}{ Language Usage } \\
\hline English Dominant & 244 & 80.8 & 80.8 \\
\hline Spanish Dominant & 58 & 19.2 & 19.2 \\
\hline \multicolumn{4}{|l|}{ Participant's Country of Birth } \\
\hline Outside of U.S. & 84 & 27.8 & 28.8 \\
\hline In the U.S. & 204 & 67.5 & 69.9 \\
\hline In Puerto Rico & 4 & 1.3 & 1.4 \\
\hline Missing & 10 & 3.3 & \\
\hline
\end{tabular}

As shown in Table 2, the age range of the sample $(N=307)$ was between 13 and 19 years old. The respondents' answers for survey item 3.1 were stratified into three age categories. The distribution within the chosen age categories was higher for participants 
between the ages of 13 to 15 (54.8 percent), followed by the ages of 16 to 17 (29.3 percent), and the lowest rate of participation being among the ages of 18 to 19 (15.9 percent). The proportion of female (50.5 percent) respondents was slightly higher than that of male (41.7 percent) respondents. In regards to denominational affiliation, the respondents' answers to survey item 2.8 were stratified from thirty-three into four religious traditions categories (see Appendix B for full list). The majority of participants identified with Pentecostal (38.4 percent) and Evangelical (32.6 percent) religious traditions. There was a good response rate as well from participants who identify with the Catholic church (24.8 percent); however, participation from those affiliated with Mainline religious traditions was very low (2.3 percent).

Furthermore, Table 3 shows that respondents listed nine diverse Hispanic/Latino group identification categories, out of the original eleven categories provided in the survey instrument. None of the participants identified as Cuban or Cuban American, while Mexican American (34.1 percent) and Mexican (26.8 percent) were the two groups with the highest identification rate. Respondents who identify as Puerto Rican (18.2 percent) and Central American (10.9 percent) also represented a substantial ratio of participation. All five remaining Hispanic/Latino group identification categories, when combined, account for seven percent of the sample. In regards to language usage, the respondents' answers to survey items $3.5 \mathrm{a}, \mathrm{b}, \mathrm{c}, \mathrm{d}$, and e, were stratified into two language usage categories, those being English Dominant and Spanish Dominant. The majority of respondents (80.8 percent) indicated that they are English Dominant, as they read, think, write, and speak more in English than in Spanish. The language usage results are congruent with the report on the participant's country of birth information, where 
67.5 percent indicated being born in the United States, 1.3 percent in Puerto Rico, and 27.8 percent outside of the United States.

\section{Research Question 1}

Through the statistical data analysis, this dissertation sought to explore the relationship between factors that are of interest to answering the general research question, namely: What is the relationship between the level of youth's Religious Participation, and their level of engagement with two contributing ecological factors characteristic of Latino congregations: Social Service Involvement and Engagement in Leadership Tasks? To this end, Research Question 1 asked: What is the level of Religious Participation among youth in Chicago Latino congregations, as measured by the aggregate score?

To explore this research question, a total Religious Participation score was created as an aggregate of: frequency of attendance to worship services at this congregation, frequency of attendance to religious education classes at this congregation, frequency of participation in worship team, drama group, or choir at this congregation, hours spent per week in church-related activities, involvement in any religious youth group, and frequency of attendance to religious youth group's meetings and events (see Table 1 for Construct Variables). For the purpose of contextual score description within this study, the aggregate scores from the three constructed criterion and predictor variables are operationally categorized under the following range: those that fall at or under the 25 percentiles are considered low scores; those that fall between the 26 to 49 percentiles are medium scores, those between the 50 to 75 percentiles are considered high, and those that fall at or above the 76 percentiles are considered extremely high scores. 
Table 4 shows the means and standard deviations for the aggregate score, as well as each individual item from survey questions indicating Religious Participation among youth in Chicago Latino congregations $(N=302)$. Religious Participation was assessed using Likert Scales with a continuum range, and one nominal item, where a higher score indicates a higher level of participation. Youth in Chicago Latino congregations who participated in this study obtained a mean score of 22.9 for Religious Participation $(\bar{X}=$ $22.9, S D=5.25)$. Based on the operational score range established for this study, the

Table 4

Descriptive Statistics: Religious Participation of Youth in Latino Congregations

\begin{tabular}{|c|c|c|c|c|c|c|}
\hline \multirow{2}{*}{ Variables } & \multirow{2}{*}{$N$} & \multirow{2}{*}{$\begin{array}{l}\text { Possible } \\
\text { Range }\end{array}$} & \multicolumn{4}{|c|}{ Obtained Scores } \\
\hline & & & Min & Max & $M$ & $S D$ \\
\hline $\begin{array}{l}\text { Religious Participation Total } \\
\text { Aggregate Score }\end{array}$ & 302 & 5 to 31 & 8 & 31 & 23.6 & 5.25 \\
\hline $\begin{array}{l}\text { Frequency: Attendance } \\
\text { worship services at this } \\
\text { congregation }\end{array}$ & 286 & 1 to 7 & - & - & 6.3 & 1.29 \\
\hline $\begin{array}{l}\text { Frequency: Attendance } \\
\text { religious education classes at } \\
\text { this congregation }\end{array}$ & 284 & 1 to 6 & - & - & 4.52 & 1.71 \\
\hline $\begin{array}{l}\text { Frequency: Participation in } \\
\text { worship team, drama group, } \\
\text { or choir at this congregation }\end{array}$ & 297 & 1 to 4 & - & - & 2.72 & 1.14 \\
\hline $\begin{array}{l}\text { Hours spent per week in } \\
\text { church related activities }\end{array}$ & 302 & 1 to 7 & - & - & 4.37 & 1.54 \\
\hline $\begin{array}{l}\text { Currently involved in any } \\
\text { religious youth group }\end{array}$ & 302 & 0 to 1 & - & - & 1 & 0 \\
\hline $\begin{array}{l}\text { Frequency: Attendance } \\
\text { religious youth group's } \\
\text { meetings/events }\end{array}$ & 298 & 1 to 6 & - & - & 4.73 & 1.2 \\
\hline
\end{tabular}


mean score of the reported participation translates to a relatively high score for Religious Participation, as it represents obtaining 74 percent of the possible maximum total score for this aggregate variable which ranges from a minimum of five to a maximum score of 31.

Additionally, using raw data collected, frequencies where calculated for each survey item comprising the Religious Participation total score. Table 5 shows the percentage distribution for each of the participant's responses. The results indicate that 83.8 percent of youth in Latino Chicago congregations attend worship services or mass once (25.2 percent) or more than once a week (58.6 percent). In addition, 67.6 percent of respondents attend once or more than once a week to Sunday, Sabbath, catechesis or Bible school (religious education classes). Furthermore, in regards to participation in additional religious activities, 56.2 percent of youth reported participating fairly (20.2 percent) or very often (35.1 percent) in worship team, drama group, or choir at their respective congregation, with 55.3 percent spending between one and five hours per week in church related activities. All participants (100 percent) also reported being currently involved in a religious youth group, and 70.2 percent attend the religious youth group's meetings and events about once per week (42.4 percent) or more (27.8 percent).

\section{Research Question 2}

Research Question 2 is concerned with how does the level of youth's Religious Participation, as measured by the aggregate score, relate to denominational affiliation, age, gender, Hispanic/Latino group identification, language usage, and participant's country of birth. A GML ANOVA was conducted to investigate these 
Table 5

Frequencies of Individual Survey Items in Religious Participation Total Score (Percentages)

\begin{tabular}{lccc}
\hline Survey Item & Frequency & Percent & Valid \\
& $N=302$ & $100 \%$ & $\begin{array}{c}\text { Percent } \\
100 \%\end{array}$ \\
\hline
\end{tabular}

1.1 About how often do you usually attend worship services or mass at a local congregation or parish?

Never

$\begin{array}{ccc}6 & 2.0 & 2.1 \\ 6 & 2.0 & 2.1 \\ 6 & 2.0 & 2.1 \\ 3 & 1.0 & 1.0 \\ 12 & 4.0 & 4.2 \\ 76 & 25.2 & 26.6 \\ 177 & 58.6 & 61.9 \\ 16 & 5.3 & \end{array}$

1.2 In the last year, how often, if at all, have you participated in a Sunday or Sabbath school, catechesis, Bible school, or religious education class?

Never

A few times a year

Once a month

8

Two or three times a month

15

2.6

2.8

Once a week

106

5.0

5.3

More than once a week

98

35.1

37.3

Missing

18

32.5

34.5

6.0 
Table 5-Continued

\begin{tabular}{|c|c|c|c|}
\hline Survey Item & $\begin{array}{l}\text { Frequency } \\
N=302\end{array}$ & $\begin{array}{l}\text { Percent } \\
100 \%\end{array}$ & $\begin{array}{c}\text { Valid } \\
\text { Percent } \\
100 \%\end{array}$ \\
\hline \multicolumn{4}{|c|}{$\begin{array}{l}\text { 1.6 How often have you participated in a } \\
\text { worship team, drama group, or choir at church? }\end{array}$} \\
\hline Never & 57 & 18.9 & 19.2 \\
\hline Sometimes & 73 & 24.2 & 24.6 \\
\hline Fairly Often & 61 & 20.2 & 20.5 \\
\hline Very Often & 106 & 35.1 & 35.7 \\
\hline Missing & 5 & 1.7 & \\
\hline \multicolumn{4}{|c|}{$\begin{array}{l}\text { 1.11 Approximately, how many hours a week } \\
\text { do you spend in church related activities? }\end{array}$} \\
\hline None & 4 & 1.3 & 1.3 \\
\hline Less than one hour & 17 & 5.6 & 5.6 \\
\hline One to three hours & 77 & 25.5 & 25.5 \\
\hline Three to five hours & 90 & 29.8 & 29.8 \\
\hline Five to seven hours & 40 & 13.2 & 13.2 \\
\hline Seven to nine hours & 26 & 8.6 & 8.6 \\
\hline More than nine hours & 48 & 15.9 & 15.9 \\
\hline \multicolumn{4}{|c|}{$\begin{array}{l}\text { 1.12a Are you currently involved in ANY } \\
\text { religious youth group? By "religious youth } \\
\text { group" we mean an organized group of young } \\
\text { people that meets regularly for social time } \\
\text { together, prayer, or to learn more about their } \\
\text { religious faith. }\end{array}$} \\
\hline No & 0 & 0.0 & 0.0 \\
\hline Yes & 302 & 100.0 & 100.0 \\
\hline
\end{tabular}


Table 5-Continued

Survey Item

$\begin{array}{ccc}\text { Frequency } & \text { Percent } & \text { Valid } \\ N=302 & 100 \% & \begin{array}{c}\text { Percent } \\ 100 \%\end{array}\end{array}$

$1.12 b$ If yes, about how often do you attend this youth group's meetings and events?

\begin{tabular}{lccc} 
Almost never & 1 & 0.3 & 0.3 \\
A few times a year & 19 & 6.3 & 6.4 \\
Two to three times a month & 37 & 12.3 & 12.4 \\
About once a month & 29 & 9.6 & 9.7 \\
About once a week & 128 & 42.4 & 43.0 \\
More than once a week & 84 & 27.8 & 28.2 \\
Missing & 4 & 1.3 & \\
\hline
\end{tabular}

demographic variables in relationship to the level of Religious Participation, and found the overall model did account for a significant proportion of unique variance $[F(17,263)$ $\left.=370.22, p<.001, \eta^{2}=.962\right]$, with an adjusted $\mathrm{R}^{2}=.960$. As reported on Table 6 , while holding all other variables constant, the only variable that explained a significant

Table 6

GLM ANOVA: Relationship Between Religious Participation and Demographic Variables

\begin{tabular}{lcccc}
\hline Variables & $d f$ & $F(17,263)$ & $p$ & $\eta^{2}$ \\
\hline Gender & 1 & 2.31 & .130 & .009 \\
Denominational Affiliation & 3 & 12.14 & $<.001 * *$ & .129 \\
Hispanic/Latino Group Identification & 8 & 0.67 & .720 & .021 \\
Language Usage & 1 & 2.97 & .086 & .012 \\
Participant's Country of Birth & 2 & 0.56 & .570 & .005 \\
Age & 1 & 1.03 & .312 & .004 \\
\hline $\mathrm{R}^{2}=.960 . F(17,263)=370.22 . p<.001 . \eta^{2}=.962 . * * p<.001$. & & &
\end{tabular}


proportion of unique variance was the difference in denominational affiliation among participants $\left[F(3,263)=12.14, p<.001, \eta^{2}=.129\right]$.

To further investigate the differences between denominational affiliation on youth's average Religious Participation score, a multiple comparison was conducted with a Bonferroni correction. As can be seen on Table 7, participants affiliated with the Catholic Church had an overall lower average Religious Participation score than those affiliated with the Evangelical Church $(M=20.60, p=.003)$ and Pentecostal Church $(M$ $=22.33, p=.000$ ), but it was not statistically different compared to those affiliated with the Mainline Church $(M=17.82, p=1.00)$. There were also no statistically significant differences between the Mainline Church and the Evangelical Church $(p=.847)$ or the Pentecostal Church $(p=.101)$. Nor was there a statistically significant difference between the Evangelical Church and the Pentecostal Church $(p=.101)$.

Table 7

Multiple Comparison With a Bonferroni Correction: Religious Participation Differences Between Denominational Affiliation

\begin{tabular}{llccc}
\hline Denomination (i) & Denomination (j) & M (i-j) & SE & $p$ \\
\hline Catholic Church & Mainline Church & -0.22 & 1.92 & 1.000 \\
& $\begin{array}{l}\text { Evangelical Church } \\
\text { Pentecostal Church }\end{array}$ & -3.01 & 0.86 & $.003^{*}$ \\
& & -4.74 & 0.81 & $.000^{* *}$ \\
Mainline Church & Evangelical Church & -2.78 & 1.88 & 0.847 \\
& Pentecostal Church & -4.50 & 1.88 & 0.101 \\
Evangelical Church & Pentecostal Church & -1.73 & 0.72 & 0.101 \\
\hline
\end{tabular}
$p=.05 . * p=.003 . * * p=.000$. 


\section{Hypothesis $2 \mathrm{a}$}

To further explore Research Question 2, the research Hypotheses 2a and 2b were formulated. Hypothesis 2a stated that there is a statistically significant relationship between Age and the level of Religious Participation among youth in Chicago Latino congregations. To investigate this Hypothesis, a simple linear regression analysis was conducted. Hypothesis 2 a was found to be statistically significant, as the analysis revealed that Age did account for a significant portion of unique variance in predicting the level of Religious Participation $[F(1,300)=5.78, p=0.017]$, with an $R^{2}=.019$. It was also found that the score for Religious Participation increased .39 with each year of age (see Table 8).

Table 8

Linear Regression Analysis Summary: Age Predicting Religious Participation

\begin{tabular}{lccccc}
\hline Variable & B & SE B & B & t & $p$ \\
\hline Age & 0.39 & 0.16 & 0.14 & 2.41 & $0.017^{*}$ \\
\hline$R^{2}=0.19 . F(1,300)=5.78 . p=0.017 . *{ }^{*} p<.05$. & &
\end{tabular}

\section{Hypothesis $2 b$}

Furthermore, Research Hypothesis $2 \mathrm{~b}$ also used a linear regression analysis to explore whether there is a statistically significant relationship between Gender and level of Religious Participation among youth in Chicago Latino congregations. As can be seen from Table 9, the relationship between Gender and the level of Religious Participation is 
not statistically significant in this sample $[F(1,277)=0.44, p=0.51]$, with an $R^{2}=.002$. Therefore, Research Hypothesis $2 b$ is rejected.

Table 9

Linear Regression Analysis Summary: Gender Predicting Religious Participation

\begin{tabular}{lccccc}
\hline Variable & $\mathrm{B}$ & $\mathrm{SE} \mathrm{B}$ & $\mathrm{B}$ & $\mathrm{t}$ & $p$ \\
\hline Gender & -0.415 & 0.629 & -0.04 & -0.66 & 0.51 \\
\hline
\end{tabular}

$\mathrm{R}^{2}=0.002 . F(1,277)=0.44 \cdot p=0.51$.

Note. $1=$ Male; $0=$ Female.

\section{Research Question 3}

Research Question 3 investigated the level of Social Service Involvement among youth in Chicago Latino congregations, as measured by the aggregate score. To explore this research question, a total Social Service Involvement score was created as an aggregate of: participation in community service/volunteer activity, frequency of volunteer work, time spent volunteering, volunteer work organized by the congregation, helping others (on your own, not through an organization), and volunteer work encouraged by someone in church (see Table 1 for Construct Variables). For the purpose of contextual score description within this study, the aggregate scores are operationally categorized under the following range: those that fall at or under the 25 percentiles are considered low scores; those that fall between the 26 to 49 percentiles are medium scores, those between the 50 to 75 percentiles are considered high, and those that fall at or above the 76 percentiles are considered extremely high scores.

Table 10 displays the means and standard deviations for the total Social Service Involvement score, as well as each of the individual items from survey questions 
Table 10

Descriptive Statistics: Social Service Involvement of Youth in Latino Congregations

\begin{tabular}{|c|c|c|c|c|c|c|}
\hline \multirow{2}{*}{ Variables } & \multirow{2}{*}{$N$} & \multirow{2}{*}{$\begin{array}{l}\text { Possible } \\
\text { Range }\end{array}$} & \multicolumn{4}{|c|}{ Obtained Scores } \\
\hline & & & Min & Max & $M$ & $S D$ \\
\hline $\begin{array}{l}\text { Social Service Involvement Total } \\
\text { Aggregate Score }\end{array}$ & 287 & 5 to 31 & 5 & 73 & 13.06 & 8.23 \\
\hline $\begin{array}{l}\text { Participation community } \\
\text { service/volunteer activity }\end{array}$ & 279 & 1 to 3 & - & - & 1.85 & 0.91 \\
\hline Frequency of volunteer work & 206 & 0 to 56 & - & - & 4.55 & 7.87 \\
\hline Time spent volunteering & 242 & 1 to 4 & - & - & 2.14 & 0.85 \\
\hline $\begin{array}{l}\text { Volunteer work organized by } \\
\text { congregation }\end{array}$ & 267 & 1 to 5 & - & - & 2.66 & 1.40 \\
\hline $\begin{array}{l}\text { Helping others (not through } \\
\text { an organization) }\end{array}$ & 274 & 1 to 8 & - & - & 2.11 & 1.48 \\
\hline $\begin{array}{l}\text { Volunteer work encouraged } \\
\text { by someone in church }\end{array}$ & 281 & 1 to 2 & - & - & 1.73 & 0.44 \\
\hline
\end{tabular}

indicating Social Service Involvement among youth in Chicago Latino congregations $(N$ =287). Social Service Involvement was assessed using Likert Scales with a continuum range, and one nominal item, where a higher score indicates higher involvement. The statistical analysis shows that youth in Chicago Latino congregations who participated in this study obtained a mean score of 13.06 for Social Service Involvement $(\bar{X}=13.06, S D$ $=8.23$ ). Based on the operational score range established for this study, the mean score of the reported participation translates to a relatively low score for Social Service Involvement, as it represents obtaining 17 percent of the possible maximum total score for this aggregate variable which ranges from a minimum of 5 to a maximum score of 78 . 
Table 11

Frequencies of Individual Survey Items in Social Service Involvement Total Score (Percentages)

\begin{tabular}{|c|c|c|c|}
\hline Survey Item & $\begin{array}{c}\text { Frequency } \\
N=302\end{array}$ & $\begin{array}{c}\text { Percent } \\
100 \%\end{array}$ & $\begin{array}{c}\text { Valid Percent } \\
100 \%\end{array}$ \\
\hline $\begin{array}{l}\text { 7.1a Have you ever spent time participating in } \\
\text { a community service or volunteer activity? By } \\
\text { volunteer activity, we mean working in some } \\
\text { way to help others for no pay. If yes, has it } \\
\text { been in the last } 12 \text { months? }\end{array}$ & & & \\
\hline Yes, have done it in the past 12 months & 139 & 46.0 & 49.8 \\
\hline $\begin{array}{l}\text { Yes, have done it but not in the past } 12 \\
\text { months }\end{array}$ & 42 & 13.9 & 15.1 \\
\hline No, have not done it & 98 & 32.5 & 35.1 \\
\hline Missing & 23 & 7.6 & \\
\hline
\end{tabular}

7.2a About how many times in an AVERAGE MONTH do you do volunteer work or community service work? [Participants were asked to write down their answer in numbers within the survey. Times categories were created for ease of reporting.]

Zero times per month 55

One to five times per month

$107 \quad 35.4$

Six to ten times per month

Eleven to fifteen times per month

Sixteen to thirty times per month

Thirty-one to fifty-six times per month

Missing

7.2b On a typical day that you do volunteer, how much time on average do you volunteer?

Less than 30 minutes

About 1 or 2 hours

About 3 or 4 hours

Over 5 hours

Missing

60

19.9 
Table 11-Continued

\begin{tabular}{|c|c|c|c|}
\hline Survey Item & $\begin{array}{c}\text { Frequency } \\
N=302\end{array}$ & $\begin{array}{l}\text { Percent } \\
100 \%\end{array}$ & $\begin{array}{l}\text { Valid Percent } \\
100 \%\end{array}$ \\
\hline \multicolumn{4}{|c|}{$\begin{array}{l}7.2 \mathrm{c} \text { How much of this volunteer work or } \\
\text { community service was organized by a } \\
\text { religious organization or } \\
\text { congregation/parish? }\end{array}$} \\
\hline None & 72 & 23.8 & 27.0 \\
\hline Some & 68 & 22.5 & 25.5 \\
\hline About half & 42 & 13.9 & 15.7 \\
\hline Most & 48 & 15.9 & 18.0 \\
\hline All & 37 & 12.3 & 13.9 \\
\hline Missing & 35 & 11.6 & \\
\hline \multicolumn{4}{|c|}{$\begin{array}{l}7.3 \text { About how often, in an average week, } \\
\text { do you help homeless people, needy } \\
\text { neighbors, family, friends, or other people } \\
\text { in need, directly not through an } \\
\text { organization? [Includes giving money] }\end{array}$} \\
\hline None & 122 & 40.4 & 44.5 \\
\hline Less than 1 hour & 84 & 27.8 & 30.7 \\
\hline 2 hours & 31 & 10.3 & 11.3 \\
\hline 3 hours & 13 & 4.3 & 4.7 \\
\hline 4 hours & 11 & 3.6 & 4.0 \\
\hline 5 hours & 8 & 2.6 & 2.9 \\
\hline 6 hours & 1 & 0.3 & 0.4 \\
\hline 7 hours or more & 4 & 1.3 & 1.5 \\
\hline Missing & 28 & 9.3 & \\
\hline \multicolumn{4}{|c|}{$\begin{array}{l}7.5 \text { Have you ever been encouraged to get } \\
\text { involved in volunteering for community } \\
\text { service by someone in your church? }\end{array}$} \\
\hline No & 75 & 24.8 & 26.7 \\
\hline Yes & 206 & 68.2 & 73.3 \\
\hline Missing & 21 & 7.0 & \\
\hline
\end{tabular}


Additionally, frequencies where calculated for each survey item comprising the Social Service Involvement construct variable. Table 11 shows the percentage distribution for raw data from each of the participant's responses. The results indicate that 46 percent of youth in Latino Chicago congregations have spent time participating in a community service or volunteer activity in the 12 months prior to answering the survey, however, 32.5 percent of youth have not participated at all. Youth also reported on the number of times they volunteer or do community service in an average month: 35.4 percent reported doing so one to five times per month, nine percent reported doing so six to 10 times per month, and yet others, reported volunteering up to 31 to 56 times per month (five percent). On a typical day of volunteering, the majority of youth reported spending about one to two hours (35.1 percent) and about three or four hours (20.9 percent) each time they volunteer. Of the volunteer work in which youth reported being involved, they reported that only 23.8 percent of that work was not organized by a religious organization or congregation/parish. Regarding being involved in helping others directly, not through work planned by an organization, the majority of youth reported spending no time (40.4 percent), or less than one hour (27.8 percent) in an average week. Furthermore, 68.2 percent of participants reported that they have been encouraged to get involved in volunteering for community service by someone in their church.

\section{Research Question 4}

Research Question 4 asks how does the level of youth's Social Service Involvement, as measured by the aggregate score, relate to: denominational affiliation, age, gender, Hispanic/Latino group identification, language usage, and participant's country of birth. To explore this research question, a GLM ANOVA was conducted and 
the overall model did account for a statistically significant proportion of unique variance $\left[F(17,255)=34.34, p<.001, \eta^{2}=.710\right]$, with an adjusted $\mathrm{R}^{2}=.690$. However, as can be seen in Table 12, none of these individual demographic variables accounted for a statistically significant proportion of unique variance in predicting Social Service Involvement.

Table 12

GLM ANOVA: Relationship Between Social Service Involvement and Demographic Variables

\begin{tabular}{lcccc}
\hline Variables & $D f$ & $F(17,255)$ & $p$ & $\eta^{2}$ \\
\hline Gender & 1 & 2.61 & 0.107 & 0.011 \\
Denominational Affiliation & 3 & 0.91 & 0.437 & 0.011 \\
Hispanic/Latino Group Identification & 8 & 0.18 & 0.993 & 0.006 \\
Language Usage & 1 & 0.34 & 0.562 & 0.001 \\
Participant's Country of Birth & 2 & 0.20 & 0.819 & 0.002 \\
Age & 1 & 0.03 & 0.854 & 0.000 \\
\hline $\mathrm{R}^{2}=.690 . F(17,255)=34.34 . p<.001 . \eta^{2}=.710$. & & &
\end{tabular}

\section{Hypothesis 4a}

Further exploring Research Question 4, Hypotheses 4a and 4b were formulated. Hypothesis 4a states that there is a significant relationship between Gender and the level of Social Service Involvement among youth in Chicago Latino congregations. A simple linear regression was conducted to predict social service involvement by Gender. Gender was found not to be a statistically significant predictor of Social Service Involvement $[F(1,263)=2.402, p=0.12]$, with an $\mathrm{R}^{2}=.009($ see Table 13$)$, therefore research Hypothesis 4a was rejected. 
Table 13

Regression Analysis Summary: Gender Predicting Social Service Involvement

\begin{tabular}{lccccc}
\hline Variable & $\mathrm{B}$ & $\mathrm{SE} \mathrm{B}$ & $\beta$ & $\mathrm{t}$ & $p$ \\
\hline Gender & 1.62 & 1.05 & 0.10 & 1.55 & 0.12
\end{tabular}

$\mathrm{R}^{2}=0.009 . \mathrm{N}=264 . p<.05$.

Note. $1=$ Male; $0=$ Female.

\section{Hypothesis $4 b$}

Hypothesis $4 \mathrm{~b}$ also utilized a GLM ANOVA to explore whether there is a statistically significant difference between denominational affiliation and level of Social Service Involvement among youth in Chicago Latino congregations. As shown in Table 14 , although there are slight variations in the average Social Service Involvement totals between those affiliated with the Mainline Church $(M=14.4)$ and the Catholic Church $(M=14.1)$, and participants affiliated with these two denominations also have higher social engagement over those affiliated with the Evangelical Church $(M=12.9)$ and the Pentecostal Church $(M=12.5)$, these differences were not found to be statistically significant $[F(3,282)=0.61, p=.609]$, therefore Hypothesis $4 \mathrm{~b}$ was also rejected.

Table 14

GLM ANOVA: Difference in Social Service Involvement by Denominational Affiliation

\begin{tabular}{lccccc}
\hline Denominational Affiliation & N & M & SD & $F(3,282)$ & $p$ \\
\hline Catholic Church & 70 & 14.1 & 7.9 & 0.61 & .609 \\
Mainline Church & 7 & 14.4 & 7.4 & & \\
Evangelical Church & 92 & 12.9 & 7.8 & & \\
Pentecostal Church & 117 & 12.5 & 8.9 & & \\
\hline
\end{tabular}




\section{Research Question 5}

Research Question 5 is concerned with the level of Engagement in Leadership Tasks among youth in Chicago Latino congregations, as measured by the aggregate score. To explore this research question, a total Engagement in Leadership Tasks score was created as an aggregate of: public speaking, influencing others (inviting friends to church), helping organize events or programs at church, being a leader in their current youth group, and being involved in planning events, leading meetings, or public speaking (see Table 1 for Construct Variables). For the purpose of contextual score description within this study, the aggregate scores are operationally categorized under the following range: those that fall at or under the 25 percentiles are considered low scores; those that fall between the 26 to 49 percentiles are medium scores, those between the 50 to 75 percentiles are considered high, and those that fall at or above the 76 percentiles are considered extremely high scores.

Table 15 displays the means and standard deviations for the total Engagement in Leadership Tasks score, as well as each of the individual items from survey questions indicating Engagement in Leadership Tasks among youth in Chicago Latino congregations $(N=302)$. Engagement in Leadership Tasks was assessed using Likert Scales with a continuum range, and one nominal item, where a higher score indicates higher involvement. Youth in Chicago Latino congregations who participated in this study obtained a mean score of 9.22 for Engagement in Leadership Tasks $(\bar{X}=9.22, S D=$ 2.28). Based on the operational score range established for this study, the mean score of the reported participation translates to a relatively high score for Engagement in Leadership Tasks, as it represents obtaining roughly 58 percent of the possible maximum 
Table 15

Descriptive Statistics: Engagement in Leadership Tasks of Youth in Latino Congregations

\begin{tabular}{|c|c|c|c|c|c|c|}
\hline \multirow{2}{*}{ Variables } & \multirow{2}{*}{$N$} & \multirow{2}{*}{$\begin{array}{l}\text { Possible } \\
\text { Range }\end{array}$} & \multicolumn{4}{|c|}{ Obtained Scores } \\
\hline & & & Min & Max & $M$ & $S D$ \\
\hline $\begin{array}{l}\text { Engagement in Leadership Tasks } \\
\text { Total Aggregate Score }\end{array}$ & 302 & 5 to 16 & 5 & 15 & 9.22 & 2.28 \\
\hline Public speaking & 298 & 1 to 4 & - & - & 1.89 & 0.84 \\
\hline $\begin{array}{l}\text { Influencing Others (Inviting } \\
\text { friends) }\end{array}$ & 299 & 1 to 4 & - & - & 2.22 & 0.87 \\
\hline Organizing Events & 297 & 1 to 4 & - & - & 2.27 & 0.94 \\
\hline Leader in Youth Group & 290 & 1 to 2 & - & - & 1.73 & 0.45 \\
\hline $\begin{array}{l}\text { Planning Events, Leading } \\
\text { Meetings, Public Speaking }\end{array}$ & 274 & 1 to 2 & - & - & 1.40 & 0.49 \\
\hline
\end{tabular}

total score for this aggregate variable which ranges from a minimum of five to a maximum score of 16 .

Furthermore, frequencies where calculated for each survey item comprising the Engagement in Leadership Tasks total score, Table 16 shows the percentage distribution for each of the participant's responses. The results indicate that only 35.4 percent of youth in Latino Chicago congregations have never spoken in front of the congregation or parish, while the rest engage in this activity sometimes (44.7 percent), fairly often (12.9 percent), or very often (5.6 percent). Regarding influencing others by inviting friends their age to church, only 18.5 percent of youth have never invited a friend to church, likewise, only 21.9 percent of youth in Latino congregations have never helped organize 
Table 16

Frequencies of Individual Survey Items in Engagement in Leadership Tasks Total Score (Percentages)

\begin{tabular}{lccc}
\hline Survey Item & Frequency & Percent & Valid \\
& $N=302$ & $100 \%$ & $\begin{array}{c}\text { Percent } \\
100 \%\end{array}$ \\
\hline
\end{tabular}

1.3 How often have you done the following activities in the church/parish that you attend? Spoken in front of the congregation/parish.

Never

Sometimes

Fairly often

Very often

Missing

1.4 How often have you done the following activities in the church/parish that you attend? Invited a youth friend to your church.

Never

Sometimes

Fairly often

Very often

Missing

1.5 How often have you done the following activities in the church/parish that you attend? Helped organize an event or program at church.

Never

Sometimes

Fairly often

Very often

Missing
107

135

39

17

4

35.4

44.7

12.9

5.6

1.3
35.9

13.1

5.7

56

18.5

18.7

151

50.0

50.5

61

20.2

20.4

31

10.3

10.4

3

1.0
66

120

76

35

5
21.9

39.7

25.2

11.6

1.7
22.2

40.4

25.6

11.8 
Table 16-Continued

\begin{tabular}{lccc}
\hline Survey Item & $\begin{array}{c}\text { Frequency } \\
N=302\end{array}$ & $\begin{array}{c}\text { Percent } \\
100 \%\end{array}$ & $\begin{array}{c}\text { Valid } \\
\text { Percent } \\
100 \%\end{array}$ \\
\hline $\begin{array}{l}\text { 1.12c Would you say that you are a leader or } \\
\text { a participant in your current youth group? }\end{array}$ & & & \\
$\quad$ Participant & 211 & 69.9 & 72.8 \\
$\quad$ Leader & 79 & 26.2 & 27.2 \\
$\quad$ Missing & 12 & 4.0 & \\
$\begin{array}{l}\text { 7.4a In the last year, have you been involved } \\
\text { in any organization in which you yourself }\end{array}$ & & & \\
have planned an event, led a meeting, or & & & \\
given presentations or speeches? & & & \\
$\quad$ No & 165 & 54.6 & 60.2 \\
$\quad$ Yes & 109 & 36.1 & 39.8 \\
$\quad$ Missing & 28 & 9.3 & \\
\hline
\end{tabular}

an event or program at church, with 36.8 percent of participants reporting helping fairly often (25.2 percent) and very often (11.6 percent). Of those who participated in the study, 26.2 percent report that they are a leader in their church's religious youth group, and 36.1 percent of participants also report being involved in an organization in which they planned an event, led a meeting, or gave presentations or speeches.

\section{Research Question 6}

Research Question 6 explored how does the level of youth's Engagement in Leadership Tasks, as measured by the aggregate score, relate to: denominational affiliation, age, gender, Hispanic/Latino group identification, language usage, and participant's country of birth? To explore this research question, a GLM ANOVA was conducted to investigate the relationship of the demographic variables to the level of Engagement in Leadership Tasks. It was found that the overall model did account for a 
statistically significant proportion of unique variance $\left[F(17,263)=292.19, p<.001, \eta^{2}=\right.$ .953], with an adjusted $\mathrm{R}^{2}=.950$.

As can be seen in Table 17, while holding all other variables constant, the Gender $\left[F(1,263)=14.70, p<.001, \eta^{2}=.056\right]$, Hispanic/ Latino Group Identification $[F(8,263)$ $\left.=2.16, p=.031, \eta^{2}=.066\right]$, and Age $\left[F(1,263)=4.182, p=.042, \eta^{2}=.017\right]$ variables all accounted for a statistically significant proportion of unique variance in predicting Engagement in Leadership Tasks.

Table 17

GML ANOVA: Relationship Between Engagement in Leadership Tasks and Demographic Variables

\begin{tabular}{lcccc}
\hline Variables & $d f$ & $F(17,263)$ & $p$ & $\Pi^{2}$ \\
\hline Gender & 1 & 14.70 & $<.001$ & .056 \\
Denominational Affiliation & 3 & 2.45 & .064 & .029 \\
Hispanic/Latino Group Identification & 8 & 2.16 & .031 & .066 \\
Language Usage & 1 & 2.60 & .108 & .010 \\
Participant's Country of Birth & 2 & 0.96 & .386 & .008 \\
Age & 1 & 4.18 & .042 & .017 \\
$\mathrm{R}^{2}=.950 . F(17,263)=292.19 . p<.001 . \eta^{2}=.953 . * p<.001 . * * p<.001$. &
\end{tabular}

To investigate further the differences between Gender and Hispanic/ Latino Group Identification with youth's average Engagement in Leadership Tasks score, a multiple comparison was conducted with a Bonferroni correction for each of the variables. As shown on Table 18 , female participants $(M=8.88, p=.000)$ had a higher score in Engagement in Leadership Tasks than males $(M=7.81, p=.000)$. Additionally, 
Table 18

Multiple Comparison With a Bonferroni Correction: Engagement in Leadership Tasks Differences Between Gender

\begin{tabular}{llccc}
\hline Gender (i) & Gender $(\mathrm{j})$ & $\mathrm{M}(\mathrm{i}-\mathrm{j})$ & $\mathrm{SE}$ & $p$ \\
\hline Female & Male & 1.069 & .279 & $.000^{*}$ \\
Male & Female & -1.069 & .279 & .000 \\
\hline
\end{tabular}

$p=.05 . * p=.000$.

Note. $1=$ Male; $0=$ Female.

Table 19 reports that on average, Puerto Ricans have a higher score by 1.35 points when compared to the various other Hispanic/Latino groups. $(p=.047)$. Lastly, the results of the linear regression analysis that was done for Age predicting participant's score for Engagement in Leadership Tasks are shown in Table 20. It was found that the score increased by .156 per each additional year of age.

\section{Hypothesis $6 \mathrm{a}$}

Further exploring Research Question 6, Hypotheses 6a and 6b were formulated. Hypothesis 6a predicts there is a significant relationship between Gender and the level of Engagement in Leadership Tasks among youth in Chicago Latino congregations. To compare the effect of Gender on Engagement in Leadership Tasks, a GLM ANOVA was conducted. The GLM showed that there was a statistically significant difference in the level of Engagement in Leadership Tasks across Gender, with females $(M=8.9)$ engaging in statistically more leadership tasks than males $(M=7.9)[F(1,277)=14.75, p$ $\left.<.001, \eta^{2}=.051\right]$ (see Table 21$)$, therefore the research hypothesis was accepted. 
Table 19

Multiple Comparison With a Bonferroni Correction: Engagement in Leadership Tasks Differences Between Hispanic/ Latino Group Identification

\begin{tabular}{|c|c|c|c|c|}
\hline Hispanic Group (i) & Hispanic Group (j) & $M(i-j)$ & SE & $p$ \\
\hline \multirow[t]{8}{*}{ Mexican American } & Mexican & -0.81 & 0.43 & 1.000 \\
\hline & Puerto Rican & -1.35 & 0.42 & $.047 *$ \\
\hline & Dominican & -0.17 & 2.21 & 1.000 \\
\hline & Colombian & -2.34 & 2.18 & 1.000 \\
\hline & Native American & -0.02 & 1.11 & 1.000 \\
\hline & Central American & -0.38 & 0.47 & 1.000 \\
\hline & South American & -0.55 & 0.90 & 1.000 \\
\hline & Other & 1.90 & 1.29 & 1.000 \\
\hline \multirow[t]{7}{*}{ Mexican } & Puerto Rican & -0.54 & 0.51 & 1.000 \\
\hline & Dominican & 0.64 & 2.19 & 1.000 \\
\hline & Colombian & -1.53 & 2.20 & 1.000 \\
\hline & Native American & 0.79 & 1.13 & 1.000 \\
\hline & Central American & 0.43 & 0.50 & 1.000 \\
\hline & South American & 0.26 & 0.87 & 1.000 \\
\hline & Other & 2.70 & 1.31 & 1.000 \\
\hline \multirow[t]{6}{*}{ Puerto Rican } & Dominican & 1.18 & 2.23 & 1.000 \\
\hline & Colombian & -0.99 & 2.18 & 1.000 \\
\hline & Native American & 1.33 & 1.13 & 1.000 \\
\hline & Central American & 0.97 & 0.51 & 1.000 \\
\hline & South American & 0.80 & 0.93 & 1.000 \\
\hline & Other & 3.24 & 1.29 & .452 \\
\hline \multirow[t]{5}{*}{ Dominican } & Colombian & -2.17 & 3.09 & 1.000 \\
\hline & Native American & 0.15 & 2.44 & 1.000 \\
\hline & Central American & -0.21 & 2.22 & 1.000 \\
\hline & South American & -0.38 & 2.32 & 1.000 \\
\hline & Other & 2.07 & 2.55 & 1.000 \\
\hline \multirow[t]{4}{*}{ Colombian } & Native American & 2.32 & 2.42 & 1.000 \\
\hline & Central American & 1.96 & 2.20 & 1.000 \\
\hline & South American & 1.79 & 2.33 & 1.000 \\
\hline & Other & 4.24 & 2.49 & 1.000 \\
\hline \multirow[t]{3}{*}{ Native American } & Central American & -0.36 & 1.14 & 1.000 \\
\hline & South American & -0.53 & 1.37 & 1.000 \\
\hline & Other & 1.92 & 1.66 & 1.000 \\
\hline \multirow[t]{2}{*}{ Central American } & South American & -0.17 & 0.92 & 1.000 \\
\hline & Other & 2.27 & 1.32 & 1.000 \\
\hline South American & Other & 2.44 & 1.54 & 1.000 \\
\hline
\end{tabular}

$p=.05 . * p=.047$. 
Table 20

Linear Regression Analysis Summary: Age Predicting Engagement in Leadership Tasks

\begin{tabular}{lccccc}
\hline Variable & B & SE B & B & t & $p$ \\
\hline Age & 0.156 & 0.08 & 0.17 & 2.05 & $0.042^{*}$ \\
\hline $\mathrm{R}^{2}=.950$. & $F(17,246)=$ & $292.19 . p$ & $<.001 . \eta^{2}=.953 . * p<.042$. &
\end{tabular}

Table 21

GLM ANOVA: Relationship of Gender and Level of Engagement in Leadership Tasks

\begin{tabular}{lcccccc}
\hline Source & $D f$ & SS & MS & $F$ & $p$ & $\prod^{2}$ \\
\hline Between Groups & 1 & 74.24 & 74.24 & 14.75 & $<.001$ & .051 \\
Within Groups & 277 & 1394.14 & 5.03 & & & \\
Total & 278 & 1468.39 & & & & \\
\hline
\end{tabular}

Hypothesis $6 b$

Research Hypothesis $6 \mathrm{~b}$ also used a GLM ANOVA to explore whether there is a statistically significant difference between Denominational Affiliation and the level of Engagement in Leadership Tasks among youth in Chicago Latino congregations. As can be seen in Table 22, there were statistically significant differences in participants' scores for Engagement in Leadership Tasks by Denominational Affiliation $[F(3,297)=4.13, p=$ $\left..007, \eta^{2}=.04\right]$. Therefore, the research hypothesis was accepted. However, the only statistically significant difference on Engagement in Leadership Tasks was between two denominations, where on average participants affiliated with the Pentecostal Church have a higher score by 1.12 points, compared to participants affiliated with the Catholic Church $(p=.005)($ see Table 23). 
Table 22

GML ANOVA: Differences in the Level of Engagement in Leadership Tasks by Denominational Affiliation

\begin{tabular}{lcccccc}
\hline Source & $d f$ & SS & MS & $F$ & $p$ & $\prod^{2}$ \\
\hline Between Groups & 3 & 62.26 & 20.75 & 4.13 & .007 & .04 \\
Within Groups & 297 & 1492.92 & 5.03 & & & \\
Total & 300 & 1555.18 & & & & \\
\hline
\end{tabular}

Table 23

Multiple Comparison With a Bonferroni Correction: Engagement in Leadership Tasks Differences Between Denominational Affiliation

\begin{tabular}{llccc}
\hline Denomination (i) & Denomination (j) & M (i-j) & SE & $p$ \\
\hline Catholic Church & Mainline Church & -0.51 & 0.89 & 1.00 \\
& Evangelical Church & -0.44 & 0.34 & 1.00 \\
& Pentecostal Church & -1.12 & 0.33 & $.005^{* *}$ \\
& & & & \\
Mainline Church & Evangelical Church & 0.07 & 0.88 & 1.00 \\
& Pentecostal Church & -0.61 & 0.87 & 1.00 \\
& & & & \\
Evangelical & & & & \\
Church & Pentecostal Church & -0.68 & 0.30 & .153 \\
\hline$p=.05 . * * p<.01$. & & & &
\end{tabular}

\section{Research Question 7 and Hypothesis 7}

Research Question 7 investigated whether there is a statistically significant relationship between the total aggregate scores of Social Service Involvement and Religious Participation among youth in Chicago Latino congregations, and it was hypothesized that there is a significant relationship (see Hypothesis 7). A simple linear regression was conducted to test this relationship. The analysis revealed that Religious Participation significantly predicted Social Service Involvement $[F(1,285)=5.336, p=$ 
$\left.0.02, R^{2}=.018\right]$ among youth in Latino congregations, thus the research hypothesis was accepted. Participant's Social Service Involvement scores increased 0.02 points for each increase in the Religious Participation score (see Table 24).

Table 24

Regression Analysis Summary: Religious Participation Predicting Social Service Involvement

\begin{tabular}{lccccc}
\hline Variable & $\mathrm{B}$ & $\mathrm{SE}$ & $\beta$ & $\mathrm{t}$ & $p$ \\
\hline Religious Participation Total & 0.22 & 0.09 & 0.14 & 2.31 & $0.02^{*}$ \\
\hline $\mathrm{R}^{2}=0.018 . F(1,285)=5.336 . p=0.02 . * p<.05$. & & &
\end{tabular}

\section{Research Question 8 and Hypothesis 8}

Finally, Research Question 8 explored the relationship between the total aggregate scores of Engagement in Leadership Tasks and Religious Participation among youth in Chicago Latino congregations, and it was hypothesized that there is a significant relationship (see Hypothesis 8). To explore the research question, a simple linear regression was conducted to predict Engagement in Leadership Tasks by Religious Participation. Religious Participation was found to be a statistically significant predictor of Engagement in Leadership Tasks $[F(1,300)=64.427, p<.001]$, with an $R^{2}=0.177$. Participants' scores in Engagement in Leadership Tasks increased .182 points for each increase in the Religious Participation score (see Table 25).

\section{Summary}

The summary of all the research questions and hypotheses can be seen in Table 26. Research Questions 1, 3 and 5 were descriptive in nature and therefore do not have 
Table 25

Regression Analysis Summary: Religious Participation Predicting Engagement in Leadership Tasks

\begin{tabular}{lccccc}
\hline Variable & B & SE B & $\beta$ & $\mathrm{t}$ & $p$ \\
\hline Religious Participation & 0.182 & 0.023 & 0.42 & 8.027 & $<0.001^{* *}$ \\
\hline $\mathrm{R}^{2}=0.177 . F(1,300)=64.427 . p<.001 .{ }^{* *} p<.01$. & &
\end{tabular}

statistical significance assigned. This was indicated by a dash on the summary table (see Table 26). Research Questions 2, 4, and 6 utilized GLM ANOVA analyses with the demographic variables (i.e., control variables) of denominational affiliation, age, gender, Hispanic/Latino group identification, language usage, and participant's country of birth to investigate differences on the outcome of Religious Participation, Social Service Involvement, and Engagement in Leadership Tasks. Research Question 2 found the demographic variables to be statistically significant $(p<.001)$ in relationship to the level of Religious Participation, with the only variable that explained a significant proportion of unique variance being the difference in denominational affiliation among participants, and the Catholic church being the only denomination that accounted for unique variance with an overall lower average participation score. Research Hypothesis 2a was found to be statistically significant, as Age did account for a significant proportion of unique variance in predicting the level of Religious Participation $(p=.019)$ among participants. However, Research Hypothesis $2 \mathrm{~b}$ was rejected as there was no statistically significant difference in the level of Religious Participation differentiated by Gender $(p=.51)$. Research Question 4 indicated that while the model with the demographic variables did account for a statistically significant proportion of unique variance in Social Service 
Table 26

Summary of Results for Research Questions and Hypotheses

\begin{tabular}{llcc}
\hline RQ\# / & Research Question or Research Hypothesis & $p$ & Significant \\
RH \# & RQ 1 & $\begin{array}{l}\text { The level of Religious Participation among youth in } \\
\text { Chicago Latino congregations. }\end{array}$ & - \\
& - & -
\end{tabular}

RQ 2 The level of youth's Religious Participation varies by: denominational affiliation; age; gender;

Hispanic/Latino group identification; language usage; $\quad<.001 \quad$ Yes and participant's country of birth.

RH 2a There is a significant relationship between age and the level of Religious Participation. $.019 \quad$ Yes

RH 2b There is a significant relationship between gender and the level of Religious Participation.

RQ 3 The level of Social Service Involvement among youth in Chicago Latino congregations.

RQ 4 The level of youth's Social Service Involvement varies by: denominational affiliation; age; gender;

Hispanic/Latino group identification; language usage; $\quad<.001 \quad$ Yes and participant's country of birth.

RH 4a There is a significant relationship between gender and the level of Social Service Involvement.

$\mathrm{RH} 4 \mathrm{~b}$ There is a significant relationship between denominational affiliation and the level of Social Service Involvement.

RQ 5 The level of Engagement in Leadership Tasks among youth in Chicago Latino congregations.

RQ 6 The level of youth's Engagement in Leadership Tasks varies by: denominational affiliation; age; gender; Hispanic/Latino group identification; language usage; $\quad<.001 \quad$ Yes and participant's country of birth

RH 6a There is a significant relationship between gender and the level of Engagement in Leadership Tasks. 


\begin{tabular}{|c|c|c|c|}
\hline $\begin{array}{l}\text { RQ\# / } \\
\text { RH \# }\end{array}$ & Research Question or Research Hypothesis & $p$ & Significant \\
\hline RH 6b & $\begin{array}{l}\text { There is a significant relationship between } \\
\text { denominational affiliation and the level of } \\
\text { Engagement in Leadership Tasks. }\end{array}$ & .007 & Yes \\
\hline $\begin{array}{l}\mathrm{RQ} / \\
\mathrm{RH} 7\end{array}$ & $\begin{array}{l}\text { There a significant relationship between Social } \\
\text { Service Involvement and Religious Participation } \\
\text { among youth in Chicago Latino congregations. }\end{array}$ & .02 & Yes \\
\hline $\begin{array}{l}\mathrm{RQ} / \\
\mathrm{RH} 8\end{array}$ & $\begin{array}{l}\text { There a significant relationship between Engagement } \\
\text { in Leadership Tasks and Religious Participation } \\
\text { among youth in Chicago Latino congregations. }\end{array}$ & $<.001$ & Yes \\
\hline
\end{tabular}

Involvement $(p<.001)$, none of the individual variables accounted for a significant proportion of unique variance. This held true for Research Hypothesis 4a which investigated gender differences on who scored higher, males or females, on Social Service Involvement $(p=.12)$ and Hypothesis $4 \mathrm{~b}$ which investigated differences by denominational affiliation on Social Service Involvement $(p=.609)$, therefore, both research hypotheses were rejected. In Research Question 6, statistical significance was found in the model with the demographic variables, as these did account for a statistically significant proportion of unique variance in Engagement in Leadership Tasks $(p<.001)$. Additionally, Research Hypotheses 6a (H6a) and 6b (H6b) were both accepted, as the analyses revealed that both Gender $(\mathrm{H} 6 \mathrm{a})(p<.001)$ and denominational affiliation $(\mathrm{H} 6 \mathrm{~b})$ $(p=.007)$ did account for statistical significance on the level of Engagement in Leadership Tasks among participants. Specifically, females $(M=8.9)$ engage statistically more in Leadership Tasks than males $(M=7.9)$, and participants who affiliate with the Pentecostal Church report a statistically higher level of Engagement in Leadership Tasks than those affiliated with the Catholic Church $(p=.005)$. The analysis for Research 
Question 7 revealed that there is a statistically significant relationship between the level of Social Service Involvement and the level of Religious Participation among participants ( $p=.02)$, thereby accepting Research Hypothesis 7. Lastly, Research Question 8 also found that there is a statistically significant relationship between the level of Engagement in Leadership Tasks and the level of Religious Participation $(p=.001)$; thus, Research Hypothesis 8 was accepted.

Through this group of analyses, the relationship between factors were studied in order to answer the general research question: What is the relationship between the level of youth's Religious Participation, and their level of engagement with two contributing ecological factors characteristic of Latino congregations: Social Service Involvement and Engagement in Leadership Tasks? The results of the analyses revealed that among youth in Chicago Latino congregations who participated in this study, based on the operational score range established for this study, there is a relatively high level (58 percent) of Engagement in Leadership Tasks $(\bar{X}=9.22, S D=2.28)$. However, the scores in their Social Service Involvement $(\bar{X}=13.06, S D=8.23)$ can be described as relatively low (17 percent). Nevertheless, both the level of their Engagement in Leadership Tasks and Social Service Involvement (i.e., criterion construct variables) have a statically significant relationship with Religious Participation; therefore, the more youth participate in religious activities, the higher their score becomes related to the two criterion construct variables. 


\section{CHAPTER 5}

\section{DISCUSSION}

\section{Introduction}

This final chapter discusses the findings of the study within its seven sections. The first section provides a brief summary of the study, the second presents the findings, the third discusses the results, and the fourth section draws conclusions based on the research questions which guided this study. The remaining three sections provide an overview of implications for practice, followed by recommendations for further study in this field of research, and closing with an epilogue.

\section{Summary}

In the ecology of church dynamics and practices, including those related to leadership development, the Latino church in the U.S. has developed dynamics and practices that set it apart from the church in the ethnocultural majority (Maldonado \& Martínez, 2008; Maldonado Pérez, 2005; Martínez, 2008; Montoya, 1987), two of which were of interest to this study.

First, in the Latino church, one often sees new leaders emerging and developing under organic dynamics (i.e., less formalized processes) that arise within local congregations. These differ from some of the traditional approaches to church leadership development which tend to require following a curriculum of study, completing a training 
program, being elected into such positions, or fulfilling a set of theological education requirements. Instead, they focus on developing one's leadership through hands-on action (Hernández et al., 2016; Maldonado Pérez, 2005; Martínez, 2008; Tamez Méndez, 2017).

Second, Latino churches find themselves with a large number of younger congregants, many of whom often acquire roles and responsibilities that are de facto leadership tasks and responsibilities, and through which they actively contribute towards local congregational and community life (Maldonado Pérez, 2005; Martínez, 2008; Tamez Méndez, 2017). These active roles constitute them as what could be seen as emerging leaders in these churches. Their leadership development thus arises from the opportunities to actively engage in activities such as public speaking, organizing events, and rendering service to the community.

Because these dynamics are so important for the development of leaders in Latino congregations, it is crucial to identify, describe, and empirically analyze some of the dynamics and factors involved, both at the individual and institutional level. Hence, the purpose of this socioreligious study is to analyze the relationship of youths' religious participation in Latino congregations to their development as leaders, by measuring the level of youth's involvement with two selected ecological contributing factors within their congregations: social service involvement and engagement in leadership tasks.

The theoretical framework of PYD provided a means by which to study some of the observed and anecdotally identified and described organic dynamics and practices present in Latino congregations that seem to be contributing towards the leadership development of their youth congregants. Researchers have already established that youth leadership development is a process that takes place over time, that early leadership 
experiences can provide an important foundation for exercising leadership later in life, and that these early experiences often come in the form of opportunities through activities that are provided to youth in ecological contributing contexts such as religious organizations (Avolio, 2005; Avolio \& Gibbons, 1988; Avolio \& Vogelgesang, 2011; Day, 2011; Day et al., 2014; Day et al., 2012; Day \& Sin, 2011; Murphy \& Reichard, 2011). Thus for this study, two such potentially contributing activities characteristic of Latino congregations were selected to guide the empirical analysis: social service involvement and engagement in leadership tasks (Crane, 2003; Martínez, 2008; Mulder et al., 2017; Stepick et al., 2009).

Social service involvement and engagement in leadership tasks are some of the many different types of activities and opportunities that literature identifies as pathways towards nurturing and strengthening youths' leadership abilities (Klau et al., 2006; Lerner, 2004c). These types of activities provide opportunities for engaging in a variety of repeated tasks that help exercise youths' skills, knowledge, and talents which contribute to leadership development (Klau et al., 2006; MacNeil, 2006; Murphy \& Reichard, 2011; van Linden \& Fertman, 1998), also known within PYD as the behavioral indicator of exercising leadership (Benson et al., 2011) or reaching the Sixth C Contribution (Schmid Callina et al., 2014). Social service involvement and engagement in leadership tasks have been independently hypothesized to have a positive relationship with children's, adolescents', and young adults' leadership development and their fulfilment of leadership roles later in life as adults (Giles \& Eyler, 1994; Lerner, 2004c; Lerner, Lerner, et al., 2005; Murphy \& Reichard, 2011; RMC Research Corporation, 2002). 
To this end, and to obtain data from a large pool of youth participants ages 13 to 19 and also have representation from a diverse range of church denominations, portions of the existing data collected through the CLCS-YS (Burwell et al., 2010) were used to study the ecologically contributing dynamics and to construct the variables for analysis. The CLCS study was originally conducted through the Center for the Study of Latino Religion at the University of Notre Dame.

The results of this study can be used to deepen understanding and strengthen the efforts congregations and denominations make towards nurturing leadership development among youth. The insights gained contribute new knowledge which can also be used towards the strategic plans of educational entities such as seminaries and universities who are interested in encouraging young people to consider ministry as a vocation. Finally, this study also adds findings towards the efforts of the CLCS, while also providing verifiable knowledge for the following fields of research: sociology of religion, leadership development, youth development, culturally diverse youth studies, theological education, and ministerial practice.

A review of literature and pertinent studies revealed scarce empirical research available related to the topics which pertain to this study. The research and academic literature in the fields of leadership development, leadership and youth, and religion and youth, are still in their emerging stages. Research on youth leadership development within the Latino community is even more sparse. Nevertheless, contemporary developmental science research and theories provided the theoretical foundation for this study, primarily through the framework of PYD Theory, which indicates that certain characteristics present in contributing social or ecological contexts (e.g., home, school, 
churches, etc.) support the healthy development and thriving of young people (Lerner et al., 2013; Lerner et al., 2009). This is especially true for those contexts which provide young people with positive and sustained adult-youth relationships, and opportunities to be actively engaged with activities that strengthen their skills and competencies, including their leadership abilities (Larson \& Hansen, 2005; Overton, 2013a).

Therefore, the first sections of the literature review focused specifically on youth leadership development rooted in PYD and other developmental theories. These theories emphasize the difference between adult and youth approaches to leadership and further highlight that leadership is a capacity that develops in an individual through a series of processes over time (Clinton, 1989, 2012; Murphy \& Johnson, 2011; Murphy \& Riggio, 2003), that it is influenced by experiences over the course of a person's lifespan (Avolio \& Gibbons, 1988; Day \& Sin, 2011), and among youth, it is developed through active practice (Murphy \& Johnson, 2011; Murphy \& Reichard, 2011). Youth who are involved and growing in their leadership skills early in life, will more likely continue to develop and act as leaders later in life (Murphy \& Johnson, 2011; Murphy \& Reichard, 2011).

Subsequently, a description of some of the characteristics and dynamics present in Latino churches which support the focus of this study, was included. The overview also had a particular emphasis on describing the practices and challenges present in these contexts as it relates to working with young congregants. This was followed by a summary of research and theories which link social service involvement and engagement in leadership tasks as two specific developmental activities which promote leadership development among youth (Cress et al., 2001; Giles \& Eyler, 1994; Lerner, 2004c; Lerner, Lerner, et al., 2005; Strobel \& Nelson, 2007; Waldstein \& Reiher, 2001; Yates \& 
Youniss, 1996). These two particular mediating factors were chosen as they reflect unique characteristics that make the local institutional dynamics in some Latino congregations different when compared to other ethno-cultural groups (Crane, 2003; Martínez, 2008; Stevens-Arroyo et al., 2003). Observation and anecdotal accounts have also pointed to these aspects being present in congregations that nurture the previously mentioned organic dynamic of leadership development among youth. These aspects, and the results of previous studies conducted in different contributing contexts (e.g., colleges, schools, and after-school programs), contributed towards the selection of the two criterion variables as well as the construction of the Social Service Involvement and Engagement in Leadership Tasks scales used in this study. The final sections of the literature review provide an overview of sociodemographic characteristics of the U.S. Latino population, followed by a brief description of the CLCS, which includes other studies drawing data from the CLCS.

To form the construct variables, all 104 items of the original CLCS-YS questionnaire were reviewed for applicability. A total of 23 items were selected which resulted in six components of the Social Service Involvement criterion construct variable, five components of the Engagement in Leadership Tasks criterion construct variable, six components of the Religious Participation predictor construct variable, and six components of the Demographic Characteristics control variables (see Table 1). The sample population in this study was 307 adolescents and young adults. All cases selected for the study were for participants between 13 and 19 years of age. The proportion of female respondents was slightly higher (50.5 percent), and the majority identify with the Pentecostal (38.4 percent) and Evangelical (32.6 percent) church denominations. 
Regarding Hispanic/Latino group identification categories, Mexican American (34.1 percent) and Mexican (26.8 percent) were the largest groups. Most respondents indicated that they read, think, write, and speak more in English than in Spanish (80.8 percent). In total 67.5 percent indicated being born in the United States, 1.3 percent in Puerto Rico, and 27.8 percent outside of the United States.

Eight research questions and eight research hypotheses were tested in this survey study. The statistical procedures used were ex post facto research design Type III (Newman et al., 2006), with $F$-test for the statistical significance of the proposed relationships in the hypotheses, and descriptive, correlational, and GLM ANOVAs for analyzing whether there were significant relationships between the predictor variables and the outcomes, while controlling for covariates thereby allowing the testing of the alternative hypotheses (Fox, 2015; Howell, 2010). Furthermore, Type I error buildup was controlled through the Bonferroni test (Newman et al., 2000).

\section{Research Findings}

Using the data collected through the CLCS-YS instrument, this dissertation sought to explore the relationship between factors that are of interest to answering the general research question: What is the relationship between the level of youth's Religious Participation, and their level of engagement with two contributing ecological factors characteristic of Latino congregations: Social Service Involvement and Engagement in Leadership Tasks? To this end, based on the general research question, the data analysis was conducted in accordance with the eight Research Questions and their corresponding Research Hypotheses. 
Research Questions 1, 3, and 5 tested the level of Religious Participation, Social Service Involvement, and Engagement in Leadership Tasks among youth in Chicago Latino congregations.

Research Questions 2, 4, and 6 tested the differences between the demographic variables of denominational affiliation, age, gender, Hispanic/Latino group identification, language usage, and the participant's country of birth, and the outcomes on the level of Religious Participation, Social Service Involvement, and Engagement in Leadership Tasks.

Research Hypotheses 2a, 2b, 4a, 4b, 6a, and $6 \mathrm{~b}$ tested differences in the level of Religious Participation, Social Service Involvement, and Engagement in Leadership Tasks differentiated by relevant demographic characteristics chosen accordingly: age, gender, and denominational affiliation.

Research Questions 7 and 8 tested the relationship between the level of Religious Participation and the level of Service Involvement and Engagement in Leadership Tasks among participants. Research Hypotheses 7 and 8 were tested under the premise that there is a statistically significant relationship among the variables.

The following sections are structured where the pertinent findings of Research Questions 1 and 2, with the corresponding Research Hypotheses 2a and 2b, will constitute one combined reporting section dealing with Religious Participation. Next, the Social Service Involvement section will report the results for Research Questions 3, 4, and 7, with their corresponding Research Hypotheses 4a, 4b, and 7. Finally, the third section reports on results regarding Engagement in Leadership Tasks which covers 
Research Questions 5, 6, and 8, along with Research Hypotheses 6a, 6b, and 8. Further details regarding the results of the data analysis can be found in Chapter 4.

\section{General Overview of Findings}

In general, the results of the frequencies on the raw data for each individual survey item used were consistent with the findings of relevant research in this field of study, mainly the results for Latino youth in the NSYR. What is unique in the present study, is the use of construct variables as a means of identifying, measuring, and describing the presence of ecological contributing factors both at individual and congregational levels within Latino congregations. Based on PYD theory, the construct variables were created by categorizing youth participants' survey-reported data regarding their experiences and involvement in Chicago Latino congregations (see Table 1).

Furthermore, both construct variables for Social Service Involvement and Engagement in Leadership Tasks, were tested for their relationship to Religious Participation. The possible implications of the frequencies and the relationships among variables towards potentially promoting and supporting leadership development among youth in Latino congregations are presented in the Discussion of the Results section of this chapter.

As a reference note, throughout the following report, for the purpose of contextual score description within this study, the aggregate scores from the three constructed criterion and predictor variables are operationally categorized and described under the following range: those that fall at or under the 25 percentiles are considered low scores; those that fall between the 26 to 49 percentiles are medium scores, those between the 50 
to 75 percentiles are considered high, and those that fall at or above the 76 percentiles are considered extremely high scores.

\section{Religious Participation Findings}

Research Question 1 asked: What is the level of Religious Participation among youth in Chicago Latino congregations, as measured by the aggregate score? Descriptive statistics were computed to determine the aggregate score, these indicated that youth in Chicago Latino congregations $(N=302)$ who participated in the study obtained a mean score of 22.9 for Religious Participation $(\bar{X}=22.9, S D=5.25)$. Based on the operational score range established for this study, the mean score of the reported participation translates to a relatively high score for Religious Participation, as it represents obtaining 74 percent of the possible maximum total score for this aggregate variable.

Subsequently, the frequencies on the raw data for each individual survey item comprising the Religious Participation total score were also calculated. First, 83.8 percent of youth in Latino Chicago congregations attend worship services or mass once or more than once a week. Likewise, 67.6 percent of respondents reported attending Sunday, Sabbath, catechesis or Bible school classes (i.e., religious education classes) once or more than once a week. Furthermore, in regards to involvement in additional religious activities, 56.2 percent of youth reported participating fairly or very often in worship team, drama group, or choir at their respective congregation. Likewise, 67.5 percent of all survey participants report spending between three and more than nine hours per week in church-related activities. All survey participants (100 percent) also reported being currently involved in a religious youth group, and 70.2 percent attend the religious youth group's meetings and events about once per week or more. 
To further investigate youth's Religious Participation, Research Question 2 asked: How does the level of youth's Religious Participation, as measured by the aggregate score, relate to denominational affiliation, age, gender, Hispanic/Latino group identification, language usage, and participant's country of birth? A GLM ANOVA was computed using each of the demographic variables to investigate the variance on the level of Religious Participation. The demographic variables were found to be statistically significant in relationship to the level of Religious Participation, yet only the difference in denominational affiliation among participants accounts for a significant proportion of unique variance. Among the four denominational categories, participants affiliated with the Catholic Church had a statistically lower average Religious Participation score when compared only to those affiliated with the Evangelical and Pentecostal church, there was no statistical difference when compared to the Mainline Church.

Further testing of Research Hypotheses 2a and 2b through linear regression analyses showed that in this sample age did account for a significant proportion of unique variance in predicting the level of Religious Participation among youth, with the score increasing as the age of participants increased. However, gender does not represent a statistically significant difference in the scores.

\section{Social Service Involvement Findings}

Research Question 3 investigated the level of Social Service Involvement among youth in Chicago Latino congregations, as measured by the aggregate score. Descriptive statistics were computed to determine the aggregate score, these indicated that youth in Chicago Latino congregations $(N=287)$ who participated in the study obtained a mean score of 13.06 for Social Service Involvement $(\bar{X}=13.06, S D=8.23)$. Based on the 
operational score range established for this study, the mean score of the reported involvement translates to a relatively low score for Social Service Involvement, as it represents obtaining 17 percent of the possible maximum total score for this aggregate variable.

Subsequently, the frequencies on the raw data for each individual survey item comprising the Social Service Involvement total score were also computed. In total, 46 percent of youth in Latino Chicago congregations reported having spent time participating in a community service or volunteer activity in the 12 months prior to participating in the study, however, 32.5 percent of youth have not participated at all. Youth also reported on the number of times they volunteer or do community service in an average month. In total, 35.4 percent reported doing so one to five times per month, nine percent reported doing so six to 10 times per month, and only 18.2 percent reported not spending time volunteering on a regular basis in an average month. On a typical day of volunteering, 56 percent of youth reported spending between one to four hours each time they volunteer. Of the volunteer work youth reported being involved in, they reported that a total of 64.6 percent of the work was organized by a religious organization or congregation/parish at least some of the time (22.5 percent), if not all of the time (12.3 percent). Regarding being involved in helping others directly, not through work planned by an organization, youth reported spending no time (40.4 percent), or less than one hour (27.8 percent) in an average week. Furthermore, 68.2 percent of participants reported that they have been encouraged to get involved in volunteering for community service by someone in their church. 
Further investigating Social Service Involvement, Research Question 4 asked: How does the level of youth's Social Service Involvement, as measured by the aggregate score, relate to denominational affiliation, age, gender, Hispanic/Latino group identification, language usage, and participant's country of birth? A GLM ANOVA was computed using each of the demographic variables to investigate differences in the outcome of Social Service Involvement. The demographic variables were found to be statistically significant in relationship to the level of Social Service Involvement, yet none of these individual demographic variables accounted for a statistically significant proportion of unique variance in predicting Social Service Involvement. In further investigating Research Hypotheses $4 \mathrm{a}$ and $4 \mathrm{~b}$ through linear regression analysis and GLM ANOVA, the testing revealed that neither gender or denominational affiliation are a statistically significant predictor of Social Service Involvement.

Finally, Research Question 7 explored whether there is a statistically significant relationship between the total aggregate scores of Social Service Involvement and Religious Participation among youth in Chicago Latino congregations. It was hypothesized that there is a significant relationship (Hypothesis 7). A simple linear regression was conducted to test this relationship. The analysis revealed that Religious Participation significantly predicted Social Service Involvement among youth in Latino congregations. Thus, participants' Social Service Involvement scores increased as a result of their Religious Participation scores increasing.

\section{Engagement in Leadership Tasks Findings}

Research Question 5 examined the level of Engagement in Leadership Tasks among youth in Chicago Latino congregations, as measured by the aggregate score. 
Descriptive statistics were computed to determine the aggregate score, these indicated that youth in Chicago Latino congregations $(N=302)$ who participated in the study obtained a mean score of 9.22 for Engagement in Leadership Tasks $(\bar{X}=9.22, S D=$ 2.28). Based on the operational score range established for this study, the mean score of the reported participation translates to a relatively high score for Engagement in Leadership Tasks, as it represents obtaining roughly 58 percent of the possible maximum total score for this aggregate variable.

Subsequently, the frequencies on the raw data for each individual survey item comprising the Engagement in Leadership Tasks total score were also computed. The results indicate that 63.2 percent of youth in Latino Chicago congregations have spoken in front of the congregation or parish, ranging from sometimes (44.7 percent), to fairly often (12.9 percent), and very often (5.6 percent). Regarding influencing others by inviting friends their age to church, 80.5 percent report having invited a friend to church at least sometimes (50 percent). Furthermore, 76.5 percent of youth in Latino congregations have helped to organize an event or program at church at least sometimes, with 25.2 percent of participants reporting helping fairly often, and 11.6 percent reporting helping very often. Of those who participated in the study, 26.2 percent report that they are a leader in their church's religious youth group, and 36.1 percent of participants also report being involved in an organization in which they themselves had planned an event, led a meeting, or given presentations or speeches.

Further investigating youth's Engagement in Leadership Tasks, Research Question 6 asked: How does the level of youth's Engagement in Leadership Tasks, as measured by the aggregate score, relate to denominational affiliation, age, gender, 
Hispanic/Latino group identification, language usage, and participant's country of birth? A GLM ANOVA was conducted using each of the demographic variables to investigate differences in the outcome of Engagement in Leadership Tasks. The variables for gender, Hispanic/Latino group identification, and age were found to be statistically significant in relationship to the level of Engagement in Leadership Tasks. Female participants have a higher score in Engagement in Leadership Tasks than males, and participants' score also increased by .156 with each additional year of age. Moreover, Research Hypotheses $6 \mathrm{a}$ and $6 \mathrm{~b}$ were also tested through GLM ANOVAs. Hypothesis 6a confirmed that gender is a statistically significant predictor of Engagement in Leadership Tasks, with females engaging in statistically more leadership tasks than males. Research Hypothesis $6 \mathrm{~b}$ found denominational affiliation also to be statistically significant. However, the only statistically significant differences on Engagement in Leadership Tasks were between two denominations, where on average, participants affiliated with the Pentecostal Church have higher scores compared to participants affiliated with the Catholic Church.

Finally, Research Question 8 explored whether there is a statistically significant relationship between the total aggregate scores of Engagement in Leadership Tasks and Religious Participation among youth in Chicago Latino congregations, and it was hypothesized that there is a statistically significant relationship (Hypothesis 8). A linear regression was conducted to test this relationship. The analysis revealed that Religious Participation significantly predicted Engagement in Leadership Tasks among youth in Latino congregations, thus, participants' Engagement in Leadership Tasks scores increased in function of the increase in their Religious Participation scores. 


\section{General Research Question Findings}

Through this group of analyses, the relationship between factors was studied in order to answer the general research question: What is the relationship between the level of youth's Religious Participation, and their level of engagement with two contributing ecological factors characteristic of Latino congregations: social service involvement and engagement in leadership tasks?

The results of the analyses revealed that among youth in Chicago Latino congregations, there is a level of Engagement in Leadership Tasks that can be described as falling in the higher range $(\bar{X}=9.22, S D=2.28)$. The scores in their Social Service

Involvement indicated that their level as low $(\bar{X}=13.06, S D=8.23)$. Nevertheless, both the level of their Engagement in Leadership Tasks and Social Service Involvement (i.e., criterion construct variables) have a statically significant relationship with Religious Participation; therefore, the more youth participate in religious activities, the higher their score becomes related to the two criterion construct variables.

\section{Discussion of the Results}

Grounded on the research questions addressed in this study, the hypotheses tested, and findings from previous research, the following three sections present the discussion of the results. Each subsection covers accordingly both individual congregant-level and institutional-level aspects of youths' religious participation, involvement in social service, and engagement in leadership tasks within Chicago Latino congregations, and the implications for leadership development.

The discussion has an emphasis on three areas of interest: first, comparing the results of the frequencies for the survey items used in this study to those of the NSYR; 
second, also based on the frequencies for each individual survey item, providing a contextual description of social phenomena and indicators present in the setting where the survey research was conducted; third, based on PYD theory, discussing the attributes present in Chicago Latino congregations which seem to be reflecting characteristics found within ecological contributing contexts that support healthy development and thriving among youth (Eccles \& Gootman, 2002), particularly the behavioral indicator of exercising leadership (Benson et al., 2011) or reaching the Sixth C - Contribution (Schmid Callina et al., 2014). For details on the results from the statistical analysis, see Chapter 4 and the Research Findings section within this chapter.

\section{Limitations and Explanatory Notes}

As a general note regarding the concepts and information presented in both the Discussion of the Results and Implications for Practice sections of this chapter, there are a few issues and limitations of the study (by virtue of its design) that I want to address beforehand to help frame the dialogue.

First, it is important to highlight that contextual aspects such as personal identity, country of origin, denominational affiliation, community life, spaces, location, context, and degree of assimilation to the mainstream, among many other factors, all influence and create distinct cultural variations in the characteristics among Latino congregations, congregants, and the youth in their communities. Furthermore, structural differences and congregational systems among Catholic, Evangelical, Mainline, and Pentecostal denominations also have varying norms, regulations, polity, rituals, narratives, hierarchies, and traditions. Therefore, the assessments and recommendations offered herein are not intended to represent Latino congregations or youth as homogeneous 
groups, or to lean on stereotypical statements or ethnoracial essentialization. Rather, they simply offer general concepts, which need to be transliterated to each context and situation, so that these can be useful to those reading this study. Furthermore, being that this study is grounded on survey research methodology, the research design limits the findings and conclusions in that these are not representative of, and cannot be applied to the population at large, the findings only provide a contextual description of social indicators present in the setting where the survey research was conducted (Glewwe \& Levin, 2005).

Second, it is also imperative to note that due to the data collection procedures used in the CLCS (see Chapter 3), it is highly probable that the methodology skewed the results towards young congregants that participate in smaller congregations and that are also more active in their congregation, especially when compared to respondents in many large, especially Catholic congregations (Burwell et al., 2010). Furthermore, the data analysis indicates that overall there was a higher percentage of participants in the CLCSYS from Pentecostal (38.4 percent) and Evangelical (32.6 percent) denominations, consequently, the data and contextual descriptions might be more representative of the particular institutional and congregational dynamics among these two denominations.

Third, socioreligious researchers have also reported that there is a tendency among survey and poll participants to over-report their attendance to religious services and therefore somewhat inflate the survey data relative to what might actually be taking place in a congregation (Hadaway \& Marler, 2005; Voas, 2007). Moreover, quantifying religious participation and practices has its challenges. Even with all the measures of religion and religiosity available, test-retest reliability can be low. There are also aspects 
of privacy, personal identity, and subjective feelings which can interfere with the manner in which participants report their habits and beliefs (Voas, 2007). These dynamics need to be taken into consideration when interpreting the results.

Fourth, survey items with aggregate scores were used to construct the three variables for analysis (Religious Participation, Social Service Involvement, and Engagement in Leadership Tasks), and this process may contribute to some limitations in the study. On the one hand, an aggregate score may not be the best way to measure the variables. The classical testing method with the principle that there is an underlying construct that is manifested in multiple ways but cannot be fully captured in a single observation was followed, consequently using the theoretical framework to select the survey items that compose the construct variable (Lord, 2012; Voas, 2007). Thus, the assumption that an aggregate score was representative of the concept and construct was followed. In future studies, perhaps following a method such as item response theory (Lord, 2012; van der Linden \& Hambleton, 2013) might prove to be more adequate for constructing and analyzing the scales in the construct variables of this study. Item response theory recognizes that each individual question in a survey has a different degree of difficulty, and therefore there needs to be a comparison not only of one individual to another, but also the difference in one score with another (Voas, 2007).

Likewise, there are limitations to using a previously designed survey tool. This dissertation was restricted by the predetermined content of each of the selected survey questions of the CLCS-YS. The manner in which the questions were asked regarding the topic of interest was another limitation. My observation and opinion based on decades of working with youth are that some of the questions in the survey may have been hard for 
youth to understand, therefore rendering responses that might not be accurate. For example, some of the questions are very long and include elaborate explanations which tend to make it hard to remember what the question was initially asking. I believe the survey questions needed to be more specific about actions, habits, and opinions, and done so through brief and direct expressions that are easier for youth understand.

Nonetheless, in spite of possible complications, the data collected and analyzed through this study provide a path for creating a contextual description of socioreligious phenomena present in Chicago Latino congregations, as well as a wider reference into the religious lives and practices of Latino youth.

Finally, throughout the presentation of the material and recommendations in this chapter, the terms "youth minister" or "youth ministry" have been intentionally omitted. It is my ministerial philosophy and outlook that, in general, the cultural, organizational, and community dynamics in our Latino congregations call for a different approach and model to serving youth than what is traditionally known under the previously referred to terms. Especially when operating from a base that conceives a person's development as lifelong, multidimensional, multidisciplinary, and multidirectional (Avolio \& Gibbons, 1988; Day, 2011; Lamb \& Freund, 2010; Lerner, 2004a). Within our Latino congregations, which tend to be communal, family-oriented, intergenerational, smallersized, and closely-knit, an outlook and ministerial approach which promotes the entire congregation as "youth ministers," and all congregational outreach and service efforts as "youth ministry," tends to be better fitting of the assets and particular needs of our community (Tamez Méndez, 2017). It is from this ministerial perspective and philosophy that I want to invite readers to view the material presented herein. 
Youth, Religious Participation, and

Leadership Development

Religious Participation served as the predictor variable in this study and it provides us with data that aids in describing the phenomena unfolding in Chicago Latino congregations which seem to be reflecting developmental attributes found within ecological contributing contexts that support PYD and thriving among youth (Eccles \& Gootman, 2002).

\section{Religious Participation Frequencies Comparison}

To further support the survey items results and how these hold-up to the findings in other pertinent studies of youth and religion, in the following section the reported frequencies of the CLCS-YS are compared with the frequencies of Wave 1 of the NSYR among Latino youth (Johnson-Mondragón, 2007; Smith \& Denton, 2009).

Within the reported frequencies, it was found in this study that 58.6 percent of youth in Chicago Latino congregations (all denominational affiliations combined) reported attending worship service or mass more than once a week, and 25.2 percent reported attending once a week. In comparison, in the NSYR, six percent of Catholic and 33 percent of Protestant Latino youth reported attending worship service or mass more than once a week, and 31 percent of Catholic and 24 percent of Protestant youth reported attending once a week.

Concerning attendance to religious education classes (e.g., Sunday, Sabbath, catechesis or Bible school), 21 percent of Catholic and 40 percent of Protestant youth who participated in the NSYR reported attending at least once a week or more. In comparison, in the CLCS-YS, 35.2 percent of youth in Latino congregations (all 
denominational affiliations combined) reported attending religious education classes more than once a week, and 35.1 percent reported attending once a week.

One area where the results were significantly dissimilar between those in the NSYR and those in this study was regarding participant's reported involvement in a religious youth group. Only 20 percent of Catholics and 44 percent of Protestants in the NSYR study reported currently being involved in a religious youth group. In contrast, 100 percent of participants who responded to the CLCS-YS reported being involved in a religious youth group, with 42.4 percent attending once a week, and 27.8 percent attending more than once a week.

\section{Contextual Descriptions and Implications for PYD}

In general, as presented in the Research Findings section and in the frequency comparisons above, both the results from the frequencies and the relationships among the construct variables indicate that the level of religious participation and engagement of youth in Chicago Latino congregations can be operationally described as high. These results obtained are congruent with past studies throughout the decades which have consistently noted the tendency among Latino youth towards high levels of religious participation and engagement when compared to their White peers (e.g., Benson et al., 1986; Johnson-Mondragón, 2007).

Furthermore, being that the healthy development of an individual occurs in a bidirectional relationship between the individual and the multiple levels of their environments, Latino congregations are affording youth congregants an ecological context where they are part of community life, are receiving support, and are having the 
opportunity to regularly engage in positive interactions with others (Eccles \& Gootman, 2002; Lerner et al., 2009; Lerner \& Overton, 2008). Therefore, in agreement with PYD theory, the reported tendency among youth in Chicago Latino congregations towards high levels of participation in their religious community, and the fact that Chicago Latino congregations are providing multiple programs and activities by which youth can connect with their religious communities, these dynamics and practices have the potential for being a strong influence towards the emergence and development of their leadership capacities.

Chicago Latino congregations show indications of serving as ecological contributing contexts which support PYD because in this study the majority of youth reported spending three or more hours per week in church-related activities. This regularity of attendance is a potential contributing characteristic being that previous studies, such as that of Scales et al. (2000), have pointed out that spending three or more hours a week participating in clubs or organizations in the community is one of the developmental assets which is highly linked to youth's thriving outcomes.

Likewise, Damon and others (Damon et al., 2003; Mariano \& Damon, 2008) found that the relationship between spirituality, religion, purpose, and different aspects of PYD, provide a pathway of support for youth to reach the Sixth C of Contribution (see Chapter 2, Lerner's PYD model). In this current study, the majority of youth not only reported attending at least once per week to religious services and spending more than three hours per week in church related activities, they also indicated that these activities include options such as religious education classes, worship teams, drama groups, choir, and youth group meetings. Thereby giving youth an ample variety of options through 
which they might have the opportunity to connect with other peers and caring adults, put their skills to use, and be rooted in the community life of their congregations. Youth's high participation results are also supported by the high mean score obtained for Religious Participation.

Moreover, among youth who partook in this study their Religious Participation aggregate score increased as their age increased. This is a very important research result which further emphasizes that, among Chicago Latino congregations, youth seem to be finding a socioreligious context with which to connect even as they age. Researchers have found that when youth develop in environments that respond to their changing needs and that provide them with positive and sustained adult-youth relationships for at least a year, they are more likely to experience healthy outcomes (Blum, 2003; Eccles, 2004; Eccles \& Gootman, 2002; Eccles et al., 1993; Eccles \& Wigfield, 2002; Lerner, 2004a, 2004c; Rhodes, 2002; Roth \& Brooks-Gunn, 2003a, 2003b).

Additionally, this finding also seems to indicate a contrast in the level of religious participation among youth in Latino congregations when compared to youth in the cultural majority, because studies report that youth in the cultural majority are less likely to attend services or identify with a religious group than any other group in recent history (e.g., Kinnaman \& Hawkins, 2011; Pew Research Center, 2015).

However, it is important to point out the results of this study indicate that among the four denominational categories, participants affiliated with the Catholic Church had a statistically lower average Religious Participation score when compared to those affiliated with the Evangelical and Pentecostal church. Therefore, the points included in this discussion might reflect differently among Catholic congregations. These findings 
warrant further study in order to identify to what extent young people are engaged in Latino congregations, and what are the similarities and differences among denominations. Still, this reported level of participation can potentially contribute towards the opportunities youth have to practice and develop their leadership abilities.

Taking into account this collection of results which indicate a high level of religious participation and involvement among youth in Chicago Latino congregations, it is likely that these dynamics and the opportunities provided to youth are contributing towards their thriving, and more specifically, the behavioral indicator of exercising leadership (Benson's PYD model) or reaching the Sixth C of Contribution (Lerner's PYD model). However, definitive conclusions and correlations will have to be drawn in subsequent studies, as the current study did not investigate the specific factors, circumstances, dynamics, and direct contextual characteristics under which an involvement in Chicago Latino congregations, and the religious activities provided therein, lead to leadership development among youth.

\section{Youth, Church, Social Service Involvement,} and Leadership Development

The first potentially mediating variable between religious participation and leadership development that was analyzed in this study was Social Service Involvement. The analysis provides us with data that aids in describing the phenomena unfolding in Chicago Latino congregations which seem to be reflecting developmental attributes found within ecological contributing contexts that support PYD and thriving among youth (Eccles \& Gootman, 2002). 
As presented in the Research Findings section, based on the mean score for Social Service Involvement, the level of involvement of youth in Chicago Latino congregations can be operationally described as low. However, when the frequencies for each individual survey item were calculated, these indicated that participants have a level of involvement in community service and volunteer work which ranged in the mid percentages.

The low total aggregate score for Social Service Involvement among youth who participated could be attributed to a couple of limitations in the study. On the one hand, an aggregate score may not be the best way to measure the variable. Likewise, there are limitations to using a previously designed survey tool, as the answers reported may not be accurate. For example, survey item 7.2a which asked: “About how many times in an AVERAGE MONTH do you do volunteer work or community service work?" This survey item allowed participants to write in their answer, rather than choose from multiple choice answers with a range of possible times in a month. As a result, some participants wrote numbers that seem excessively high, such as volunteering 20, 33, 45, and 56 times per month (3.5 percent). Such answers to this survey item contributed to what I suspect is an elevated maximum possible total aggregate score by which to measure Social Service Involvement.

\section{Social Service Involvement Frequencies Comparison}

To further support the survey items results and how these hold-up to the findings in other pertinent studies of youth and religion, in the following section the reported frequencies of the CLCS-YS are compared with the frequencies of Wave 1 of the National Study of Youth and Religion among Latino youth (Johnson-Mondragón, 2007; Smith \& Denton, 2009). 
Within the reported frequencies, it was found in this study that 46 percent of youth in Latino Chicago congregations reported having spent time participating in a community service or volunteer activity in the 12 months prior to participating in the study. In comparison, in the NSYR, 57 percent of Catholic and 67 percent of Protestant Latino youth reported having been involved in volunteer work or community service at least a few times.

Moreover, in the NSYR, 38 percent of Catholic and 32 percent of Protestant Latino youth reported that the volunteer work they were involved in was not organized by a religious group. In this dissertation based on the responses to the CLCS-YS, youth in Latino congregations (all denominational affiliations combined) reported that 23.8 percent of the volunteer work they were involved in was not organized by a religious organization, congregation, or parish.

\section{Contextual Descriptions and Implications for PYD}

In general, as presented in the Research Findings section and in the frequency comparisons above, the results in this study for youth's involvement in social service or volunteering are mixed. The mean aggregate score for Social Service Involvement obtained is low, however the frequencies for each individual survey item show that 46.0 percent of the youth reported being involved in social service in the past 12 months.

In this case, the frequencies of the reported habits, actions, and behaviors regarding Social Service Involvement provide us with what appears to be a clearer path by which to describe the phenomena in the context of the Chicago Latino Congregations. Overall, almost half of the youth in Chicago Latino congregations were involved in social 
service or volunteering in the past year prior to answering the questionnaire, although it is also important to note that almost one-third of the youth also reported never participating in social service or volunteer work before. Being that none of the demographic variables tested were statistically significant in predicting a significant proportion of unique variance for the aggregate score of Social Service Involvement, future studies will need to focus on exploring the reasons why some of the youth in Latino congregations are not participating in social service or volunteer work, especially those related to the ecological contributing context.

About half the youth in Chicago Latino congregations report being involved in volunteer work or social service at least once per month, and that on a typical day of volunteering, they are spending one or two hours, if not more, working. They also reported that the volunteer work or social service they are involved in, is organized by a religious organization, congregation or parish some to all of the time. However, half the participants also indicated that in an average week, they also help people in need without going through an organization at least an hour per week or more. Thus, about half of the youth who participated in the survey are involved in volunteering or social service in and out of their local congregation.

Therefore, these results seem to indicate that young congregants in Chicago Latino churches are having opportunities to be actively involved in doing social service or volunteer work, and that they are partaking in them. Based on the survey reports, there seems to be an indication that their congregations are organizing efforts that give them the opportunity to do so. Furthermore, the majority of youth also report being encouraged by others in their church to be involved in social service, indicating that they are in a 
supportive context. The analysis of variance on Social Service Involvement indicated that demographic variables, do not account for a statistically significant proportion of variance, thus this report and descriptions are likely reflective of the different congregations and their respective denominations represented in the study. Additionally, the testing of the hypothesis confirmed that Religious Participation does significantly predict Social Service Involvement among youth in Chicago Latino congregations. Hence, participants' Social Service Involvement scores increased as their Religious Participation scores increased.

The contextual description above provides us with insight on phenomena taking place within Chicago Latino congregations that is of interest to the purpose of this study, particularly regarding the dynamics related to youths' social service involvement and congregations as ecological contributing contexts. Being involved in a Latino congregation seems to be an important factor that contributes to exposing and involving young people to social service opportunities, while also receiving encouragement to be actively involved from people in the congregation. As previous studies have indicated, when an organization provides social service opportunities for young people, their involvement in these types of activities promotes development of PYD characteristics (Lerner, 2004c; Mitra \& Serriere, 2012; Mohamed \& Wheeler, 2001). Due to the focus that most religious organizations have of tending to the needs of the community, past studies have also found churches to be key social settings for exposing and involving young people in social service from a young age (Hodgkinson \& Weitzman, 1990).

The congregations represented in this study seem to be fostering opportunities for youth to get involved in social service work, in and out of their congregations. These are 
institutional dynamics which theory points to as being essential towards supporting youth's development of social skills, growing awareness of, and empathy towards the needs of others, and strengthening their ability to work in teams (Andolina et al., 2003; McNutt, 2013; Mitra \& Serriere, 2012). This gives youth opportunities by which to engage in repeated actions and practices that nurture their leadership emergence and development, and it also increases the likelihood that they will fulfill leadership roles in adulthood (Murphy \& Reichard, 2011; Wilson \& Simson, 2006). Chicago Latino congregations thus seem to be ecological contexts with PYD characteristics regarding social service involvement opportunities for youth. These are characteristics that can in turn support youths' healthy development, including contributing towards their leadership development.

\section{Youth, Church, Engagement in Leadership Tasks, and Leadership Development}

The second potentially mediating variable between religious participation and leadership development that was analyzed in this study was engagement in leadership tasks. The analysis provides us with data that aids in describing the phenomena unfolding in Chicago Latino congregations which seem to be reflecting developmental attributes found within ecological contributing contexts that support PYD and thriving among youth (Eccles \& Gootman, 2002).

As presented in the Research Findings section, both the results from the frequencies and the relationships among the construct variables, indicate that the level of engagement in leadership tasks of youth in Chicago Latino congregations can be described as high. 


\section{Engagement in Leadership Tasks \\ Frequencies Comparison}

To further support the survey items results and how these hold-up to the findings in other pertinent studies of youth and religion, in the following section the reported frequencies of the CLCS-YS are compared with the frequencies of Wave 1 of the National Study of Youth and Religion among Latino youth (Johnson-Mondragón, 2007; Smith \& Denton, 2009).

The results on frequencies for the raw data for each individual survey item in this study indicated that 36.1 percent of youth in Latino congregations (all denominational affiliations combined) reported having planned an event, led a meeting, or given a presentation or speech in the last year. In the NSYR study, among Catholic Latino youth, 26 percent reported having planned an event, led a meeting, or given a presentation or speech in the last year, and 31 percent of Protestants reported doing so.

Furthermore, in the NSYR, three percent of Catholics and 15 percent of Protestant youth reported being a leader in their youth group. In the CLCS-YS, 26.2 percent of youth reported being a leader in their youth group.

\section{Contextual Descriptions and Implications for PYD}

In general, as presented in the Research Findings section and in the frequency comparisons above, both the results from the frequencies and the relationships among the construct variables, indicate that youths' level of engagement in leadership tasks within Chicago Latino congregations can be operationally described as high. The mean score obtained for Engagement in Leadership Tasks is high and the frequencies for each individual survey item indicated that a relatively mid to high percentage of youth 
reported frequent engagement within their congregation. They reported speaking in front of the congregation, inviting their friends to church, helping organize an event or program, and being a leader in their youth group, with some youth engaging in leadership tasks even outside their congregation.

The results of the study seem to indicate that young congregants in Chicago Latino churches are having opportunities within their congregations to be actively engaged in activities that are de facto leadership tasks and responsibilities. The survey items do not report if the congregations are intentionally creating opportunities for them to do so, nevertheless, there seems to be an indication that the congregations are affording them the space to have these types of experiences. In subsequent studies, specific questions about the ways in which congregations are affording youth these types of opportunities need to be included in the survey. Furthermore, it is also useful to gather data to learn if the opportunities to be engaged in leadership tasks at church are encouraging youth to be engaged with these types of opportunities outside of the congregation, or vice versa.

Regarding the analysis of variance on Engagement in Leadership Tasks, it indicated that demographic variables do account for a statistically significant proportion of variance, thus this report and descriptions are likely to vary among other sample population groups that differ from this study in percentage distribution on aspects of age, gender, denominational affiliation, and Hispanic/Latino group identification. This being especially the case since females and Puerto Ricans had statistically significant higher scores, and the scores also increased with each additional year of age.

Additionally, it is important to point out the results of this study indicate that 
among the four denominational categories, participants affiliated with the Pentecostal Church had statistically higher scores when compared to those affiliated with the Catholic Church. Therefore, the points included in this discussion might reflect differently among Catholic and Pentecostal congregations. Furthermore, the testing of the hypothesis confirmed that Religious Participation does significantly predict Engagement in Leadership Tasks among youth in Chicago Latino congregations. Hence, participants' Engagement in Leadership Tasks scores increased as their Religious Participation scores increased.

These findings create a "snap-shot" of some potentially ecological contributing factors present in Latino congregations which can potentially support leadership emergence and development in youth. This is especially true as youth seem to be having opportunities of learning by doing, as well as strengthening their leadership abilities through a variety of repeated tasks. The majority of youth reported that they are engaging, at least sometimes, in tasks such as public speaking, influencing others, and helping organize events or programs. Positive Youth Development theory indicates that it is key for youth to actively partake in these types of opportunities in order to nurture their leadership development (Lerner, Lerner, et al., 2005; Lerner \& Overton, 2008). Particularly as these dynamics provide youth with a way to affect both themselves and their social context positively (Benson et al., 2006), build upon their strengths and constructive interests (Lerner, Lerner, et al., 2005), and engage in opportunities to gain practice and experience (Klau, 2006).

Furthermore, as there is a statistically significant relationship between the Engagement in Leadership Tasks scores and age, with scores increasing with age, and 
there is also a statistically significant relationship between the Engagement in Leadership Tasks and Religious Participation, these results provide us with another contextual description. It appears to be that as youth age, they are more involved in exercising leadership in their congregations, and their religious participation is supporting this increment. This is another important dynamic being that PYD postulates youth leadership development as a process that takes place over time, that early leadership experiences can provide an important foundation for exercising leadership later in life, and that these early experiences come in the form of opportunities through activities that are provided to youth in ecological contributing contexts (Avolio, 2005; Avolio \& Gibbons, 1988; Avolio \& Vogelgesang, 2011; Day, 2011; Day et al., 2014; Day et al., 2012; Day \& Sin, 2011; Murphy \& Reichard, 2011).

Yet, there seems to be a difference among some church denominations as to the dynamics present which provide youth with opportunities, where possibilities to be engaged in leadership tasks are higher than in others, as evidenced by the demographic variable analysis results in this study. This is likely in part because of the differences in church structures. The hierarchical nature of some churches can make it less likely for young people to find ways in which to exercise their leadership skills within the congregation (Johnson-Mondragón, 2005). However, a comparative study among denominations needs to be conducted in the future to provide insight as to the specific reasons for the differences found in this study.

The analysis in this study also revealed a difference in scores between genders, as young women have a higher score in Engagement in Leadership Tasks compared to their male counterparts in Chicago Latino congregations. The reasons behind this finding will 
need to be the focus of a future study. However, other church leaders and authors have also pointed out in their observations this tendency towards women being more involved in leadership tasks within their congregations when compared to men (Maldonado Pérez, 2005; Martell-Otero et al., 2013; Martínez, 2008). Additionally, national studies continue to report that the religious composition of Christian Latinos is comprised of a higher percentage of women (Pew Research Center, 2014a).

Chicago Latino congregations thus seem to be ecological contexts with PYD characteristics regarding offering opportunities for youth to engage in leadership tasks. These congregations are providing them with pathways towards acquiring, practicing, strengthening, and using their leadership skills. These are characteristics that can in turn support youths' healthy development, including contributing towards their leadership development.

\section{Latino Congregations and Organic Dynamics for Leadership Development}

As a way of empirically studying the organic dynamics (i.e., less formalized processes) of leadership development that are present in Latino congregations, particularly as it pertains to youth congregants, this dissertation sought to explore the relationship between factors that are of interest to answering the general research question: What is the relationship between the level of youth's Religious Participation, and their level of engagement with two contributing ecological factors characteristic of Latino congregations: Social Service Involvement and Engagement in Leadership Tasks? The relationship was confirmed, and it was also found that participants' scores in both Social Service Involvement and Engagement in Leadership Tasks increased as a result of 
their Religious Participation scores increasing.

By applying concepts of PYD theory, the analysis also provided insight into the relationship of youths' religious participation in Latino congregations to their development as leaders, by way of identifying, describing, and analyzing ecological contributing factors characteristic of the congregational dynamics that contribute to the relationship and influence the lives and positive development of their younger congregants.

An addition, this study also provided a socioreligious description of Latino youth, which is an important contribution, since this is a demographic group that generally continues to be under-represented in studies related to youth and religion, among other fields. In fact, even the NSYR study had a very low sample size of Latino youth with only 451 participants, and only 94 of those participants being non-Catholic Christians.

Based on the combined results, Chicago Latino congregations can be described as socioreligious contributing ecologies that are rich in PYD characteristics that can potentially support leadership development among their youth congregants. To date, within PYD research, schools, colleges, afterschool programs, and sports leagues have been the primary settings for the study of ecological contributing contexts. Although further research needs to be conducted in the context of religious settings, this study provides baseline data for an initial insight into Latino congregations as socioreligious ecologies with characteristics and dynamics that can potentially contribute towards the leadership development of youth.

These findings therefore support the observations and anecdotal accounts regarding the level of engagement youth have with organic dynamics for leadership 
development in Latino congregations. Based on PYD theory, the study also provided a proposed set of variables and measurements by which to approach future studies on this topic. Youth congregants are involved in hands-on experiences such as social service projects and exercising leadership tasks, and they are also engaging very frequently with their supportive religious community. These are all characteristics of ecological contributing contexts which PYD postulates can potentially contribute towards the leadership development of youth, and their continued contribution as leaders in adulthood (Avolio \& Vogelgesang, 2011; Murphy \& Reichard, 2011)

\section{Conclusions}

The following conclusions can be drawn from the data analysis guided by the research questions and hypotheses, as well as the contextual descriptions based on the individual survey items of this study:

1. Dynamics present in Latino congregations support the leadership development of youth. The reported data in this study give individual and institutional-level indications that Chicago Latino congregations are rich in characteristics that can promote leadership development among their youth congregants. Positive Youth Development theory calls such socioreligious environments "contributing ecologies" which tend to cultivate youths' continued contribution as leaders in adulthood.

2. The more youth participate in their congregations, the more their involvement in social service and their engagement in leadership tasks increase. The two contributing ecological factors characteristic of Latino congregations chosen for this study (Social Service Involvement and Engagement in Leadership Tasks) were tested for their relationship with Religious Participation. It was found that the participants' scores in both 
Social Service Involvement and Engagement in Leadership Tasks increased as a result of their Religious Participation scores increasing. Previous studies have reported youths' involvement in these types of activities as potentially contributing towards their leadership development.

3. Youth in Latino congregations are present, are actively engaged, and their participation increases with age. Both the reports from the frequencies and the aggregate score indicate that the level of Religious Participation among youth in Chicago Latino congregations can be operationally described as high. There are some distinctions however, as participants affiliated with the Catholic Church tended to have lower scores in Religious Participation when compared to those of Evangelicals and Pentecostals, and the analysis also found youths' scores increased with age. Thus, there seems to be an indication that youth are increasing their religious participation in Latino congregations with age rather than disassociating and disengaging as they grow older.

4. Latino congregations are providing multiple programs and activities through which youth are participating in and connecting with their religious communities. Youth in Chicago Latino churches report participating very frequently within their congregation in aspects such as religious services, religious education classes, youth group, and other related activities (e.g., worship team and drama group).

5. Youth in Latino congregations are very involved in social service, and they are being encouraged to do so by others in their congregation. Although the results of the aggregate score for the level of Social Service Involvement among youth in Chicago Latino congregations can be operationally described as low, the reports from the frequencies indicate that about half of the youth congregants are frequently involved in 
social service, both through their congregation and on their own. A high percentage of youth also report being encouraged by others in their congregation to be involved in social service, and over 35 percent of youth report the frequency of their involvement being one to five times per month.

6. Youth are highly engaged in exercising leadership tasks within their Latino congregations, and this tendency increases with age. Both the reports from the frequencies and the aggregate score indicate that the level of Engagement in Leadership Tasks among youth in Chicago Latino congregations can be operationally described as high. There are some distinctions however, as participants affiliated with the Pentecostal Church have higher scores in Engagement in Leadership Tasks when compared to those of Catholics, and female participants have higher scores than the male participants in this study. The analysis also found youths' Engagement in Leadership Tasks scores increasing with age, thus, further supporting the previously mentioned results that youth in Latino congregations are increasing their religious participation with age, and they are doing so in a very hands-on manner by partaking in leadership activities.

7. Latino congregations are providing opportunities through which youth can be engaged in leadership tasks. Youth in Chicago Latino churches report engaging very frequently within their congregation in opportunities to exercise and practice their leadership abilities through tasks such as public speaking, organizing events, inviting their friends to church, and being leaders in their youth group.

\section{Implications for Practice}

The theoretical framework, findings, contextual descriptions, and conclusions in this study provide some important implications for practice regarding what Latino 
congregations and church leaders, denominational entities, religious educational institutions, grant funding organizations, and NG3 can do concerning ministry and research among Latino youth. More specifically, in sustaining the healthy development and thriving of youth within Latino congregations, particularly in ways which can impact their leadership emergence as we seek to develop the next generation of leaders in the church and community. The following sections present a selected few recommendations.

Before going further into the proposed recommendations, it is important to keep in mind that what must precede all activities, programs, and all other types of efforts is adopting and intentionally cultivating within congregational practices the foundational values and principles of PYD upon which this dissertation was built; these are:

1. Viewing youth through a positive lens as "assets to be developed" and not problems to be managed.

2. Being contributing ecological contexts that create opportunities for youth to discover, strengthen, and exercise their skills and competencies through positive experiences, relationships, and environments.

3. Acknowledging that the relationship is bidirectional, thus healthy and thriving youth also make positive and valuable contributions to their environment.

\section{What Congregations and Church Leaders Can Do}

First, the results of this study indicate that youth in Chicago Latino congregations have high levels of participation in religious activities. Therefore, as a pathway towards sustaining the reported high levels of participation, it is important for congregations to continue providing activities, programs, and opportunities such as the ones reported by the youth in the study: regular worship services, religious education classes, worship 
team or choir, drama group, youth group, community service and volunteer work, public speaking, helping organize events and programs, and serving in leadership roles within their youth groups. Thereby giving youth an ample variety of options through which they might have the opportunity to connect with other peers and caring adults, put their skills to use, and be rooted in the community-life of their congregations.

Furthermore, being that this study found both youths' Religious Participation and Engagement in Leadership Tasks scores increasing with age, there seems to be an indication that youth are more involved within their local congregations as they grow older, versus disassociating and disengaging. Congregations benefit from being intentional in generating an environment that responds and adjusts to the changing needs of youth during each stage of life, and that provides them as well with positive and sustained relationships and meaningful connections with their faith community. This creates the necessity for congregations to continue providing both age-specific, as well as multigenerational opportunities so that this trend in increased religious participation and engagement in leadership tasks can continue. Especially considering that leadership development is a process that takes place over time, therefore, having opportunities at every stage in life to exercise leadership is a key component towards reaching the goal of developing leaders for the church.

Moreover, it is also important to note that the study indicated that both in aspects of religious participation and engagement in leadership tasks, youth affiliated with the Catholic church had statistically lower scores when compared to those of Evangelical and Pentecostals. Hence, the Catholic church will benefit from focusing its efforts and engaging with the youth in their congregations to explore the congregant-level and 
institutional-level factors that are contributing towards youth in Latino congregations not being up to par with their peers in other denominations, and consequently, what can be done to increase their participation scores. This is particularly important as 55 percent of the Latino population in the U.S. identifies as Catholic (Pew Research Center, 2013), thus Catholic churches have a prime opportunity to invest in the leadership development of Latino youth.

Regarding the findings on the relationship of variables, it was confirmed that participants' scores in both Social Service Involvement and Engagement in Leadership Tasks increased as a result of their Religious Participation scores increasing. Thus, we know that youth participating in their congregations is supporting the two chosen variables of social service involvement and engagement in leadership tasks, therefore there seems to be an indication that congregations are contributing positively to both of these efforts, and this ought to be continued. The following are some recommendations on the implications for practice addressing each factor specifically.

Participant's Social Service Involvement scores were found to be low; therefore, this seems to indicate that this is an area in need of strengthening and growth in congregational efforts. Especially as 32.5 percent of youth report never having been involved in social service or volunteer opportunities. However, it is also important to highlight that in the reports from the survey frequencies, about half of the youth who participated in this study indicated that they are frequently involved in social service, both through their congregation and on their own. Youth also report being encouraged by others in their congregation to be involved in social service, which seems to indicate that they are in a supportive context that values their participation in these types of activities. 
Therefore, congregations can nurture youths' leadership development by being intentional in providing opportunities and activities by which youth can be actively involved in social service or volunteer work, and by continuing to create a supportive environment.

There are many different types of social service involvement efforts that congregations can organize, such as school supply drives, community clean-up days, setting up tutoring programs for students in the neighborhood, or even partnering with other congregations to create collaborative projects. It is important for these types of social service activities to aim at helping the youth who participate in areas such as strengthening their social skills, growing in their awareness and empathy towards the needs of others, and working together with someone else or a group towards generating and implementing ideas that can help solve a community problem. This gives youth opportunities by which to engage in actions and practices that nurture their leadership emergence and development, and it also increases the likelihood that they will fulfill leadership roles in adulthood. Furthermore, congregations will benefit from investigating and understanding the reasons behind why about one-third of youth congregants have not been involved in social service efforts, even when there seems to be opportunities provided through their congregation.

Concerning Engagement in Leadership Tasks, the scores among participants were found to be high. This finding seems to indicate that youth congregants are finding ways by which to engage in leadership tasks, however, the survey items do not report how youth are finding these opportunities, and if their congregations are intentionally creating opportunities for them to do so. Nevertheless, there seems to be an indication that their 
congregations are affording them the space to exercise and practice their leadership abilities through tasks such as public speaking, organizing events, influencing others, and leading their youth group.

Congregations that find ways for youth to be involved in leadership tasks, contribute to their leadership development, and the likelihood that they will continue to function as leaders in the future. Some practical ideas include finding opportunities and giving space for youth to engage in leadership tasks in as many activities and programs within the congregation as possible. For example, within the worship service, religious education classes, worship team, choir, or other programs or activities regularly offered in the congregation, allow youth to discover, exercise, and strengthen their leadership skills and abilities by inviting them to help organize the logistics or to do something that entails public speaking, such as sharing a brief testimony or greeting the congregation at the beginning of an event. Other ways can include involving youth in the church's media needs, reading Scripture or leading music during worship, or by mentoring them to teach a Bible class, for example.

Furthermore, the opportunities for engagement in leadership tasks that congregations offer can also extend to creating spaces for dialogue where adult leaders and youth can discuss issues related to ministry, community, and congregational dynamics. Making space for asking questions, fostering conversations, and listening to the dreams, ideas, insights, opinions, and concerns of youth, can help congregational efforts go further in nurturing youth as leaders. Another practical idea is by giving youth opportunities to be involved in church governance. Despite their limited life experience, young people have a wealth of knowledge, innovative ideas, and energy which can 
strengthen church governance. These types of efforts stress the role of youth as equal contributors and educators rather than the recipients of our plans and programs.

Finally, there are two other aspects to consider for practice based on the results of this study. The analysis showed that females scored higher than their male peers in aspects of engagement in leadership tasks. Thus, it is important for congregations to find ways to encourage both males and females to be equally involved. It serves congregations to investigate and identify potential causes for the differences and what contextual solutions can be implemented to address this trend. Moreover, with 100 percent of participants indicating being involved in their congregation's youth group, and 26.2 percent reporting that they are leaders in their youth group, this provides congregations insight that youth are responding extremely positively in regards to attendance to these types of programs and activities. This response seems to indicate that congregations should continue to invest in these efforts, while also learning what are some of the needs and opportunities that arise as a result of this phenomenon. This is especially important as a good percentage of youth report finding space within these programs to exercise leadership. Congregations have the opportunity to see in which ways they can support these efforts, contribute towards sustainability, and identify needs such as providing specialized training, etc.

The combination of these experiences congregations are providing for youth, especially for those youth who engage in them over a prolonged period, can help spark interest, build skills, strengthen commitment, and teach youth leadership aspects in a very hands-on way -an approach that reflects the life-long learning framework. It is through these types of experiences that we actively develop leadership in youth, rather than 
approaching leadership development as an exercise where information is presented through a course or conference. As PYD proposes, this type of approach has a greater long-term impact among youth when they are in their formative years.

However, providing activities and programs in which youth are involved are only a part of the efforts needed to support their healthy development and the nurturing of their leadership abilities. The activities are simply pathways that provide a means by which to exercise the PYD values that make the programs and activities profitable towards reaching developmental goals, in particular that of leadership development. Creating a congregational culture that is supportive of youth as leaders, calls for congregations to first assess if youth are at the center of congregational life, and not in the periphery, or basically overlooked until they reach adulthood. The reported high scores in religious participation can be potentially profitable in developing youth as leaders, but only if they are being active contributors among their congregations and not passive spectators.

The study revealed characteristics of Latino congregations that show signs of being socioreligious contributing ecologies that are rich in PYD characteristics which can potentially support leadership development among their youth congregants. We need to recognize our congregational strengths in these matters so that we may intentionally continue to cultivate them, and in turn, youth will continue to participate actively in the congregation and step into further leadership roles now and in the future.

\section{What Denominational Entities Can Do}

In light of the results of this study, denominational entities have the opportunity to invest in initiatives, programs, and activities which support and complement the 
congregational efforts already taking place that are likely contributing towards youth leadership development. These efforts can also include encouraging collaborations among congregations to develop larger-scale projects among Latino youth, with the aim of supporting their leadership development. The goal is to maintain and increase youths' levels of religious participation, social service involvement, and engagement in leadership tasks. The more opportunities youth have by which to connect and exercise leadership within their church structures, the more it is likely that their leadership development is being nurtured.

Other efforts to support youths' leadership development, and to extend the high levels of participation and engagement from the congregations to the denominational level, can include inviting them to form part of advisory councils or committees within denominational structures, creating spaces for conversations where they can give their ideas and input regarding strategies for denominational efforts, and being intentional in creating opportunities for youth to exercise leadership tasks such as participating in public speaking and event planning at denominational level events and programs.

Finally, as this study found differences in the scores for religious participation and engagement in leadership tasks among different denominations, denominational entities have the opportunity to create collaborations across denominations and learn from one another about the congregant-level and institutional-level factors that are contributing towards the differences in the levels of participation and engagement among their youth in Latino congregations.

All in all, the high levels of religious participation and engagement in leadership tasks among youth in Latino congregations, indicate that investments and efforts geared 
towards these congregations and demographic group, are likely to support the goal towards developing leaders for the church.

\section{What Religious Educational Institutions Can Do}

Regarding religious educational institutions such as theological seminaries and Christian universities that offer ministerial training, there is room within this sector as well to benefit from the findings of this study.

This study shows that there seems to be a tendency towards a high number of youth engaging and being active within their Latino congregations, and they are having the opportunity to partake in activities which shape and strengthen their leadership skills. Being that youth are taking these steps in their leadership development at the congregational level, educational institutions can come alongside of congregations and look for ways to support the young people who might be interested in pursuing formal theological and ministerial education as an extension of their leadership development. For example, by creating special programs for younger youth to visit the campus of religious educational institutions and participate in leadership development activities. This can be useful in sparking their imagination and dreams into ways in which they can continue growing in their leadership abilities, while also contemplating ministry as a vocation.

Moreover, with 100 percent of participants indicating being involved in their congregation's youth group, and 26.2 percent reporting that they are leaders in their youth group, this phenomenon can be an indication of how important it is for educational institutions to provide training opportunities related to youth ministry and working with Latino youth, rooted in a framework of PYD. 
When engaging in these recommendations, it is important for religious

educational institutions to take the aspects of the Latino experience presented within this dissertation into account and support the strength of the organic leadership development dynamics already present in Latino congregations by tailoring the curriculum offered to fit these contextual needs and opportunities.

\section{What Grant Funding Organizations Can Do}

Taking into account the current high percentage of youth among the Latino population, the exponential growth this demographic group will continue to experience in the coming decades, and the central role that religion plays in the lives of Latinos, it is imperative to conduct more studies among Latino youth. We need to gain further insight into their habits, experiences, culture, and the details of their involvement in religious, social service, and leadership activities. Grant funding organizations have the opportunity to make an intentional move into funding research projects which specifically focus on Latinos. The knowledge gained will not only provide us with necessary insight into this demographic group, it also contributes to our collective learning on developing young leaders for the church and the community in general.

The research projects developed to date within the field of sociology of religion with a focus on a Latino youth demographic have contributed to the initial steps as we advance our understanding of Latino youth, their leadership development, and congregational dynamics. However, further funding is needed so that studies can be conducted with larger samples, at a national level, through various research methods, and allowing for comparisons among variables such as denominational affiliation and acculturation levels. We need to further our understanding of the trends and direction of 
religion in the U.S., and this cannot be done without an intentional focus on the Latino experience.

\section{What New Generation3 Can Do}

New Generation3's years of ministry experiences and observations regarding leadership development and the congregational characteristics which support youth are in large part backed by the findings in this study. The findings indicate that the materials, training, curriculum for ministry, and consultations NG3 provides need to focus on helping Latino congregations recognize the strengths within their current efforts and their organic dynamics for leadership development which are likely contributing towards the leadership development of youth. While also helping congregations find ways by which to maintain and improve the level of participation, involvement, and engagement among their young congregants. Integrating these findings into our work at NG3 can also serve as a way of helping congregations from other cultural, ethnic, and contextual backgrounds learn from the organic leadership dynamics found in Latino congregations.

\section{Recommendations for Further Research}

The data from the CLCS-YS analyzed through this study has contributed towards our understanding of Latino youth, Latino congregations, and the characteristics present in socioreligious contexts which promote PYD, in particular leadership development. As with any other research study, what is learned inevitably leads to new areas that need to be explored and research questions by which to probe even deeper. Therefore, the following are selected recommendations for future research in this field: 
1. This study analyzed only two variables that can potentially contribute to leadership development among youth: Social Service Involvement and Engagement in Leadership Tasks. Further studies need to investigate other variables that could be helpful towards identifying other key factors present in Latino congregations and among its young congregants.

2. Although the survey questions within the CLCS-YS implied some institutional characteristics present within congregations which contribute towards the leadership development of youth, further research needs to be conducted to document and analyze the practices, behaviors, institutional culture, dynamics, and opportunities congregations provide, and to establish which are most successful at supporting leadership development of young people in Latino congregations.

3. In this study, the scales for the criterion and predictor variables were based on, and limited by, the items of the original questionnaire of the CLCS-YS. Based on the theoretical framework, the relevant questionnaire items were labeled as Religious Participation, Social Service Involvement, and Engagement in Leadership Tasks. A future study would benefit from including new questionnaire items that cover a wider spectrum of items related to the topics at hand. There is also a need to improve the way in which the questions are asked and the terms employed, in order to make it easier for youth to understand what is being asked and therefore be able to give more accurate responses.

4. The CLCS-YS included both quantitative and qualitative data collection. This dissertation only used portions of the quantitative data. Further research that analyzes the 
rest of the quantitative data as well as the qualitative data gathered will provide rich insights and added detail into the characteristics of Latino youth and their congregations.

5. The results of this study can only be generalized to Latino churches and their congregants in the Chicago area. However, this research framework can be used to study other Latino congregations throughout the country. There is a need to explore whether similar results would be obtained if one compared practices among different denominations, urban versus rural congregations, and congregations whose primary attendance are first and second-generation Latinos versus those who are more acculturated to and assimilated in the mainstream culture. In order to grasp the particularities of their experiences, the aspects of acculturation, language, socioeconomic status, and social environment are always important to integrate into research dealing with the Latino population and congregational dynamics.

6. Although in this study the total Social Service Involvement aggregate score was found to be low among participants in the study, the frequencies based on the raw data indicated that about half the youth are involved in volunteer work. Thus, further research might provide better insight into the type and level of involvement among youth in the congregational efforts related to Social Service Involvement. About one-third of youth also reported never having gotten involved in social service or volunteer work, the reasons contributing to this trend also need to be investigated.

7. This study found youth have a high level of Religious Participation and Engagement in Leadership Tasks. Future studies are needed to gather further insight into the extent of this level of participation, and if congregations are intentionally providing 
opportunities for youth to engage in leadership tasks, and if so, through what types of activities, initiatives, or programs?

8. The demographic variables of denominational affiliation, age, and gender were found to have a statistically significant relationship with Religious Participation and Engagement in Leadership Tasks. Potential reasons behind these results need to be further investigated in order to have a better grasp of the individual-level and institutional-level phenomena that could be contributing towards these results. A comparative analysis of the differences in characteristics, dynamics, and practices between denominations might prove useful to analyze this specific variable.

9. The CLCS-YS data set used in this study afforded access to a greater pool of Latino youth participants in comparison to the NSYR. However, the data collection was limited to the Chicago area. A nationwide study, longitudinal in nature and with mixed research methodologies, would provide the opportunity to gather further and richer insights into the relationship of religious participation and leadership development among youth in Latino congregations.

10. Lerner et al. (2013) point out the need to broaden the scope of contexts within which PYD is researched, embraced, and practiced. Latino faith communities need to be studied more extensively to identify the assets and developmental opportunities available there. Definitive conclusions and correlations will need to be drawn in subsequent studies, as the current study did not investigate the specific factors, circumstances, and contextual characteristics under which an involvement in religious communities leads to leadership development or Contribution. 


\section{Epilogue}

This project began, and will continue, as a labor of passion, hope, and conviction that youth are the greatest assets we have. A new season in North American Christianity is unfolding. The future of the church, its renewal, vibrancy, impact, and direction are all hinging on how we view and engage with our youth, particularly with youth of diverse ethnocultural backgrounds. This study yet again reinforced the message that other voices in the past have expressed: in our Latino church youth are present, religion is a significant part of their lives, and they are actively engaged in their congregations. In fact, this study found their participation increases as their age increases.

The Census data reports that 34 percent of the Latino population is younger than 18 years of age (U.S. Census Bureau, 2015). It has also been noted that Latino Protestantism will continue to be a very important trend within U.S. religion in the next few decades as it continues to grow (Mulder et al., 2017) and a large number of Latinos will continue to identify with the Catholic church (Pew Research Center, 2014a). Considering these facts, it is very clear that knowing, understanding, and supporting the religious lives of Latino youth is imperative, not only to inform the way we engage and minister to youth within individual congregations, but also towards shaping the vision and strategic plans within denominational work.

Yet only last night, I had a conversation with a seasoned Latino Christian leader and scholar regarding leadership development in the church and the state of our youth in the Latino church. I heard from him the common discourse which claims that young people are leaving the church, that disparities between the assimilation and acculturation styles between clergy and youth are to blame, and that as a socioreligious community we 
are still in the exploration stages towards deciphering how to approach the challenges ahead of us. The conversation left me a bit restless and realizing yet again that our paradigms regarding youth and the Latino church are not shifting at a rate that matches the needs, realities, and opportunities. Even worse, we are appropriating the messages of other socioreligious groups in the U.S. and claiming them as our own. Research reports that youth in the cultural majority are not identifying with the church at the degree they did in the past, and therefore their participation is dwindling, in contrast, the results of this study show a high level of engagement among youth in Latino congregations. Does the Latino church and its leaders recognize its strength in the midst of other competing messages?

There are global movements towards recognizing and realigning paradigms to the realization that youth are our most important assets. A vision for a different future is being forged under an ideology and frameworks for youth outreach practices and public policy that advocate for engaging with youth through positive approaches. In fact, I left my architectural career in order to devote myself to promote, research, and train others on this view on youth and what they contribute to our society and religious systems. But where does the church stand on this? Are youth in our congregations experiencing this level of openness and value towards them?

In all of this, once again, young people have something to teach us. I believe that it is no coincidence that youth activists who support an immigration reform through DACA have chosen Mexico's monarch butterfly as the symbol of this plight. This is a butterfly species which migrates every year from Canada to Mexico in search of its breeding sanctuary where it thrives in the mountain tops of Michoacán, Mexico. This 
annual migration supports a rich natural ecology in all three countries, as well as the economic system in the region. Like this butterfly, we have a generation of Latino youth with a large population count, with the ability to move freely across borders, and who impact the systems within them - whether physical, ideological, or cultural. In the church, they too hold the answers to the balance and restructuring that our congregational ecological systems need. They too are in search of those mountain tops where they can develop positively, thrive, and lead. Has the church recognized this asset in our midst?

It is time for the Latino church in the U.S. to be self-empowering. It needs to recognize, claim, and cultivate its strengths found in the nature of our sociocultural characteristics and our ways of practicing and understanding Christianity. It is time to assert our own ways of knowledge construction, discovery, and pathways for developing leaders. We already have within ourselves and our systems the answers we seek about developing leaders for the church - young people in our congregations are being nurtured as such. It is time to discover the power within, and to take strategic and intelligent steps forward. We have a richness of life and spirituality from which the U.S. church at large will benefit as we all decipher our way forward as a Christian community.

At the same time, we also need to confront any barriers that can hinder progress, lest young people receive the message that leadership opportunities are not available to them, and this deflates their excitement and interest in putting their skills, ideas, and energy to use in the church. The more we provide spaces and opportunities for youth to have a voice, take action, exercise leadership, and teach us, the better job we will do as church leaders in casting a vision that takes the church forward, remains relevant, and which shows signs of health by reproducing and developing leaders. 
Youth are the barometer that determines the health and future of our ministries, congregations, denominations -indeed of the church at large! Youth define our Latino population. If the young people in our congregations are not finding pathways by which to be actively engaged and empowered, they will find other ways, and we will be overlooking the most precious assets we possess as Latinos and as a faith community.

Wake up Latino church! Wake up! — lest we lose the most valuable assets God has bestowed upon us for such a time as this — the young people in our midst. Young people have the potential and capacity to spread their wings, develop their skills, and the power to lead in benefit of themselves, their families, their communities, and their congregations. They are looking for adults who walk alongside and fully empower them to do so. Will they find this in you? 
APPENDIX A

CHICAGO LATINO CONGREGATIONS

STUDY YOUTH SURVEY 


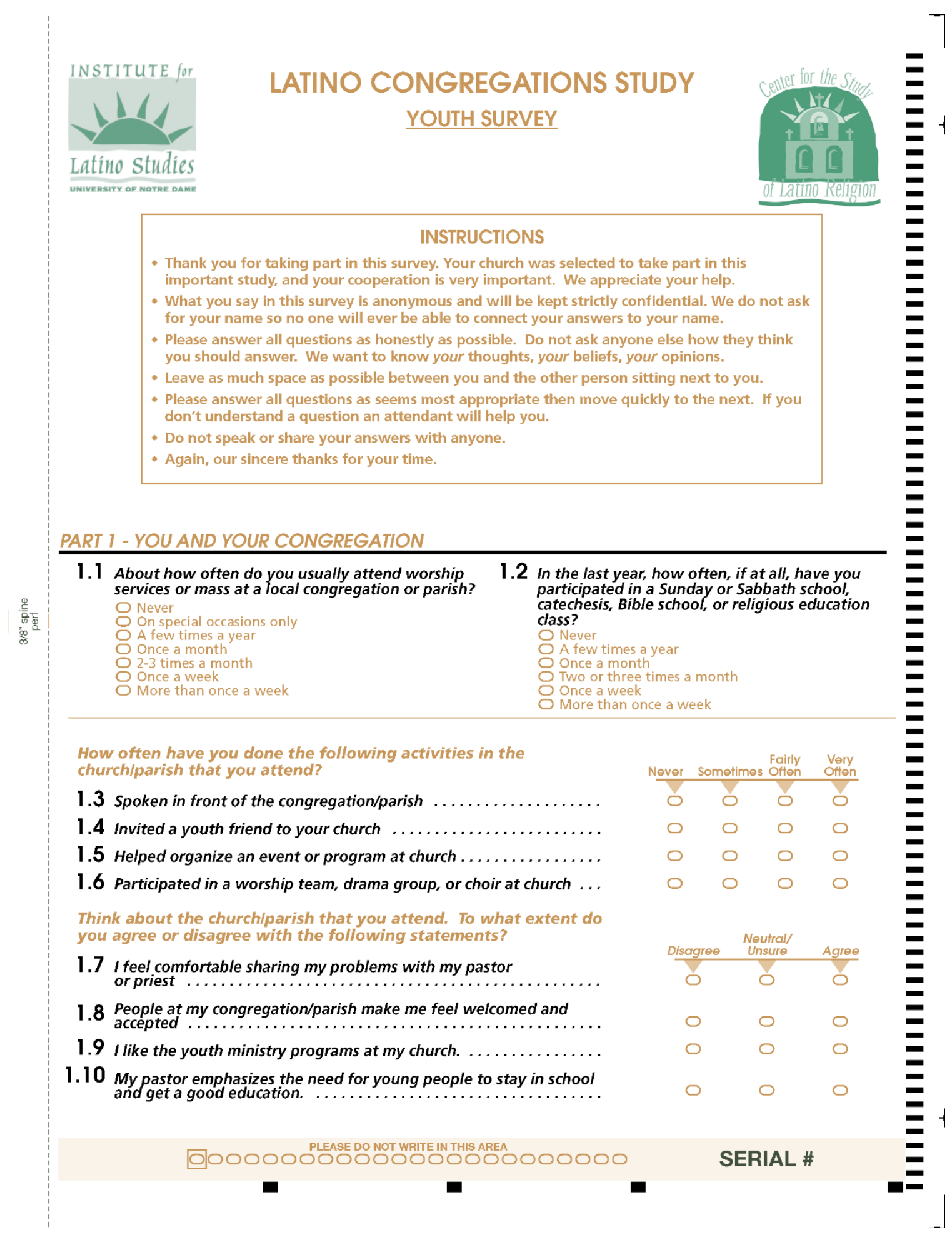




\subsection{Approximately, how many hours a week do you spend in church related activities?}

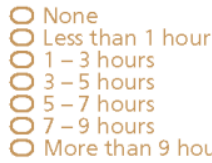

1.12 a. Are you CURRENTLY involved in ANY religious youth group? By "religious youth group" we mean an organized group of young people that meets regularly for social time together, prayer, or to learn more about their religious faith.

$$
\text { No }
$$

$\rightarrow$ b. If yes, about how often do you attend this youth group's meetings and events?

Almost never

A few times a year

Orimes a month

S About once a month

Alout once a week

c. Would you say that you are a leader or a participant in your current youth group?

$\bigcirc$ Leader

1.13 of your closest five (5) personal friends, how many attend this congregation/parish? (Mark one response.)
○
$\bigcirc 1$
02
$\bigcirc 3$
$04 \quad \circ 5$

1.14 If it was totally up to you (without your parents influence), how often would you attend religious services? Would you attend:

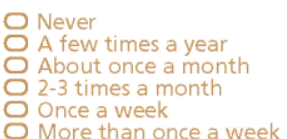

1.15 How often do your parent(s) or guardian(s) attend worship services or mass?

Never

On special occasions only

A few times a year

Once a month

Or-3 times a month

Once a week

More than once a week

1.16 How often does your mother and/or father live a good example of a Christian life (practice what they believe)?

a. Mother

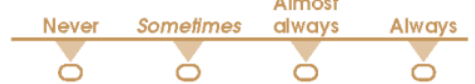

b. Father

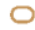

PART 2 - ABOUT YOUR FAITH

How often do you do the following activities?

2.1 Pray or meditate

2.2 Read the Bible

2.3 Read inspirational religious books

2.4 Listen to Gospel or Christian music.........

Never $\begin{gathered}\text { Hardly } \\ \text { Ever }\end{gathered}$

$\begin{array}{lll}\text { Once a } & \text { Oncea } \\ \text { onth or Week or Once a More than }\end{array}$
More More Day OnceaDay 
2.5 How interested are you in learning more about your religious beliefs?

Not at all interested

Not very interested

Somewhat interested
Very interested

2.6 How often does your family talk about God, read the Bible or other religious materials together?

Never

A few times a year or monthly

About once to a few times a week

Every day

2.7 How important would you say religion is in your life?

Not important at al.

Not very important

Important

Extremely important

2.8 What is your religious or denominational affiliation or preference? With what religious group or tradition do you most identify with? (For example, Catholic, Methodist, Pentecostal. Assemblies of God, Southern Baptists.)

2.9 How distant or close do you feel to God most of the time?

$\bigcirc$ Extremely distant

Very distant

Somewhat distant

Somewhat close

Very close

Extremely close

(FOR CATHOLICS ONLY): Answer 2.10-2.13 In the last year:

2.10 Have you taken First Communion?

2.11 Have you been to confession or a reconciliation liturgy?

2.12 Have you participated in any religious pilgrimages,

processions, way of the cross, or other similar religious practices?

2.13 Did you pray the rosary, pray novenas, or offer prayers to special saints?

PART 3 - BACKGROUND INFORMATION

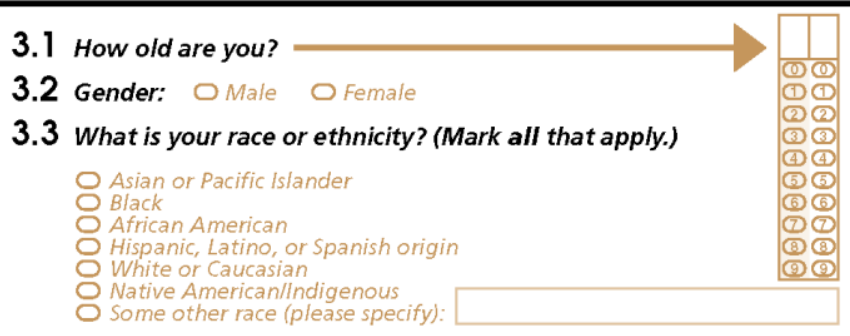

3.4 If you marked Hispanic, Latino, or Spanish origin, please indicate with which Hispanic/latino group you most identify. (Mark only one.)

$\bigcirc$ Mexican American/Chicano $\bigcirc$ Native American/Indigenous
$\bigcirc$ Mexican

Mexican

Puerto Rican

Cuban American

Cuban

Colombian

(please specify):

south American

(please specify):

Other

(please specify):

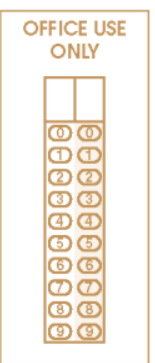

00000000000000000000000

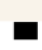

SERIAL \#

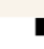




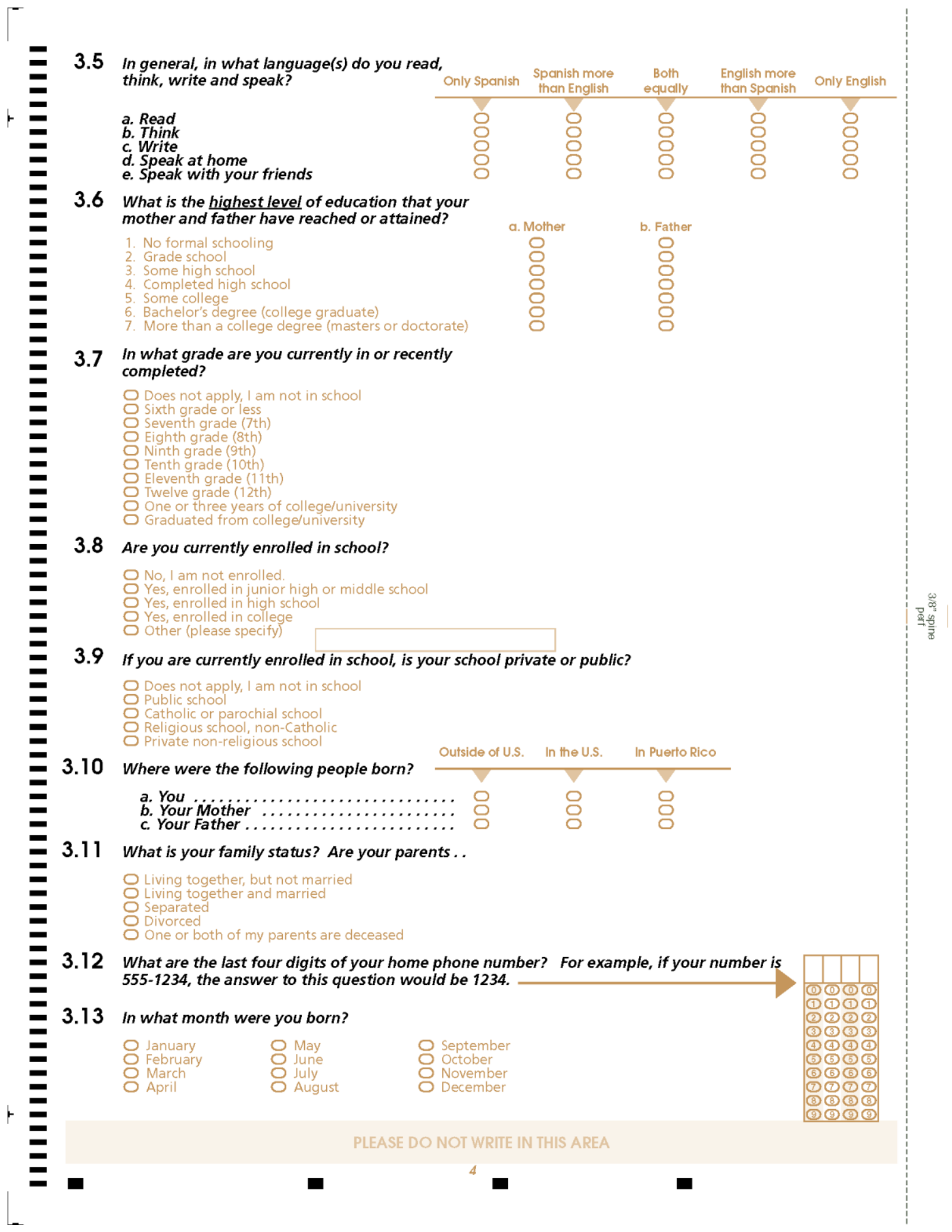


4.1 lenjoy going to school

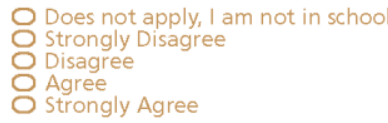

4.2 Which of the following does your family have in your home? (Mark all that apply)

$\bigcirc$ A specific place for you to study

A daily newspaper

A computer

4.3 How many days of school did you miss this school year? (Mark only ONE answer.)

$\bigcirc$ Does not apply, I am not in school

None

1 - 3 days

3 - 5 days

$5-7$ days
More than 8 days

4.4 How often do you cut or skip classes? (Mark only one)

Does not apply, I am not in school

Never or almost never

Sometimes, but less than once a week

Not every day, but a least once a week

$\bigcirc$ Daily

4.5 Were you ever held back (made to repeat) a grade in school?

8 No

4.6 What grades do you have in school? (Mark only ONE.)

Not applicable, not in school or my classes are not graded

Mostly A's

About half A's and half B's

Mostly B's

About half B's and half C's

Mostly C's

About half C

Mostly D's

Mostly below D

4.7 About how much time, in a school day do you spend doing homework? (Mark only ONE.)

$\bigcirc$ Does not apply, I am not in school

Oress tha do any homework

Liss than 1 ho

82 hours

$3-4$ hours

More than 4 hours

4.8 During the school year, how many hours a day do you USUALLY watch TV? (Mark only ONE.)

Don't watch TV

Less than one hour a day

O

年

Over 6 hours a day 


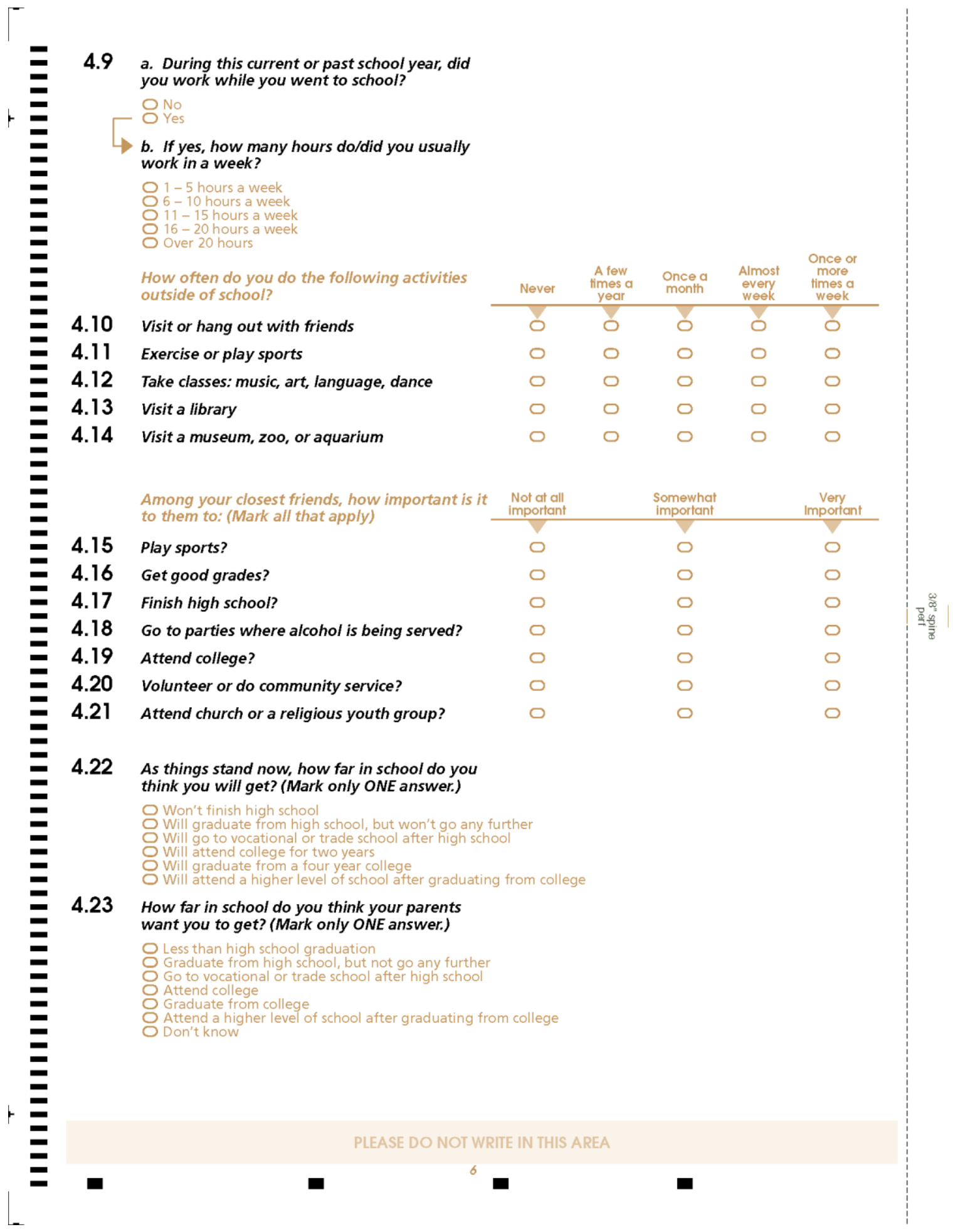


How often do your parents or guardians do the following?

5.1 Check on whether you have done your homework

5.2 Limit the amount of time for going out with friends

5.3 Help you with your homework

5.4 Limit the amount of time you can spend watching $T V$ or playing video games

5.5 Know where you are most afternoons after school

How much do you agree or disagree with each

of the following?

5.6 My parents talk over important family decisions with me

5.7 Iget along well with my parents

5.8 My parents give me help and support when I need it

PART 6 - YOUR OPINIONS ABOUT YOURSELF. ATIITUDES AND LIFE EXPERIENCES

How do you feel about each of the following statements?

6.1 I feel good about myself

6.2 I am able to do things as well as most other people

6.3 It is more important to enjoy life now than to plan for the future.

6.4 I feel I do not have much to be proud of

6.5 I am optimistic and hopeful about the future

6.6 I worry that my parents might get separated or divorced

6.7 How often do you feel very sad or depressed?

$$
\begin{aligned}
& \bigcirc \text { Never } \\
& \bigcirc \text { Rarely } \\
& \bigcirc \text { Sometimes } \\
& \bigcirc \text { Usually } \\
& \bigcirc \text { Always }
\end{aligned}
$$

How many times, during the last 12 months did you do each of the following? Choose from these answers:

6.8 Drink alcohol (beer, liquor, wine, etc.)

6.9 Smoke cigarettes or chew tobacco

6.10 Attend a party where people were drinking alcohol

6.11 Use an illegal drug (marijuana, cocaine, etc.)

6.12 Have five alcoholic drinks or more in a row

\begin{tabular}{cccc} 
Never & Rarely & Sometimes & Often \\
\hline \multirow{2}{V}{} & 0 & 0 & $\bigcirc$
\end{tabular}

00000

$\circ \quad 0$

0000

$\circ \quad 0 \quad 0$

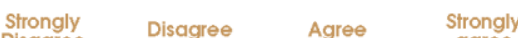

Disagree Disagree $\quad$ Agree $\quad \begin{gathered}\text { Strongly } \\ \text { agree }\end{gathered}$

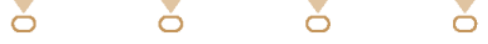

$\circ \quad 0 \quad 0 \quad 0$

$\circ \quad 0$ 
6.13 Do you think it is important to be married before having sexual intercourse?

O Not important

Somewhat important

very important

6.14 Would you consider having a child if you were not married?

$\bigcirc$ No

O Maybe

S Yon't know

6.15 During the last twelve months, how many times have you had sexual intercourse ("got laid," "made love")?

$\bigcirc$ Never

Once

$2-5$ times

10 times or more

6.16 Which of the following statements comes closest to your personal views about abortion? (Mark only one.)

$\bigcirc$ Abortion is always acceptable

Abortion is acceptable under most circumstances

Abortion is acceptable only under certain extreme

circumstances (threat to the mother's life, rape, or incest).
Abortion is never acceptable.

6.17 Have you ever received information regarding HIVIAIDS at your congregation or parish?

$\bigcirc$ No

$\bigcirc$ Yes

Don't know

PART 7 - SOCIAL SERVICE AND CIVIC ACTIVISM

7.1 a. Have you ever spent time participating in a community service or volunteer activity? By volunteer activity, we mean working in some way to help others for no pay. If yes, has it been in the last 12 months?

- Yes, have done it in the past 12 months

Yes, have done it but not in the past 12 months

, have not done It.

b. If yes, have you volunteered for any of these organizations in the past 12 months or more than 12 months? (Mark all that apply.)

Religious organization

Political organization or candidate running for office

Environmental organization

th or social services

An organization involved with children, youth or education

Other

7.2 a. About how many times in an AVERAGE MONTH do you do volunteer work or community service work?

b. On a typical day that you do volunteer, how much time on average do you volunteer?

Less than 30 minutes

About 1 or 2 hours

Over 5 hours

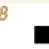


7.2 continued

c. How much, of this volunteer work or community service was organized by a religious organization or congregation/parish?

None

About half

Most

All

d. How much, of this volunteer or community service work did you do because you were required to by a school, or juvenile justice program?

None

About half

About ha

Most

e. How much, of this volunteer or community service work did you do because you were encouraged by your parents?

None

Some

About half

Most

7.3 About how often, in an average week, do you help homeless people, needy neighbors, family friends, or other people in need, directly, NOT THROUGH AN ORGANIZATION? [INCLUDES GIVING MONEY]

$\bigcirc$ None

Less than 1 hour

2 hours

3 hours

4 hours

5 hours

6 hours

7 hours or more

7.4 a. In the last year, have you been involved in any organization in which you yourself have planned an event, led a meeting, or given presentations or speeches? $\bigcirc$ No

b. If yes, did you do these things in a religious organization, a non-religious organization, or both?

Religious

Non-Religious

7.5 Have you ever been encouraged to get involved in volunteering for community service by someone in your church?

$\bigcirc$ No

You have completed the survey! Thank you very much! 


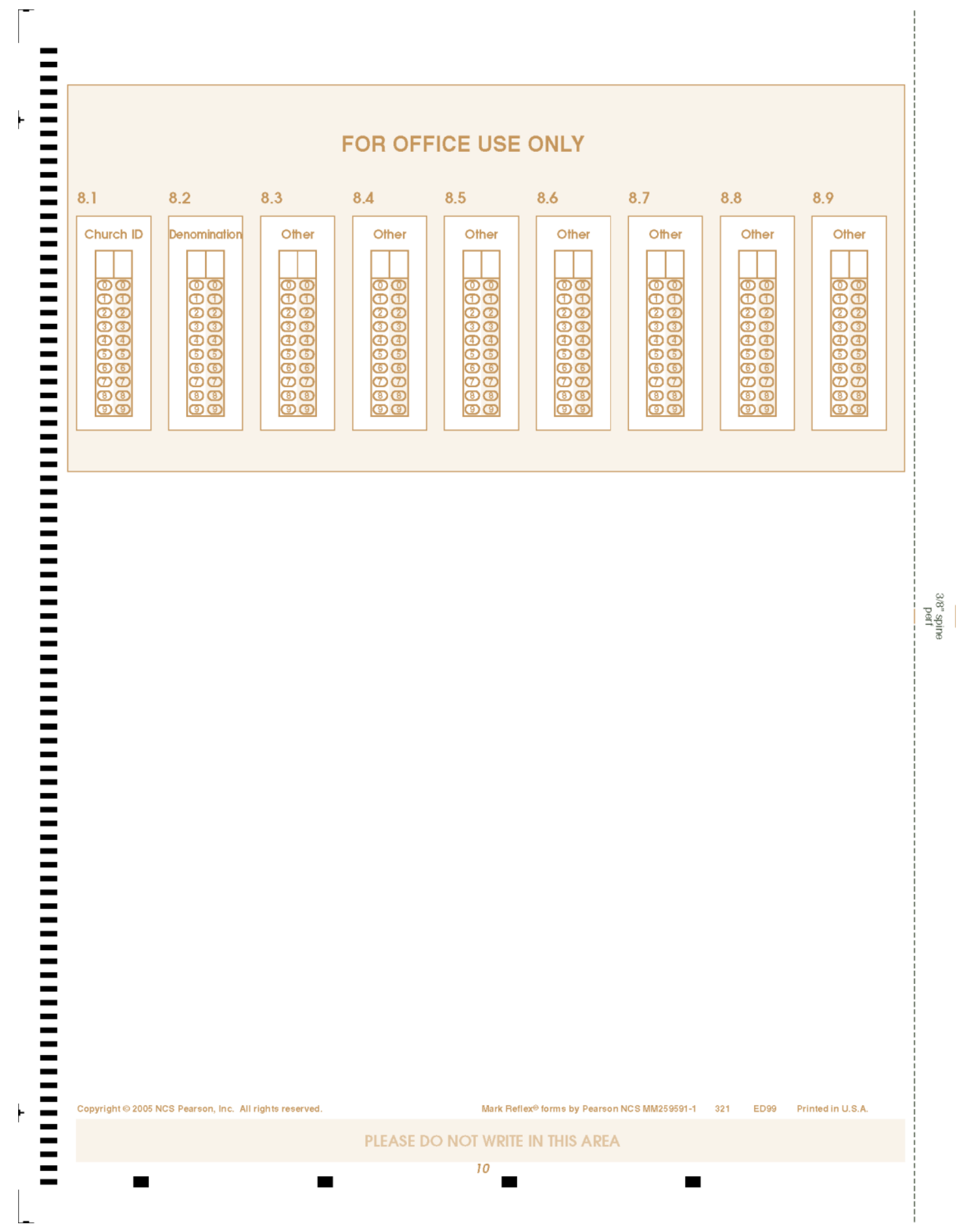




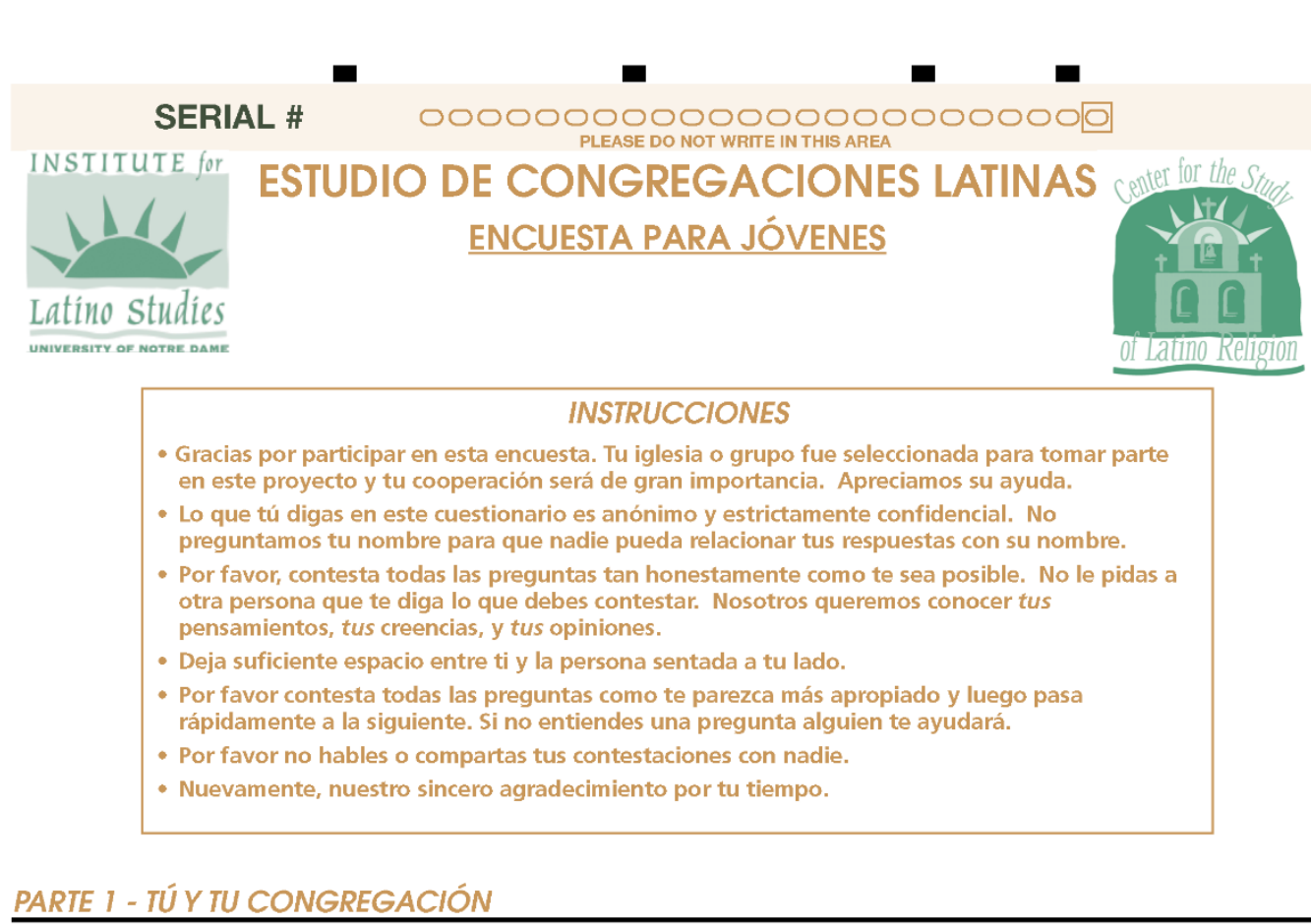

1.1 ¿Cuántas veces vas a servicios de adoración (cultos) 1.2 En el último año, ¿Cuántas veces participaste en o a misas en una congregación o parroquia? una escuela dominical o sabática, catecismo,

O Nunca

On ocasiones especiales solamente

O pocas veces al año

O Una vezal mes

2-3 veces al mes

Una vez a la semana

O Más de una vez a la semana escuela bíblica o clase de educación religiosa?

O Nunce

Pocas veces al año

O una vez al mes

Dos o tres veces al mes

O Una vez a la semana

Más de una vez a la semana

¿Cuántas veces hiciste las siguientes actividades en la iglesia/parroquila a la que vas?

1.3 Hablaste al frente de la gente en la congregación/parroquia ......

1.4 Invitaste a un amigo joven a tu iglesia

1.5 Ayudaste a organizar un evento o programa en la iglesia .........

1.6 Participaste en un equipo de adoración, grupo de drama o coro en la

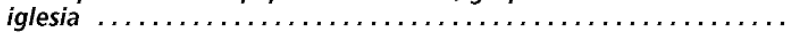

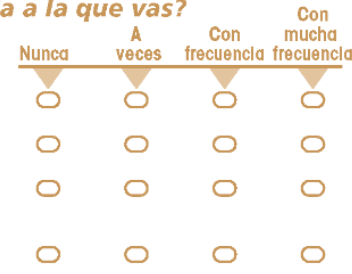

Piensa en la iglesia/parroquia a la que vas. ¿Hasta qué punto estás de acuerdo o en desacuerdo con las siguientes declaraciones?

1.7 Me siento cómodo/a compartiendo mis problemas con

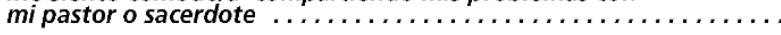

1.8 Las personas de mi congregación/parroquia me hacen sentir bienvenido/a y aceptado/a.

1.9 Me gustan los programas del ministerio de jóvenes de mi iglesia.

1.10 Mi pastor enfatiza la necesidad de que los jóvenes permanezcan en la escuela y obtengan una buena educación. .................

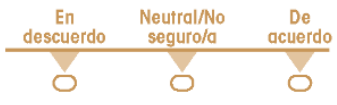

000

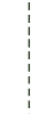




\section{PLEASE DO NOT WRITE IN THIS AREA}

1.11 Aproximadamente, ¿cuántas horas a la semana pasas en actividades relacionadas con la iglesia?

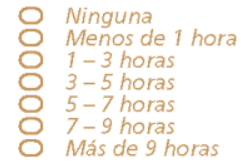

1.12 a. ¿Estás ACTUALMENTE involucrado/a en ALGÚN grupo religioso de jóvenes? Por "grupo religioso de jóvenes" nos referimos a un grupo organizado de jóvenes que se reúne regularmente para socializar juntos, orar/rezar, o aprender más de su fe religiosa.

$\bigcirc$ No

$\rightarrow$ b. Si respondiste Si, ¿aproximadamente cuántas veces vas a reuniones y eventos de este grupo de jóvenes?

$\bigcirc$ Casi nunca

Unas pocas veces al año

Aproximadamente una vez al mes

2-3 veces al mes

S Aproximadamente una vez por semana
Más de una vez la semana

c. ¿Dirias tú que eres un líder o un participante en tu grupo de jóvenes?

Lider

Participante

1.13 De tus cinco (5) amigos más cercanos, ¿cuántos vienen a esta congregación/parroquia? (Marque una respuesta)

1.14 si dependiese completamente de ti (sin la influencia de tus padres), ¿con cuánta frecuencia asistirías a los

$\bigcirc 0$

$\bigcirc 1$

○ 2 servicios religiosos? Asistiría:

Nunca

$\checkmark$ Unas pocas veces al año

8 como una vezal mes

2-3 veces al mes

O Una vez a la semana

1.15 ¿Cuántas veces van tu(s) padre(s) a servicios de adoración/cultos o misas?

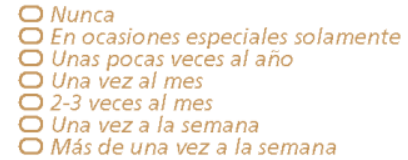

1.16 ¿Con cuánta frecuencia da tu madre y/o padre un buen ejemplo de vida cristiana (practican lo que creen)?

PARTE 2 - ACERCA DE TU FE

¿Con cuán ta frecuencia haces las

siguientes actividades?

2.1 Oras/rezas o meditas

2.2 Lees la Biblia

2.3 Lees libros religiosos inspiradores

2.4 Escuchas música "gospel" o cristiana .......

\begin{tabular}{|c|c|c|c|c|c|}
\hline Nunca & $\begin{array}{c}\text { Casi } \\
\text { Nunca }\end{array}$ & $\begin{array}{c}\text { Una vez al } \\
\text { mes } \\
0 \text { más }\end{array}$ & $\begin{array}{l}\text { Una vez a la } \\
\text { semana o más }\end{array}$ & $\begin{array}{l}\text { Una vez al } \\
\text { día }\end{array}$ & $\begin{array}{l}\text { Más de una } \\
\text { vez al día }\end{array}$ \\
\hline$V$ & $\nabla$ & $\nabla$ & $V$ & $V$ & $V$ \\
\hline 0 & 0 & 0 & 0 & 0 & 0 \\
\hline 0 & 0 & 0 & 0 & 0 & 0 \\
\hline 0 & 0 & 0 & 0 & 0 & 0 \\
\hline $\mathrm{O}_{2}$ & 0 & 0 & 0 & 0 & 0 \\
\hline
\end{tabular}




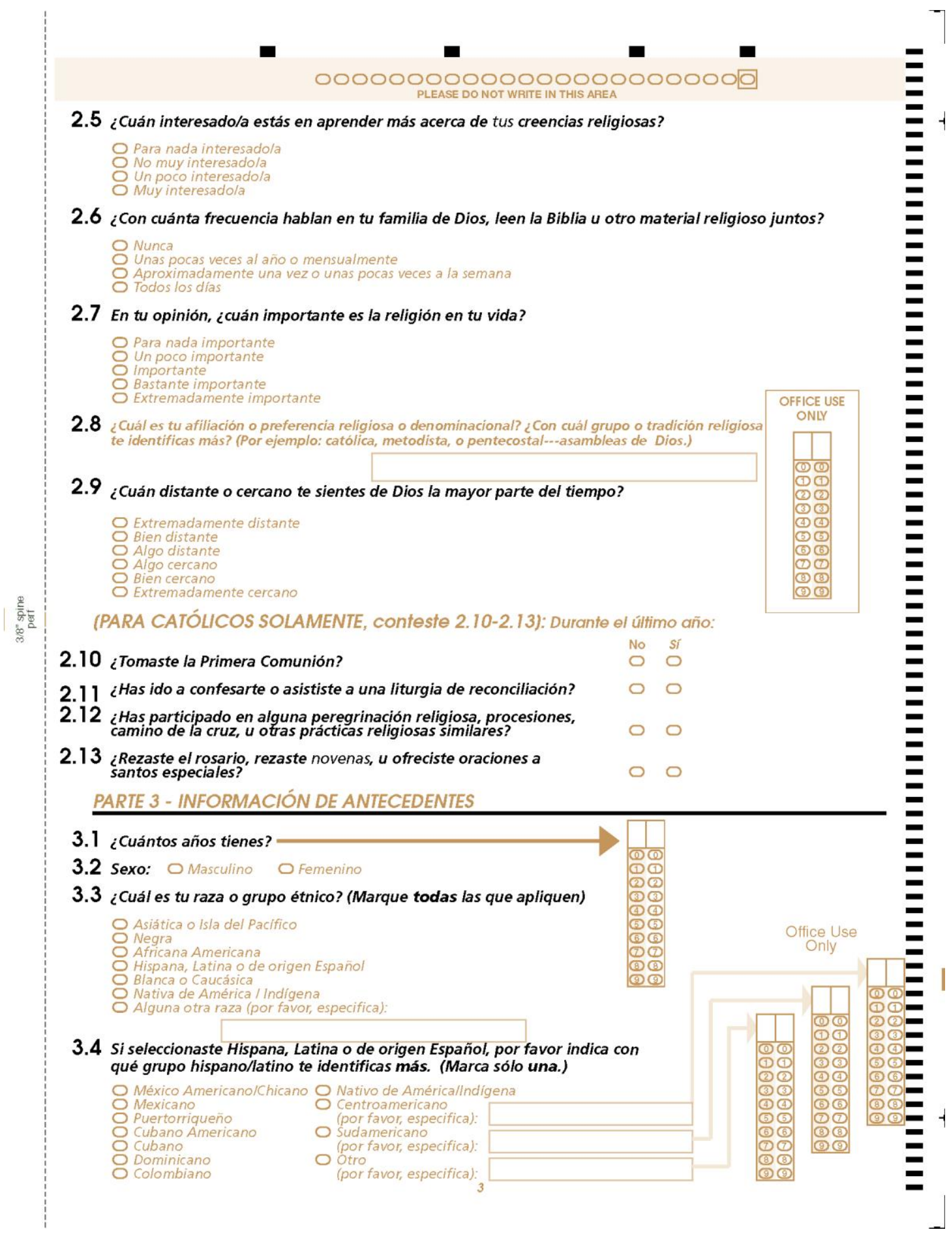




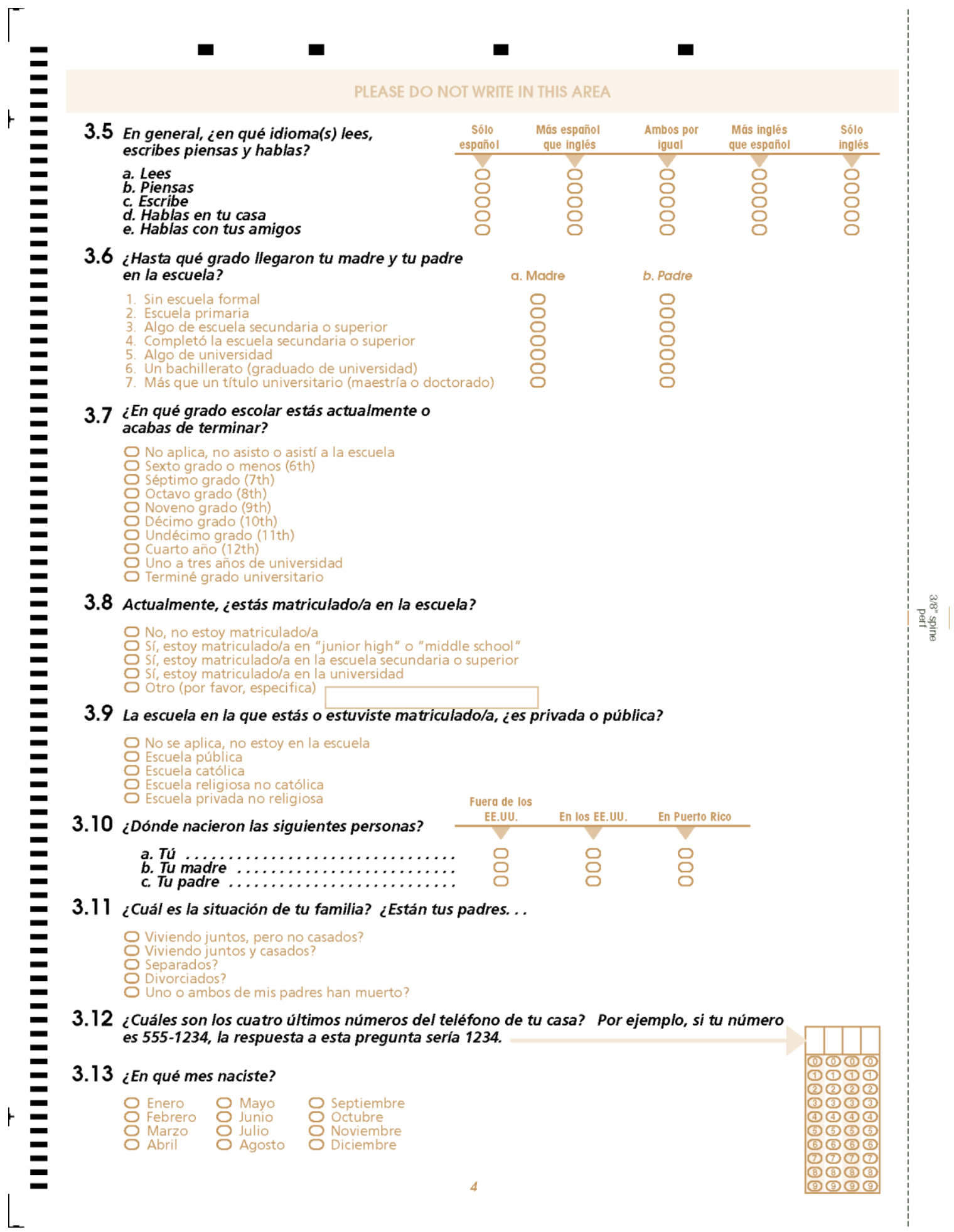




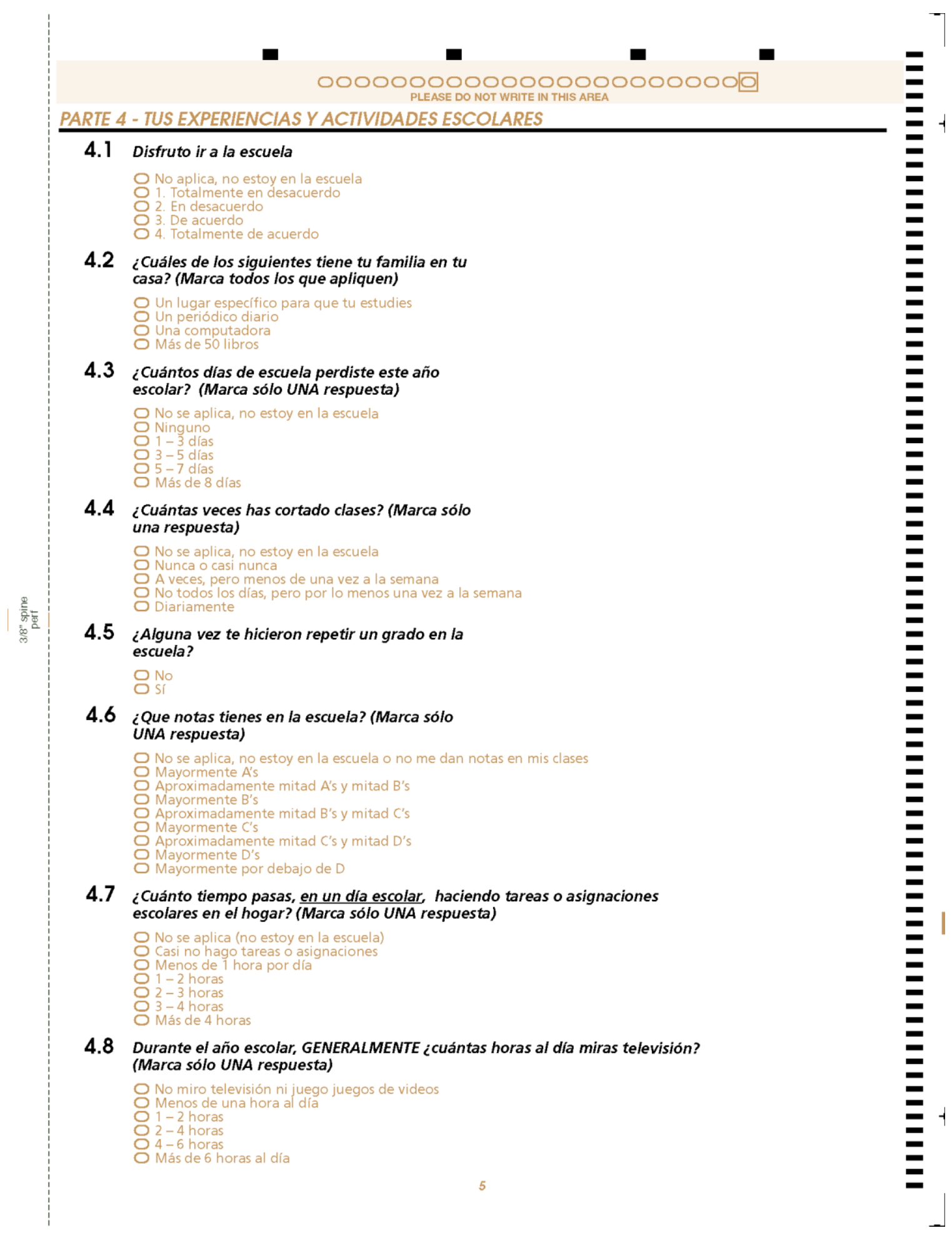




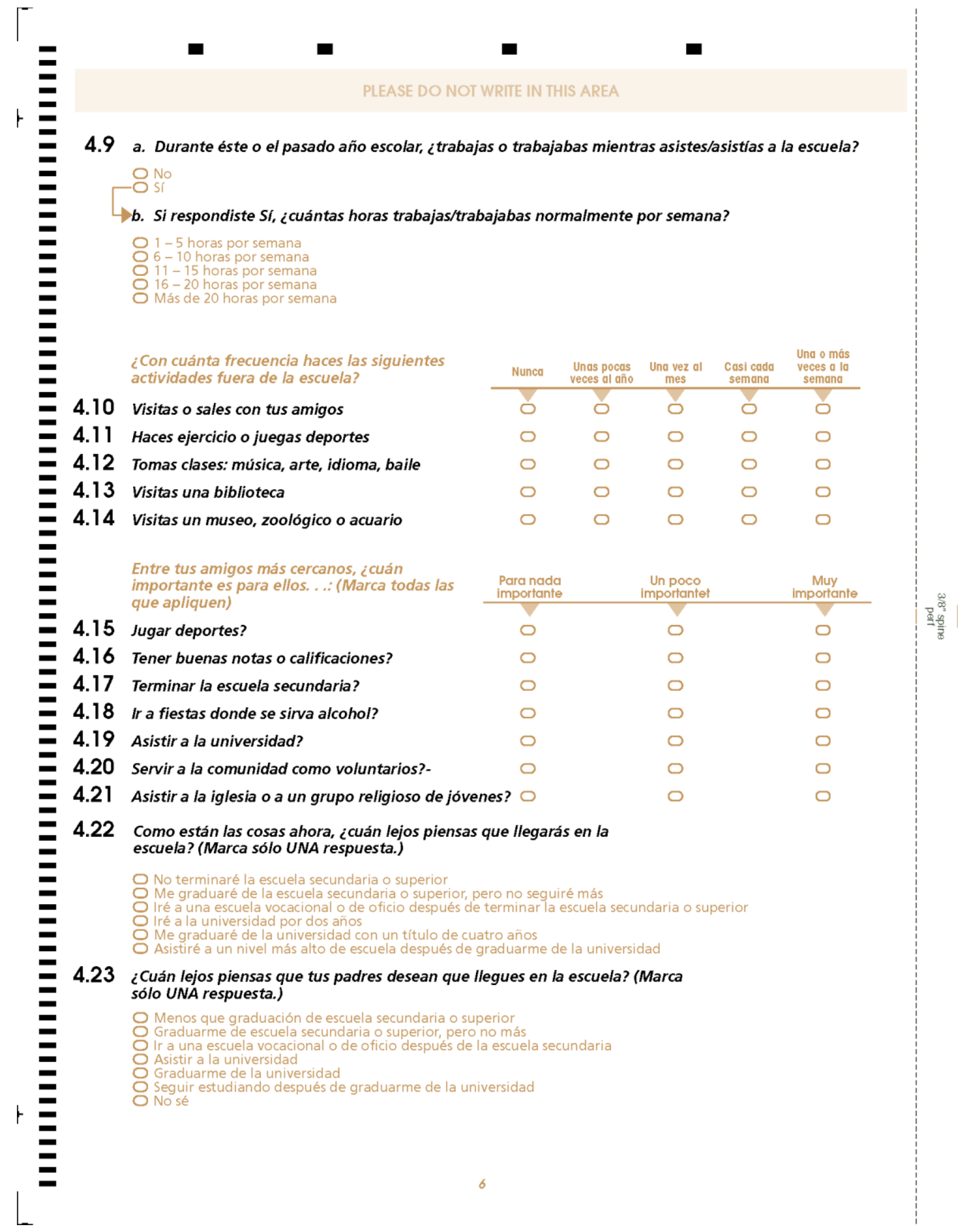




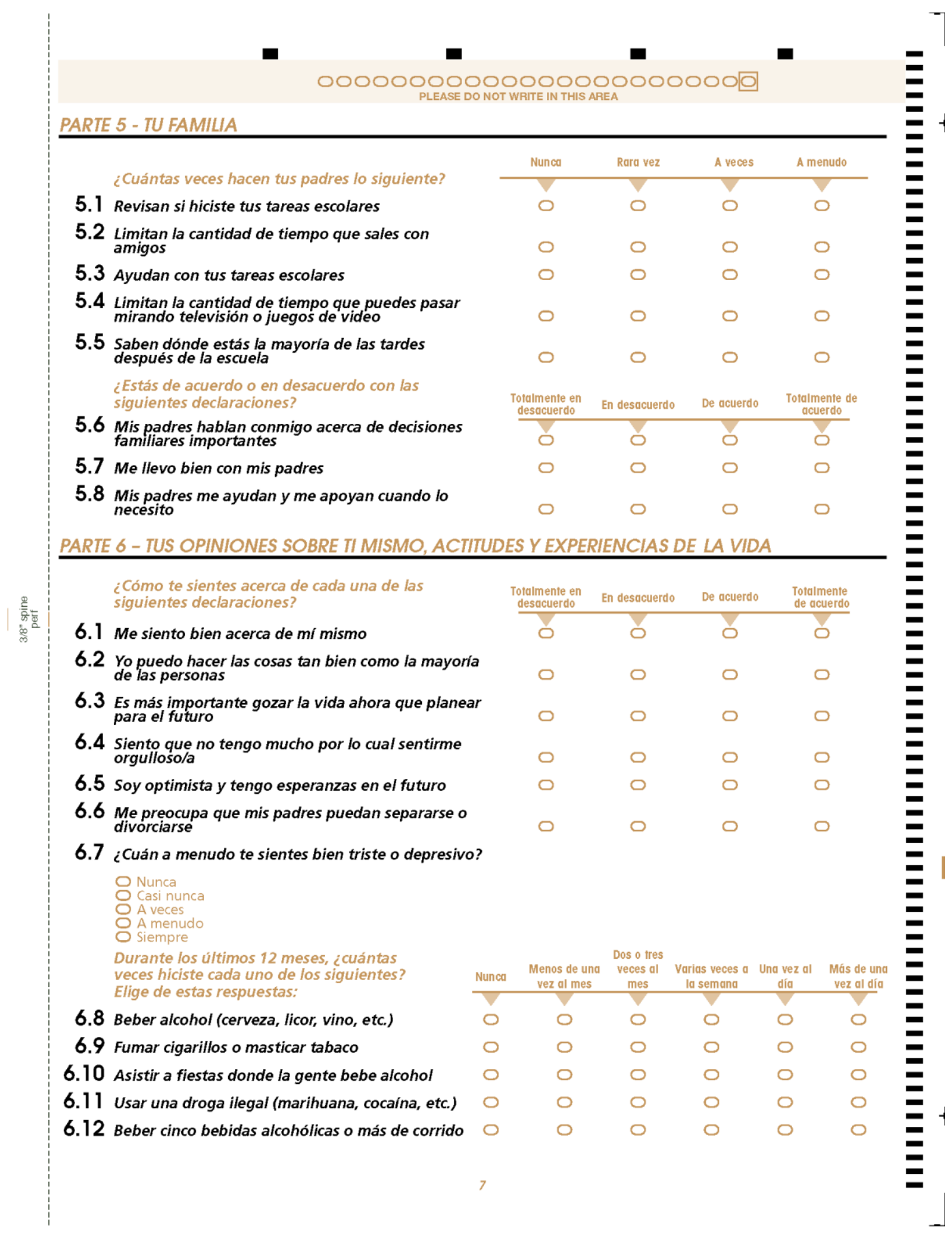




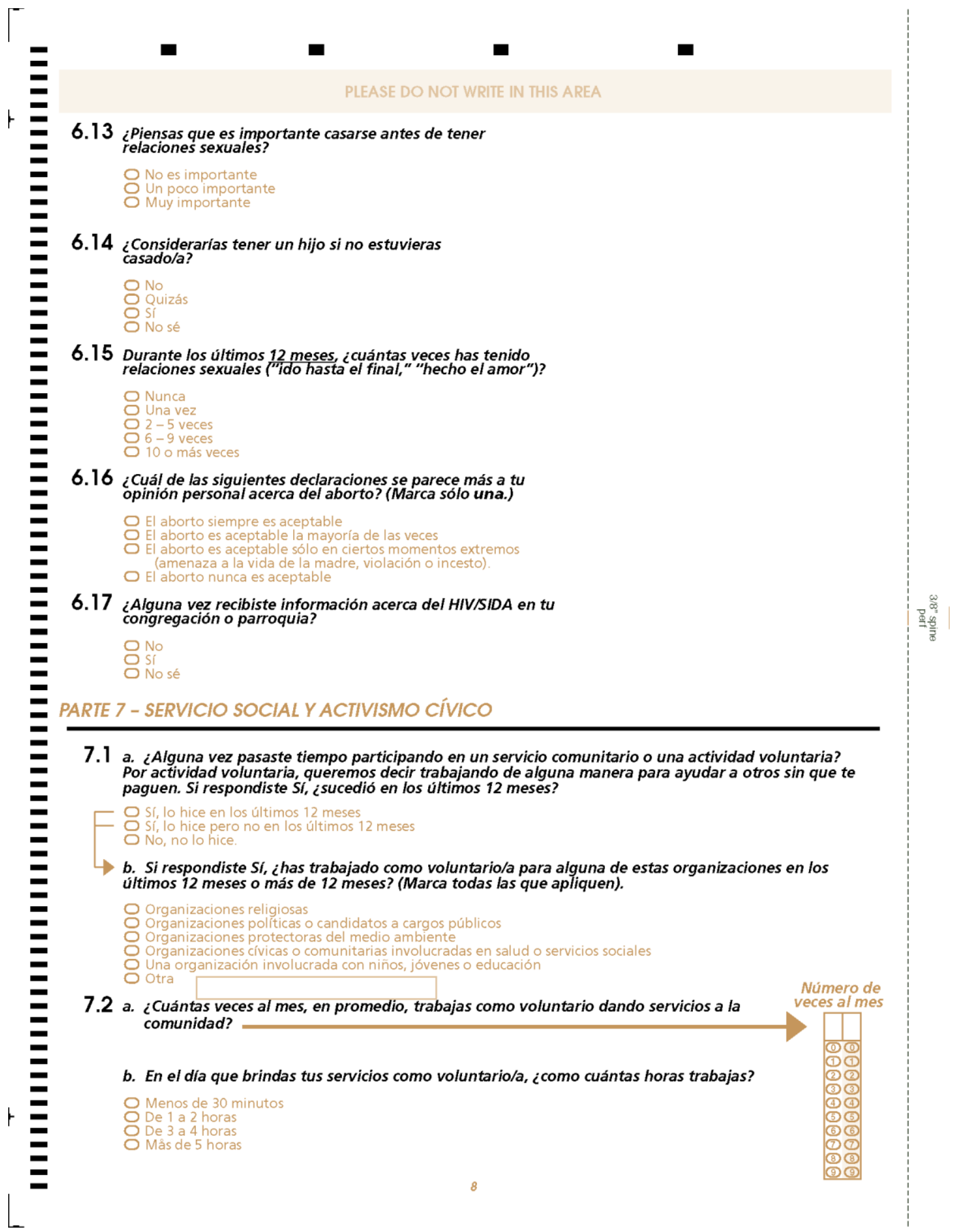




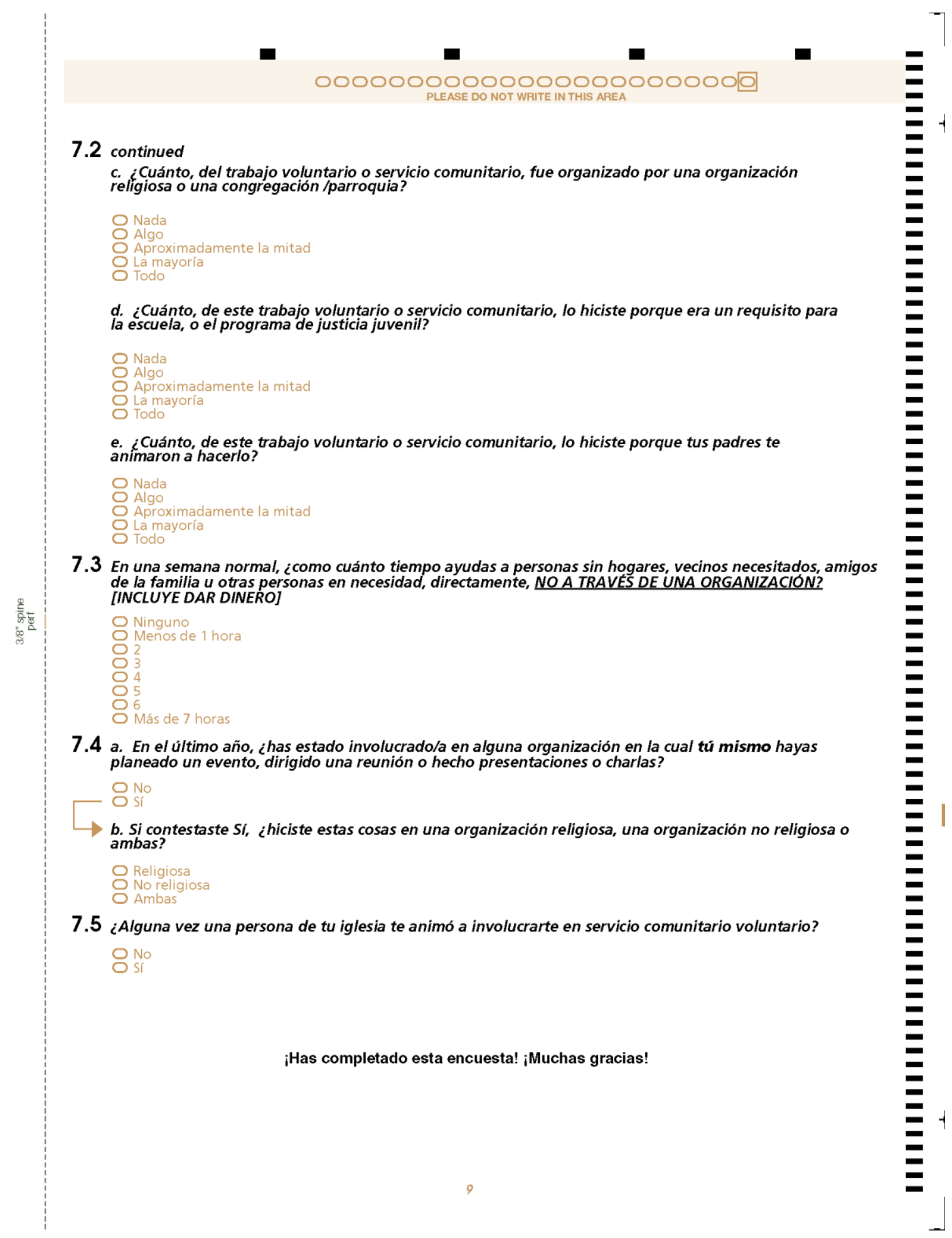




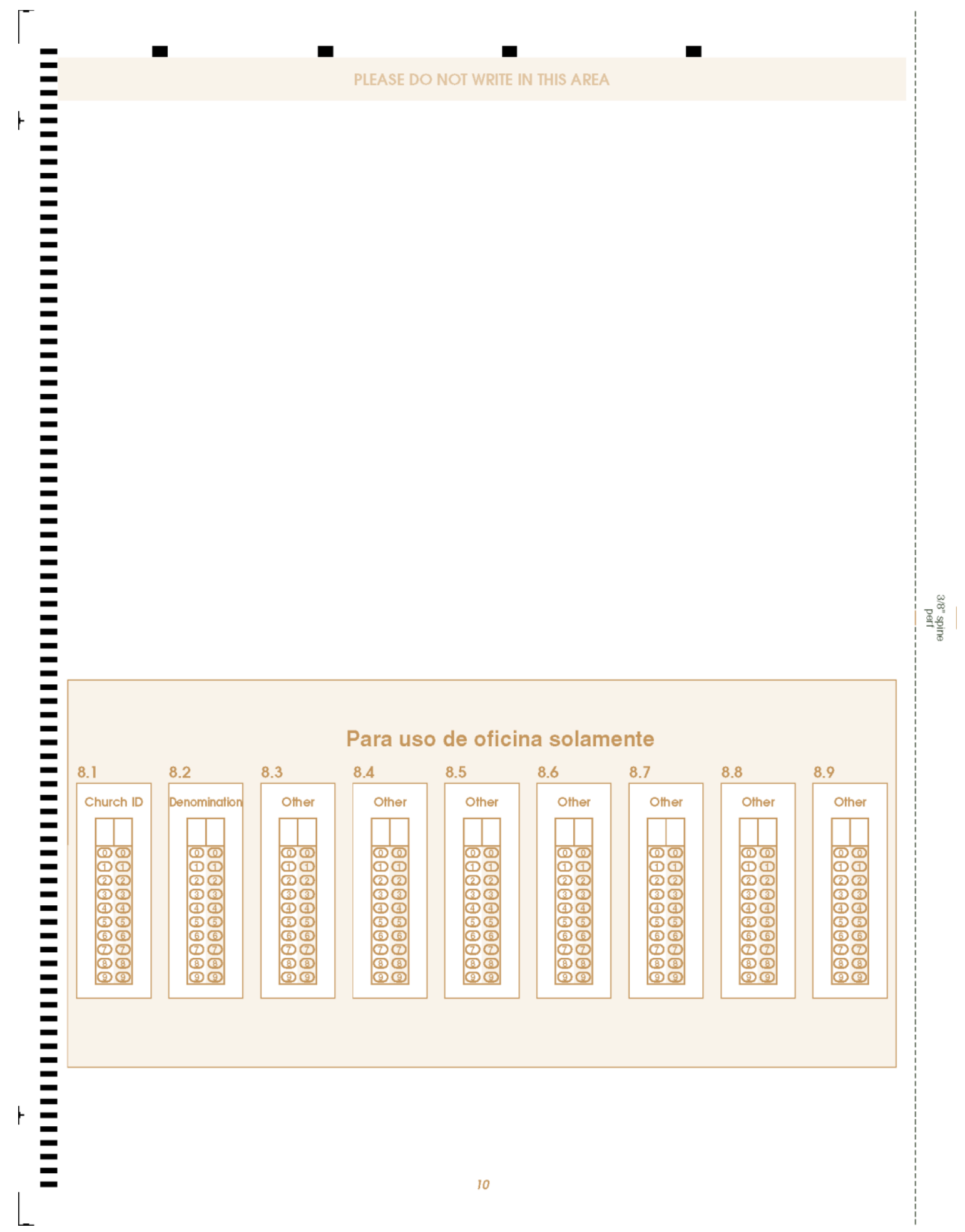




\section{APPENDIX B}

THE CHICAGO LATINO CONGREGATIONS STUDY (CLCS) METHODOLOGICAL CONSIDERATIONS REPORT 


\title{
the Chicago Latino Congregations Study (CLCS): METHOdOLOGICAL CONSIDERATIONS
}

\author{
RebecCA BuRWELL \\ EDWIN I. HERnÁNDEZ \\ MILAgros PeÑa \\ JEFFREY SMITH \\ DAVID SIKKINK
}

May 2010

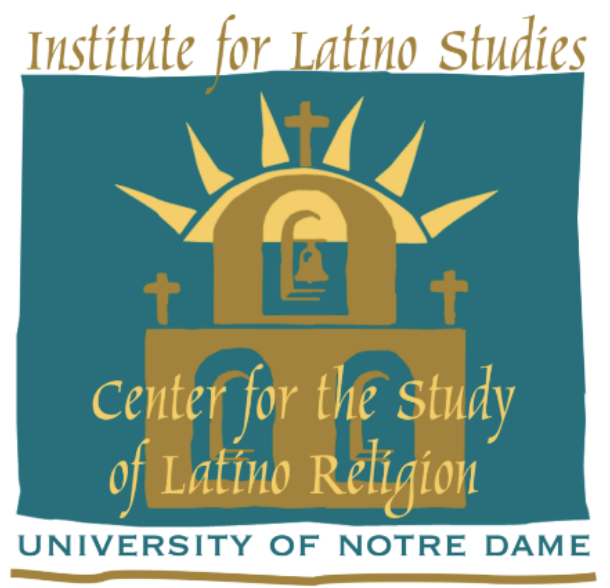

The Chicago Latino Congregations Study (CLCS) was made possible by generous grants from The Pew Charitable Trusts, The Richard and Helen DeVos Foundation, the Louisville Institute, and the Annie E. Casey Foundation. 


\section{Table of Contents}

Introduction

Part I: Sampling Frame

Part II: Survey Instruments and Data Collection Process

Part III: Survey Instrument Comparison and Weighting

Part IV: Qualitative Data and Analysis

16

Appendix A: Categorization of Denominations

Appendix B: Focus Group Interview Schedules

Appendix C: Protocol for In-Depth Interviews with Adult Congregants on Religious Switching and Religious Identity

Appendix D: Field Note Guide for Observations at Latino Churches 


\section{Introduction}

Completed in early 2007, the Chicago Latino Congregations Study (CLCS) - a multi-level, comprehensive study of Latino congregations in metropolitan Chicago that includes surveys of clergy, lay leaders, and congregants - provides a unique, in-depth window into Latino Christianity. The CLCS was designed to explore the following aspects of Latino congregational life:

1. The growth and vitality of Latino congregations, including the influence of clergy, worship style, social outreach, and youth and family ministry programs on congregational outcomes.

2. The extent of community services provided by Latino congregations, with a particular focus on the impact of Latino congregations on the spiritual and material well-being of needy families.

3. The formal and informal ways that Latino churches are networked with other faith-based organizations and community agencies, and how these networks improve the delivery of services by nurturing successful strategies for needy families.

4. The role of Latino church leaders, whether clergy or laity, in sustaining spiritually vibrant and socially engaged congregations, and the professional development needs of church leaders.

Other questions the CLCS is designed to address include: What are the characteristics of members and leaders of Latino congregations? What are the religious practices of youth and adult Latino churchgoers, and how do these practices impact their family lives, educational outcomes, and civic engagement? What explains religious switching among Latinos/as; for example, conversion from Catholic to evangelical Protestant congregations? To what extent and in what ways are Latino/a religious leaders and congregants engaged in civic life? In what activities are community-oriented Latino/a ministers engaged? How does leadership style impact whether congregants take action in their communities? What are the contours of Latino churchgoers' political attitudes and behaviors?

The density of Latino neighborhoods in the Chicago metropolitan area offers a unique opportunity to conduct an investigation into the characteristics and outcomes of Latino congregations. The scope of the data collection process and the diversity of questions and issues addressed across three levels of analysis - the laity, the leadership, and the congregation - make the CLCS the largest and most complex study of Latino congregations to date.

This methodological report is divided into four sections. First, we discuss the sampling frame; second, survey instruments and data collection; third, weighting; and, fourth, qualitative data and analysis. The first section explains how the project constructed a comprehensive list of Latino congregations in Chicago. The second briefly describes the survey instruments, issues related to data collection, and the different samples collected. The third section compares the samples using relevant statistics and describes the weights applied to each sample. The fourth and final section describes the qualitative design of the study, which included focus groups, interviews, and other field research. 


\section{Sampling Frame}

The CLCS focused on the universe of Latino Christian churches in the Chicago metropolitan area. The researchers concluded that limiting the research to the Chicago city limits would artificially exclude some of the major concentrations of Latinos/as in the area. Given the growth and expansion of the city's Latino population into nearby suburbs, the researchers expanded their geographic reach to include the towns of Berwyn and Cicero-adjacent suburbs with 38 percent and 77 percent Latino populations, respectively. The geographical proximity of both of these towns and their important historical connections to Chicago makes these communities virtually indistinguishable from the city of Chicago. ${ }^{1}$ They are also the most common destinations for Latinos/as who move out of the city and into the surrounding areas.

The next step was to develop for this geographic area a sampling frame of Catholic, Mainline Protestant, Evangelical, and Pentecostal congregations that were Latino. ${ }^{2}$ Developing a sampling frame included two challenging tasks: 1) defining the sampling frame, including choosing a definition of "Latino congregation" that would best suit the purposes of the study; and 2) constructing a list of congregations within the defined geographic area.

The researchers first confronted the challenge of what qualifies a congregation as "Latino." While self-identification as a Latino congregation is a reasonable definition, some churches may have a large or even majority population of Latinos/as and yet not define themselves as a Latino church. This may be especially the case for Catholic churches, which may self-identify as simply "Catholic" (rather than "Latino Catholic") in view of Catholic tradition and their connections to the broader Catholic Church. The prevalence of large Catholic parishes with a significant Latino presence also raised the question of congregations that serve a large number of Latinos/as who nonetheless do not comprise a majority of the parishioners. For example, the researchers would not want to overlook the experiences of 2,000 Latino/a churchgoers because they attend a Catholic parish of, say, 5,000 members. Though Latino/a attendees might not comprise a numerical majority in a large parish, the parish is nonetheless a significant Latino-serving congregation.

In light of this complexity, the researchers ultimately defined their sampling frame of "Latino congregations" in terms of the percentage of Latinos/as in the congregation - a statistic that could be attained with relative ease and accuracy during screening interviews with congregational informants. The threshold for inclusion for Protestant congregations was that at least 50 percent of its congregants be Latino/a; for Catholic parishes, inclusion in the sampling frame was limited to churches in which Latino/as made up at least 30 percent of parishioners.

Next, the researchers attempted to construct a list of all Latino congregations within the geographic area. Using a diverse set of sources in order to capture as closely as possible the total population of Latino congregations in the Chicago metro area, the CLCS efforts included the following steps:

\footnotetext{
${ }^{1}$ John P. Koval, Larry Bennet, Michael I. J. Bennett, Fassil Demissie, Roberta Garner, and Kiljoong Kim, eds. The New Chicago: A Social and Cultural Analysis (Philadelphia: Temple University Press, 2006).

${ }^{2}$ Religious groups such as Jehovah's Witnesses, The Church of Jesus Christ of Latter-day Saints, and groups that fit the classification of new religious movements were not included.
} 
1) Church lists obtained from various organizations and research efforts.

Researchers solicited lists of Chicago Latino churches from a wide variety of organizations. Lists were supplied by the following: a) 25 denominational or church councils; b) 5 pastoral associations, coalitions, and para-church organizations; c) 5 community organizations; d) the Mayor"s office and the office of a local alderman; and e) other research on Chicago-area churches. The research lists included churches gleaned from the Chicago Latino household survey that was conducted through the University of Notre Dame's Institute for Latino Studies in 2003. In that study, randomly selected Latinos/as in Chicago who were involved in a congregation reported the name and location of their church. Another important church list was provided by Dr. Wilbur Zelinsky of Penn State University, who conducted a street-by-street inspection of houses of worship in Chicago in 1999. From an overall list of Chicago congregations, Dr Zelinsky gleaned 500 congregations that appeared to be Latino (based on congregation name). A third list came from Dr. Lowell Livezey`s study of Chicago churches in the early 1990s, and a fourth was compiled by Dr. Juan Sandoval of Northwestern Iniversity in 2003 using phone book listings $(\mathrm{N}=769)$. While each list had limitations, together the lists greatly strengthened the likelihood of a nearly complete list of the universe of Latino churches.

2) Physical inspections of growing Latino neighborhoods and new dispersion areas.

Researchers did street-by-street inspections in targeted areas to identify churches. This effort was concentrated in ten zip codes that had experienced significant growth in their Latino populations over the prior ten years. Zip codes were included that, according to the US Census, had experienced between ten and fifty percent growth in Latino population.

CLCS intensified efforts to find churches in these newer dispersion areas for two reasons. First, newer waves of immigrants settling in these areas include many people from Central American countries, which, while still majority Catholic, have seen considerable growth in newer Pentecostal and independent church movements. ${ }^{3}$ Since these churches tend to be newly established and unconnected to US-based church councils, it was possible they would not have appeared on the existing lists from which the master list of Latino congregations was built. Second, the attempt to identify Latino Catholic parishes in these areas is more difficult using official Archdiocesan lists. The Archdiocese identified parishes as "Latino" only if they had an Hispanic Ministries program. The relative newness of the I atino growth in parishes in newer dispersion areas made it likely that such programs had not yet been established. Thus it was important to use physical inspections in these areas to capture parishes with significant numbers of Latino congregants. ${ }^{3}$ Pew Forum on Religion \& Public Life. 2006. "Spirit and Power: A 10-Country Survey of Pentecostals."
Washington DC, October. 


\section{3) List verification.}

After combining these various lists into one, the researchers cross-referenced and eliminated duplicates, which resulted in a master list of 670 churches. If the researchers were not sure whether a listed congregation met the definition of a Latino church, they called the congregation to confirm. They also verified the existence of a randomly selected list of congregations in zip codes in areas of high ( 50 pereent or more) and middle (25-49 percent) Latino population densities by physically inspecting the selected churches. In total, they conducted physical inspections of 425 of the 670 churches in 20 out of the 36 zip codes on the master list, including the 10 new dispersion areas. In addition, they asked a group of "insiders"-leaders representing various constituencies within the diverse Latino religious community in Chicago - to verify the list.

\section{4) Final cleaning of the list.}

Through the physical inspections, researchers eliminated churches that did not fall within their established definition of a Latino church or that fell outside of the study's geographic area. The researchers then eliminated congregations that, when contacted to participale in the study, did not meet the definition of a Latino church. After these efforts, the final master list was reduced from 670 to a total of 606 Latino churches in Chicago, Berwyn, and Cicero. From this final list, the CLCS drew samples for the different phases of the study.

Based on survey data collected from the churches on this list as well as information provided by denominational offices, the religious tradition breakdown of the final 606 churches was as follows: 20 percent Catholic, 13 percent Mainline Protestant, 21 percent Evangelical, 33 percent Pentecostal, and 14 percent unknown. 


\section{Survey Instruments and Data Collection Process}

To ensure a broad denominational representation of Latino congregations in the sample, the researchers stratified the 606 churches by religious tradition. Five religious traditions were defined in the stratum; Catholic, Mainline Protestant, Evangelical, Pentecostal, and Unknown (see Appendix A for a breakdown of the religious tradition categories). 100 of the churches were then randomly sampled from each religious category in proportion to its relative representation within the total sample, and set aside for the longer, more intensive phase of the survey.

Several survey instruments were designed for the multiple samples in the CLCS design. The complete text of each of the survey can be found in the appendix:

Survey 1: A short mail survey sent to Latino/a lay and professional ministers in 506 of the 606 identified Latino churches.

Survey 2: A longer structured survey of Latino/a lay and professional ministers at the random sample of 100 churches, conducted via face-to-face interviews and recorded on a standardized instrument.

Survey 3: A self-administered instrument left with each sampled minister who participated in the in-person interview (i.e., respondents to Survey 2).

Survey 4: A survey of adult churchgoers administered on-site at the sampled churches whose ministers participated in Surveys 2 and 3.

Survey 5: A survey of youth churchgoers administered on-site at the sampled churches whose ministers participated in Surveys 2 and 3.

\section{II.1 Phase I: Population Survey}

After setting aside the random sample of 100 churches, the remaining 506 Latino congregations on the master list were targeted for the population survey. Of those, 52 were later dropped since they had incorrect addresses or had recently moved. The researchers mailed Survey 1 to the remaining 454 congregations. Those that did not complete the survey on the first request received a second mailing of the survey. Excluding duplicates, these efforts netted 65 completed surveys. Compared to the population of Latino churches, completed cases for Survey 1 slightly overrepresented Catholic parishes and underrepresented Pentecostal.

To help improve the response rate and offset this denominational imbalance, the researchers distributed Survey 1 at an event held for Pentecostal ministers in the metropolitan Chicago area. This event was organized by a network of six Pentecostal councils that together include one-third of all Pentecostal congregations in the city. ${ }^{4}$ All of the Latino/a ministers in the greater Chicago area who belong to these councils were invited to the event. Approximately 100 people attended,

\footnotetext{
${ }^{4}$ The six councils are: Church of God, Mission Board; Church of God, International Mission; Assembly of God; Latin American Council; Assembly of Christian Churches; and Assembly of Pentecostal Churches of Jesus Christ.
} 
including ministers and their spouses. This event supplied 19 unduplicated surveys from leaders of congregations that were on the project's initial master list of churches, and brought the combined total of responses to Survey 1 to 84 congregations. ${ }^{5}$ It should be noted that though these additional Pentecostal congregations helped increase both the size of our sample and the proportion of Pentecostal responses, the surveys collected at this event were not randomly selected and bias the sample towards Pentecostal churches that are active participants in these six large councils.

\section{Phase II: The Sampled Latino Congregations}

\section{A. Ministerial Surveys (Surveys 2 and 3 )}

Phase II was more multifaceted and hence time-consuming than Phase I. Researchers first called religious leaders in the 100 randomly sampled churches. They typically followed up with a visit either to the church office during the week or after weekend services. If the minister could not be accessed via phone or a visit to the church, the research team enlisted the help of area Latino/a religious leaders to gain access. In addition, each minister was sent a letter introducing the project, signed by the Principal Investigator. When introducing the project to the religious leaders of sampled churches, research assistants followed a script that addressed the importance of the study as well as confidentiality issues.

Of the 100 sampled congregations in Phase II, 49 churches in total did not respond. ${ }^{6}$ Leaders at 34 of these churches refused to participate and among the remaining 15 non-respondents, there were three reasons for non-cooperation: the church was in pastoral transition and the lay leadership was unwilling to cooperate; the church had merged with another church or closed its doors between the time of finalizing the sampling frame and the initial contact; or the researchers were unable to contact the leadership of the church after multiple attempts. For each nonresponding church, a replacement church was chosen that matched as closely as possible the denominational affiliation, size, and geographic proximity of the non-responding church. As Table 1 shows, 22 of the 34 refusals were eventually replaced with other congregations as were 9 of the 15 churches that were in transition or otherwise unreachable.

In all, leaders at 82 churches ( 51 original and 31 replacement) completed both of the ministerial surveys in Phase II (Survey 2 - the face-to-face interview, and Survey 3 - the self-administered follow-up survey). Assuming that replacement churches closely matched the non-responding churches on important dimensions leads to a response rate of 82 percent for this phase of the study. Congregations among the Catholic subgroup had a slightly better response rate than those in the Protestant and unknown categories. This most likely reflects the fact that the culture and structure of Catholic parishes is generally more accessible to researchers, and that the parishes tended to know and trust the University of Notre Dame, the institutional sponsor of the study.

\footnotetext{
${ }^{5}$ A number of additional surveys collected at the event came from leaders who had previously mailed in a response, a leader from a church at which another leader had already returned the survey, and leaders whose congregations were outside of the geographical area of the study. None of these surveys were included in the final data set.

${ }^{6}$ Some of these non-responders were present at the Pentecostal church council event described above and wound up completing the Phase I survey at that event and are thus included in that phase of the data rather than Phase II.
} 
Table 1

Non-Response Congregational Distribution

\begin{tabular}{|c|c|c|c|c|c|}
\hline & Replaced & Not Replaced & Total & $\begin{array}{c}\% \text { of } \\
\text { Subgroup }\end{array}$ & $\%$ Replaced \\
\hline \multicolumn{6}{|c|}{ Nature of Non-Response } \\
\hline Refusal & 22 & 12 & 34 & - & - \\
\hline In Transition & 4 & - & 4 & - & - \\
\hline Closed/Unreachable & 5 & 6 & 11 & - & - \\
\hline Total & 31 & 18 & 49 & - & - \\
\hline \multicolumn{6}{|l|}{ Denomination } \\
\hline Catholic & 6 & 0 & 6 & $30 \%$ & $100 \%$ \\
\hline Mainline & 5 & 2 & 7 & $58 \%$ & $71 \%$ \\
\hline Evangelical & 10 & 2 & 12 & $57 \%$ & $83 \%$ \\
\hline Pentecostal & 6 & 10 & 16 & $48 \%$ & $38 \%$ \\
\hline Unknown & 4 & 4 & 8 & $57 \%$ & $50 \%$ \\
\hline Total & 31 & 18 & 49 & $49 \%$ & $63 \%$ \\
\hline
\end{tabular}

Only one set of survey instruments was completed at each cooperating church. Though senior pastoral staff members were the most likely informant, on some occasions the researchers collected data from professional and lay ministers who maintained primary responsibility for the Latino community and ministries within a congregation. Lay informants were more likely in large Catholic parishes in which the priests were not Latino. In that case, the researchers targeted the highest-ranking Latino/a religious leader. While only one respondent from each congregation completed the questions on leadership in the survey instruments, at times, particularly in larger congregations, it was appropriate to ask other leaders for information pertaining to budgetary or programmatic issues. But in every congregation, the individual-level data about the religious leader came from the highest-ranking Latino/a on staff, whether lay or ordained.

The team invested considerable resources in order to gain cooperation from the sampled congregations. On average, the researchers spent 10 hours securing an interview with a minister. It was particularly difficult to contact bi-vocational ministers-i.e., those who have full- or parttime jobs in addition to their pastorate responsibilities. Researchers often visited a church 2 to 3 times before being able to complete an interview with a minister. This meant visiting ministers after late-night prayer meetings or on Sundays, or waiting for ministers after attending long weekend services. Gaining ministers' interest and trust in the study was also difficult since many of the Pentecostal and Evangelical ministers were not familiar with the University of Notre Dame and were somewhat suspicious of the research team. Ministers with large numbers of undocumented immigrants in their congregations were often hesitant to allow outside researchers to ask questions of their congregants. The research assistants on the team were mostly Latino/a and conversant in Spanish, and had religious backgrounds representing Catholic, Pentecostal, and Mainline Protestant traditions. These qualifications helped ease some of the entrée issues. The fact that 82 religious leaders did participate in Phase II of the project and that many of these participants were from small, independent churches and denominations that are typically hard to access demonstrates that these intensive efforts made an important difference. The result is a 
unique dataset that is unusual in its representation of the religious diversity of the population of Latino Christian congregations and the very difficult to reach religious communities of small and Pentecostal Latino churches.

\section{B. Surveys of Adults and Youth in Latino Congregations}

In addition to the face-to-face interviews and self-administered minister instruments in this phase of the study, researchers administered separate instruments to adult and youth attendees (Survey 4 and 5, respectively) at the congregations which completed leader surveys 2 and 3 . If possible, congregations were asked to distribute the survey during their main worship service to every person older than 12 years. The congregants would then complete the survey before leaving the church. Altogether, 2,368 adults at 74 of the randomly sampled congregations and 607 youth at 63 of the randomly sampled congregations completed Surveys 4 and 5.

Individual-level response rates varied widely by congregation. Some ministers - mostly at the non-Catholic congregations - strongly encouraged everyone to complete the instrument before leaving a church service. Other churches did not agree to conduct the survey during a main religious service. Particularly in Catholic parishes, pastors would ask those attending the service to find researchers in a back room of the church building. Based on the field researchers' estimates of attendance at each worship service in which participants were invited to complete the survey, the response rate across all cooperating congregations was 25 percent. In other words, about 2,368 out of roughly 9,500 attendees completed adult or youth surveys. In general, smaller congregations had better attendee response rates than larger congregations. The average response rate at the congregational level was therefore higher. In the average participating congregation, about 55 percent of those attending the worship service completed the survey.

This methodology skews toward congregants that are in smaller congregations and that are more active in the congregation. Of those that completed Survey 4 and 5, over 96 percent of adult and 90 percent of youth respondents reported attending their congregation at least once a month.

Respondents in smaller churches, in which the response rates were higher, are overrepresented in the final sample compared to respondents in many of the large, especially Catholic, congregations.

Table 2 shows the denominational breakdown of adult and youth respondents based on the religious tradition of the congregation that the respondent attended.

Table 2

Denominational Affiliation of Youth and Adult Laity

\begin{tabular}{|l|c|c|c|c|}
\hline & Adult (N) & Adult (\%) & Youth (N) & Youth (\%) \\
\hline Catholic & 679 & $29 \%$ & 193 & $32 \%$ \\
\hline Mainline & 110 & $5 \%$ & 18 & $3 \%$ \\
\hline Evangelical & 696 & $29 \%$ & 181 & $30 \%$ \\
\hline Pentecostal & 883 & $37 \%$ & 215 & $35 \%$ \\
\hline Total & $\mathbf{2 , 3 6 8}$ & & $\mathbf{6 0 7}$ & \\
\hline
\end{tabular}




\section{Survey Instrument Comparison and Weighting}

One important issue the research team faced was whether the Phase I and Phase II data from congregational informants could be combined to increase the overall sample size for the leader data. Almost all of the questions on the Phase I survey instrument were replicated in one of the two Phase II ministerial survey instruments. In a few cases, the response categories were simplified in Phase II to reduce respondent burden. The survey parallels allow analysts to combine the responses of congregational leaders in Phase I with those in Phase II. Considering only the questions in common across the leader surveys, 166 (84 in Phase I and 82 in Phase II) of the 606 Latino churches in the Chicago area are represented in the CLCS, or 27 percent of the entire population of Latino churches.

The questionnaires for the leader surveys in Phase II included a number of follow-up questions to the Phase I questions as well as questions unique to that instrument. Comparisons of the Phase I and Phase II minister responses revealed some demographic differences that were statistically significant. In particular the national origin and generation in the United States of the pastors differed between Phase I and II respondents (see Table 3). These differences are most pronounced among Catholics, in part because a high percentage of white non-Hispanic priests responded to the Phase I mail-in survey while there were a higher number of Latino/a lay leaders in the Phase II sample. Un-weighted analyses would need to take this overrepresentation into account. Due to the small sample size and large number of categories, the differences among the Phase I and Phase II Protestants often depend on only 1 or 2 respondents. 
Table 3

Un-Weighted Comparisons of Demographic Breakdown of Phase I and Phase II Minister Responses

\begin{tabular}{|c|c|c|c|c|c|}
\hline & \multicolumn{2}{|c|}{ Protestant } & \multicolumn{2}{|c|}{ Catholic } & \multirow[b]{2}{*}{$\begin{array}{l}\text { Merged } \\
\text { Samples }\end{array}$} \\
\hline & $\begin{array}{l}\text { Phase I } \\
(\mathrm{N}=54)\end{array}$ & $\begin{array}{c}\text { Phase II } \\
(\mathrm{N}=62)\end{array}$ & $\begin{array}{c}\text { Phase I } \\
(\mathrm{N}=\mathbf{3 0})\end{array}$ & $\begin{array}{c}\text { Phase II } \\
(\mathrm{N}=\mathbf{2 0})\end{array}$ & \\
\hline \multicolumn{6}{|l|}{ National Origin** } \\
\hline Puerto Rican & $48 \%$ & $34 \%$ & $7 \%$ & $15 \%$ & $31 \%$ \\
\hline Mexican & $13 \%$ & $19 \%$ & $17 \%$ & $65 \%$ & $22 \%$ \\
\hline European/White & $2 \%$ & $3 \%$ & $63 \%$ & $10 \%$ & $15 \%$ \\
\hline South American & $9 \%$ & $16 \%$ & $10 \%$ & $5 \%$ & $11 \%$ \\
\hline Central American & $7 \%$ & $18 \%$ & $3 \%$ & $0 \%$ & $10 \%$ \\
\hline Other Latino & $11 \%$ & $7 \%$ & $0 \%$ & $5 \%$ & $7 \%$ \\
\hline Missing/Other & $9 \%$ & $3 \%$ & $0 \%$ & $0 \%$ & $4 \%$ \\
\hline \multicolumn{6}{|c|}{ Generation in the USA* } \\
\hline First & $69 \%$ & $78 \%$ & $33 \%$ & $80 \%$ & $64 \%$ \\
\hline Second & $16 \%$ & $17 \%$ & $10 \%$ & $5 \%$ & $13 \%$ \\
\hline Third & $6 \%$ & $2 \%$ & $10 \%$ & $5 \%$ & $5 \%$ \\
\hline Fourth or more & $10 \%$ & $3 \%$ & $47 \%$ & $10 \%$ & $14 \%$ \\
\hline \multicolumn{6}{|c|}{ Educational Background } \\
\hline Less than BA & $52 \%$ & $45 \%$ & $3 \%$ & $35 \%$ & $39 \%$ \\
\hline BA degree & $18 \%$ & $15 \%$ & $7 \%$ & $20 \%$ & $15 \%$ \\
\hline Graduate degree & $30 \%$ & $40 \%$ & $90 \%$ & $45 \%$ & $46 \%$ \\
\hline \multicolumn{6}{|c|}{ Theological Orientation } \\
\hline Conservative & $41 \%$ & $36 \%$ & $3 \%$ & $10 \%$ & $28 \%$ \\
\hline Moderate & $41 \%$ & $50 \%$ & $60 \%$ & $50 \%$ & $49 \%$ \\
\hline Liberal & $7 \%$ & $8 \%$ & $27 \%$ & $20 \%$ & $13 \%$ \\
\hline Other/Missing & $11 \%$ & $6 \%$ & $20 \%$ & $10 \%$ & $10 \%$ \\
\hline \multicolumn{6}{|c|}{ Leadership Position $* * * *$} \\
\hline Clergy & $94 \%$ & $98 \%$ & $90 \%$ & $20 \%$ & $86 \%$ \\
\hline Lay Leader & $6 \%$ & $2 \%$ & $10 \%$ & $80 \%$ & $14 \%$ \\
\hline
\end{tabular}

Interestingly, although only 8 percent of Latinos/as in Chicago are Puerto Rican, 31 percent of Latino/a congregational leaders in this sample are so. This may simply reflect the fact that the sample does not represent the general Chicago Latino population but rather ministers of Latino congregations in Chicago. A high proportion of Latino Pentecostal and Evangelical congregations in the area have Puerto Rican pastors.

In spite of some differences across Phase I and II in the pastor survey (Table 3), a comparison of the congregations by phase of the study shows that they are quite similar in age, size, primary worship language, budget, and percent of congregants who are immigrants (see Table 4). Phase 
II congregations tend to be slightly younger, have a higher percentage of immigrants, and use Spanish in their worship life at somewhat greater frequency; however, these differences are not statistically significant.

Table 4

Un-Weighted Comparisons of Phase I and Phase II Congregations on Selected Demographic Variables

\begin{tabular}{|c|c|c|c|}
\hline & $\begin{array}{c}\text { Phase I } \\
(\mathrm{N}=82)\end{array}$ & $\begin{array}{c}\text { Phase II } \\
(\mathrm{N}=84)\end{array}$ & $\begin{array}{l}\text { Merged } \\
\text { Samples }\end{array}$ \\
\hline \multicolumn{4}{|l|}{ Year founded } \\
\hline Mean & 1944 & 1963 & 1954 \\
\hline \multicolumn{4}{|c|}{ Size of congregation two years ago } \\
\hline Median & 115 & 120 & \\
\hline \multicolumn{4}{|c|}{ \# Who regularly participate in religious life of congregation } \\
\hline Median & $100-150$ & $100-150$ & $100-150$ \\
\hline \multicolumn{4}{|c|}{ Language of primary worship service } \\
\hline Mostly/only Spanish & $56 \%$ & $66 \%$ & $61 \%$ \\
\hline Equally & $25 \%$ & $20 \%$ & $22 \%$ \\
\hline Mostly/only English & $19 \%$ & $15 \%$ & $17 \%$ \\
\hline \multicolumn{4}{|c|}{ Annual operating budget } \\
\hline$\$ 0-20 \mathrm{~K}$ & $14 \%$ & $15 \%$ & $14 \%$ \\
\hline$\$ 21-40 \mathrm{~K}$ & $8 \%$ & $11 \%$ & $9 \%$ \\
\hline$\$ 41-100 \mathrm{~K}$ & $27 \%$ & $27 \%$ & $27 \%$ \\
\hline$\$ 101-200 \mathrm{~K}$ & $16 \%$ & $17 \%$ & $17 \%$ \\
\hline$\$ 201-500 \mathrm{~K}$ & $22 \%$ & $26 \%$ & $24 \%$ \\
\hline$\$ 501 \mathrm{~K}+$ & $12 \%$ & $5 \%$ & $9 \%$ \\
\hline \multicolumn{4}{|c|}{ \% of Latino/a congregants who are immigrants } \\
\hline Less than $20 \%$ & $35 \%$ & $23 \%$ & $29 \%$ \\
\hline $21-40 \%$ & $7 \%$ & $14 \%$ & $11 \%$ \\
\hline $41-60 \%$ & $17 \%$ & $19 \%$ & $18 \%$ \\
\hline
\end{tabular}

This analysis finds important similarities between the average Phase I and Phase II congregation, despite the varying methods of data collection. We therefore conclude that on shared variables it is appropriate to merge the minister data from both phases into a combined minister sample $(\mathrm{N}=166)$.

Two weights were created for the data. The first is appropriate for the pastor data after merging Phase I and II pastor data. The second is created for the Phase II stratified sample. Creating the weights involved two steps. First, a weight was created to correct for non-response among the stratified Phase II sample. This weight ensures that each religious tradition is represented in the sample proportionate to the religious tradition distribution found in the population of Latino churches (see Table 5). 
Table 5

Comparison of the Population Universe of Latino Congregations in Chicago and Phase II Sample Weighting by Religious Family

\begin{tabular}{|l|c|c|c|c|c|}
\hline Religious Family & $\begin{array}{c}\text { Latino Church } \\
\text { Universe (N) }\end{array}$ & $\begin{array}{c}\text { Latino } \\
\text { Church } \\
\text { Universe (\%) }\end{array}$ & $\begin{array}{c}\text { Phase II } \\
(\mathrm{N})\end{array}$ & $\begin{array}{c}\text { Phase II } \\
\text { Weight }\end{array}$ & $\begin{array}{c}\text { Weighted } \\
\text { Phase II (N) }\end{array}$ \\
\hline Catholic & 120 & $19.80 \%$ & 20 & 0.81188 & 16.2 \\
\hline Mainline & 77 & $12.70 \%$ & 10 & 1.04191 & 10.4 \\
\hline Evangelical & 126 & $20.80 \%$ & 19 & 0.89734 & 17 \\
\hline Pentecostal & 198 & $32.70 \%$ & 23 & 1.16487 & 26.8 \\
\hline Unknown & 85 & $14.00 \%$ & 10 & 1.15017 & 11.5 \\
\hline Total & $\mathbf{6 0 6}$ & $\mathbf{1 0 0 . 0 0 \%}$ & $\mathbf{8 2}$ & & $\mathbf{8 2}$ \\
\hline
\end{tabular}

Subsequent research allowed the team to assign a denominational identity to almost all of the sampled congregations in the unknown category. With this information, final weights were created for the Phase II sample of congregations and the merged sample of ministerial surveys. These weights are described in Table 6.

Table 6

Denominational Weights for Phase II and Pastor Surveys (Merged Sample)

\begin{tabular}{|l|c|c|c|c|c|c|c|c|}
\hline & $\begin{array}{c}\text { Phase II } \\
\text { Weighted } \\
\text { by } \\
\text { Subgroup } \\
(\mathrm{N})\end{array}$ & $\begin{array}{c}\text { Phase II } \\
\text { Weighted } \\
\text { by } \\
\text { Subgroup } \\
(\%)\end{array}$ & $\begin{array}{c}\text { Phase II } \\
\text { Denom } \\
\text { Weight }\end{array}$ & $\begin{array}{c}\text { Denom } \\
\text { Weighted } \\
\text { Phase II } \\
(\mathrm{N})\end{array}$ & $\begin{array}{c}\text { Merged } \\
\text { Sample } \\
(\mathrm{N})\end{array}$ & $\begin{array}{c}\text { Merged } \\
\text { Sample } \\
(\%)\end{array}$ & $\begin{array}{c}\text { Merged } \\
\text { Denom } \\
\text { Weight }\end{array}$ & $\begin{array}{c}\text { Denom } \\
\text { Weighted } \\
\text { Merged } \\
(\mathrm{N})\end{array}$ \\
\hline Catholic & 16.2 & $19.80 \%$ & 1.00165 & 16.3 & 50 & $30 \%$ & 0.658512 & 32.9 \\
\hline Mainline & 12.1 & $14.70 \%$ & 0.87594 & 10.6 & 21 & $13 \%$ & 1.019126 & 21.4 \\
\hline Evangelical & 19 & $23.10 \%$ & 1.23587 & 23.4 & 25 & $15 \%$ & 1.898711 & 47.5 \\
\hline Pentecostal & 34.7 & $42.30 \%$ & 0.91737 & 31.9 & 70 & $42 \%$ & 0.921133 & 64.5 \\
\hline Total & $\mathbf{8 2}$ & $\mathbf{1 0 0} \%$ & & $\mathbf{8 2 . 1}$ & $\mathbf{1 6 6}$ & $\mathbf{1 0 0} \%$ & & $\mathbf{1 6 6 . 3}$ \\
\hline
\end{tabular}




\section{Summary of Quantitative Research Design and Cooperation}

The CLCS is a comprehensive quantitative study that focuses on Latino congregations. The cooperation rate, while modest by traditional standards, is very strong relative to the difficulty of enlisting Latino churches in research of any kind, especially given the nature of many Latino churches, which tend to be small, under-resourced, and suspicious of outsiders given the number of undocumented persons therein. More impressively, after careful substitution of nonresponding randomly sampled congregations, the CLCS is very likely to provide the most accurate representation of Latino congregations currently available. Adding to these strengths is the research design that combines individual with organizational level data - something that is not often available for congregations, and nearly unknown for Latino congregations. The response rates are admittedly low for the individual level CLCS surveys, but must be judged relative to the difficulty of the task and to the rapidly decreasing response rates for general individual level surveys in the American adult population. Finally, while the CLCS focuses on Chicago, the findings for Latino churches and laity here could help inform research on Latino congregations in other areas of the country. Given the size and importance of Chicago to the Latino community in the United States, the insights gained through analysis of the CLCS data are likely to hold for most areas of high Latino concentration. The unique, multi-level and comprehensive nature of the data collection effort in Chicago provides our first window into the vital and complex diversity of Latino churches in the US. 


\section{Qualitative Data and Analysis}

In addition to the quantitative data described above, researchers conducted extensive field observations of select Chicago-area Latino congregations.

\section{IV.1 Field Work at Phase II Congregations}

At four of the congregations from Phase II of the study, case studies were conducted to deepen the understanding of how Latino churches connect their congregants with other community groups to provide needed spiritual and material support, as well as how they work to strengthen families and their neighborhoods. The cases studies also sought to shed light on how churches attract, maintain, and engage congregants in the life of the church.

The primary qualitative work for the CLCS involved participant observation, focus groups, and unstructured interviews. This purposive sample was selected based on religious tradition and key research topics. One congregation each was selected to represent the denomination subgroups used throughout the study - Catholic, Mainline Protestant, Evangelical, and Pentecostal. In addition, the four congregations were selected since they were known among leaders of community-based organizations and Latino religious organizations as congregations that were very engaged in the Latino community. The selection was also informed by the analysis of the quantitative data. The selected churches were typical Latino congregations in terms of their emphasis on encouraging and strengthening family relationships, their work in the community especially on labor/work issues, the percentage of congregants who had switched within and between religious faith traditions, and the diverse range of individual and communal faith practices found therein. The cases studies were conducted in churches that were Catholic, Mennonite, Lutheran, and independent Pentecostal.

\section{A. Focus Groups}

Focus groups were arranged in each of the four congregations in order to better understand the communal life of Latino churches. Researchers conducted a total of 8 focus groups among the 4 targeted churches -3 with youth informants and 5 with adult congregants (see Table 7 for a breakdown by church).

Table 7

Focus Groups by Church and Age Group

\begin{tabular}{|l|c|c|c|c|}
\hline & Mennonite & Catholic & Pentecostal & Lutheran \\
\hline Adults & 1 & 1 & 2 & 1 \\
\hline Youth & 1 & 1 & 1 & 0 \\
\hline
\end{tabular}

A total of 77 people participated in the focus groups altogether. Each group had between four and eight participants who were recruited by researchers with the help of leaders of the congregations. The focus group interviews were conducted either in Spanish or English, depending on the preference of the group. Participants signed informed consent forms and were informed that their names and identifying information would remain confidential. 
The adult focus group discussions focused on the congregation's work in the community, congregants' individual and communal religious practices, and how the church connects congregants with the community. Focus group moderators also asked participants specific questions related to labor and work issues.

The youth focus group was designed to examine the relationship between youth and family, reasons for and the process of becoming involved in the church, types of community or social service work, and devotional practices and religious beliefs. See Appendix B for more information on the types of questions asked in adult and youth focus groups.

\section{B. Face-to-Face Interviews}

Researchers conducted five face-to-face unstructured interviews with adult congregants in the selected congregations. The interviews focused on religious identity, vitality, and religious switching (see Table 8 for a breakdown by church). The selected interviewees were identified by church leaders as very active in the congregation. The interviews at the Catholic parish were conducted with persons who were involved in the Charismatic movement. Interviews lasted between one and two hours. The protocol for in-depth interviews with adult congregants on religious switching and religious identity is available in Appendix C.

Table 8

Number of Face-to-Face Interviews Conducted at Each Church

\begin{tabular}{|c|c|c|c|}
\hline Mennonite & Catholic & Pentecostal & Lutheran \\
\hline 0 & 2 & 1 & 2 \\
\hline
\end{tabular}

All of the focus groups and interviews were recorded, transcribed, and translated (from Spanish to English) for content analysis.

\section{Participant Observation}

Additionally, researchers were participant observers in all four churches. This included attending worship services, youth events, Sunday school fairs, prayer meetings, Wednesday night Bible studies, and other community outreach events. Guidelines for participant observation are shown in Appendix D. 


\section{IV.2 ISSUE-SPECIFIC FIELD STUdY WORK}

Researchers also conducted two separate investigations of Latino-serving congregations in Chicago that focused on understanding the role of Latino congregations in social service provision and HIV/AIDS.

\section{A. Investigating the Role of Latino Churches in Social Service Provision}

As part of research for the Annie E. Casey Foundation on the role of Latino/a religious leadership in social ministries, the research team conducted two case studies of socially engaged churches in the city of Chicago - one a Mainline Protestant congregation and the other a Catholic parish. These case studies examined the ways, best practices, and challenges for church leadership of social service provision in Latino congregations. ${ }^{7}$

\section{B. Latino Churches and HIV/AIDS}

Lastly, the study included qualitative research at Latino churches involved in HIV/AIDS-related ministry. These unstructured and informal interviews with Protestant and Catholic lay-leaders and community workers, as well as field observations in the churches and community, provided rich insights into Latino congregational activity regarding HIV/AIDS and related issues.

The data collection included participant observation, interviews, and case studies that focused on HIV/AIDS communication and social service provision. As part of this effort, seven face-to-face interviews were conducted with two Latino/a clergy, four Latino/a lay-leaders, and one Latina community health worker. All interviewees were Protestant except for a Catholic lay-leader. Four men and three women were interviewed. Researchers used an open-ended interview schedule that included questions focused specifically on HIV/AIDS and church responses to HIV/AIDS and related issues.

In addition to observing congregational worship settings, researchers conducted field work at community events for World AIDS Day, at church health fairs, and at a church memorial service for unknown victims of HIV/AIDS. The researchers also participated in an HIV/AIDS training for Latino/a ministers, and attended a youth presentation at a Latino church on preventing HIV/AIDS. ${ }^{8}$

\footnotetext{
${ }^{7}$ For more information on this analysis see Leadership Matters: The Role of Latino/a Religious Leadership in Social Ministry. A report prepared for the Annie E. Casey Foundation. Edwin I. Hernández, Rebecca Burwell, Marciana Popescu, Milagros Peña, and Juan Carlos Rivera. March 2006. Available at: http://atinostudies.nd.edu/pubs/pubs/LeadershipMatters.pdf

${ }^{8}$ For more on these findings see Answering the Call: How Latino Churches Can Respond to the HIV/AIDS Epidemic: A Study of Latino Congregations in Chicago. Edwin I. Hernández, Rebecca Burwell, and Jeffrey Smith. Notre Dame, IN: The Institute for Latino Studies, June 2007. Available at: http://atinostudies.nd.edu/pubs/pubs/HIV_AIDS_Companion_WEB.pdf
} 
Appendix A:

Categorization of Denominations

\section{Catholic}

Mainline

Episcopal

Lutheran

Lutheran - ELCA

Presbyterian

Reformed Church in America

United Church of Christ

United Methodist

\section{Evangelical}

Baptist

Baptist - Southern

Baptist - General Conference

Mennonite

Church of the Nazarene

Christian and Missionary Alliance

Evangelical Free

Evangelical Covenant

Evangelical

Seventh-day Adventist

\section{Pentecostal}

Assembly of God (AG)

Asamblea de Iglesias Cristianas (AIC)

Asamblea de Iglesias Pentecostales de Jesucristo (AIPJC)

Church of God, MB

First Christian Charismatic Church

Iglesia de Cristo Ministerios Ebenezer

Iglesia de Cristo Ministerio Elim-Miel

Iglesia de Dios, MI

Iglesia Elim

Independent (Pentecostal)

Luz del Mundo

Non-denominational

Pentecostal

Victory Outreach

Vineyard Fellowship 


\section{Appendix B:}

Focus Group Interview Schedules

\section{INTERVIEW SchedUle \#1: Adult Focus Groups}

General Questions about Church Life, Community Ministry, and Labor Issues

INSTRUCTIONS: Your church is one of 4 congregations that have been selected to be studied indepth. This is a conversation where we would like everyone to participate. There is no right or wrong answer. We simply want to know your feelings, beliefs, and opinions about different aspects of your congregation. What you say in this conversation is confidential. No one will ever be able to connect your answers to your name. We will be recording the conversation. We need you to sign the consent form before we begin. We expect our conversation with you today to take approximately one to two hours. Thank you for your time and cooperation.

[Instructions for Interviewers: Please make sure to ask the "probe" questions. Many times people will have other comments, but we want to elicit information about these areas as well.]

\section{Religious and Spiritual Life: Individual Practices and Communal Norms}

1. Think about the first time you came to this church. What attracted you most to this church? Be specific. Probe: Did a family member or friend invite you? Describe for us your very first visit to this church. What still attracts you most to this church?

2. This church has been growing in numbers in recent years. From your perspective what are the key reasons for this growth? Probe: What role do pastors, key leaders, programming, warm/friendly culture play in this growth? Do you do things with other churches, support their ministries?

3. From your perspective, what are the greatest challenges that parents face in supporting the development of their children's faith? Probe: Be specific - how does your church help people in dealing with the needs of their children? Does the church have programs or initiatives that help to support the development of children or adolescents' faith?

\section{Civic/Community Engagement: The Collective Story of the Church's Work in the Community}

4. What do you think is the most important way in which your church serves the local community? What social issues does the church engage? [Note to Interviewers: we are talking about programs that mostly serve people outside of the church.] Probe: How does the church address this issue? In what way are you involved in any ministries or programs that serve the community? What do you do? What does it mean to you to be involved in this way? 
5. Is getting the church involved in social service ministry an important mission/value of your church? [For interviewer: Wait for answer and discussion, then ask]: If so, how is this made evident to the members? Probe: Through preaching. teaching, key lay-leaders, etc?

6. What types of things do you do as a church to minister to families in need? Probe: From your perspective how well is your church ministering to their needs? Has this church ever helped you or your immediate family with any type of assistance (housing, cash assistance, counseling)?

7. How does your church work with other churches or other community organizations when doing community outreach and ministry? [For Interviewer: Don't cut off discussion.] Probe: Who do you work most closely with? Do you ever work with non-religious groups? Why or why not? Do you work with churches outside of your tradition? What have you done? Do you work with non-Latino churches? Why or why not?

8. Do you in any way volunteer with a community organization outside of your church? If so, how are you involved? Probe: Do you volunteer as an individual or with other people from your church? Does your pastor or others at the church encourage you to be involved in volunteering outside of the church?

\section{Labor Issues:}

Now, we"d like to talk to you more specifically about how your church has helped people with work-related issues.

9. Have you or anyone you have known been helped, through your church (or through a member of the church) to find a job? If yes, how were you/they helped?

- Were you referred to another organization?

- Is there an informal network of people who help people in your church find jobs? Probe: Who helped them find the job? What did that person do? Referral? Introduced me to a business? Wrote a letter? Was it individual help or did they get help through a program?

10. Have you helped someone from your church get a job? (If yes) Probe: Can you describe how you helped them what specifically did you do for them to help them find a job?

11. Does your church have a specific program or work with a specific organization (or send people to that organization) to help people find work or improve their job skills? Probe: ask them to talk about the program and if they've been involved or someone they know has been involved in the program. What was the experience like? If there is no program, ask them about other churches or community groups that they might work with or refer people to when a job-related issue arises what does that group do? How is the church involved with them? 
12. Does your pastor or priest ever talk about labor issues during mass or other worship services? [For Interviewer: If not specifically, do religious leaders at the church ever mention work in the context of discussions about immigration?] Probe: does your minister ever mention the importance of good working conditions or fair wages? Does your pastor encourage getting involved politically to address a work-related issue? If your pastor doesn't say anything publicly. have you had private conversations with him/her about this issue?

13. Are you or anyone you know at your church involved with a union? Probe: In your opinion, does the church support member's' involvenent in unions?

14. IIave you ever approached your pastor/priest or someone at church because of a workrelated issue? Probe: If so, who did you approach? What was it about? What did that person do? Were you referred to a community organization or other group that works on job-related issues?

15. Is there anything that your church isn't doing that you think they should do in terms of outreach to the community? Probe: Why don't you think there is any ministry right now addressing this issue? What is keeping the church from forming a ministry or program around this issue? How likely is it that the church would start a ministry like that? 


\section{INTERVIEW SchedULE \#2: Youth Focus GROUPS}

Instructions: Your church is one of 4 congregations that have been selected to be studied indepth. This is a conversation where we would like everyone to participate. There are no right or wrong answers. We simply want to know your feelings, beliefs, and opinions about different aspects of your congregation. What you say in this conversation is anonymous and confidential. No one will ever be able to connect your answers to your name. We will be recording the conversation. We need you to sign the consent form before we begin. Thank you for your time and cooperation.

[Instructions for Interviewers: Please make sure to ask the "probe" questions. Many times people will have other comments, but we want to elicit information about these areas as well.]

\section{Participation in Life of the Church}

1. How did you get involved in this congregation? Can you describe the types of activities that you participate in at this church? Probe: Do you attend weekly worship services, Sunday/Sabbath School/CCD, or youth events?

2. What is it about this church that you like? Probe: Was there anyone who was instrumental in getting you involved with the church? What did that person do?

3. In what ways are youth active in your congregation? Probe: Do you do anything in the worship services, or help with religious education? Are you a Sunday School teacher or Eucharistic minister or liturgical reader, musician, or serve in other ministries?

4. If left to you to decide, would you continue to come to this church? Probe: Would you attend another church? Or stop attending church altogether? Why?

\section{Religious Vitality}

5. Describe an experience in your life that brought you closer to God. Probe: Did the church play a role in any way in bringing you closer to God? How? What ministry or program of your congregation has helped you grow in faith?

6. Describe what you like and dislike about the worship services in your church.

7. What, in your opinion, is the single greatest barrier to involving more youth in the church? 


\section{The Church and Its Impact on the Community}

8. In what ways are you involved in the community outreach ministries of your church? [Note to Interviewer: We are talking about programs that mostly serve people outside of the church.] Probe: Are you encouraged by leaders or others in your church to be involved in programs serving the community? Are there other ways in which you are involved in the community, other than through your church (such as school or another organization)?

9. Has your involvement in community service helped you grow in your faith? Probe: How has this work helped you?

10. Does the pastoral staff at your church emphasize in any way the importance of getting an education? Probe: What types of things does the church do to support the educational needs and aspirations of the youth at the church (scholarships, tutoring. etc.)?

11. If you could recommend one thing to your pastor and church leaders that your church could do to help serve the needs of youth in your community, what would that be?

\section{Relationships with Family and Friends}

12. Who do you go to for advice? Probe: Are there adults at your church that you feel close to that support you? How did those relationships develop?

13. How important is religion/faith in your home? Probe: Do you attend church with family members? Who attends with you? Who first brought you to church?

14. How does going to church make a difference in your life? How does it affect the types of activities you engage in? Probe: How has it affected your relationships with family? With friends or people at school?

15. Does your faith or religious life influence your educational life? Probe: If so, how does your faith or religious life influence your education? Your study habits? Your attitudes towards learning? Your future educational or vocational aspirations?

16. Do you have a lot of friends at church? Probe: In what ways are your relationships at church different than the relationships you have with peers at school?

\section{Thank you so much for your participation!!}




\section{Appendix C: \\ Protocol for In-Depth Interviews with Adult Congregants on Religious Switching and Religious Identity}

These questions assume that the person has switched within or between traditions/churches. Depending on the exact context (example: person switching between a conservative Pentecostal council and an independent church, or a Catholic person switching into charismatic movement), questions should be addressed in such a way as to speak to the person's experience. The following questions are broken down between Catholic Charismatic respondents and Protestant/other Catholic respondents. However, each set of questions should be tailored for specific informants.

INSTRUCTIONS: Your church is one of 4 congregations that have been selected to be studied in-depth. Think of this as a conversation where we would like to hear from you about how you got involved in this church and why. There is no right or wrong answer. We simply want to know your feelings, beliefs, and opinions about different aspects of your church and your faith. What you say in this conversation is confidential. No one will ever be able to connect your answers to your name. We will be recording the conversation. We expect our conversation with you today to take approximately one hour. We need you to sign the consent form before we begin. Thank you for your time and cooperation.

\section{For Respondents that have Switched from Catholic-Protestant Churches (or vice versa) or switched within the Protestant tradition:}

1. Tell me about your experience with the church growing up? Did you attend church regularly as a child? As an adolescent? With whom did you attend church? How involved was that person(s) in the church? What kind of church did you attend and how involved were you in that church?

2. Were you involved in a similar church before you started attending this church? How many churches have you attended in your adult life?

3. Do you have family members or friends that are members of or attend this church? Do you have family members that remained in the congregation or tradition that you were previously involved with?

4. Before you switched into your new tradition/church, how involved were you with the old church? How many times a week did you attend? What types of church activities were you involved with?

5. Why did you switch tradition/churches? Was there some experience that made you switch? Were there people who were instrumental in getting you involved in this church?

6. What types of activities are you involved in with this church? How did you get involved in these activities? 
7. Do you do things with other churches, such as attend services or support their ministries in any way? If so, is that church from the same tradition or similar to your own church?

8. Have you helped bring other people to this church? If so, how? What specific things did you do?

9. How is your church perceived by other churches? For example, are you considered more conservative or liberal or moderate by other churches? Why?

10. Are there ways in which you combine different practices from the different churches of which you've been a part through your life? Do you recite certain prayers or sing different songs from various churches from your past?

\section{For Catholic Respondents involved in the Charismatic Movement:}

1. Tell me about your experience with the church growing up. What kind of church did you attend and how involved were you in that church? Did you attend church regularly as a child? As an adolescent? With whom did you attend church? How involved was that person(s) in the church?

2. How did you get involved in the Charismatic movement? What difference has it made in your life?

3. Do you have family members or friends that are part of the Charismatic movenent? Do you have family members that attend the traditional Catholic mass regularly?

4. Before you switched into the Charismatic movement, how involved were you with the traditional Catholic mass? How many times a week did you attend? What types of church activities were you involved with?

5. Why did you become Charismatic? Was there some experience that made you switch? Were there people who were instrumental in getting you involved in this movement?

6. What types of activities are you involved in with this church? How did you get involved in these activities?

7. How does this group relate with the larger Catholic Church? What is the group's relationship like with the head priest?

8. Do you collaborate with other groups within the church (such as Comunidades de base, Cursillo Movement, etc.). such as attend services or support their ministries in any way? If so, what do you do together?

9. Have you helped bring other people to the Charismatic movement? If so, how? What specific things did you do? 
10. How is the Charismatic movement perceived by other members of the church? For example, are you considered more conservative or liberal or moderate by other churches? Why?

11. Are there ways in which you combine different practices from the different movements within the Catholic churches? For example, do you recite certain prayers or sing different songs from various movements in the Catholic churches (such as speak in tongues and pray the rosary?)?

Thank you so much for your participation!! 


\title{
Appendix D: Field Note Guide for Observations at Latino Churches
}

\begin{abstract}
Name:
Date:

Organization:

This information will help us to understand the life of Latino churches in Chicago. As you are conducting participant observation, any materials you might pick up at the site are relevant to include with your notes: brochures, bulletins, or religious booklets, etc. As you are participating in services and church activities, please keep in mind these areas and include them in your field notes if they are relevant to the particular activity that you are observing.
\end{abstract}

\section{Spatial Map}

A. Physical Structures

- In what type of structure is the church housed (office building, school, church, retail space, old industrial facility)?

- Is there more than one building related to/owned by this organization?

- Did the main building used to be a church of another denomination?

- Is there parking? How much space is allotted for cars? Is it zoned?

- What is the arrangement of the church space (sanctuary upstairs, fellowship hall in basement, education classes in another building?)?

- What is the condition of the building on the outside? What are indoor spaces like? (new, modern, freshly painted, multiple bathrooms)?

- Are there other churches/organizations using the space?

- Is the space conducive to the types of activities taking place (is there enough seating, is the sound system good, do they have space for multiple groups of people, such as children, the elderly, the disabled?)? Is there ample space in the reception/waiting areas?

- What types of technology does the church have (large sound system, computers in church offices, multiple microphones?)?

B. Aesthetics: Religious and Cultural Symbols

- Are there religious symbols around the buildings (cross, banners, Virgen de Guadalupe)?

- Are there cultural or national symbols in the space (Puerto Rican flag, etc.)?

- Are the aesthetics reflective of the groups that use the space? That is, the choice of posters, paint, etc. - what does that say to people about who uses the space? Is it geared so that Latinos/as (or perhaps, more specifically, a particular group, such as Mexicans) feel that the programs or organizations value and welcome them?

- Was there religious literature in the vestibule, fellowship hall or other areas in the church (besides the sanctuary?)? What did the literature address? 
- Were there any types of posters, brochures, or flyers hanging on the walls or scattered around the church? If yes, what topics did they address (HIV/AIDS posters. pamphlets on domestic violence, flyers for community protests, cultural festivals, etc.)?

\section{Neighborhood Context}

- Briefly describe the immediate neighborhood where the church is located (1-2 block area) - socio-economic aspects, racial/ethnic composition, housing stock, green space, if any.

- Is the building where the church is located visible and easily identifiable?

- Is the building accessible to public transportation?

- Are there other churches and/or community based organizations in the immediate proximity (1-2 blocks)? If identifiable, which faith communities and/or issues do they address (San Lucas Worker's Rights Center, Salon de Testigos de Jehova, etc.)?

\section{Social Map}

D. Approximate \# of people in church at particular activity you are observing

E. Demographic characteristics: $\Lambda$ ge, gender, race of participants

F. How many different groups were at the site (children under 12. adolescents and young adults, middle aged adults and the elderly)? Were there non-church members there or people from the community?

G. Who appear to be the leaders (women, men, Latinos/as, Anglos, ages, etc.)?

H. Does leadership appear to be shared? Are there multiple members of one family in leadership positions in the church?

\section{Temporal Map}

I. What activities were going on?

J. What is the interaction between congregants like? (people interacting, talking, sitting alone, praying together, was there much physical contact? Crying? Quiet meditation, praying in tongues or praying out loud?)?

$\mathrm{K}$. Were there outside groups/people (non-church people) coming in and out of the space?

L. What is the interaction between leaders and congregants like? Between men and women, young and old? Latinos/as and non-Latinos/as (if applicable)?

M. What types of issues did the leaders and congregants discuss? What themes emerged in sermons, prayer meetings, youth groups, or other activities?

$\mathrm{N}$. What types of activities are going on in the street/sidewalk, immediately outside of the church? 


\section{APPENDIX C}

\section{GENERALIZED LINEAR EQUATION MODELS}




\section{GENERALIZED LINEAR EQUATION MODELS}

Research Question 1: What is the level of Religious Participation among youth in Chicago Latino congregations, as measured by the aggregate score?

Research Question 2: How does the level of youth's Religious Participation (RPi and RPii), as measured by the aggregate score, relate to: denominational affiliation; age; gender; Hispanic/Latino group identification; language usage; and participant's country of birth?

Model 1: Generalized linear (GLM) analysis of variance (ANOVA) equation model for Research Question 2. See Chapter 3 section titled Coding of the Selected Variables for coding details and related items.

$$
\begin{aligned}
& \left.Y_{\mathrm{RPi}}=b_{0} \mathrm{U}+\mathrm{b}_{1}(\text { Denomination })+\mathrm{b}_{2}(\text { Age })+b_{3}(\text { Gender })+b_{4}(\text { Hispanic })+b_{5} \text { (Language }\right) \\
& \quad+b_{6}(\text { Country of Birth })+E_{1} \\
& Y_{\mathrm{RPii}}=\mathrm{b}_{0} \mathrm{U}+\mathrm{b}_{1}(\text { Denomination })+\mathrm{b}_{2}(\text { Age })+\mathrm{b}_{3}(\text { Gender })+\mathrm{b}_{4}(\text { Hispanic })+\mathrm{b}_{5} \\
& \quad(\text { Language })+\mathrm{b}_{6}(\text { Country of Birth })+\mathrm{E}_{2}
\end{aligned}
$$

Where:

$\mathrm{Y}_{\mathrm{RPi}}=$ religious participation (criterion variable $\mathrm{i}$, weighted sum aggregate scores) (items $1.1,1.2,1.6,1.11$, and 1.12b)

$\mathrm{Y}_{\mathrm{RPii}}=$ religious participation (criterion variable ii, categorical) (item 1.12a)

Denomination $=$ participant's denominational affiliation (predictor variable, categorical) (item 2.8)

Age $=$ participant's age in years (predictor variable, continuous) (item 3.1)

Gender $=$ participant's gender (Male/Female) (predictor variable, categorical) (item 3.2)

Hispanic $=$ participant's Hispanic/ Latino Group Identification (predictor variable, categorical) (item 3.4)

Language $=$ participant's country of birth (predictor variable, categorical) (items 3.5a, $3.5 \mathrm{~b}, 3.5 \mathrm{c}, 3.5 \mathrm{~d}$, and $3.5 \mathrm{e}$ ) 
Country of Birth $=$ participant's country of birth (predictor variable, categorical) (item 3.10a)

$\mathrm{U}=$ unit vector of 1 for every subject in the sample

$\mathrm{b}_{0}=$ intercept

$\mathrm{b}_{1,2,3,4,5,6}=$ analysis of variance weights

$\mathrm{E}_{1,2}=$ error (observed score minus the predicted score $=$ error vector)

Hypothesis 2a: There is a significant relationship between Age and the level of Religious Participation (RPi and RPii).

Model 2: Generalized linear (GLM) analysis of variance (ANOVA) equation model for Hypothesis 2a. See Chapter 3 section titled Coding of the Selected Variables for coding details and related items.

$$
\begin{aligned}
& \mathrm{Y}_{\mathrm{RPi}}=\mathrm{b}_{0} \mathrm{U}+\mathrm{b}_{1}\left(\mathrm{X}_{\mathrm{AGE}}\right)+\mathrm{E}_{1} \\
& \mathrm{Y}_{\mathrm{RPii}}=\mathrm{b}_{0} \mathrm{U}+\mathrm{b}_{1}\left(\mathrm{X}_{\mathrm{AGE}}\right)+\mathrm{E}_{2}
\end{aligned}
$$

Where:

$\mathrm{Y}_{\mathrm{RPi}}=$ religious participation (criterion variable $\mathrm{i}$, weighted sum aggregate scores) (items $1.1,1.2,1.6,1.11$, and $1.12 \mathrm{~b})$

$\mathrm{Y}_{\mathrm{RPii}}=$ religious participation (criterion variable ii, categorical) (item 1.12a)

$\mathrm{X}_{\mathrm{AGE}}=$ participant's age in years (predictor variable, continuous) (item 3.1)

$\mathrm{U}=$ unit vector of 1 for every subject in the sample

$\mathrm{b}_{0}=$ intercept

$b_{1}=$ analysis of variance weights

$\mathrm{E}_{1,2}=$ error (observed score minus the predicted score $=$ error vector)

Hypothesis $2 b$ : There is a significant relationship between Gender and the level of Religious Participation (RPi and RPii). 
Model 3: Generalized linear (GLM) analysis of variance (ANOVA) equation model for Hypothesis 2b. See Chapter 3 section titled Coding of the Selected Variables for coding details and related items.

$$
\begin{aligned}
& \mathrm{Y}_{\mathrm{RPi}}=\mathrm{b}_{0} \mathrm{U}+\mathrm{b}_{1}\left(\mathrm{X}_{\mathrm{GENDER}}\right)+\mathrm{E}_{1} \\
& \mathrm{Y}_{\mathrm{RPii}}=\mathrm{b}_{0} \mathrm{U}+\mathrm{b}_{1}\left(\mathrm{X}_{\mathrm{GENDER}}\right)+\mathrm{E}_{2}
\end{aligned}
$$

Where:

$\mathrm{Y}_{\mathrm{RPi}}=$ religious participation (criterion variable $\mathrm{i}$, weighted sum aggregate scores) (items $1.1,1.2,1.6,1.11$, and $1.12 \mathrm{~b})$

$\mathrm{Y}_{\mathrm{RPii}}=$ religious participation (criterion variable ii, categorical) (item 1.12a)

$\mathrm{X}_{\mathrm{GENDER}}=$ participant's gender (predictor variable) (item 3.2)

$\mathrm{U}=$ unit vector of 1 for every subject in the sample

$\mathrm{b}_{0}=$ intercept

$\mathrm{b}_{1}=$ analysis of variance weights

$\mathrm{E}_{1,2}=$ error (observed score minus the predicted score $=$ error vector)

Research Question 3: What is the level of Social Service Involvement among youth in Chicago Latino congregations, as measured by the aggregate score?

Research Question 4: How does the level of youth's Social Service Involvement (SSIi and SSTii), as measured by the aggregate score, relate to: denominational affiliation; age; gender; Hispanic/Latino group identification; language usage; and participant's country of birth?

Model 4: Generalized linear (GLM) analysis of variance (ANOVA) equation model for Research Question 4. See Chapter 3 section titled Coding of the Selected Variables for coding details and related items. 


$$
\begin{aligned}
& Y_{\text {SSli }}=b_{0} \mathrm{U}+b_{1}(\text { Denomination })+b_{2}(\text { Age })+b_{3}(\text { Gender })+b_{4}(\text { Hispanic })+b_{5} \\
& \quad(\text { Language })+b_{6}(\text { Country of Birth })+E_{1} \\
& Y_{\text {SSlii }}=b_{0} \mathrm{U}+b_{1}(\text { Denomination })+b_{2}(\text { Age })+b_{3}(\text { Gender })+b_{4}(\text { Hispanic })+b_{5} \\
& \quad(\text { Language })+b_{6}(\text { Country of Birth })+E_{2}
\end{aligned}
$$

Where:

$\mathrm{Y}_{\mathrm{SSIi}}=$ social service involvement (criterion variable $\mathrm{i}$, weighted sum aggregate scores) (items 7.1a, 7.2a, 7.2b, 7.2c, and 7.3)

$Y_{\text {SSlii }}=$ social service involvement (criterion variable ii, categorical) (item 7.5)

Denomination $=$ participant's denominational affiliation (predictor variable, categorical) (item 2.8)

Age $=$ participant's age in years (predictor variable, continuous) (item 3.1)

Gender $=$ participant's gender (Male/Female) (predictor variable, categorical) (item 3.2)

Hispanic $=$ participant's Hispanic/ Latino Group Identification (predictor variable, categorical) (item 3.4)

Language $=$ participant's country of birth (predictor variable, categorical) (items 3.5a, $3.5 \mathrm{~b}, 3.5 \mathrm{c}, 3.5 \mathrm{~d}$, and $3.5 \mathrm{e}$ )

Country of Birth = participant's country of birth (predictor variable, categorical) (item 3.10a)

$\mathrm{U}=$ unit vector of 1 for every subject in the sample

$\mathrm{b}_{0}=$ intercept

$\mathrm{b}_{1,2,3,4,5,6}=$ analysis of variance weights

$\mathrm{E}_{1,2}=$ error (observed score minus the predicted score $=$ error vector)

Hypothesis 4a: There is a significant relationship between Gender and the level of Social Service Involvement (SSIi and SSIii).

Model 5: Generalized linear (GLM) analysis of variance (ANOVA) equation model for Hypothesis 4a. See Chapter 3 section titled Coding of the Selected Variables for coding details and related items. 


$$
\begin{aligned}
& \mathrm{Y}_{\mathrm{SSIi}}=\mathrm{b}_{0} \mathrm{U}+\mathrm{b}_{1}\left(\mathrm{X}_{\mathrm{GENDER}}\right)+\mathrm{E}_{1} \\
& \mathrm{Y}_{\mathrm{SSTii}}=\mathrm{b}_{0} \mathrm{U}+\mathrm{b}_{1}\left(\mathrm{X}_{\mathrm{GENDER}}\right)+\mathrm{E}_{2}
\end{aligned}
$$

Where:

$\mathrm{Y}_{\mathrm{SSIi}}=$ social service involvement (criterion variable I, weighted sum aggregate scores) (items 7.1a, 7.2a, 7.2b, 7.2c, and 7.3)

$Y_{\text {SSlii }}=$ social service involvement (criterion variable ii, categorical) (item 7.5)

$\mathrm{X}_{\mathrm{GENDER}}=$ participant's gender (predictor variable) $($ item 3.2$)$

$\mathrm{U}=$ unit vector of 1 for every subject in the sample

$\mathrm{b}_{0}=$ intercept

$\mathrm{b}_{1}=$ analysis of variance weights

$\mathrm{E}_{1,2}=$ error (observed score minus the predicted score $=$ error vector)

Hypothesis $4 b$ : There is a significant relationship between Denominational Affiliation and the level of Social Service Involvement (SSIi and SSIii).

Model 6: Generalized linear (GLM) analysis of variance (ANOVA) equation model for Hypothesis 4b. See Chapter 3 section titled Coding of the Selected Variables for coding details and related items.

$$
\begin{aligned}
& Y_{\mathrm{SSIi}}=b_{0} \mathrm{U}+\mathrm{b}_{1}\left(\mathrm{X}_{\mathrm{DA} 1}\right)+\mathrm{b}_{2}\left(\mathrm{X}_{\mathrm{DA} 2}\right)+\mathrm{b}_{3}\left(\mathrm{X}_{\mathrm{DA} 3}\right)+\mathrm{b}_{4}\left(\mathrm{X}_{\mathrm{DA} 4}\right)+\mathrm{E}_{1} \\
& \mathrm{Y}_{\mathrm{SSIii}}=\mathrm{b}_{0} \mathrm{U}+\mathrm{b}_{1}\left(\mathrm{X}_{\mathrm{DA} 1}\right)+\mathrm{b}_{2}\left(\mathrm{X}_{\mathrm{DA} 2}\right)+\mathrm{b}_{3}\left(\mathrm{X}_{\mathrm{DA} 3}\right)+\mathrm{b}_{4}\left(\mathrm{X}_{\mathrm{DA} 4}\right)+\mathrm{E}_{2}
\end{aligned}
$$

Where:

$\mathrm{Y}_{\mathrm{SSIi}}=$ social service involvement (criterion variable I, weighted sum aggregate scores) (items 7.1a, 7.2a, 7.2b, 7.2c, and 7.3)

$Y_{\text {SSlii }}=$ social service involvement $($ criterion variable ii, categorical) (item 7.5)

$\mathrm{X}_{\mathrm{DA1}, 2,3,4}=$ participant's denominational affiliation (predictor variable) (item 2.8)

$\mathrm{U}=$ unit vector of 1 for every subject in the sample

$\mathrm{b}_{0}=$ intercept 
$\mathrm{b}_{1,2,3,4}=$ analysis of variance weights

$\mathrm{E}_{1,2}=$ error (observed score minus the predicted score $=$ error vector $)$

Research Question 5: What is the level of Engagement in Leadership Tasks among youth in Chicago Latino congregations, as measured by the aggregate score?

Research Question 6: How does the level of youth's Engagement in Leadership Tasks (ELTi, ELTii, and ELTiii), as measured by the aggregate score, relate to: denominational affiliation; age; gender; Hispanic/Latino group identification; language usage; and participant's country of birth?

Model 7: Generalized linear (GLM) analysis of variance (ANOVA) equation model for Research Question 6. See Chapter 3 section titled Coding of the Selected Variables for coding details and related items.

$$
\begin{aligned}
& \mathrm{Y}_{\mathrm{ELTi}}=\mathrm{b}_{0} \mathrm{U}+\mathrm{b}_{1}(\text { Denomination })+\mathrm{b}_{2}(\text { Age })+\mathrm{b}_{3}(\text { Gender })+\mathrm{b}_{4}(\text { Hispanic })+\mathrm{b}_{5} \\
& \quad(\text { Language })+\mathrm{b}_{6}(\text { Country of Birth })+\mathrm{E}_{1} \\
& \mathrm{Y}_{\mathrm{ELTii}}=\mathrm{b}_{0} \mathrm{U}+\mathrm{b}_{1}(\text { Denomination })+\mathrm{b}_{2}(\text { Age })+\mathrm{b}_{3}(\text { Gender })+\mathrm{b}_{4}(\text { Hispanic })+\mathrm{b}_{5} \\
& \quad(\text { Language })+\mathrm{b}_{6}(\text { Country of Birth })+\mathrm{E}_{2} \\
& \left.\mathrm{Y}_{\mathrm{ELTiii}}=\mathrm{b}_{0} \mathrm{U}+\mathrm{b}_{1} \text { (Denomination }\right)+\mathrm{b}_{2}(\text { Age })+\mathrm{b}_{3}(\text { Gender })+\mathrm{b}_{4}(\text { Hispanic })+\mathrm{b}_{5} \\
& \quad(\text { Language })+\mathrm{b}_{6}(\text { Country of Birth })+\mathrm{E}_{3}
\end{aligned}
$$

Where:

$\mathrm{Y}_{\mathrm{ELTi}}=$ engagement in leadership tasks (criterion variable $\mathrm{i}$, weighted sum aggregate scores) (items 1.3, 1.4, and 1.5)

$\mathrm{Y}_{\mathrm{ELTii}}=$ engagement in leadership tasks (criterion variable ii, categorical) (item 1.12c)

$\mathrm{Y}_{\mathrm{ELTiii}}=$ engagement in leadership tasks (criterion variable iii, categorical) (item 7.4a)

Denomination $=$ participant's denominational affiliation $($ predictor variable, categorical $)$ (item 2.8)

Age $=$ participant's age in years (predictor variable, continuous) (item 3.1)

Gender $=$ participant's gender $($ Male/Female $)($ predictor variable, categorical $)($ item 3.2) 
Hispanic $=$ participant's Hispanic/ Latino Group Identification (predictor variable, categorical) (item 3.4)

Language $=$ participant's country of birth (predictor variable, categorical) (items $3.5 \mathrm{a}$, $3.5 \mathrm{~b}, 3.5 \mathrm{c}, 3.5 \mathrm{~d}$, and $3.5 \mathrm{e}$ )

Country of Birth = participant's country of birth (predictor variable, categorical) (item $3.10 \mathrm{a})$

$\mathrm{U}=$ unit vector of 1 for every subject in the sample

$\mathrm{b}_{0}=$ intercept

$\mathrm{b}_{1,2,3,4,5,6}=$ analysis of variance weights

$\mathrm{E}_{1,2,3}=$ error (observed score minus the predicted score $=$ error vector)

Hypothesis 6a: There is a significant relationship between Gender and the level of Engagement in Leadership Tasks (ELTi, ELTii, and ELTiii).

Model 8: Generalized linear (GLM) analysis of variance (ANOVA) equation model for Hypothesis 6a. See Chapter 3 section titled Coding of the Selected Variables for coding details and related items.

$$
\begin{aligned}
& Y_{\text {ELTi }}=b_{0} U+b_{1}\left(X_{\text {GENDER }}\right)+E_{1} \\
& Y_{\text {ELTii }}=b_{0} U+b_{1}\left(X_{\text {GENDER }}\right)+E_{2} \\
& Y_{\text {ELTiii }}=b_{0} U+b_{1}\left(X_{\text {GENDER }}\right)+E_{3}
\end{aligned}
$$

Where:

$\mathrm{Y}_{\text {ELTi }}=$ engagement in leadership tasks (criterion variable $\mathrm{i}$, weighted sum aggregate scores) (items 1.3, 1.4, and 1.5)

$\mathrm{Y}_{\text {ELTii }}=$ engagement in leadership tasks (criterion variable ii, categorical) (item 1.12c)

$\mathrm{Y}_{\text {ELTiii }}=$ engagement in leadership tasks (criterion variable iii, categorical) (item 7.4a)

$\mathrm{X}_{\mathrm{GENDER}}=$ participant's gender (predictor variable) $($ item 3.2)

$\mathrm{U}=$ unit vector of 1 for every subject in the sample

$\mathrm{b}_{0}=$ intercept 
$\mathrm{b}_{1}=$ analysis of variance weights

$\mathrm{E}_{1,2,3}=$ error (observed score minus the predicted score $=$ error vector)

Hypothesis $6 b$ : There is a significant relationship between Denominational Affiliation and the level of Engagement in Leadership Tasks (ELTi, ELTii, and ELTiii).

Model 9: Generalized linear (GLM) analysis of variance (ANOVA) equation model for Hypothesis $6 \mathrm{~b}$. See Chapter 3 section titled Coding of the Selected Variables for coding details and related items.

$$
\begin{aligned}
& Y_{\mathrm{ELTi}}=b_{0} \mathrm{U}+\mathrm{b}_{1}\left(\mathrm{X}_{\mathrm{DA} 1}\right)+\mathrm{b}_{2}\left(\mathrm{X}_{\mathrm{DA} 2}\right)+\mathrm{b}_{3}\left(\mathrm{X}_{\mathrm{DA} 3}\right)+\mathrm{b}_{4}\left(\mathrm{X}_{\mathrm{DA} 4}\right)+\mathrm{E}_{1} \\
& \mathrm{Y}_{\mathrm{ELTii}}=b_{0} \mathrm{U}+\mathrm{b}_{1}\left(\mathrm{X}_{\mathrm{DA} 1}\right)+\mathrm{b}_{2}\left(\mathrm{X}_{\mathrm{DA} 2}\right)+\mathrm{b}_{3}\left(\mathrm{X}_{\mathrm{DA} 3}\right)+\mathrm{b}_{4}\left(\mathrm{X}_{\mathrm{DA} 4}\right)+\mathrm{E}_{2} \\
& \mathrm{Y}_{\mathrm{ELTiii}}=\mathrm{b}_{0} \mathrm{U}+\mathrm{b}_{1}\left(\mathrm{X}_{\mathrm{DA} 1}\right)+\mathrm{b}_{2}\left(\mathrm{X}_{\mathrm{DA} 2}\right)+\mathrm{b}_{3}\left(\mathrm{X}_{\mathrm{DA} 3}\right)+\mathrm{b}_{4}\left(\mathrm{X}_{\mathrm{DA} 4}\right)+\mathrm{E}_{3}
\end{aligned}
$$

Where:

$\mathrm{Y}_{\mathrm{ELTi}}=$ engagement in leadership tasks (criterion variable $\mathrm{i}$, weighted sum aggregate scores) (items 1.3, 1.4, and 1.5)

$\mathrm{Y}_{\mathrm{ELTii}}=$ engagement in leadership tasks (criterion variable ii, categorical) (item 1.12c)

$\mathrm{Y}_{\mathrm{ELTiii}}=$ engagement in leadership tasks (criterion variable iii, categorical) (item 7.4a)

$\mathrm{X}_{\mathrm{DA1}, 2,3,4}=$ participant's denominational affiliation (predictor variable) (item 2.8)

$\mathrm{U}=$ unit vector of 1 for every subject in the sample

$\mathrm{b}_{0}=$ intercept

$\mathrm{b}_{1,2,3,4}=$ analysis of variance weights

$\mathrm{E}_{1,2,3}=$ error (observed score minus the predicted score $=$ error vector)

Research Question 7: Is there a significant relationship between Social Service Involvement and Religious Participation among youth in Chicago Latino congregations? 
Hypothesis 7: There is a significant relationship between the level of Social Service Involvement (SSIi and SSTii) and the level of Religious Participation (RPi and RPii) among youth in Chicago Latino congregations.

Model 10: Generalized linear (GLM) analysis of variance (ANOVA) equation model for Hypothesis 7. See Chapter 3 section titled Coding of the Selected Variables for coding details and related items.

$$
\begin{aligned}
& Y_{S S l i}=b_{0} U+b_{1}\left(X_{R P i}\right)+b_{2}\left(X_{R P i i}\right)+E_{1} \\
& Y_{S S S i i}=b_{0} U+b_{1}\left(X_{R P i}\right)+b_{2}\left(X_{R P i i}\right)+E_{2}
\end{aligned}
$$

Where:

$\mathrm{Y}_{\text {SSli }}=$ social service involvement (criterion variable $\mathrm{i}$, weighted sum aggregate scores) (items 7.1a, 7.2a, 7.2b, 7.2c, and 7.3)

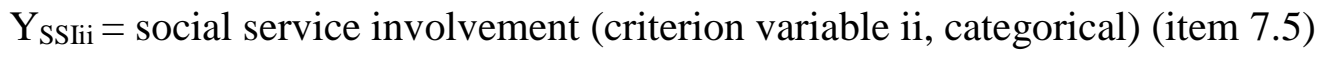

$\mathrm{X}_{\mathrm{RPi}}=$ religious participation (criterion variable $\mathrm{i}$, weighted sum aggregate scores) (items $1.1,1.2,1.6,1.11$, and $1.12 \mathrm{~b})$

$\mathrm{X}_{\mathrm{RPii}}=$ religious participation (criterion variable ii, categorical) (item 1.12a)

$\mathrm{U}=$ unit vector of 1 for every subject in the sample

$\mathrm{b}_{0}=$ intercept

$\mathrm{b}_{1,2,3}=$ analysis of variance weights

$\mathrm{E}_{1,2}=$ error (observed score minus the predicted score $=$ error vector)

Research Question 8: Is there a significant relationship between Engagement in Leadership Tasks and Religious Participation among youth in Chicago Latino congregations? Hypothesis 8: There is a significant relationship between the level of Engagement in Leadership Tasks (ELTi, ELTii, and ELTiii) and the level of Religious Participation (RPi and RPii) among youth in Chicago Latino congregations. 
Model 11: Generalized linear (GLM) analysis of variance (ANOVA) equation model for Hypothesis 8. See Chapter 3 section titled Coding of the Selected Variables for coding details and related items

$$
\begin{aligned}
& Y_{E L T i}=b_{0} U+b_{1}\left(X_{R P i}\right)+b_{2}\left(X_{R P i i}\right)+E_{1} \\
& Y_{E L T i i}=b_{0} U+b_{1}\left(X_{R P i}\right)+b_{2}\left(X_{R P i i}\right)+E_{2} \\
& Y_{E L T i i i}=b_{0} U+b_{1}\left(X_{R P i}\right)+b_{2}\left(X_{R P i i}\right)+E_{3}
\end{aligned}
$$

Where:

$\mathrm{Y}_{\mathrm{ELTi}}=$ engagement in leadership tasks (criterion variable $\mathrm{i}$, weighted sum aggregate scores) (items 1.3, 1.4, and 1.5)

$\mathrm{Y}_{\mathrm{ELTii}}=$ engagement in leadership tasks (criterion variable ii, categorical) (item 1.12c)

$\mathrm{Y}_{\mathrm{ELTiii}}=$ engagement in leadership tasks (criterion variable iii, categorical) (item 7.4a)

$\mathrm{X}_{\mathrm{RP}}=$ religious participation (criterion variable $\mathrm{i}$, weighted sum aggregate scores) (items $1.1,1.2,1.6,1.11$, and $1.12 \mathrm{~b}$ )

$\mathrm{X}_{\mathrm{RPii}}=$ religious participation (criterion variable ii, categorical) (item 1.12a)

$\mathrm{U}=$ unit vector of 1 for every subject in the sample

$\mathrm{b}_{0}=$ intercept

$\mathrm{b}_{1,2}=$ analysis of variance weights

$\mathrm{E}_{1,2,3}=$ error (observed score minus the predicted score $=$ error vector) 


\section{APPENDIX D}

LETTER OF REQUEST FOR AUTHORIZATION FROM

THE CLCS PRINCIPAL RESEARCHER 
November 3, 2014

Dr. Edwin I. Hernández

Senior Program Officer

DeVos Family Foundation

P.O. Box 230257

Grand Rapids, MI 49523

Dear Dr. Hernández,

Thank you for the opportunity to connect with you and the team of researchers at the Center for the Study of Latino Religion at the University of Notre Dame.

Currently I am in the dissertation stage for the Ph.D. in Leadership degree at Andrews University. My research interests and practice trajectory focus on aspects dealing with Latino congregations in the United States. In particular, as part of my dissertation research project, I plan to focus on aspects dealing with religious commitment and social service / civic engagement. For this reason, I would like to request permission to utilize and analyze the data collected within The Chicago Latino Congregations Study (CLCS). With this data I plan to research issues related to the role of Latino congregations in creating pathways towards social service / civic activism for youth members of these congregations.

In accessing and utilizing the CLCS data set, I understand that I hereby agree that all my publications based on this data set, beyond the dissertation, will be done so in co-authorship and partnership with the research team that conducted the CLCS.

Thank you for your consideration of this request and the opportunity to contribute towards the study and understanding of our Latino congregations. Please feel free to contact me should there be any questions or further information required.

Sincerely,

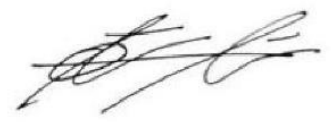

Rev. Elizabeth Tamez Méndez 
APPENDIX E

LETTERS OF AUTHORIZATION FROM THE CLCS

PRINCIPAL RESEARCHER 
From: Edwin Hernandez <edwinh@dvfoundations.org>

To: Jessica Hamar Martinez <jhamar@email.arizona.edu>

Cc: Elizabeth Tamez <etm76@rocketmail.com>

Sent: Tuesday, November 4, 2014 10:38 AM

Subject: FW: Chicago Hispanic Churches data set / Dissertation guidance

Dear Jessica,

Via this email I would like to introduce you to Elizabeth Tamez who is a graduate student at Andrews University working on her dissertation. She is interested in using the CLCS data for her dissertation and I have agreed to let her use the youth data. I am very pleased that she is interested in the data. See her note below and the attached document for more information about her work.

Could you please forward the Latino youth data and related documents to her? Thanks also for answering any technical questions that Elizabeth may have related to the data.

Thanks so much,

Edwin 
ADVENTIST UNIVERSITY

OF HEALTH SCIENCES

Florida Hospital's University

February 14, 2017

To Whom It May Concern:

I am writing this letter to confirm that I give permission to have Elizabeth Tamez use the Chicago Latino Congregations Study data for purposes of her dissertation research.

My colleagues and I, who worked on this research project, are available for any technical support that she may need.

Sincerely,

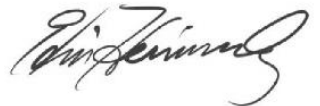

Edwin I. Hernandez, Ph.D.

Provost

671 Winyah Drive $\mid$ Orlando, FL 32803 | (407) 303-7747 | ADU.edu 


\section{APPENDIX F}

IRB EXEMPTION LETTER 


\title{
Andrews Q University
}

February 27, 2017

Elizabeth Tamez Mendez

Tel. (469) 371-7412

Email: tamezmel@andrews.edu

\begin{abstract}
RE: APPLICATION FOR APPROVAL OF RESEARCH INVOLVING HUMAN SUBJECTS IRB Protocol \#:17-022 Application Type: Original Dept.: Leadership

Review Category: Exempt Action Taken: Approved Advisor: Erich Baumgartner Title: The relationship of religious participation to social service involvement and engagement in leadership tasks: Implications for leadership emergence among youth in Latin congregations.
\end{abstract}

Your IRB application for approval of research involving human subjects entitled: "The relationship of religious participation to social service involvement and engagement in leadership tasks: Implications for leadership emergence among youth in Latin congregations" IRB protocol \# 17-022 has been evaluated and determined Exempt from IRB review under regulation 46.101 (b) (4). You may now proceed with your research.

Please note that any future changes (see IRB Handbook pages 11-12) made to the study design and/or informed consent form require prior approval from the IRB before such changes can be implemented. Incase you need to make changes please use the attached report form.

While there appears to be no more than minimum risks with your study, should an incidence occur that results in a research-related adverse reaction and/or physical injury, (see IRB Handbook pages 12) this must be reported immediately in writing to the IRB. Any research-related physical injury must also be reported immediately to the University Physician, Dr. Katherine, by calling (269) 473-2222.

We ask that you reference the protocol number in any future correspondence regarding this study for easy retrieval of information.

Best wishes in your research.

Sincerely,

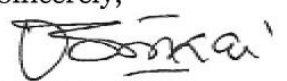

Mordekai Ongo

Research Integrity and Complaince Officer

Institutional Review Board - 4150 Administration Dr Room 322 - Berrien Springs, MI 49104-0355 Tel: (269) 471-6361 Fax: (269) 471-6543 E-mail: irb@andrews.edu 


\section{REFERENCE LIST}




\section{REFERENCE LIST}

Althoff, A. (2006). Religious identities of Latin American immigrants in Chicago: Preliminary findings from field research. Retrieved from https://divinity.uchicago.edu/sites/default/files/imce/pdfs/webforum/062006/altho ff_religious_identities.pdf

Andolina, M. W., Jenkins, K., Zukin, C., \& Keeter, S. (2003). Habits from home, lessons from school: Influences on youth civic engagement. Political Science and Politics, 36(02), 275-280.

Anglin, A. E., Johnson-Pynn, J. S., \& Johnson, L. R. (2012). Ethnic identity and civic attitudes in Latino and Caucasian youth. Journal of Youth Studies, 15(5), 621643.

Archard, N. (2013). Adolescent leadership: The female voice. Educational Management Administration \& Leadership, 41(3), 336-351. doi:10.1177/1741143212474804

Armitage, J. S., \& Dugan, R. E. (2006). Marginalized experiences of Hispanic females in youth-based religious groups. Journal for the Scientific Study of Religion, 45(2), 217-231. doi:10.1111/j.1468-5906.2006.00302.x

Avolio, B. J. (2005). Leadership development in balance: Made/born. Mahwah, NJ: Erlbaum \& Associates.

Avolio, B. J., \& Gibbons, T. C. (1988). Developing transformational leaders: A life span approach. In J. A. Conger \& R. N. Kanungo (Eds.), Charismatic leadership: The elusive factor in organizational effectiveness (pp. 276-308). San Francisco, CA Jossey-Bass.

Avolio, B. J., \& Hannah, S. T. (2008). Developmental readiness: Accelerating leader development. Consulting Psychology Journal: Practice and Research, 60(4), 331-337.

Avolio, B. J., \& Vogelgesang, G. R. (2011). Beginnings matter in genuine leadership development. In S. E. Murphy \& R. J. Reichard (Eds.), Early development and leadership: Building the next generation of leaders (pp. 179-204). New York, NY: Taylor \& Francis Group.

Badillo, D. A. (2006). Latinos and the new immigrant church. Baltimore, MD: Johns Hopkins University Press. 
Baltes, P. B., Lindenberger, U., \& Staudinger, U. (2006). Life span theory in developmental psychology. In W. Damon \& R. M. Lerner (Eds.), Handbook of child psychology: Vol. 1. Theoretical models of human development (6th ed., pp. 569-664). Hoboken, NJ: John Wiley \& Sons.

Baltes, P. B., Staudinger, U. M., \& Lindenberger, U. (1999). Lifespan psychology: Theory and application to intellectual functioning. In S. J. T., J. M. Darley, \& D. J. Foss (Eds.), Annual Review of Psychology (Vol. 50, pp. 471-507). Palo Alto, CA Annual Reviews.

Barber, C., Mueller, C. T., \& Ogata, S. (2013). Volunteerism as purpose: Examining the long-term predictors of continued community engagement. Educational Psychology, 33(3), 307-326. doi:10.1080/01443410.2013.772775

Barton, P. (2006). Hispanic Methodists, Presbyterians, and Baptists in Texas. Austin, TX: University of Texas Press.

Bass, B. M. (1990). Bass \& Stogdill's handbook of leadership (3rd ed.). New York, NY: Free Press.

Beckford, J. A., \& Demerath III, N. J. (Eds.). (2007). The SAGE handbook of the sociology of religion. Thousand Oaks, CA: SAGE Publications.

Benson, P. L. (1997). All kids are our kids: What communities must do to raise caring and responsible children and adolescents. San Francisco, CA: Jossey- Bass.

Benson, P. L. (2003). Developmental assets and asset-building community: Conceptual and empirical foundations. In R. M. Lerner \& P. L. Benson (Eds.), Developmental assets and asset-building communities: Implications for research, policy, and practice (pp. 19-43). New York, NY: Luwer Academic/ Plenum Press.

Benson, P. L. (2007). Developmental assets: An overview of theory, research, and practice. In R. K. Silbereisen \& R. M. Lerner (Eds.), Approaches to positive youth development (pp. 35-58). Thousand Oaks, CA: SAGE Publications.

Benson, P. L. (2008). Sparks: How parents can help ignite the hidden strenghts of teenagers. San Francisco, CA: Jossey-Bass.

Benson, P. L., Roehlkepartain, E. C., \& Rude, S. P. (2003). Spiritual development in childhood and adolescence: Toward a field of inquiry. Applied Developmental Science, 7, 204-212.

Benson, P. L., \& Saito, R. N. (2001). The scientific foundations of youth development. In P. L. Benson \& K. J. Pittman (Eds.), Trends in youth development: Visions, realities, and challenges (pp. 135-154). Norwell, MA: Kluwer Academic. 
Benson, P. L., Scales, P. C., Hamilton, S. F., \& Sesma, A. (2006). Positive youth development: Theory, research, and applications. In W. Damon \& R. M. Lerner (Eds.), Handbook of child psychology: Vol. 1. Theoretical models of human development (6th ed., pp. 894-941). New York, NY: John Wiley \& Sons.

Benson, P. L., Scales, P. C., \& Syvertsen, A. K. (2011). The contribution of the developmental assets framework to positive youth development theory and practice. In R. M. Lerner, J. V. Lerner, \& J. B. Benson (Eds.), Advances in child development and behavior: Positive youth development (Vol. 41, pp. 195-228). London, England: Academic Press.

Benson, P. L., Yeager, R. J., Wood, P. K., Guerra, M. J., \& Manno, B. V. (1986). Catholic high schools: Their impact on low-income students. Washington, DC: National Catholic Educational Association.

Beyerlein, K., \& Hipp, J. R. (2006). From pews to participation: The effect of congregation activity and context on bridging civic engagement. Social Problems, 53(1), 97-117.

Beyerlein, K., \& Vaisey, S. (2013). Individualism revisited: Moral worldviews and civic engagement. Poetics, 41(4), 384-406.

Blum, R. W. (2003). Positive youth development: A strategy for improving adolescent health. In R. M. Lerner, F. Jacobs, \& D. Wertlieb (Eds.), Handbook of applied developmental science: Promoting positive child, adolescent, and family development through research, policies, and programs, Vol. 2: Enhancing the life chances of youth and families: Public service systems and public policy perspectives (pp. 237-252). Thousand Oaks, CA: SAGE Publications

Bottenberg, R. A., \& Ward, J. H. (1963). Applied multiple linear regression (A. M. Division Ed.). San Antonio, TX: Personnel Research Lab Lackland Air Force Base.

Brandtstädter, J. (2006). Action perspectives on human development. In W. Damon \& R. M. Lerner (Eds.), Handbook of child psychology: Vol. 1. Theoretical models of human development (6th ed., pp. 516-568). Hoboken, NJ: John Wiley \& Sons.

Bronfenbrenner, U. (1979). The ecology of human development: Experiments by nature and design. Cambridge, MA: Harvard University Press.

Bronfenbrenner, U. (1986). Ecology of the family as a context to human development: Research perspectives. Development Psychology, 22, 723-742.

Bronfenbrenner, U. (2001). Human development, bioecological theory of. In N. J. Smelser \& P. B. Baltes (Eds.), International encyclopedia of the social and behavioral sciences (Vol. 20, pp. 6963-6970). Oxford, England: Elsevier Science. 
Bronfenbrenner, U., \& Morris, P. A. (2006). The bioecological model of human development. In W. Damon \& R. M. Lerner (Eds.), Handbook of child psychology: Vol. 1. Theoretical models of human development (6th ed., pp. 793828). Hoboken, NJ: John Wiley \& Sons.

Burwell, R., Hernández, E. I., Peña, M., Smith, J., \& Sikkink, D. (2010). The Chicago Latino congregations study (CLCS): Methodological considerations. South Bend, IN: Institute for Latino Studies at University of Notre Dame.

Cairns, R. B. (1998). The making of developmental psychology. In R. M. Lerner (Ed.), Handbook of child psychology: Vol. 1. Theoretical models of human development (5th ed., pp. 419-448). New York, NY: John Wiley \& Sons.

Calvillo, J. E., \& Stanley, R. B. (2015). Latino religious affiliation and ethnic identity. Journal for the Scientific Study of Religion, 54(1), 57-78.

Clinton, J. R. (1989). Leadership emergence theory: A self-study manual for analyzing the development of a Christian leader. Altadena, CA: Barnabas Resources.

Clinton, J. R. (2012). The making of a leader: Recognizing the lessons and stages of leadership development. Colorado Springs, CO: NavPress.

Connors, J. J., \& Swan, B. G. (2006). A synthesis of leadership development research in agricultural education: 1988-2003. Journal of Agricultural Education, 47(2), 113.

Consul, P. C., \& Famoye, F. (1992). Generalized poisson regression model. Communications in Statistics-Theory and Methods, 21(1), 89-109. doi:https://doi.org/10.1080/03610929208830766

Crane, K. R. (2003). Latino churches: Faith, family, and ethnicity in the second generation. New York, NY: LFB Scholarly Publishing.

Crespo, O. (2003). Being Latino in Christ: Finding wholeness in your ethnic identity. Downers Grove, IL: InterVarsity Press.

Cress, C. M., Astin, H. S., Zimmerman-Oster, K., \& Burkhardt, J. C. (2001). Developmental outcomes of college students' involvement in leadership activities. Journal of College Student Development, 41(1), 15-27.

Crooks, C. V., Chiodo, D., Thomas, D., \& Hughes, R. (2010). Strengths-based programming for first nations youth in schools: Building engagement through healthy relationships and leadership skills. International Journal of Mental Health \& Addiction, 8(2), 160-173. doi:10.1007/s11469-009-9242-0 
Cummings, E. (2003). Foreword. In D. Wertlieb, F. Jacobs, \& R. M. Lerner (Eds.), Handbook of applied developmental science: Promoting positive child, adolescent, and family development through research, policies, and programs, Vol. 3: Promoting positive youth and family development: Community systems, citizenship, and civil society (pp. ix-xi). Thousand Oaks, CA: SAGE Publications.

Damon, W. (2003). Noble purpose: The joy of living a meaningful life. West Radnor, PA: Templeton Foundation Press.

Damon, W. (2004). What is positive youth development? Annals of the American Academy of Political and Social Science, 591, 13-24.

Damon, W. (2008). The path to purpose: Helping our children find their calling in life. New York, NY: Simon \& Shuster.

Damon, W., Menon, J., \& Bronk, K. (2003). The development of purpose during adolescence. Applied Developmental Science, 7, 199-127.

Davis, K. G. (2007). Hispanic youth are the U.S. church's best investment. National Catholic Reporter, 43.

Davis, M. A. (1997). Latino leadership development: Beginning on campus. National Civic Review, 86(3), 227-233.

Dawes, N. P., \& Larson, R. (2011). How youth get engaged: Grounded-theory research on motivational development in organized youth programs. Developmental Psychology, 47(1), 259-269. doi:10.1023/A:1005399417256

Day, D. V. (2000). Leadership development: A review in context. The Leadership Quarterly, 11(4), 581-613. doi:http://dx.doi.org/10.1016/S1048-9843(00)00061-8

Day, D. V. (2011). Integrative perspectives on longitudinal investigations of leader development: From childhood through adulthood. The Leadership Quarterly, 22(3), 561-571. doi:http://dx.doi.org/10.1016/j.leaqua.2011.04.012

Day, D. V., Fleenor, J. W., Atwater, L. E., Sturm, R. E., \& McKee, R. A. (2014). Advances in leader and leadership development: A review of 25 years of research and theory. The Leadership Quarterly, 25(1), 63-82. doi:http://dx.doi.org/10.1016/j.leaqua.2013.11.004

Day, D. V., Harrison, M. M., \& Halpin, S. M. (2012). An integrative approach to leader development: Connecting adult development, identity, and expertise. New York, NY: Routledge.

Day, D. V., \& Sin, H. P. (2011). Longitudinal tests of an integrative model of leader development: Charting and understanding developmental trajectories. The Leadership Quarterly, 22(3), 545-560. doi:http://dx.doi.org/10.1016/j.leaqua.2011.04.011 
Dias, E. (2013). The rise of Evangélicos. TIME Magazine, 20-26.

Dugan, J. P., \& Komives, S. R. (2007). Developing leadership capacity in college students: Findings from a national study. College Park, MD: National Clearinghouse for Leadership Programs.

Dworkin, J. B., Larson, R., \& Hansen, D. (2003). Adolescents' accounts of growth experiences in youth activities. Journal of Youth and Adolescence, 32(1), 17-26.

Ebstyne King, P., \& Furrow, J. L. (2008). Religion as a resource for positive youth development: Religion, social capital, and moral outcomes. Psychology of Religion and Spirituality, S(1), 34-39. doi:10.1037/1941-1022.S.1.34

Eccles, J. S. (2004). Schools, academic motivation, and stage-environment fit. In R. M. Lerner \& L. Steinberg (Eds.), Handbook of adolescent psychology (2nd ed., pp. 125-153). Hoboken, NJ: Wiley.

Eccles, J. S., Barber, B. L., Stone, M., \& Hunt, J. (2003). Extracurricular activities and adolescent development. Journal of Social Issues, 59(4), 865-889.

Eccles, J. S., \& Gootman, J. A. (2002). Community programs to promote youth development. Washington, DC: National Academy Press.

Eccles, J. S., Midgley, C., Buchanan, C., Wigfield, A., Reuman, D., \& MacIver, D. (1993). Development during adolescence: The impact of stage/environment fit on young adolescents' experiences in schools and families. American Psychologist, 48(2), 90-101.

Eccles, J. S., \& Wigfield, A. (2002). Motivational beliefs, values, and goals. Annual Review of Psychology, 53, 109-132.

Elliston, E. J. (1992). Home grown leaders. Pasadena, CA: William Carey Library.

Enfield, R. (2008). Social capital and implications for positive youth development. Retrieved from http://fourhcyd.ucdavis.edu

Flanagan, C. A., \& Christens, B. D. (Eds.). (2011). Youth civic development : Work at the cutting edge (Vol. Winter). San Francisco, CA: Jossey-Bass.

Ford, D. H., \& Lerner, R. M. (1992). Developmental systems theory: An integrative approach. Newbury Park, CA: SAGE Publications.

Fox, J. (2015). Applied regression analysis and generalized linear models. Thousand Oaks, CA: Sage Publications. 
Frey, W. H. (2010). Analysis of U.S. decennial census data through 2010 from William H. Frey, Brookings Institution and University of Michigan's social science data analysis network. Retrieved from http://www.censusscope.org/2010Census/PDFs/RaceEth-Cities.pdf

Furlong, A. (2012). Youth studies: An introduction. New York, NY: Routledge.

Furrow, J. L., King, P. E., \& White, K. (2004). Religion and positive youth development: Identity, meaning, and prosocial concerns. Applied Developmental Science, 8(1), $17-26$.

Geddert, A. J. (2010). A cultural and philosophical critique of positive youth development theory. (Ph.D.), Fuller Theological Seminary, Pasadena, CA. (3486294)

Geldhof, G. J., Bowers, E. P., Boyd, M. J., Mueller, M. K., Napolitano, C. M., Schmid, K. L., , . Lerner, R. M. (2014). Creation of short and very short measures of the five Cs of positive youth development. Journal of Research on Adolescence, 24(1), 163-176. doi:10.1111/jora.12039

Gestsdóttir, S., Urban, J. B., Bowers, E. P., Lerner, J. V., \& Lerner, R. M. (2011). Intentional self-regulation, ecological assets, and thriving in adolescence: A developmental systems model. New Directions for Child \& Adolescent Development, 2011(133), 61-76. doi:10.1002/cd.304

Gibson, T. (2008). Religion and civic engagment among America's youth. The Social Science Journal, 45(3), 504-514. doi:https://doi.org/10.1016/j.soscij.2008.07.007

Giles, D. E., \& Eyler, J. (1994). The impact of a college community service laboratory on students' personal, social, and cognitive outcomes. Journal of adolescence, 17(4), $327-339$.

Glewwe, P., \& Levin, M. (2005). Presenting simple descriptive statistics from household survey data. In P. Cheung (Ed.), Household sample surveys in developing and transition countries (ST/ESA/STAT/SER.F/96). New York, NY: United Nations.

González, J. L. (1996). Santa Biblia: Reading the Bible through Hispanic eyes. Nashville, TN: Abingdon.

Gore, A. (2003). Foreword. In R. M. Lerner \& P. L. Benson (Eds.), Developmental assets and asset-building communities: Implications for research, policy, and practice (pp. xi-xii). Norwell, MA: Kluwer.

Gottfried, A. E., Gottfried, A. W., Reichard, R. J., Guerin, D. W., Oliver, P. H., \& Riggio, R. E. (2011). Motivational roots of leadership: A longitudinal study from childhood through adulthood. The Leadership Quarterly, 22(3), 510-519. doi:http://dx.doi.org/10.1016/j.leaqua.2011.04.008 
Gottlieb, G. (1997). Synthesizing nature-nurture: Prenatal roots of instinctive behavior. Mahwah, NJ: Lawrence Erlbaum.

Gracia, J. J. E. (2000). Hispanic/Latino identity: A philosophical perspective. Malden, MA: Blackwell Publishers.

Hadaway, C. K., \& Marler, P. L. (2005). How many Americans attend worship each week? An alternative approach to measurement. Journal for the Scientific Study of Religion, 44(3), 307-322. doi:10.1111/j.1468-5906.2005.00288.x

Hamar-Martínez, J. (2014). Religious switching among Latinos: The congregational context. The University of Arizona, Tucson, AZ. (UMI 3620102)

Hancock, D., Dyk, P. H., \& Jones, K. (2012). Adolescent involvement in extracurricular activities: Influences on leadership skills. Journal of Leadership Education, 11(1), $84-101$.

Hernández, E. I. (2007). The religious experience of Latino/a protestant youth. In K. Johnson-Mondragón (Ed.), Pathways of hope and faith among Hispanic teens: Pastoral reflections and strategies inspired by the national study of youth and religion (Vol. 1, pp. 291-319). Stockton, CA: Instituto Fe y Vida.

Hernández, E. I., Burwell, R., \& Smith, J. (2007). Answering the call: How Latino churches can respond to the HIV/AIDS epidemic - A study of Latino congregations in Chicago. Retrieved from https://latinostudies.nd.edu/assets/95281/original/hiv_aids_companion_web.pdf

Hernández, E. I., Davis, K. G., Peña, M., Schiopu, G., Smith, J., \& Loveland, M. T. (2007). Faith and values in action: Religion, politics, and social attitudes among US Latinos/as. Research Reports, 1.

Hernández, E. I., Peña, M., Sotelo Viernes Turner, C., \& Salazar, A. M. (2016). Spanning the divide: Latinos/as in theological education. Orlando, FL: Asociación para la Educación Teológica Hispana (AETH).

Hernández, E. I., Smith, J., Burwell, R., Peña, M., \& Sikkink, D. (2010). Healing hands: The health of Latino/a churchgoers and health outreach among Latino congregations in Chicago. Retrieved from https://curate.nd.edu/show/pk02c82401m

Hocking, R. R. (2013). Methods and applications of linear models: Regression and the analysis of variance (3rd ed.). Somerset, NJ: John Wiley \& Sons.

Hodgkinson, V. A., \& Weitzman, M. S. (1990). Volunteering and giving among American teenagers 14 to 17 years of age: Findings from a national survey. Washington, DC: Independent Sector. 
Hoge, D. R., \& Roozen, D. A. (Eds.). (1979). Understanding church growth and decline: 1950-1978. New York, NY: The Pilgrim Press.

Horn, L. R. (2011). Leadership skill development: The perceptions of Connecticut 4-H adolescent 4-H leaders in the Connecticut 4-H youth development program. (3468063 Ph.D.), University of Connecticut, Stamford, CT. ProQuest Dissertations \& Theses Full Text database.

Howell, D. C. (2010). Statistical methods for psychology (7th ed.). Belmont, CA: Wadsworth Cengage Learning.

Hughes, R. L., Ginnett, R. C., \& Curphy, G. J. (2012). Leadership: Enhancing the lessons of experience (7th ed.). New York, NY: McGraw-Hill Irwin.

Jeličič, H., Bobek, D., Phelps, E. D., Lerner, J. V., \& Lerner, R. M. (2007). Using positive youth development to predict contribution and risk behaviors in early adolescence: Findings from the first two waves of the 4-H study of positive youth development. International Journal of Behavioral Development, 31(3), 263-273.

Johnson-Mondragón, K. (2002). The status of Hispanic youth and young adult ministry in the United States: A preliminary study. Stockton, CA: Instituto Fe y Vida.

Johnson-Mondragón, K. (2005). Youth ministry and the socioreligious lives of Hispanic and White Catholic teens in the U.S.: Based on the national study of youth and religion (NSYR) (Vol. 2). Stockton, CA: Instituto Fe y Vida.

Johnson-Mondragón, K. (2010). Hispanic youth and young adult ministry in the United States: Bridging Hispanic and mainstream ministry to forge the church anew in 21 st century America. Stockton, CA: Instituto Fe y Vida.

Johnson-Mondragón, K. (Ed.) (2007). Pathways of hope and faith among Hispanic teens: Pastoral reflections and strategies inspired by the national study of youth and religion (Vol. 1). Stockton, CA: Instituto Fe y Vida.

Kehily, M. J. (2007). Understanding youth: Perspectives, identities \& practices. London, England: SAGE Publications.

Kerestes, M., Youniss, J., \& Metz, E. (2004). Longitudinal patterns of religious perspective and civic integration. Applied Developmental Science, 8(1), 39-46.

Kerlinger, F. N. (1973). Foundations of behavioral research: Educational, psychological and sociological inquiry (2nd ed.). New York, NY: Holt, Rinehart and Winston.

Kerlinger, F. N., \& Lee, H. B. (2000). Foundations of behavioral research (4th ed.). Northridge, CA: Wadsworth - Thomson Learning.

King, P. E. (2003). Religion and identity: The role of ideological, social, and spiritual contexts. Applied Developmental Science, 7(3), 196-203. 
King, P. E., \& Boyatzis, C. J. (2004). Exploring adolescent spiritual and religious development: Current and future theoretical and empirical perspectives. Applied Developmental Science, 8(1), 2-6.

Kinnaman, D., \& Hawkins, A. (2011). You lost me: Why young Christians are leaving church ... and rethinking faith. Grand Rapids, MI: Baker Books.

Klau, M. (2006). Exploring youth leadership in theory and practice. In M. Klau, S. Boyd, \& L. Luckow (Eds.), Youth Leadership (Vol. 109, pp. 57-87). San Francisco, CA: Jossey-Bass.

Klau, M., Boyd, S., \& Luckow, L. (Eds.). (2006). Youth leadership (Vol. 109). San Francisco, CA: Jossey-Bass.

Kline, R. B. (2015). Principles and practice of structural equation modeling (4th ed.). New York, NY: The Guilford Press.

Koss-Chioino, J. D., \& Vargas, L. A. (1999). Working with Latino youth: Culture, development, and context. San Francisco, CA: Jossey-Bass.

Kothari, C. R. (2004). Research methodology: Methods and techniques. New Delhi, India: New Age International Publishers.

Kouzes, J. M., \& Posner, B. Z. (1987). The leadership challenge: How to get extraordinary things done in organizations. San Francisco, CA: Jossey-Bass.

Labissiere, Y., Reeder Goraczko, A., \& Stepick, A. (2009). Religious practice and civic social capital among Miami youth. In A. Stepick, T. Rey, \& S. J. Mahler (Eds.), Churches and charity in the immigrant city: Religion, immigration, and civic engagement in Miami (pp. 231-249). New Brunswick, NJ: Rutgers University Press.

Lamb, M., \& Freund, A. (2010). Social and emotional development. In R. M. Lerner (Ed.), The handbook of life-span development (Vol. 2). Hoboken, NJ: John Wiley $\&$ Sons.

Larson, R. W. (2000). Toward a psychology of positive youth development. American Psychologist, 55(1), 170-183. doi:http://dx.doi.org/10.1037/0003-066X.55.1.170

Larson, R. W., \& Hansen, D. (2005). The development of strategic thinking: Learning to impact human systems in a youth activism program. Human Development, 48, 327-349.

Larson, R. W., Hansen, D., \& Walker, K. (2005). Everybody's gotta give: Development of initiative and teamwork within youth program In J. L. Mahoney, R. W. Larson, \& J. S. Eccles (Eds.), Organized activites as contexts of development:

Extracurricular activities, after-school and community programs. Mahwah, NJ: Lawrence Erlbaum. 
Larson, R. W., Hansen, D. M., \& Moneta, G. (2006). Differing profiles of developmental experiences across types of organized youth activities. Developmental Psychology, 42(5), 849-863. doi:10.1037/0012-1649.42.5.849

Larson, R. W., Jarrett, R., Hansen, D., Pearce, N., Sullivan, P., \& Walker, K. (2004). Organized youth activities as contexts of positive development. In P. A. Linley \& S. Joseph (Eds.), Positive psychology in practice (pp. 540-560). Hoboken, NJ: John Wiley \& Sons.

Larson, R. W., Walker, K., \& Pearce, N. (2005). A comparison of youth-driven and adult-driven youth programs: Balancing inputs from youth and adults. Journal of Community Psychology, 33(1), 57-74.

Larson, R. W., \& Walker, K. C. (2006). Learning about the "real world" in an urban arts youth program. Journal of Adolescent Research, 21(3), 244-268.

Lee, J., \& Zhou, M. (2004). Asian American youth: Culture, identity and ethnicity. New York, NY: Routledge.

Leffert, N., Benson, P., Scales, P., Sharma, A., Drake, D., \& Blyth, D. (1998). Developmental assets: Measurement and prediction of risk behaviors among adolescents. Applied Developmental Science, 2(4), 209-230.

Lerner, J. V., Bowers, E. P., Minor, K., Boyd, M. J., Mueller, M. K., Schmid, K. L., . . . Lerner, R. M. (2013). Positive youth development: Processes, philosophies, and programs. In R. M. Lerner, M. A. Easterbrooks, \& J. Mistry (Eds.), Handbook of psychology (2nd ed., Vol. 6, pp. 365-392). Hoboken, NJ: Wiley \& Sons.

Lerner, J. V., Phelps, E., Forman, Y. E., \& Bowers, E. P. (2009). Positive youth development. In R. M. Lerner \& L. Steinberg (Eds.), Handbook of adolescent psychology (3rd ed., Vol. 1, pp. 524-558). Hoboken, NJ: John Wiley \& Sons.

Lerner, R. M. (2002). Concepts and theories of human development (3rd ed.). Mahwah, NJ: Lawrence Erlbaum.

Lerner, R. M. (2004a). Diversity in individual $\leftrightarrow$ context relations as the basis for positive development across the life span: A developmental systems perspective for theory, research, and application (The 2004 society for the study of human development presidential address). Research in Human Development, 1(4), 327346. doi:10.1207/s15427617rhd0104_5

Lerner, R. M. (2004b). Innovative methods for studying lives in context: A view of the issues. Research in Human Development, 1(1\&2), 5-7. doi:10.1080/15427609.2004.9683327

Lerner, R. M. (2004c). Liberty: Thriving and civic engagement among America's youth. Thousand Oaks, CA: Sage Publications. 
Lerner, R. M. (2006). Developmental science, developmental systems, and contemporary theories of human development. In W. Damon \& R. M. Lerner (Eds.), Handbook of child psychology: Vol. 1. Theoretical models of human development (6th ed., pp. 1-17). Hoboken, NJ: John Wiley \& Sons.

Lerner, R. M. (2012). Developmental science: Past, present, and future. International Journal of Developmental Science, 6(1-2), 29-36.

Lerner, R. M., Almerigi, J. B., Theokas, C., \& Lerner, J. V. (2005). Positive youth development: A view of the issues. Journal of Early Adolescence, 25(1), 10-16. doi: $10.1177 / 0272431604273211$

Lerner, R. M., Brentano, C., Dowling, E. M., \& Anderson, P. M. (2002). Positive youth development: Thriving as the basis of personhood and civil society. New Directions for Youth Development: Pathways to Positive Development Among Diverse Youth, 95, 11-33.

Lerner, R. M., Fisher, C. B., \& Weinberg, R. A. (2000). Toward a science for and of the people: Promoting civil society through the application of developmental science. Child Development, 71, 11-20.

Lerner, R. M., Lerner, J. V., Almerigi, J. B., Theokas, C., Phelps, E., Gestsdottir, S., . . . von Eye, A. (2005). Positive youth development, participation in community youth development programs, and community contributions of fifth-grade adolescents: Findings from the first wave of the 4-H study of positive youth development. The Journal of Early Adolescence, 25(1), 17-71.

Lerner, R. M., Lerner, J. V., Lewin-Bizan, S., Bowers, E. P., Boyd, M., Mueller, M., . . Napolitano, C. (2011). Positive youth development: Processes, programs, and problematics. Journal of Youth Development, 6(3), 40-64.

Lerner, R. M., \& Overton, W. F. (2008). Exemplifying the integrations of the relational developmental system: Synthesizing theory, research, and application to promote positive development and social justice. Journal of Adolescent Research, 23, 245255. doi: $10.1177 / 0743558408314385$

Lerner, R. M., Roeser, R. W., \& Phelps, E. (Eds.). (2008). Positive youth development and spirituality: From theory to research. West Conshohocken, PA: Templeton Foundation Press.

Libby, M., Sedonaen, M., \& Bliss, S. (2006). The mystery of youth leadership development: The path to just communities. In M. Klau, M. Boyd, \& L. Luckow (Eds.), Youth leadership (Vol. 109, pp. 13-25). San Francisco, CA: Wiley Periodicals. 
López, A., Yoder, J. R., Brisson, D., Lechuga-Peña, S., \& Jenson, J. M. (2015). Development and validation of a positive youth development measure: The bridge-positive youth development. Research on Social Work Practice, 25(6), 726-736. doi:10.1177/1049731514534899

Lord, F. M. (2012). Applications of item response theory to practical testing problems. New York, NY: Routledge.

MacNeil, C. A. (2006). Bridging generations: Applying "adult" leadership theories to youth leadership development. New Directions for Youth Development, 2006(109), 27-43. doi:10.1002/yd.153

Mahoney, J. L., Larson, R. W., Eccles, J. S., \& Lord, H. (2005). Organized activities as developmental contexts for children and adolescents. In J. L. Mahoney, R. W. Larson, \& J. S. Eccles (Eds.), Organized activities as contexts of development: Extracurricular activites, after-school and community programs (pp. 3-22). Mahwah, NJ: Lawrence Erlbaum.

Maldonado, J. E., \& Martínez, J. F. (Eds.). (2008). Vivir y servir en el exilio: Lecturas teológicas de la experiencia latina en los Estados Unidos (Vol. 29). Buenos Aires, Argentina: Ediciones Kairós.

Maldonado Pérez, Z. (2005). Leadership in the Latina/o community: A brief look at the meaning of leadership for today. In A. Padilla, R. Goizueta, \& E. Villafañe (Eds.), Hispanic Christian thought at the dawn of the 21st century: Apuntes in honor of Justo L. González (pp. 125-131). Nashville, TN: Abingdon Press.

Mariano, J. M., \& Damon, W. (2008). The role of spirituality in supporting purpose in adolescence. In R. Roeser, E. Phelps, \& R. M. Lerner (Eds.), Positive youth development and spirituality: From theory to research (pp. 210-230). Wast Conshohocken, PA: Templeton Foundation Press.

Martell-Otero, L. I., Maldonado Pérez, Z., \& Conde-Frazier, E. (2013). Latina Evangélicas: A theological survey from the margins. Eugene, OR: Cascade Books.

Martínez Guerra, J. F. (2004). Aculturación e iglesia evangélica latina en los Estados Unidos. In J. F. Martínez Guerra \& L. Scott (Eds.), Iglesias peregrinas en busca de indentidad: Cuadros del protestantismo latino en los Estados Unidos (pp. 147164). Buenos Aires, Argentina: Ediciones Kairós.

Martínez, J. (2008). Walk with the people: Latino ministry in the United States. Nashville, TN: Abingdon Press.

McNeil, K. A., Newman, I., \& Fraas, J. W. (2012). Designing general linear models to test research hypotheses. Lanham, MD: University Press of America. 
McNutt, M. S. (2013). The leadership, community, and civic development of rural youth. Insights to a Changing World Journal, 2013(4), 31-42.

Mitra, D. L., Lewis, T., \& Sanders, F. (2013). Architects, captains, and dreamers: Creating advisor roles that foster youth-adult partnerships. Journal of Educational Change, 14(2), 177-201. doi:10.1007/s10833-012-9201-6

Mitra, D. L., \& Serriere, S. C. (2012). Student voice in elementary school reform: Examining youth development in fifth graders. American Educational Research Journal, 49(4), 743-774. doi:10.3102/0002831212443079

Mohamed, I. A., \& Wheeler, W. (2001). Broadening the bounds of youth development: Youth as engaged citizens. New York, NY: The Ford Foundation and The Innovation Center for Community and Youth Development.

Montoya, A. D. (1987). Hispanic ministry in North America. Grand Rapids, MI: Zondervan.

Mortensen, J., Lichty, L., Foster-Fishman, P., Harfst, S., Hockin, S., Warsinske, K., \& Abdullah, K. (2014). Leadership through a youth lens: Understanding youth conceptualizations of leadership. Journal of Community Psychology, 42(4), 447462. doi:10.1002/jcop. 21620

Mulder, M. T., Ramos, A. I., \& Martí, G. (2017). Latino Protestants in America: Growing and diverse. Lanham, MD: Rowman \& Littlefield.

Murphy, S. E., \& Johnson, S. K. (2011). The benefits of a long-lens approach to leader development: Understanding the seeds of leadership. The Leadership Quarterly, 22(3), 459-470. doi:http://dx.doi.org/10.1016/j.leaqua.2011.04.004

Murphy, S. E., \& Reichard, R. (2011). Early development and leadership: Building the next generation of leaders. New York, NY: Routledge.

Murphy, S. E., \& Riggio, R. E. (2003). The future of leadership development. Mahwah, NJ: Lawrence Erlbaum.

Nakkula, M. J., \& Toshalis, E. (2006). Understanding youth: Adolescent development for educators. Cambridge, MA: Hardvard Education Press.

Newman, I. (1976). Brief note on the justification for using multiple linear regression. Multiple Linear Regression Viewpoints, 6(4), 50-53.

Newman, I., \& Benz, C. R. (1998). Qualitative-quantitative research methodology: Exploring the interactive continuum. Carbondale, IL: Southern Illinois University Press.

Newman, I., Fraas, J., \& Laux, J. M. (2000). A three-step adjustment procedure for Type I error rates. Journal of Research in Education, 10(1), 84-90. 
Newman, I., \& Newman, C. (2010). Increasing the likelihood of publishing quantitative manuscripts. In T. S. Rocco \& T. Hatcher (Eds.), The handbook of scholarly writing and publishing (pp. 179-190). San Francisco, CA: Jossey-Bass.

Newman, I., Newman, C., Brown, R., \& McNeely, S. (2006). Conceptual statistics for beginners (3rd ed.). Landham, MD: University Press of America.

Norton Jr., W. I., Murfield, M. L. U., \& Baucus, M. S. (2014). Leader emergence: The development of a theoretical framework. Leadership \& Organization Development Journal, 35(6), 513-529. doi:10.1108/lodj-08-2012-0109

Novikoff, A. B. (1945a). The concept of integrative levels and biology. Science, 101, 209-215.

Novikoff, A. B. (1945b). Continuity and discontinuity in evolution. Science, 101, 405406.

Oquendo, A. R. (1995). Re-imagining the Latino/a race. Harvard BlackLetter Law Journal, 12(93), 96-97.

Ortiz, M. (1993). The Hispanic challenge: Opportunities confronting the church. Downers Grove, IL: InterVarsity Press.

Overton, W. F. (1998). Developmental psychology: Philosophy, concepts, and methodology. In R. M. Lerner \& W. Damon (Eds.), Handbook of child psychology: Vol. 1. Theoretical models of human development (5th ed., pp. 107187). New York, NY: John Wiley \& Sons.

Overton, W. F. (2006). Developmental psychology: Philosophy, concepts, and methodology. In W. Damon \& R. M. Lerner (Eds.), Handbook of child psychology: Vol. 1. Theoretical models of human development (6th ed., pp. 1888). Hoboken, NJ: John Wiley \& Sons.

Overton, W. F. (2013a). A new paradigm for developmental science: Relationism and relational-developmental systems. Applied Developmental Science, 17(2), 94107. doi:10.1080/10888691.2013.778717

Overton, W. F. (2013b). Relationism and relational developmental systems: A paradigm for developmental science in the post-Cartesian era. In R. M. Lerner \& J. B. Benson (Eds.), Advances in child development and behavior: Embodiment and epigenesis: Theoretical and methodological issues in understanding the role of biology within the relational developmental system: Vol. 44 Philosophical, theorectical, and biological dimensions (pp. 21-64). Oxford, England: Elsevier Academic Press.

Owen, J. E. (2012). Using student development theories as conceptual frameworks in leadership education. New Directions for Student Services, 2012(140), 17-35. doi:10.1002/ss.20029 
Pepper, S. C. (1942). World hypotheses. Berkeley, CA: University of California Press.

Perks, T., \& Haan, M. (2010). Youth religious involvement and adult community participation: Do levels of youth religious involvement matter? Nonprofit and Voluntary Sector Quarterly, 40(1), 107-129.

Petersen, A. C., Koller, S. H., Motti-Stefanidi, F., \& Verma, S. (Eds.). (2017). Positive youth development in global contexts of social and economic change. New York, NY: Routledge.

Pew Hispanic Center. (2007). Changing faiths: Latinos and the transformation of American religion. Retrieved from http://www.pewforum.org/2007/04/25/changing-faiths-latinos-and-thetransformation-of-american-religion-2/

Pew Hispanic Center. (2009a). Between two worlds: How young Latinos come of age in America. Retrieved from http://www.pewhispanic.org/2009/12/11/between-twoworlds-how-young-latinos-come-of-age-in-america/

Pew Hispanic Center. (2009b). Who's Hispanic? Retrieved from http://www.pewhispanic.org/2009/05/28/whos-hispanic/

Pew Hispanic Center. (2012). When labels don't fit: Hispanics and their views of identity. Retrieved from http://www.pewhispanic.org/2012/04/04/when-labels-dont-fithispanics-and-their-views-of-identity/

Pew Research Center. (2013). National survey of Latinos and religion. Retrieved from http://www.pewforum.org/2014/05/07/the-shifting-religious-identity-of-latinosin-the-united-states/

Pew Research Center. (2014a). 2014 U.S. religious landscape study. Retrieved from http://www.pewforum.org/religious-landscape-study/religioustradition/evangelical-protestant/racial-and-ethniccomposition/latino/\#demographic-information

Pew Research Center. (2014b). The shifting religious identity of Latinos in the United States. Retrieved from http://www.pewforum.org/2014/05/07/the-shiftingreligious-identity-of-latinos-in-the-united-states/

Pew Research Center. (2015). America's changing religious landscape: Christians decline sharply as share of population; Unaffiliated and other faiths continue to grow. Retrieved from http://www.pewforum.org/2015/05/12/americas-changingreligious-landscape/

Pinedo, E., \& Segura, H. (2105). Dejen que los niños vengan a mí: Pistas bíblicoteológicas para el ministerio con la niñez y la juventud. San José, Costa Rica: Movimiento Juntos con la Niñez y la Juventud. 
Pittman, K., Irby, M., \& Ferber, T. (2001). Unfinished business: Further reflections on a decade of promoting youth development. In P. L. Benson \& K. J. Pittman (Eds.), Trends in youth development: Visions, realities, and challenges (pp. 4-50). Norwell, MA: Public/Private Ventures.

Putnam, R. D. (2000). Bowling alone: The collapse and revival of American community. New York, NY: Simon and Schuster.

Putnam, R. D. (2001). Social capital: Measurement and consequences. Canadian Journal of Policy Research, 2(1), 41-51.

Putnam, R. D. (2002). Democracies in flux: The evolution of social capital in contemporary society. Cary, NC: Oxford University Press.

Raffaelli, M., Carlo, G., Carranza, M. A., \& Gonzalez-Kruger, G. E. (2005). Understanding Latino children and adolescents in the mainstream: Placing culture at the center of developmental models. New directions for child and adolescent development, 2005(109), 23-32.

Ramírez-Johnson, J. (2008). An ethnography of social mobility: Immigrant membership in a Seventh-day Adventist Puerto Rican ethnic church. Lewiston, NY: The Edwin Mellen Press.

Rhodes, J. E. (2002). Stand by me: The risks and rewards of mentoring today's youth. Cambridge, MA: Harvard University Press

Ricketts, J. C., \& Rudd, R. D. (2002). A comprehensive leadership education model to train, teach, and develop leadership in youth. Journal of Career and Technical Education, 19(1), 7-17.

RMC Research Corporation. (2002). W.K. Kellogg foundation retrospective of $K-12$ service-learning projects, 1990-2000. Retrieved from http://www.wkkf.org/resourcedirectory\#pp=10\&p=1\&q=retrospective $\% 20$ evaluation $\& f 1=$ community- $\&$-civicengagement $\& \mathrm{f} 2=2002$

Rodríguez, D. A. (2011). A future for the Latino church: Models for multilingual, multigenerational Hispanic congregations. Downers Grove, IL: InterVarsity Press.

Rodríguez, D. A. (2015). Between two worlds: Hispanic youth ministry in the United States. In N. Medina \& S. Alfaro (Eds.), Pentecostals and Charismatics in Latin America and Latino communities (pp. 127-139). New York, NY: Palgrave Macmillan.

Roehlkepartain, E. C., Ebstyne King, P., Wagener, L., \& Benson, P. L. (2005). The handbook of spiritual development in childhood and adolescence. Thousand Oaks, CA: Sage Publications. 
Roehlkepartain, E. C., \& Scales, P. C. (1995). Youth development in congregations: An exploration of the potential and barriers. Minneapolis, MN: Search Institute.

Roth, J. L., \& Brooks-Gunn, J. (2003a). What exactly is a youth development program? Answers from research and practice. Applied Developmental Science, 7, 94-111.

Roth, J. L., \& Brooks-Gunn, J. (2003b). What is a youth development program? Identification and defining principles. In F. Jacobs, D. Wertlieb, \& R. M. Lerner (Eds.), Handbook of applied developmental science: Promoting positive child, adolescent, and family development through research, policies, and programs, Vol. 2: Enhancing the life chances of youth and families: Public service systems and public policy perspectives (pp. 197-223). Thousand Oaks, CA: Sage.

Ruano, N. E. (2011). The Holy Ghost beyond church walls: Latino Pentecostalism(s), congregations, and civic engagement. Loyola University Chicago, Chicago, IL. (UMI 3454962)

Rubin, R. S., Bartels, L. K., \& Bommer, W. H. (2002). Are leaders smarter or do they just seem that way? Exploring perceived intellectual competence and leadership emergence. Social Behavior and Personality, 30(2), 105-118. doi:10.2224/sbp.2002.30.2.105

Scales, P., Benson, P., Leffert, N., \& Blyth, D. (2000). The contribution of developmental assets to the prediction of thriving among adolescents. Applied Developmental Science, 4(1), 27-46.

Schmid Callina, K., Johnson, S. K., Buckingham, M. H., \& Lerner, R. M. (2014). Hope in context: Developmental profiles of trust, hopeful future expectations, and civic engagement across adolescence. Journal of Youth and Adolescence, 43(6), 869883. doi:10.1007/s10964-014-0096-9

Schneirla, T. C. (1957). The concept of development in comparative psychology. In D. B. Harris (Ed.), The concept of development (pp. 78-108). Minneapolis, MN: University of Minnesota Press.

Seon-Young, L., Olszewski-Kubilius, P., Donahue, R., \& Weimholt, K. (2008). The Civic Leadership Institute: A service-learning program for academically gifted youth. Journal of Advanced Academics, 19(2), 272-308.

Sherrod, L. R., Torney-Purta, J., \& Flanagan, C. A. (Eds.). (2010). Handbook of research on civic engagement in youth. Hoboken, NJ: John Wiley \& Sons.

Sikkink, D., \& Hernández, E. I. (2003). Religion matters: Predicting schooling success among Latino youth (Vol. 2003.1). South Bend, IN: Institute for Latino Studies at University of Notre Dame. 
Silbereisen, R. K., \& Lerner, R. M. (2007). Approaches to positive youth development: A view of the issues. In R. K. Silbereisen \& R. M. Lerner (Eds.), Approaches to positive youth development (pp. 3-30). London, England: Sage Publications.

Smith, C. (2003). Religious participation and network closure among American adolescents. Journal for the Scientific Study of Religion, 42(2), 259-267.

Smith, C., \& Denton, M. L. (2009). Soul searching: The religious and spiritual lives of American teenagers. New York, NY: Oxford University Press.

Smith, C., Denton, M. L., Faris, R., \& Regnerus, M. (2002). Mapping American adolescent religious participation. Journal for the Scientific Study of Religion, 41(4), 597-612.

Smith, E. (2008). Using secondary data in educational and social research. New York, NY: McGraw-Hill.

Smokowski, P. R., \& Bacallao, M. (2011). Becoming bicultural: Risk, resilience, and Latino youth. New York, NY: NYU Press.

Spencer, M. B. (2006a). Commentary on "studying diverse lives". Research in Human Development, 3, 271-280.

Spencer, M. B. (2006b). Phenomenology and ecological systems theory: Development of diverse groups. In W. Damon \& R. M. Lerner (Eds.), Handbook of child psychology: Vol. 1. Theoretical models of human development (6th ed., pp. 829893). Hoboken, NJ: John Wiley \& Sons.

Spencer, M. B., Swanson, D. P., \& Cunningham, M. (1991). Ethnicity, ethnic identity, and competence formation: Adolescent transition and cultural transformation. Journal of Negro Education, 60(3), 366-387.

Stadler, A. (2009). Practitioner's corner: Leadership emergence theory in the corporate context. International Journal of Leadership Studies, 5(1), 115-122.

Steinberg, L. (2017). Adolescence (11th ed.). New York, NY: McGraw-Hill Education.

Stepick, A., Rey, T., \& Mahler, S. J. (Eds.). (2009). Churches and charity in the immigrant city: Religion, immigration, and civic engagement in Miami. New Brunswick, N.J: Rutgers University Press.

Stevens-Arroyo, A., Goris, A., Keysar, A., Quiles, I., Tapolcai, A., Craig, D., \& Spinuso, C. (2003). The national survey of leadership in Latino parishes and congregations. Brooklyn, NY: Program for the Analysis of Religion among Latinas/os (PARAL). 
Strobel, K., \& Nelson, I. (2007). Understanding youth leadership development: An examination of the youth engaged in leadership and learning program (YELL). Retrieved from https://gardnercenter.stanford.edu/publications/model-fosteringyouth-leadership-youth-engaged-leadership-and-learning-program-yell

Sukarieh, M., \& Tannock, S. (2011). The positivity imperative: A critical look at the 'new' youth development movement. Journal of Youth Studies, 14(6), 675-691.

Taggar, S., Hackett, R., \& Saha, S. (1999). Leadership emergence in autonomous work teams: Antecedents and outcomes. Personnel Psychology, 52(4), 899-926.

Tamez Méndez, E. (2011). ¡Grandiosa celebración! 25 becas otorgadas durante el centenario. La Visión, Invierno/Primavera 2011, 14.

Tamez Méndez, E. (2015). Reaching the next generation: Ministry to culturally and ethnically diverse youth and young adults. Communitas: Journal of Education Beyond the Walls, 12, 12-18.

Tamez Méndez, E. (2017). Rethinking Latino youth ministry: Frameworks that provide roots and wings for our youth. Apuntes: Theological Reflections from the Hispanic-Latino Context, 37(2), 42-91.

Taylor, C. S. (2003). Youth gangs and community violence. In R. M. Lerner, F. Jacobs, \& D. Wertlieb (Eds.), Handbook of applied developmental science: Promoting positive child, adolescent, and family development through research, policies, and programs, Vol. 2: Enhancing the life chances of youth and families: Public service systems and public policy perspectives (pp. 65-80). Thousand Oaks, CA: Sage Publications.

Taylor, C. S., Lerner, R. M., von Eye, A., Bobek, D., Balsano, A., \& Dowling, E. (2003). Positive individual and social behavior among gang and non-gang African American male adolescents. Journal of Adolescent Research, 18, 547-574.

The United Methodist Immigration Task Force. (2017). Immigration task force issues call to action on DACA. Retrieved from http://www.umc.org/news-andmedia/task-force-issues-call-to-action-on-daca

Theokas, C., \& Lerner, R. M. (2006). Promoting positive development in adolescence: The role of ecological assets in families, schools, and neighborhoods. Applied Developmental Science, 10(2), 61-74.

U.S. Census Bureau. (2015). Profile America facts for features: Hispanic heritage month 2015. (CB15-FF.18). U.S. Census Bureau Retrieved from http://www.census.gov/newsroom/facts-for-features/2015/cb15-ff18.html.

University of Notre Dame. (2001). National study of youth and religion: Purpose of the study. Retrieved from http://youthandreligion.nd.edu/research-purpose/ 
van der Linden, W. J., \& Hambleton, R. K. (Eds.). (2013). Handbook of modern item response theory. New York, NY: Springer Science \& Business Media.

van Linden, J. A., \& Fertman, C. I. (1998). Youth leadership: A guide to understanding leadership development in adolescents. San Francisco, CA: Jossey-Bass Publishers.

Voas, D. (2007). Surveys of behaviour, beliefs, and affiliation: Micro-quantitative. In J. A. Beckford \& N. J. Demerath III (Eds.), The SAGE handbook of the sociology of religion (pp. 144-166). Thousand Oaks, CA: SAGE Publications.

von Bertalanffy, L. (1969). General systems theory. New York, NY: Braziller Press.

Waldstein, F. A., \& Reiher, T. C. (2001). Service-learning and students' civic and personal development. Journal of Experiential Education, 24(1), 7-13.

Weaver, A. J., Samford, J. A., Morgan, V. J., Lichton, A. I., Larson, D. B., \& Garbarino, J. (2000). Research on religious variables in five major adolescent research journals: 1992 to 1996. Journal of Nervous and Mental Disease, 188(1), 36-44.

Weiss, D. J. (2006). Analysis of variance and functional measurement: A practical guide. New York, NY: Oxford University Press.

Wilson, L. B., \& Simson, S. P. (Eds.). (2006). Civic engagement and the baby boomer generation: Research, policy, and practice perspectives. Binghamton, NY: The Haworth Press.

Wolff, S. B., Pescosolido, A. T., \& Druskat, V. U. (2002). Emotional intelligence as the basis of leadership emergence in self-managing teams. The Leadership Quarterly, $13(5), 505-522$.

Woolcock, M., \& Narayan, D. (2000). Social capital: Implications for development theory, research, and policy. The World Bank Research Observer, 15(2), 225-249.

Yates, M., \& Youniss, J. (1996). A developmental perspective on community service in adolescence. Social Development, 5(1), 85-111. doi:10.1111/j.14679507.1996.tb00073.x

Youniss, J. (1993). Integrating culture and religion into developmental psychology. Family Perspective, 26, 171-188.

Youniss, J., McLellan, J. A., \& Yates, M. (1997). What we know about engendering civic identity. American Behavioral Scientist, 40, 620-631.

Youniss, J., \& Yates, M. (1997). Community service and social responsibility in youth. Chicago, IL: University of Chicago Press. 
Zimmerman-Oster, K., \& Burkhardt, J. C. (1999). Leadership in the making: A comprehensive examination of the impact of leadership development programs on students. Journal of Leadership \& Organizational Studies, 6(3/4), 50-66. 


\section{CURRICULUM VITAE}




\title{
Highlighted Professional Education
}

\begin{tabular}{|c|c|c|}
\hline 2018 & Ph.D. & $\begin{array}{l}\text { Leadership } \\
\text { Andrews University, Berrien Springs, MI }\end{array}$ \\
\hline 2012 & CERT. & $\begin{array}{l}\text { Certificate in Urban Youth Ministry } \\
\text { Fuller Theological Seminary, Pasadena, CA }\end{array}$ \\
\hline 2001 & M.A. & $\begin{array}{l}\text { Interior Design } \\
\text { Universidad de Salamanca, Salamanca, Spain }\end{array}$ \\
\hline 1997 & LIC. & $\begin{array}{l}\text { Architecture } \\
\text { Universidad del Valle de México, Naucalpan, Mexico }\end{array}$ \\
\hline
\end{tabular}

\section{Highlighted Professional Experience}

\author{
2005 - present Founder and Executive Director, \\ New Generation3. Decatur, GA \\ 2016 - present $\quad$ Adjunct Professor, Latino Ministry Certificate, \\ Calvin Theological Seminary. Grand Rapids MI \\ $2010-2015 \quad$ Assoc. Dir. Student Services and Adj. Lect. Bible-Theo. Studies, \\ Baptist University of the Américas. San Antonio, TX \\ $2009-2014 \quad$ Consultant/Trainer Hispanic Education Initiative, \\ Baptist General Convention of Texas. Dallas, TX \\ 2002-2008 Youth Minister, \\ Primera Iglesia Bautista. Tyler, TX \\ $1999-2008 \quad$ Architect/Designer, \\ Humphreys \& Partners Architects. Dallas, TX
}

\section{Highlighted Scholarly Publications}

Summer 2017

Spring 2015

Fall 2010
Rethinking Latino Youth Ministry: Frameworks that Provide Roots and Wings for Our Youth. Apuntes - Journal of the Hispanic Ministries Program at Perkins School of Theology.

Ministry to Culturally and Ethnically Diverse Youth \& Young Adults. Communitas - Journal of Education Beyond the Walls.

Book Rev. \& Min. Application: Positive Youth Development and Spirituality: From Theory to Research. Journal of Applied Christian Leadership. Vol. 4, No. 2. 